UNIVERSIDADE DE BRASÍLIA

FACULDADE DE TECNOLOGIA

DEPARTAMENTO DE ENGENHARIA CIVIL E AMBIENTAL

\title{
USO DE DADOS DE DOCUMENTOS FISCAIS ELETRÔNICOS PARA O PLANEJAMENTO DO TRANSPORTE URBANO DE CARGAS
}

EVANDRO MANZANO DOS SANTOS

ORIENTADORA: ADELAIDA PALLAVICINI FONSECA

TESE DE DOUTORADO EM TRANSPORTES

\author{
PUBLICAÇÃO T.D-002/2015 \\ BRASÍLIA/DF: JUNHO - 2015
}


UNIVERSIDADE DE BRASÍLIA

FACULDADE DE TECNOLOGIA

DEPARTAMENTO DE ENGENHARIA CIVIL E AMBIENTAL

USO DE DADOS DE DOCUMENTOS FISCAIS ELETRÔNICOS PARA O PLANEJAMENTO DO TRANSPORTE URBANO DE CARGAS

\section{EVANDRO MANZANO DOS SANTOS}

TESE DE DOUTORADO SUBMETIDA AO DEPARTAMENTO DE ENGENHARIA CIVIL E AMBIENTAL DA FACULDADE DE TECNOLOGIA DA UNIVERSIDADE DE BRASÍLIA COMO PARTE DOS REQUISÍTOS NECESSÁRIOS PARA A OBTENÇÃO DO GRAU DE DOUTOR EM TRANSPORTES

APROVADA POR:

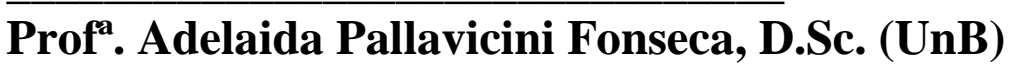
(orientadora)

Prof. Carlos Henrique Rocha, PhD. (UnB) (examinador interno)

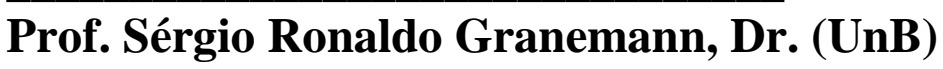
(examinador interno)

Prof $^{\text {a }}$. Leise Kelli de Oliveira, Dra ${ }^{\text {a }}$ (UFMG) (examinadora externa)

Prof. Bruno Vieira Bertoncini, Dr.(UFC) (examinador externo)

BRASÍLIA/DF, 30 DE JUNHO DE 2015. 


\section{FICHA CATALOGRÁFICA}

\begin{tabular}{|c|c|}
\hline SANTOS, EVANDRO MANZ & \\
\hline $\begin{array}{l}\text { Uso de dados de documentos fi } \\
\text { urbano de cargas. [Distrito Fede }\end{array}$ & ônicos para o planejamento do transporte \\
\hline xiii, 155 p., 210 x 297 mm (EN & 3, Doutor, Transportes, 2015). \\
\hline Tese de Doutorado - Universid & asília. Faculdade de Tecnologia. \\
\hline Departamento de Engenharia $\mathrm{C}$ & biental. \\
\hline 1. Transporte urbano de cargas & 2. Documentos Fiscais Eletrônicos \\
\hline 3. Urban Freight Transport & 4. Electronic Invoice \\
\hline I. ENC/FT/UnB & II. Título (série) \\
\hline
\end{tabular}

\section{REFERÊNCIA BIBLIOGRÁFICA}

SANTOS, E. M. (2015) Uso de dados de documentos fiscais eletrônicos para o planejamento do transporte urbano de cargas. Tese de Doutorado em Transportes Publicação T.D-002/2015, Departamento de Engenharia Civil e Ambiental, Universidade de Brasília, Brasília, DF, 155 p.

\section{CESSÃO DE DIREITOS}

AUTOR: Evandro Manzano dos Santos

TÍTULO: Uso de dados de documentos fiscais eletrônicos para o planejamento do transporte urbano de cargas. Tese de Doutorado em Transportes.

GRAU: Doutor

ANO: 2015.

É concedida à Universidade de Brasília permissão para reproduzir cópias desta tese de doutorado e para emprestar ou vender tais cópias somente para propósitos acadêmicos e científicos. O autor reserva outros direitos de publicação e nenhuma parte dessa Tese de Doutorado pode ser reproduzida sem autorização por escrito do autor.

Evandro Manzano dos Santos

Endereço: Alameda dos Eucaliptos, quadra 09, lote 16 Residencial Jardins Florença CEP 74.351-014, Goiânia, DF, Brasil.

evandrostos@yahoo.com.br /evandrostos123@gmail.com 


\section{DEDICATÓRIA}

Para Thelma, Enzo e Nathália. 


\section{AGRADECIMENTOS}

A todos os professores, servidores e colegas do Programa de Pós-Graduação em Transportes da Universidade de Brasília (PPGT/UnB), e em especial à Lucinete e Camila, sempre prestativas nos momentos de que necessitei.

A todos os gerentes das transportadoras que disponibilizaram seu tempo para que eu pudesse obter referências sobre o cenário do transporte urbano de carga fracionada no Distrito Federal.

Aos meus amigos e colegas de trabalho, Charles Sarmento, Domingos Sávio, Gunther, Serra, Paulo Roberto, Francisco Gilberto, pelo apoio nos momentos em que precisei de ajuda.

Aos meus chefes anteriores e atual, Nélio Lacerda Wanderlei, Wilson José de Paula e Hormino de Almeida Júnior, pela oportunidade em trabalhar com o QlikView na Sub-Secretaria da Receita do Distrito Federal e pelo apoio para que eu desenvolvesse este trabalho.

Ao professor José Holguín-Veras, por ter me recebido e oferecido apoio para que eu pudesse estudar no Rensselaer Polytechnic Institute, EUA, local onde pude obter novas referências sobre o tema transporte urbano de cargas, e tomar contato com ambiente acadêmico internacional.

Aos meus amigos do Rensselaer Polytechnic Institute, Lokesh Kumar, Iván Sánchez-Díaz e Carlos González-Calderón, pela orientação e companheirismo e ajuda na busca por novos conhecimentos.

À CAPES, Coordenação de Aperfeiçoamento de Pessoal de Nível Superior, do Ministério da Educação do Governo Federal, pela bolsa de estudos de doutorado sanduíche. Sem ela, não teria sido possível efetuar o estágios nos Estados Unidos.

Ao Governo do Distrito Federal, pela licença que possibilitou eu efetuar o estágio no exterior.

Aos meus pais José Vieira dos Santos e Ivanilda Joana Manzano dos Santos por terem criado as condições para o alcance dos meus objetivos.

Aos professores membros das bancas de qualificação e de defesa da tese, profa. Leise Kelli de Oliveira, profs. Bruno Vieira Bertoncini, Carlos Henrique Rocha, Sérgio Ronaldo Granemann e Orlando Fontes Lima Júnior, pelas contribuições para o desenvolvimento deste trabalho.

Novamente, ao colega Gunther Siqueira Lemos Gomes, cujo apoio foi fundamental para o desenvolvimento da metodologia de extração dos dados utilizada neste estudo.

À minha orientadora, Adelaida Pallavicini Fonseca, pessoa com muito conhecimento, sincera e que me guiou com muita seriedade e maestria. Agradeço por seu constante apoio e amizade, suas críticas e orientações valiosas para a estruturação desta tese.

Àos professores deste país, e em nome deles um agradecimento especial à professora do ensino fundamental Maria Cecília Pansera, pois sua intervenção fez a diferença para que eu continuasse a estudar e mudou minha vida.

À minha esposa, Thelma do O' Cavalcanti, mãe dos meus filhos Enzo Cavalcanti Manzano e Nathália Cavalcanti Manzano, minha companheira e maior incentivadora para que continuasse os estudos. Obrigado pela compreensão, carinho e o apoio fundamental nos momentos que precisei de sua ajuda para me dedicar a este trabalho. 


\title{
RESUMO
}

\section{USO DE DADOS DE DOCUMENTOS FISCAIS ELETRÔNICOS PARA O PLANEJAMENTO DO TRANSPORTE URBANO DE CARGAS}

\author{
Autor: Evandro Manzano dos Santos \\ Orientador: Prof ${ }^{\text {a }}$ Adelaida Pallavicini Fonseca, D.Sc. \\ Programa de Pós-graduação em Transportes - Universidade de Brasília \\ Brasília, 30 de Junho de 2015
}

Nas principais cidades brasileiras há um agravamento do congestionamento do tráfego com efeito negativo sobre as atividades econômicas e sociais, em especial sobre o transporte urbano de carga (TUC) que, por sua vez, contribui para piorar tal cenário. Para lidar adequadamente com estas questões diversos países tem adotado soluções para o TUC, porém no Brasil isto ainda é incipiente devido notadamente à falta de informações para realizar estudos sobre o tema. Buscando contribuir na solução desse problema, esta tese apresenta uma metodologia alternativa de obtenção de informações para o planejamento do transporte urbano de cargas a partir de dados de documentos fiscais eletrônicos. Esta metodologia foi validada com dados reais mostrando sua consistência. Da base de dados foram realizadas diferentes análises consideradas úteis ao planejamento do TUC e aplicadas no Distrito Federal. O referencial teórico, os resultados e as análises desta pesquisa demonstram que os dados da nota fiscal eletrônica, tratados e organizados, podem representar os fluxos de mercadorias no espaço urbano com expressivo nível de detalhes, abrangência e atualização contínua a um baixo custo. 


\title{
ABSTRACT \\ USE OF DATA FROM ELECTRONIC TAX DOCUMENTS FOR THE PLANNING OF URBAN FREIGHT TRANSPORT
}

\author{
Author: Evandro Manzano dos Santos
}

Advisor: Adelaida Pallavicini Fonseca, D.Sc.

Graduate Program in Transportation - University of Brasilia

Brasilia, Jun 30th, 2015

In the main Brazilian cities there is an aggravation of traffic jam with negative effects on the economic and social activities, particularly on urban freight transport (UFT) which, in turn, contributes to worsen that scenario. To properly address these issues many countries have adopted solutions in UFT, but its implementation in Brazil is incipient due to the lack of information in order to carry out related studies. In order to contribute to solve these problems, this thesis presents an alternative methodology of obtaining information for the planning of urban freight transport from electronic tax document data. This methodology was validated through real data, showing this consistency. Different analyses were done from this database, and they were considered useful for the planning of urban freight transport. These analyses were done over the Federal District Treasury Office database in Brasilia, Brazil. The theoretical framework, the results and the analysis of this research show that the data of electronic invoices, when processed and organized, may represent the flow of goods in urban areas with a significant level of details, coverage and continuous updates at a low cost. 


\section{LISTA DE FIGURAS}

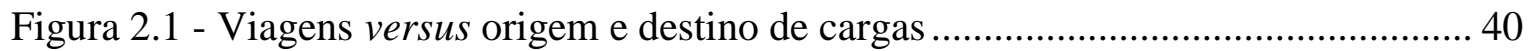

Figura 2.2 - Movimentos padrão de viagens em um sistema de transportes..................... 45

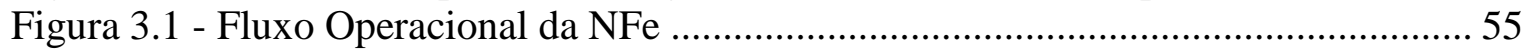

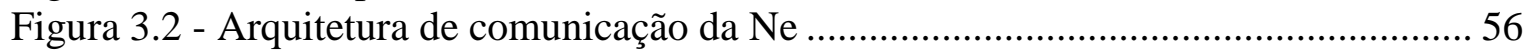

Figura 3.3 - Diagrama do Schema XML dos grupos de informações da NFe .................... 57

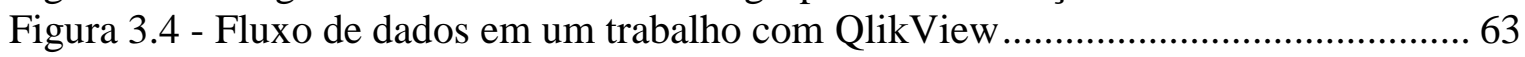

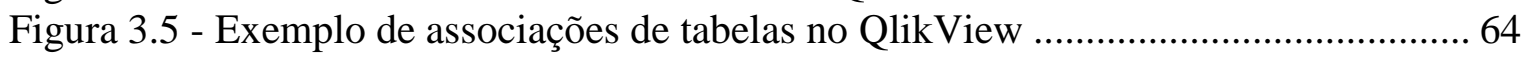

Figura 3.6 - Exemplo de comando controlador de seleções no QlikView ..........................65

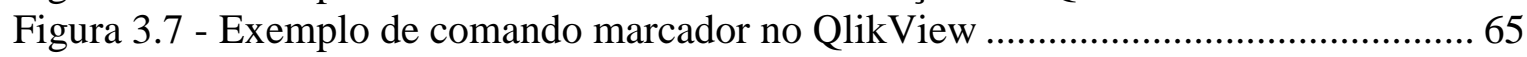

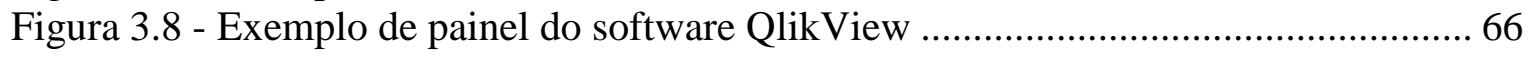

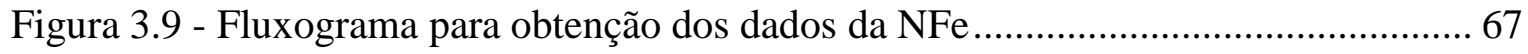

Figura 3.10 - Visualizador de tabelas do painel em QlikView ....................................... 78

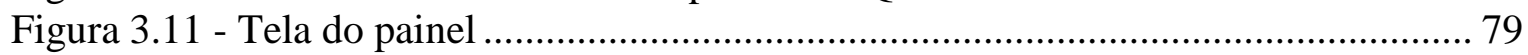

Figura 4.1 - Distribuição da quantidade por valor de NFe........................................... 88

Figura 4.2 - Percentual de NFe por produto, operações internas ..................................... 92

Figura 4.3 - Percentual de NFe por produto, origem externa para DF............................ 93

Figura 4.4 - Quantidade de despachos por atividade, operações internas .......................... 97

Figura 4.5 - Quantidade de entregas por atividade, operações internas ............................. 99

Figura 4.6 - Quantidade de entregas por atividade, operações externas para o DF ......... 100

Figura 4.7 - Maiores geradores de despachos por CEP, origem interna .......................... 105

Figura 4.8 - Maiores polos atratores de entregas por CEP, destino interno..................... 105

Figura 4.9 - Sazonalidade mensal das NFe's transacionadas, Jan 2010-Dez2014 ........... 113

Figura 4.10 - Sazonalidade diária no período mensal por quantidade de NFe ................ 113

Figura 4.11 - Sazonalidade da quantidade de NFe por dia da semana, bebidas ............... 114

Figura 4.12 - Quantidade de entregas, NCM máquinas, origem externa para PF............ 117

Figura 4.13 - Linha de desejo dos maiores atacadistas de alimentos no DF................... 124

Figura 4.14 - Quantidade de NFe's e tipos de veículos ................................................ 127

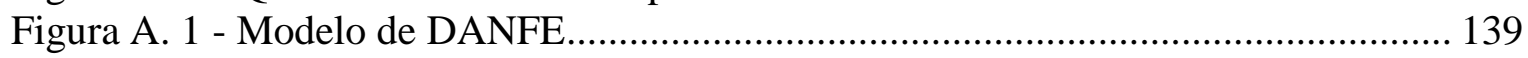

Figura A. 2 - Viagens versus origem e destino de cargas ............................................... 143

Figura A. 3 - Quantidade de paradas para entregas por rota por tipo de produtos............ 145

Figura A. 4 - Viagens pendulares versus encadeadas ..................................................... 147

Figura A. 5 - Esquema de atração e geração de viagens de carga por estabelecimentos. 148

Figura A. 6 - Relação entre geração de carga, de viagens e tamanho de remessa ............ 150

Figura A. 7 - Ligações potenciais entre embarcador, transportador e recebedor.............. 152 


\section{LISTA DE TABELAS}

Tabela 3.1 - Dados agregados em tabela pelo QlikView - Ago 2014 _............................. 75

Tabela 3.2 - Validação da metodologia de obtenção dos dados - Mar 2015 ...................... 83

Tabela 3.3 - Efeito do agrupamento de Nfe em distribuidora de bebidas - Mar 2015 ....... 84

Tabela 4.1 - Quantidade de NFe por origem e destino, Set 2013 - Ago 2014 ................... 90

Tabela 4.2 - Entregas por tipo de mercadoria para pessoa física, Set 2013 - Ago 2014... 94

Tabela 4.3 - Valor comercializado por tipo de mercadoria, Set 2013 - Ago 2014 ............ 94

Tabela 4.4 - Peso comercializado por tipo de mercadoria, Set 2013 - Ago 2014 .............. 95

Tabela 4.5 - Peso por entrega por tipo de mercadoria, Set 2013 - Ago 2014 .................... 95

Tabela 4.6 - Quantidade de despachos por tipo de atividade, Set 2013 - Ago 2014.......... 97

Tabela 4.7 - Quantidade de entregas por atividade, Set 2013 - Ago 2014 ....................... 98

Tabela 4.8 - Quantidade de entregas por atividade, Set 2013 - Ago 2014 ....................... 100

Tabela 4.9 - Maiores polos geradores de despachos por CEP, Set 2013 - Ago2014 ....... 103

Tabela 4.10 - Maiores atratores de entregas por CEP, Set 2013 - Ago 2014................... 104

Tabela 4.11 - Atividades com maior movimento de cargas, Set 2013 - Ago 2014 ......... 106

Tabela 4.12 - Geradores e atratores no comércio atacadista, Set 2013 - Ago 2014......... 108

Tabela 4.13 - Geradores e atratores comércio varejista, Set 2013 - Ago 2014 ................ 110

Tabela 4.14 - Frequência de entregas para clientes de bebidas, Set 2013 - Ago 2014 .... 115

Tabela 4.15 - Matriz OD base para seleção de CEP's, Set 2013 - Ago 2014 ................... 120

Tabela 4.16 - Matriz OD de entregas de atacadistas, Set 2013 - Ago 2014.................... 122

Tabela 4.17 - Matriz de distância de atacadistas de alimentos ...................................... 123

Tabela 4.18 - Fluxo de mercadoria no canal cosméticos, Set 2013 - Ago 2014 .............. 125

Tabela 4.19 - Tabela origem-destino de mercadorias, 1.Ago.2014 ............................... 126

Tabela 4.20 - Quantidade de entregas e peso de carga por veículo, 1 Ago 2014 ............ 128

Tabela B. 1 - Matrizes de atacadistascomo origem e destino, Set 2013 - Ago 2014 ....... 155 


\section{LISTA DE QUADROS}

Quadro 2.1- Modelos para o TUC e tipos de dados requeridos ..................................... 14

Quadro 2.2 - Fontes de dados para modelagem em transportes..................................... 15

Quadro 2.3 - Tipos de pesquisa e dados para TUC ............................................................ 21

Quadro 2.4 -Visões parciais dos agentes sobre o sistema de transporte ............................. 22

Quadro 2.5 - Comparação entre as técnicas de classificação de veículos ........................... 36

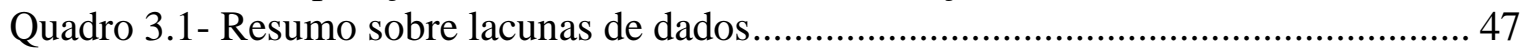

Quadro 3.2 - Campos selecionados da NFe ................................................................ 59

Quadro 3.3 - Códigos das unidades federativas do Brasil conforme padrão IBGE ........... 60

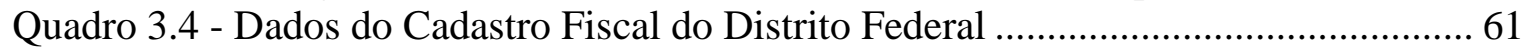

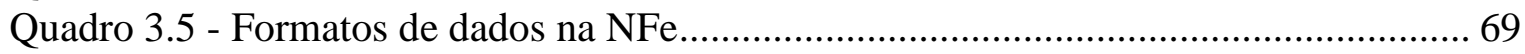

Quadro 3.6 - Período de análise para o QlikView .............................................................. 70

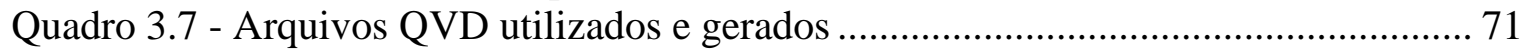

Quadro 3.8 - NFes de entrada e saída e a especificação de origens e destinos ................... 74

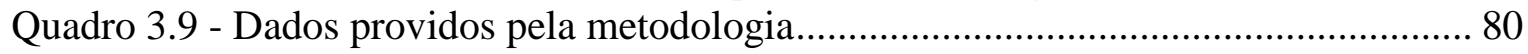

Quadro 3.10 - Dados da metodologia e modelagens em TUC ........................................ 81

Quadro A. 1- Geração de viagens: passageiros versus Carga .......................................... 142 


\section{LISTA DE ABREVIATURAS E SÍMBOLOS}

CFOP Código Fiscal de Operações e Prestações

CNAE Código Nacional de Atividades Econômicas

CTe Conhecimento de transporte eletrônico

DANFE Documento auxiliar da nora fiscal eletrônica

DF Distrito Federal

$\mathrm{DFe} \quad$ Documentos fiscais eletrônicos (NFe, cadastro de contribuintes)

FTL Full truckload (carga fechada)

LTL Less than truckload (carga fracionada)

MDFe Manifesto eletrônico de documentos fiscais

NCM Nomenclatura Comum do Mercosul, classifica os produtos

$\mathrm{NFe} \quad$ Nota fiscal eletrônica

QV QlikView

SEF-DF Secretaria de Estado da Fazenda do Distrito Federal

SPED Sistema Público de Escrituração Digital

TUC Transporte urbano de carga 


\section{SUMÁRIO}

1. INTRODUÇÃ

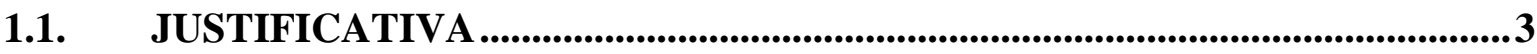

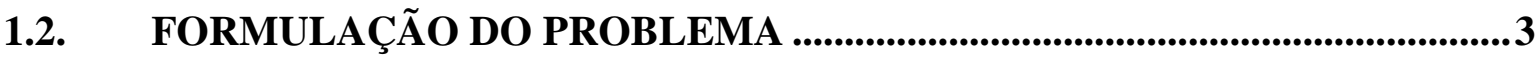

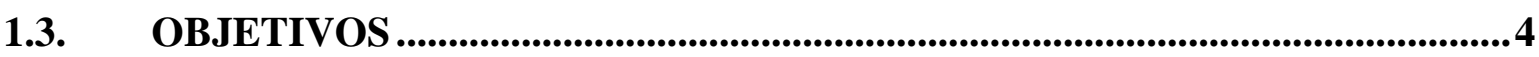

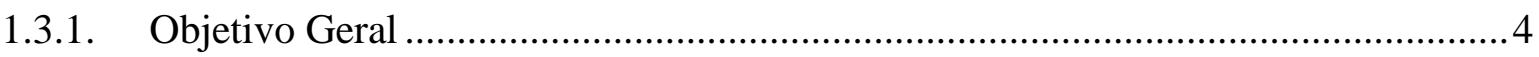

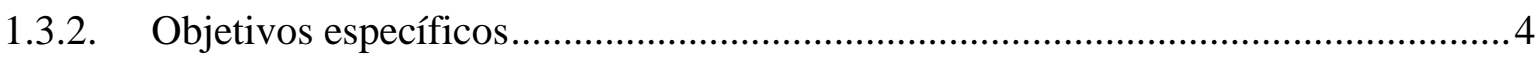

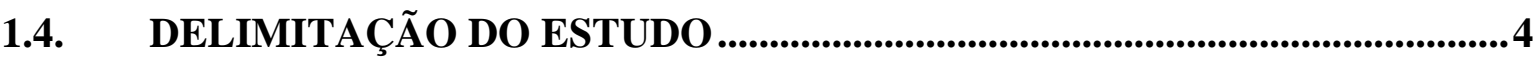

1.5. ESTRUTURA METODOLÓGICA DA PESQUISA .........................................4

1.6. ESTRUTURA DO TRABALHO ........................................................................7

2. METODOLOGIA PARA COLETA DE DADOS EM TUC ...............................9

2.1. QUAIS DADOS COLETAR?.......................................................................11

2.1.1. Dados para o TUC sob a visão de diferentes especialistas em transportes ............11

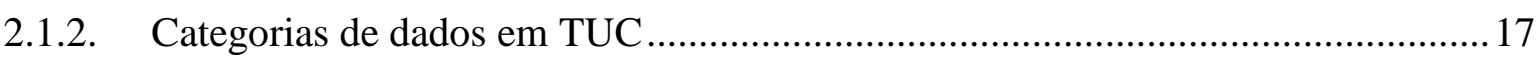

2.1.3. Quadro resumo das categorias de dados........................................................... 21

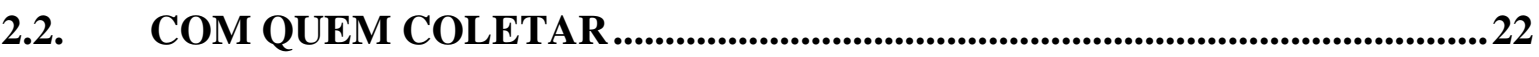

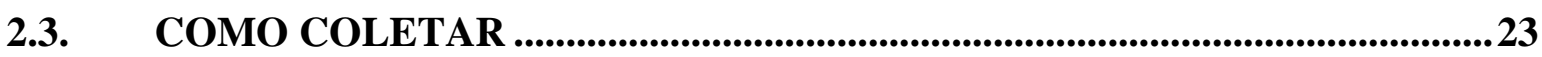

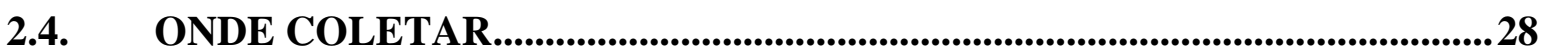

2.5. ETAPAS PARA O PLANEJAMENTO DA COLETA........................................36

2.6. DEFINIÇÃO DA ÁREA DE ESTUDO ..................................................................38

2.7. CARACTERIZAÇÃO DO OBJETO DE ESTUDO ............................................39

2.8. DEFINIÇÃO DO NÍVEL DE DESAGREGAÇÃO DOS DADOS ...................43

2.9. MOVIMENTOS PADRÃO DE VIAGENS ..........................................................44

3. METODOLOGIA PARA OBTENÇÃO DOS DADOS DE DFe.......................47

3.1. FONTES UTILIZADAS PARA A EXTRAÇÃO DOS DADOS .......................50

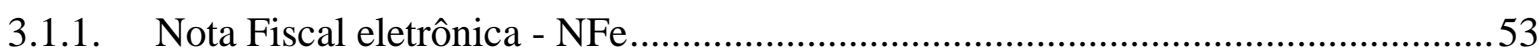

3.1.2. Cadastro Fiscal de Contribuintes do Distrito Federal ...........................................58

3.2. SELEÇÃO DOS CAMPOS DA NFE E DO CADASTRO FISCAL ................58

3.3. FERRAMENTA DE EXTRAÇÃO: SOFTWARE QLIKVIEW ......................62

3.4. FLUXOGRAMA PARA EXTRAÇÃO DOS DADOS ................................67

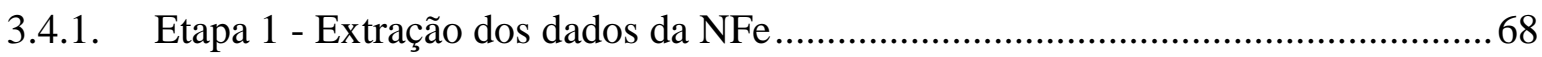

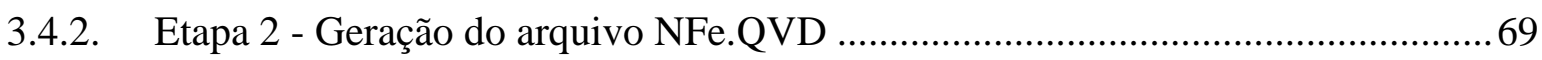

3.4.3. Etapa 3 - Geração do painel para análise ........................................................... 76

3.5. DADOS OBTIDOS E PESQUISAS COMPLEMENTARES.........................80

3.6. VALIDAÇÃO DOS DADOS OBTIDOS .........................................................82 
4. USO DOS DADOS DOS DFe NO DISTRITO FEDERAL .............................85

4.1. TUC NO DISTRITO FEDERAL ...................................................................85

4.2. ANÁLISE DO TUC UTILIZANDO DADOS DO DISTRITO FEDERAL ....86

4.3. ANÁLISE INICIAL E TRATAMENTO DOS DADOS ....................................87

4.4. MOVIMENTO PADRÃO DOS FLUXOS DE CARGAS..................................88

4.4.1. Participação dos movimentos padrão das NFe's ................................................89

4.4.2. Participação dos tipos de mercadorias no fluxo de cargas ...................................91

4.4.3. Participação dos tipos de atividades no fluxo de cargas .....................................96

4.5. MAIORES GERADORES E ATRATORES DE CARGA...........................101

4.5.1. Polos geradores e atratores de carga.............................................................. 103

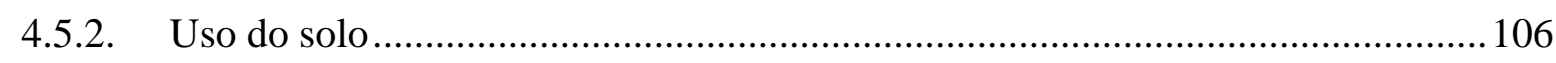

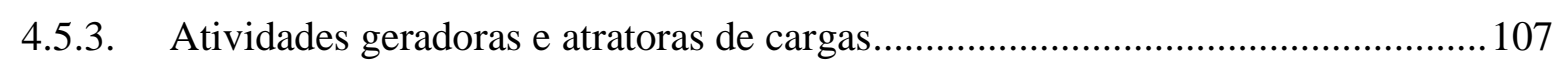

4.6. FATORES DE INFLUÊNCIA EM TUC ...........................................................111

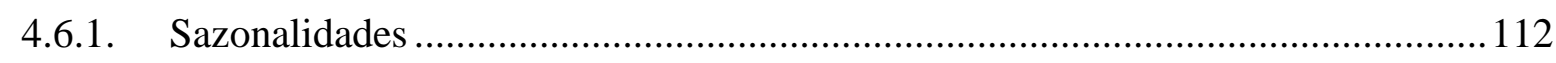

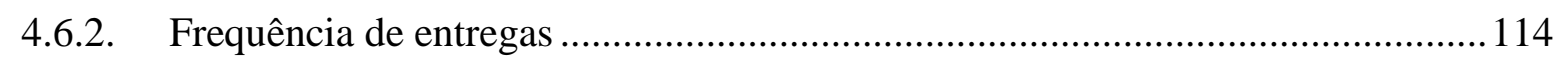

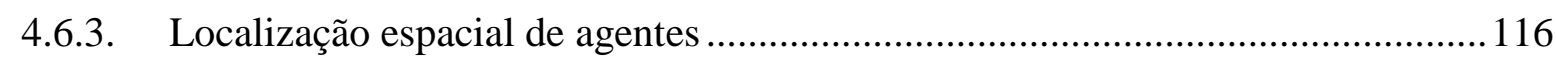

4.7. DADOS PARA MODELAGEM EM TUC .............................................118

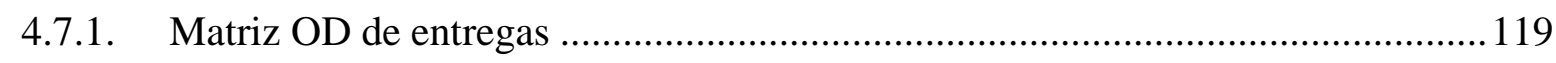

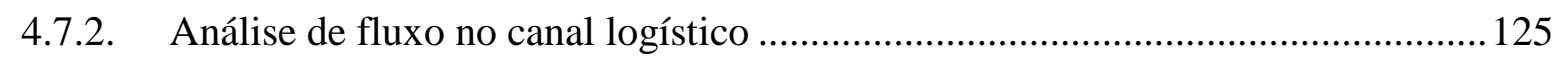

4.7.3. Tabelas OD para roteirização ...................................................................... 126

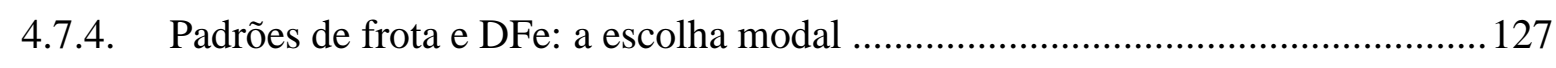

5. COMENTÁRIOS FINAIS....................................................................................130

5.1. CONTRIBUIÇÕES .............................................................................................130

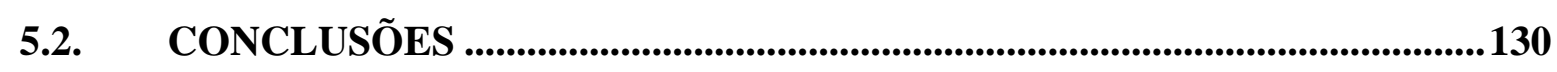

5.3. LIMITAÇÕES DO ESTUDO ...............................................................................131

5.4. RECOMENDAÇÕES DE ESTUDOS FUTUROS ...........................................132

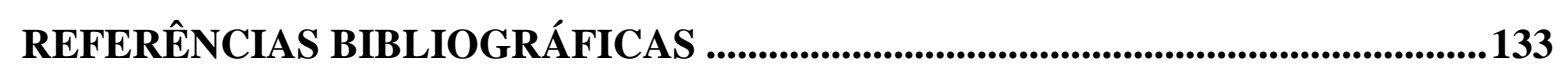

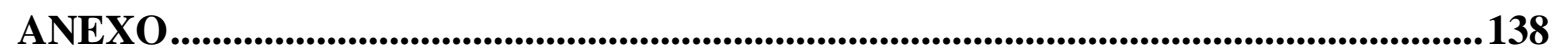

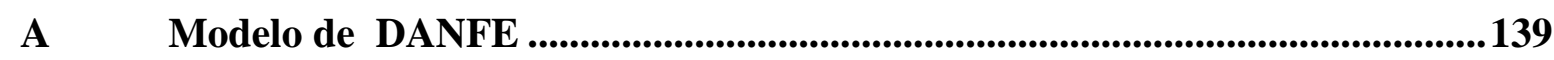

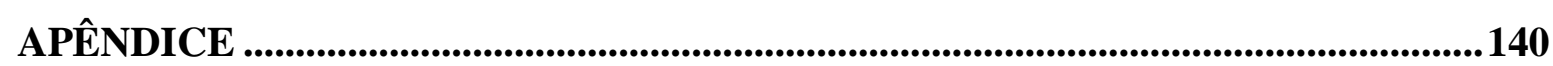

A Aspectos característicos do TUC...............................................................................141

B Tabelas base para a matriz OD de atacadistas ..................................................155 


\section{INTRODUÇÃO}

IBGE (2010) demonstra que $84,4 \%$ da população brasileira residem em áreas urbanas e, no Distrito Federal, este número salta para 97\%, com uma população de 2,57 milhões de habitantes e densidade populacional de 430 habitantes por quilômetro quadrado. Tal concentração populacional somada a um deficiente sistema de transporte coletivo tem induzido as pessoas a utilizarem o transporte individual. A título de exemplo, Brasília conta com uma relação de 1,8 habitantes por veículo (IBGE, 2010; LAMMERS, 2012). IPEA (2010) estima que o transporte individual atinja em 2030 aproximadamente $65 \%$ do total de viagens nas regiões metropolitanas brasileiras.

Este cenário sinaliza para um agravamento do congestionamento do tráfego e decréscimo da produtividade nas atividades econômicas, com efeito especial sobre o transporte urbano de carga (TUC) que, por sua vez, também contribui para ocupar o espaço urbano e gerar externalidades negativas, como poluição, ruídos e acidentes. Cintra (2014) argumenta que somente os congestionamentos paulistanos podem gerar perdas de mais de $\mathrm{R} \$ 40,0$ bilhões considerando dados de 2012. Destes, R \$ 4,0 bilhões seriam de perdas do setor transporte de mercadorias relativas à consumo de combustível, perda de produtividade, etc.

O TUC pode representar $20 \%$ da ocupação das vias quando comparado ao transporte de veículos de passeio (OLIVEIRA; BRAGA; ABREU, 2010) e de 10 a 15\% de ocupação pelos veículos de carga estacionados (CARVALHO, 1998). Oliveira e Guerra (2014) apontam que veículos de carga podem ocupar 35,7\% dos espaços para estacionamento nas ruas $^{1}$. MMA (2011) mostra que caminhões e veículos de pequeno porte, de uso típico no transporte urbano de mercadorias ${ }^{2}$, respondem no Brasil pela emissão de $61 \%$ de óxido de nitrogênio (NOx), 65\% do material particulado e 48\% de dióxido de carbono (CO2).

Para lidar de modo apropriado com estas questões diversos países tem implementado soluções para o transporte urbano de cargas (STATHOPOULOS; VALERI; MARCUCCI, 2012). Estudos e iniciativas inovadoras tem sido realizados nos Estados Unidos, Europa,

\footnotetext{
${ }^{1} \mathrm{Na}$ Europa há números similares em que o fluxo de carga ocupa $25 \%$ do fluxo de tráfego (DABLANC, 2007) e pode representar $40 \%$ dos veículos estacionados durante os dias úteis (PIARC, 2012).

2 Veículos de pequeno porte representam cerca de $80 \%$ do tráfego de cargas (HOLGUíN-VERAS et al., 2014a); Oliveira e Guerra (2014) apontam que 92\% dos veículos pesquisados em uma região de Belo Horizonte tem capacidade máxima de 5 toneladas.
} 
Japão e Austrália com expressivos resultados alcançados (ANAND et al., 2012; HOLGUÍN-VERAS et al., 2014a, 2014b).

A questão é que a tradução destas iniciativas em estudos e projetos no Brasil ainda é incipiente, pois depende notadamente de informações que possibilitem realizar estudos no complexo sistema que é a distribuição de carga urbana. Este aspecto é enfatizado por pesquisadores brasileiros. Sanches Jr., Rutkwoski e Lima Jr. (2008, p. 13) afirmam que há necessidade de "pesquisas que identifiquem o comportamento de carga na cidade e proporcionem a utilização de métodos de modelagens para auxiliar no planejamento do transporte urbano de cargas". Sanches Jr. (2008, p. 161) aponta "dados deveriam ser coletados, e estatísticas elaboradas para subsidiar o desenvolvimento de soluções para o setor".

Para contribuir com esta carência por informações e possibilitar a elaboração de estudos para o planejamento do transporte urbano de cargas, este trabalho propõe uma metodologia para extrair, disponibilizar e analisar dados da Nota Fiscal Eletrônica existente na Secretaria de Fazenda do Distrito Federal como fonte alternativa de informações para estudos do TUC, dados estes organizados e armazenados de modo padronizado em todos os estados brasileiros.

A proposta metodológica utiliza uma ferramenta de inteligência em negócios que trabalha com bases de dados de grande porte, e demonstra os passos para que transações com notas fiscais reflitam a dinâmica de entregas e coletas de mercadorias. Essa metodologia, por sua vez, se baseia nas referências colhidas durante a elaboração deste trabalho e apresenta quatro grupos de análises: dos movimentos padrão dos fluxos de cargas, dos maiores geradores e atratores de carga, dos fatores de influência em TUC, tais como sazonalidade e localização espacial de origens e destinos de cargas, e a geração de dados para modelagens, como matrizes origem-destino e tabelas OD para roteirização, dentre outros.

Enfim, espera-se que o resultado deste estudo ofereça insumos para que pesquisadores e gestores públicos possam obter dados e planejar o transporte urbano de cargas com maior dinamismo não somente no Brasil, mas também em outros países que, segundo Tavasszy e Jong (2014), em sua maioria processam as transações comerciais eletronicamente. 


\subsection{JUSTIFICATIVA}

Para viabilizar o planejamento do TUC de modo adequado há necessidade de dados que apoiem pesquisas, e obtê-los é o principal desafio (TAVASSZY; JONG, 2014). Isto porque tais informações requerem geralmente a desagregação de dados atualizados, estão dispersas entre diversos atores com visões parciais sobre o sistema de transporte, os dados geralmente são sigilosos para as empresas que os possuem e são, principalmente, de alto custo para obtenção por meio de pesquisas diretas (HOLGUÍN-VERAS; JALLER, 2014).

Como exemplo, uma pesquisa abrangente em TUC para a região metropolitana de Nova Iorque é estimada em 7,5 milhões de dólares (HOLGUÍN-VERAS et al., 2010). Isto, por sua vez, inibe a realização de pesquisas de modo sistemático, com efeitos sobre a atualização das informações em um ambiente urbano dinâmico.

Além disso, alternativas de menor custo como trabalhar com contagens amostrais de tráfego falham em interpretar os movimentos de carga urbana devido a algumas de suas características como multimodalidade, entregas encadeadas em rotas e o uso de estruturas intermediárias como depósitos (TAVASSZY; JONG, 2014). Num cenário em que faltam recursos no Brasil, torna-se urgente buscar fontes de informações alternativas de baixo custo, atualizadas e adequadas ao planejamento do transporte urbano de cargas.

Este trabalho preenche essa necessidade, pois utiliza bases de dados de documentos fiscais eletrônicos (DFe) do Distrito Federal, disponíveis de modo padronizado para todos os estados brasileiros. Estes dados são coletados, validados, armazenados e atualizados diariamente por meio de processos existentes nas receitas estaduais e federal do Brasil (SPED, 2015). Não se vislumbra a necessidade de criar novas estruturas administrativas ou entidades para sua obtenção, restando a necessidade em organizar o acesso aos dados.

\subsection{FORMULAÇÃO DO PROBLEMA}

No contexto do transporte urbano de cargas esta tese busca responder à seguinte questão:

- É possível obter, disponibilizar e utilizar dados provenientes de documentos fiscais eletrônicos como alternativa ao fornecimento de informações para o planejamento do transporte urbano de cargas? 


\subsection{OBJETIVOS}

\subsubsection{Objetivo Geral}

O objetivo principal dessa pesquisa consistiu em desenvolver uma metodologia alternativa de obtenção de informações para o planejamento do transporte urbano de cargas a partir de dados de documentos fiscais eletrônicos.

\subsubsection{Objetivos específicos}

Os objetivos específicos dessa pesquisa foram:

$>$ Organizar as etapas de coletas de dados para uso em estudos sobre o transporte urbano de cargas.

Validar a aplicação da metodologia proposta de extração de dados de documentos fiscais eletrônicos.

Propor diferentes tipos de análises que orientem a utilização dos dados obtidos e forneçam informações úteis para o planejamento do TUC.

\subsection{DELIMITAÇÃO DO ESTUDO}

Este trabalho se baseia nos dados de transações comerciais diretas com vendas de mercadorias informadas na nota fiscal eletrônica. Portanto outras atividades relacionadas com o transporte de cargas não são relacionadas no escopo deste estudo.

\subsection{ESTRUTURA METODOLÓGICA DA PESQUISA}

Esta seção descreve os principais procedimentos metodológicos e as ferramentas utilizadas nesta pesquisa. O objetivo é tornar claras as etapas, desde a identificação da oportunidade de estudo até a conclusão desta tese. 


\section{Etapa 1 - Escolha do tema}

O tema transporte urbano de cargas foi escolhido por sua importância econômica, pelo seu alto impacto no tráfego e no meio ambiente das grandes metrópoles brasileiras, e por ser um tema pouco explorado no meio acadêmico e científico.

\section{Etapa 2 - Identificacão da oportunidade de pesquisa e definicão da área de trabalho}

Após uma revisão bibliográfica nacional e internacional, foi constatado que o principal desafio dos especialistas em transportes é a falta e o alto custo para obtenção de dados para a realização de estudos sobre o transporte urbano de cargas.

A pesquisa de Tavasszy (2014) assinala que uma das fontes de dados para pode realizar os referidos estudos é a nota fiscal que ampara as transações comerciais, informações que são organizadas e armazenadas nos bancos de dados das secretarias de fazenda dos estados brasileiros sob o projeto da Nota Fiscal Eletrônica-NFe (SPED, 2015).

A partir do acesso ao banco de dados da Secretaria de Fazenda do Distrito Federal, identificou-se a oportunidade em utilizá-lo neste trabalho. Devido à abrangência dos dados disponíveis, o Distrito Federal ficou definido como área de estudo.

\section{Etapa 3 - Estudo de referências bibliográficas}

Revisões bibliográficas relacionadas ao Transporte Urbano de Cargas foram realizadas. Entre as principais referências utilizadas encontra-se Santos (2008), Santos e SánchezDíaz (2015), Holguín-Veras et al. (2014), e aquelas referências atuais que abrangessem os seguintes temas: procedimentos e métodos para o planejamento de coleta de dados em transportes; ferramentas e métodos para extração e tratamento de dados digitais; estudos sobre o transporte urbano de cargas.

\section{Etapa 4 - Dados necessários para o estudo do TUC}

O conteúdo assimilado serviu para definir quais dados da NFe seriam utilizados para os propósitos da pesquisa. 


\section{Etapa 5 - Organização das etapas de coletas de dados para uso em TUC}

Tendo como base as referências estudadas foi desenvolvido um procedimento metodológico para fazer o planejamento da pesquisa sobre coleta de dados utilizando as fontes propostas nesse estudo. $\mathrm{O}$ procedimento refere-se às etapas básicas para iniciar um estudo em transportes.

\section{Etapa 6 - Desenvolvimento de metodologia para extração de dados}

Foram estudados os conteúdos sobre a nota fiscal eletrônica (MANUAL-NFE, 2012), sobre o software de manipulação dos dados da SEF-DF (QLIKVIEW ${ }^{3}, 2011$ ) e aplicados os conhecimentos adquiridos nas etapas anteriores. Nesta etapa desenvolveuse o painel de análise dos dados baseado no software QlikView.

Ressalta-se que, pelo fato de a NFE ter sua estrutura e organização padronizadas no Brasil, esta metodologia pode ser aplicada em qualquer estado brasileiro sendo, portanto, transferível. Essa condição ensejou detalhar as etapas da metodologia para a extração dos dados de modo que outros pesquisadores possam utilizá-la com maior facilidade.

\section{Etapa 7 - Validacão da metodologia para extracão de dados}

Após a extração dos dados foram feitas validações entre diferentes tabelas para verificar se os resultados mostravam consistência.

\section{Etapa 8 - Proposta de análise dos dados para o planejamento do TUC}

Após a validação dos dados e tendo como base o painel do QlikView e as referências estudadas nas etapas anteriores, foram elaboradas diferentes propostas de análises consideradas úteis ao planejamento do TUC. A proposta engloba, portanto, como manipular e interpretar os dados em quatro grupos de análise: dos quatro movimentos

\footnotetext{
${ }^{3}$ O software QlikView foi escolhido por ser a ferramenta utilizada para manipulação dos dados da NFe na SEF-DF, e que conta com recursos mais adequados aos propósitos deste trabalho.
} 
básicos ${ }^{4}$ de transporte em uma área de estudo, dos maiores geradores e atratores de carga, de fatores que influenciam o TUC e como gerar dados para modelagens, tais como matrizes origem-destino. As análises envolvem o tipo de mercadoria, seu peso, valor e quantidade de entregas ou despachos realizados, bem como a localização espacial e atividade econômica dos agentes envolvidos.

\section{Etapa 9 - Aplicação da metodologia com os dados obtidos no Distrito Federal}

Foram feitas as análises propostas na etapa anterior com os dados obtidos de modo a analisar os movimentos de carga, seus principais geradores e atratores, para o Distrito Federal, demonstrando a validade da metodologia como fonte alternativa de dados úteis para o planejamento do TUC.

\section{Etapa 10 - Conclusões e recomendacões}

Foi feita a conclusão do trabalho onde são destacados o caráter inovador e a significativa contribuição desta tese, além da exposição das limitações do estudo e respectivas perspectivas de estudos futuros que se abrem.

\subsection{ESTRUTURA DO TRABALHO}

Este trabalho está estruturado em mais quatro capítulos além do capítulo de introdução. Estes são organizados como segue:

Capítulo 2

Apresenta o referencial teórico sobre a coleta de dados no transporte urbano de cargas (TUC). Os objetivos são proporcionar uma uniformização de conceitos relacionados ao tema, e oferecer um referencial sobre os tipos de dados requeridos para o planejamento do transporte urbano de carga, bem como sobre os tipos, métodos e técnicas de pesquisa utilizados para obtê-los. Este capítulo serve de referência para os trabalhos desenvolvidos nos capítulos 3 e 4.

\footnotetext{
${ }^{4}$ Os movimentos básicos são: internos, interno-externo, externo-interno e externos (BRUTON,1970, p. 32)
} 


\section{Capítulo 3}

Apresenta as ferramentas e os procedimentos para tratar, extrair e disponibilizar os dados da nota fiscal eletrônica. Neste caminho são feitos esclarecimentos sobre a organização dos dados de documentos fiscais eletrônicos.

\section{Capítulo 4}

Propõe análises para uso dos dados obtidos e serve de base para a aplicação da metodologia por meio de um estudo de caso realizado no Distrito Federal. São apresentados os respectivos resultados e demonstra-se como as informações obtidas com DFe podem ser utilizadas para fornecer dados para o planejamento e também analisar o comportamento do TUC .

\section{Capítulo 5}

Apresenta os comentários finais acerca das contribuições, conclusões, limitações e perspectivas de estudos futuros baseadas nesta tese. 


\section{METODOLOGIA PARA COLETA DE DADOS EM TUC}

Os estudos sobre planejamento em transportes, em geral, envolvem a utilização de diferentes tipos de informação que, dependendo de seu grau de desagregação, dos objetivos e do tamanho da área de estudo, podem conter uma quantidade considerável de dados. Notadamente nos países desenvolvidos esse processo de coleta é realizado por instituições especializadas em coleta e tratamento de dados, como é o caso da CFS (de Commodity FlowSurvey) (HOLGUÍN-VERAS; JALLER, 2014) nos Estados Unidos e o programa BESTUFS na Europa (ROUTHIER; PATIER, 2006).

No Brasil há também entidades específicas para realizar pesquisas periódicas na área de transporte, como a CODEPLAN (2015) em Brasília. Porém, essas pesquisas são expressivamente caras e por isso são realizadas com bases amostrais, entre longos intervalos e com forte viés para estudos do transporte de pessoas. Mesmo nestes casos ainda são necessárias pesquisas complementares em determinadas áreas de estudo, pois os dados ou são insuficientes ou não estão atualizados.

No caso do transporte urbano de cargas esse problema se agrava, pois o mesmo requer muitas vezes a desagregação dos dados por origens-destinos, tipos de produtos, atividades econômicas, modos de transportes, diferentes processos de entrega, coleta, carga e descarga, equipamentos utilizados, dentre outros aspectos. Trata-se ainda de um setor com pouca atenção dada pelos governos locais, que apresenta alta capilaridade e dinamismo, e para o qual se torna quase impeditivo obter dados confiáveis de modo sistemático.

Esta falta de dados e de interesse no TUC reverberam na academia, onde são observados poucos trabalhos quando se compara os estudos sobre o transporte de pessoas. Portanto referências bibliográficas que abordem metodologias para coletas de dados do TUC são escassas, e as existentes tratam de metodologias e procedimentos específicos para um determinado assunto na área de transporte de carga, como roteirização, programação de veículos, dimensionamento de frota, etc.

Pode-se afirmar que praticamente não existem metodologias consolidadas para a coleta de dados para o planejamento de transporte urbano de cargas no mesmo patamar do 
planejamento do transporte urbano de passageiros. Nestas metodologias, consolidadas no meio acadêmico tanto no nível nacional quanto internacional, observa-se bibliografias que mantém significativa coerência no uso de definições e conceitos para o transporte de passageiros. Não se pode dizer o mesmo para o TUC.

Portanto, neste contexto, e na medida em que se propõe uma metodologia alternativa de uso de dados por documentos fiscais eletrônicos (Dfe), propõe-se uma metodologia para a coleta de dados em transporte urbano de cargas considerando os métodos atualmente utilizados na obtenção destas informações. Esta proposta serve para:

a) fundamentar a elaboração da metodologia alternativa sobre aspectos como a seleção, o tratamento, a apresentação e a validação dos dados de DFe para seu uso nos estudos do TUC;

b) contextualizar em que extensão os dados obtidos dos DFe podem ser utilizados para suprir a falta de informações para o planejamento do transporte urbano de cargas e, por conseguinte, necessitam ser complementados pelos métodos tradicionais de pesquisa.

A proposta metodológica para coleta de dados em TUC é estruturada sob a seguinte sequência:

Quais dados coletar: propõe-se uma referência de categorias de dados utilizados em estudos do TUC;

Com quem coletar: indicam-se atores e suas capacidades para fornecer informações;

Como coletar: apresenta-se um resumo dos métodos de coleta de dados em transportes;

$>$ Onde coletar: listam-se o que se denomina de alvos amostrais ou técnicas de pesquisa tradicionalmente utilizados por diferentes especialistas em seus estudos sobre TUC;

Como planejar: são propostas etapas para a coleta de dados em TUC a partir de referências sobre o planejamento da coleta de dados em transportes. 


\subsection{QUAIS DADOS COLETAR?}

A seleção das variáveis do sistema de transporte que se deseja estudar define os tipos de dados que serão utilizados tanto no processo de planejamento de transporte como em suas diferentes fases de modelagem. Esta seleção é uma das etapas mais importantes do planejamento para a coleta dos dados, e deve ser feita após uma definição das necessidades

e objetivos do estudo. É o que afirma Ogden (1992, p. 307): "a coleta de dados não deve ser um fim em si, mas sim precedida e relacionada com uma clara relação de necessidades [...] Isto significa coletar dados úteis e ao mesmo tempo não consumir tempo e recursos com aqueles que nunca serão utilizados".

Porém, como definir estas necessidades e objetivos de um estudo ocorre em um contexto específico de cada projeto ou estudo (OGDEN, 1992, p. 307), e considerando não ser foco deste trabalho discutir tais aspectos, parte-se da premissa de que os mesmos sejam previamente claros e definidos. Apresenta-se então uma lista de dados utilizados ou considerados úteis por diferentes especialistas em transporte urbano de cargas em seus estudos. Em seguida, estas diferentes referências são sumarizadas e descritas sob uma lista de categorias de dados considerados úteis para estudos em TUC. Por fim, apresenta-se um quadro resumo destas categorias vinculadas a três diferentes tipos de pesquisa e seus respectivos dados.

\subsubsection{Dados para o TUC sob a visão de diferentes especialistas em transportes}

Allen, Browne e Cherrett (2012) citam que a coleta de dados em TUC focalizam três aspectos principais: as rotas de veículos de carga, das próprias cargas na área urbana e as atividades dos veículos nos estabelecimentos, sendo este o mais realizado. Os autores enfatizam que os estudos sobre o fluxo de cargas são raros (grifo nosso).

Com a ressalva sobre a definição prévia de necessidades do estudo, Ogden (1992, p. 307) aponta que os principais tipos de informação recaem em cinco áreas: 1) a descrição da frota de veículos; 2) o fluxo de veículos de carga, suas viagens; 3) fluxos de mercadorias; 4) os principais estabelecimentos geradores de carga e; 5) principais corredores de carga. 
Richardson, Ampt e Meyburg (1995) classificam as pesquisas em transportes em seis tipos que descrevem sua função no contexto do planejamento de transportes, e que indicam o perfil dos dados a serem coletados, a saber:

a) de uso do solo que buscam a localização espacial e intensidade do uso do solo pelas atividades;

b) do inventário do sistema de transporte cuja função é especificar a localização e características do sistema de transporte nos diferentes modos de transporte utilizados, públicos e privados, com três componentes básicos: sistema viário, terminais e veículos;

c) de padrão de viagens, que resultam da combinação do uso do solo pelas atividades e as características do sistema de transporte, e que buscam descrever quem (ou o que em termos de carga) vai para onde, com quem, a que tempo, por qual tipo de modo, rota e propósito de viagem;

d) de desempenho do sistema de transporte, que avaliam se o mesmo suporta a demanda dada ou futura em termos de segurança e capacidade;

e) demográficas e sócio-econômicas que visam dar suporte à previsão da demanda futura por meio da investigação das características de diferentes grupos da população, tais como renda, idade, sexo, etc.;

f) de percepção e atitudinais, que buscam conhecer como os indivíduos percebem e reagem às mudanças no sistema de transporte e que são fonte para a elaboração de modelos de demanda.

Routhier e Patier (2006) demonstram os dados coletados em três pesquisas com 4.500 estabelecimentos no programa francês Merchandises en Ville. Estes dados são aplicados no desenvolvimento do software FRETURB ${ }^{5}$, utilizado por autoridades do país para simular o tráfego no meio urbano. Os principais dados coletados são:

a) dos estabelecimentos, que inclui a descrição de sua atividade econômica, se o mesmo é matriz ou filial, seu porte, número de empregados e de veículos de carga, e o nome do principal transportador;

\footnotetext{
${ }^{5}$ Freturb: http://freturb.let.fr/
} 
b) das operações destes estabelecimentos, contendo a quantidade, tempo e frequência das operações de carga e descarga, tipo de veículo e peso das mercadorias envolvidas;

c) dos produtos, com sua descrição e tipo de embalagem, bem como o endereço do despachante da mercadoria;

d) dos motoristas, que descrevem o nome da empresa, tipo de veículo, origem e destino da rota, localização e horário de estacionamento para cada parada.

Holguin-Veras et al. (2010) apontam que os principais dados para desenvolvimento, calibragem e previsão de demanda por cargas podem ser enquadrados em oito categorias:

a) informações sobre os padrões de fluxo no canal logístico;

b) dados sobre geração de cargas;

c) dados sobre geração de viagens de carga;

d) rotas de entrega;

e) características econômicas e distribuição espacial/localização dos agentes para caracterizar o comportamento dos atores envolvidos;

f) características da malha viária;

g) processos de escolha especiais que necessitam ser identificados e;

h) outros dados econômicos que servem para caracterizar aspectos específicos da demanda por carga não cobertos nos itens anteriores.

Tendo como referência estas oito categorias de dados propostos por Holguin-Veras et al. (2010), Holguín-Veras e Jaller (2014) fazem um interessante relacionamento dos dados aos tipos de modelos utilizados na modelagem de transportes e apresentam o Quadro 2.1. Neste quadro fica claro que a maior parte dos modelos pode ser gerada a partir de informações sobre a localização e características econômicas dos agentes, e dos fluxos de cargas com dados desagregados de modo a localizar suas origens e destinos. Um aspecto de interesse analisado no referido quadro é que a geração de modelos baseados em rotas (MSh), aspecto fundamental na compreensão dos movimentos de carga urbana, necessita de dados que indiquem a sequência e localização das entregas e coletas de mercadorias, bem como a localização espacial e características econômicas dos agentes envolvidos. 
Quadro 2.1- Modelos para o TUC e tipos de dados requeridos

\begin{tabular}{|c|c|c|c|c|c|c|c|c|c|c|c|c|}
\hline \multirow{2}{*}{$\begin{array}{c}\text { Categorias de } \\
\text { dados }\end{array}$} & \multirow{2}{*}{ Tipos de dados } & \multicolumn{11}{|c|}{ Modelos para o transporte urbano de cargas } \\
\hline & & $\mathrm{GC}$ & GVC & DIST & EM & IP & VV & EEP & MS & MSh & EEP & OD \\
\hline $\begin{array}{l}\text { Informação dos } \\
\text { fluxos logísticos }\end{array}$ & Produção & & & $\mathrm{X}$ & & $\mathrm{X}$ & & $\mathrm{X}$ & $\mathrm{X}$ & $\mathrm{X}$ & $\mathrm{X}$ & \\
\hline \multirow{2}{*}{$\begin{array}{c}\text { Dados de geração } \\
\text { de carga }\end{array}$} & Produção & $\mathrm{X}$ & & & & $\mathrm{X}$ & & & $\mathrm{X}$ & $\mathrm{X}$ & $\mathrm{X}$ & $\mathrm{X}$ \\
\hline & Consumo & $\mathrm{X}$ & & & & $\mathrm{X}$ & & & $\mathrm{X}$ & $\mathrm{X}$ & $\mathrm{X}$ & $\mathrm{X}$ \\
\hline \multirow{4}{*}{ Rotas de Entrega } & Seqüência & & & & & & & & $\mathrm{X}$ & $\mathrm{X}$ & $\mathrm{X}$ & \\
\hline & Localização & & & & & & & & $\mathrm{X}$ & $\mathrm{X}$ & $\mathrm{X}$ & \\
\hline & Fluxos OD & & $\mathrm{X}$ & $\mathrm{X}$ & & $\mathrm{X}$ & $\mathrm{X}$ & & $\mathrm{X}$ & $\mathrm{X}$ & $\mathrm{X}$ & \\
\hline & Fluxos de carga vazia & & $\mathrm{X}$ & & & & $\mathrm{X}$ & & & & & \\
\hline \multirow{3}{*}{$\begin{array}{l}\text { Características } \\
\text { econômicas dos } \\
\text { agentes }\end{array}$} & Embarcadores & $\mathrm{X}$ & & & & & & & $\mathrm{X}$ & $\mathrm{X}$ & $X$ & \\
\hline & Transportadores & $\mathrm{X}$ & & & & & & & $\mathrm{X}$ & $\mathrm{X}$ & $\mathrm{X}$ & \\
\hline & Recebedores & $\mathrm{X}$ & & & & & & & $\mathrm{X}$ & $\mathrm{X}$ & $\mathrm{X}$ & \\
\hline \multirow{3}{*}{$\begin{array}{c}\text { Distribuição } \\
\text { espacial / } \\
\text { localização dos } \\
\text { agentes }\end{array}$} & Embarcadores & $\mathrm{X}$ & & & & & & & $\mathrm{X}$ & $\mathrm{X}$ & $\mathrm{X}$ & \\
\hline & \begin{tabular}{|l} 
Transportadores \\
\end{tabular} & $\mathrm{X}$ & & & & & & & $\mathrm{X}$ & $\mathrm{X}$ & $\mathrm{X}$ & \\
\hline & Recebedores & $\mathrm{X}$ & & & & & & & $\mathrm{X}$ & $\mathrm{X}$ & $X$ & \\
\hline \multirow{4}{*}{$\begin{array}{c}\text { Características da } \\
\text { Rede Viária }\end{array}$} & Tempos de viagens,custos & & $\mathrm{X}$ & $\mathrm{X}$ & & $\mathrm{X}$ & $\mathrm{X}$ & & $\mathrm{X}$ & $\mathrm{X}$ & $\mathrm{X}$ & $\mathrm{X}$ \\
\hline & Restrições de uso & & $\mathrm{X}$ & $X$ & & $\mathrm{X}$ & $X$ & & $\mathrm{X}$ & $X$ & $\mathrm{X}$ & $\mathrm{X}$ \\
\hline & Capacidade & & $\mathrm{X}$ & $X$ & & $\mathrm{X}$ & $X$ & & $\mathrm{X}$ & $X$ & $\mathrm{X}$ & $\mathrm{X}$ \\
\hline & Volumes de tráfego & & & & & & & & & & & $\mathrm{X}$ \\
\hline \multirow{3}{*}{$\begin{array}{c}\text { Processos de } \\
\text { escolha especial }\end{array}$} & Escolha modal & & & & $X$ & & & & & & & \\
\hline & Tempo de entrega & & & & & & & & & & & \\
\hline & Atributos do modo & & & & $\mathrm{X}$ & & & & & & & \\
\hline \multirow{3}{*}{$\begin{array}{l}\text { Outros dados } \\
\text { econômicos }\end{array}$} & Funções de produção & & & & & & & $\mathrm{X}$ & & & $\mathrm{X}$ & \\
\hline & Funções de demanda & & & & & & & $\mathrm{X}$ & & & $\mathrm{X}$ & \\
\hline & \multicolumn{2}{|l|}{ Coeficientes insumo/produto } & & & & $\mathrm{X}$ & & & & & & \\
\hline
\end{tabular}

Modelos de: geração de cargas (GC), geração de viagens (GVC), distribuição (DIST), escolha modal (EM), insumo/produto (IP), viagens vazias (VV), equilíbrio espacial/preço (EEP), microssimulação: baseado em viagens (MS), microssimulação híbridos: fluxo de cargas e roteirização de veículos (MSh), equilíbrio espacial/preço (EEP), matriz origem/destino (OD); X - Dado pode ser utilizado no modelo.

Fonte: Holguín-Veras e Jaller (2014, modificado)

Com uma proposta similar a de Holguín-Veras e Jaller (2014), Tavasszy e Jong (2014) relacionam os tipos de modelos com tipos de fontes de dados, porém considera-se que os autores também fornecem indicativos de que, a partir do modelo requerido, pode-se orientar a coleta de dados, e apresentam o Quadro 2.2. Neste identifica-se que notas fiscais de remessa podem ser servir: na elaboração de matrizes OD, de modelos desagregados de escolha modal e na identificação do tamanho de remessas. Do mesmo Quadro 2.2 também observam-se como diferentes fontes e métodos de pesquisa (estatísticas oficiais, entrevistas, contagens de tráfego, etc.) podem produzir diferentes modelos no interesse do planejamento de transportes de cargas. 
Quadro 2.2 - Fontes de dados para modelagem em transportes

\begin{tabular}{|c|c|}
\hline Fontes de dados & Uso na modelagem do transporte de cargas \\
\hline Estatísticas comerciais & $\begin{array}{l}\text { Estimativa de matrizes de produção/consumo (PC) em bases anuais } \\
\text { Modelos de gravidade agregados para geração e distribuição no } \\
\text { nível de produção e consumo } \\
\text { Valores para ponderação de pesos de cargas (para mercadorias } \\
\text { importadas e exportadas) }\end{array}$ \\
\hline $\begin{array}{l}\text { Dados da contabilidade do país } \\
\text { (inclui tabelas de entrada/saída } \\
\text { multi-regionais ou não) }\end{array}$ & $\begin{array}{l}\text { Estimativa de matrizes de produção/consumo em bases anuais } \\
\text { Modelos de entrada/saída e de equilibrio geral para geração e } \\
\text { distribuição }\end{array}$ \\
\hline Estatísticas de transporte & $\begin{array}{l}\text { Estimativa de: matrizes OD em bases anuais } \\
\text { modelos de gravidade para geração e distribuição no nível de OD } \\
\text { (menos apropriado do que no nível de PC) } \\
\text { modelos agregados de escolha modal } \\
\text { Fatores de carregamento (peso da carga/capacidade do veículo) } \\
\text { Modelos agregados de escolha portuária } \\
\text { Modelos de escolha do tipo de veículo, formação de rotas e viagens } \\
\text { vazias/ocupação da carga se dados desagregados estão disponíveis }\end{array}$ \\
\hline Pesquisas com embarcadores & $\begin{array}{l}\text { Estimativa de: matrizes PC anuais; } \\
\text { Estimativa de modelos desagregados de escolha modal } \\
\text { Estimativa de modelos de escolha do canal de transporte } \\
\text { Estimativa de modelos desagregados de escolha do tamanho das } \\
\text { remessas } \\
\text { Estimativa de modelos desagregados conjugados (modo e remessa; } \\
\text { modo e fornecedor) } \\
\text { Valores para ponderação de pesos de cargas }\end{array}$ \\
\hline $\begin{array}{l}\text { Entrevistas para projetos } \\
\text { específicos (especialmente } \\
\text { preferência declarada) }\end{array}$ & $\begin{array}{l}\text { Estimativa de: modelos desagregados de escolha modal } \\
\text { modelos de escolha de rotas } \\
\text { modelos de escolha do canal de transporte } \\
\text { modelos desagregados de escolha do tamanho das remessas } \\
\text { modelos desagregados conjugados (modo e remessa; modo e } \\
\text { fornecedor) } \\
\text { Valores monetários dos atributos de serviço (ex.: valor do tempo) }\end{array}$ \\
\hline $\begin{array}{c}\text { Notas Fiscais de remessa e } \\
\text { indentifação por rádio frequência } \\
\text { ID (Radio Frequency } \\
\text { Identification) }\end{array}$ & $\begin{array}{l}\text { Estimativa de: ... matrizes OD em bases anuais } \\
\text { modelos desagregados de escolha modal } \\
\text { modelos desagregados de escolha do tamanho das remessas } \\
\text { de modelos desagregados conjugados (modo e remessa; modo e } \\
\text { fornecedor) }\end{array}$ \\
\hline Contagem de tráfego & $\begin{array}{l}\text { Estimativa de matrizes OD em bases anuais } \\
\text { Estimativa de modelos de escolha de rotas } \\
\text { Dados para calibração de modelos }\end{array}$ \\
\hline Inspeção de Segurança no tráfego & Taxas de ocupação das cargas \\
\hline $\begin{array}{l}\text { Dados sobre malha viária com } \\
\text { funções de custo }\end{array}$ & $\begin{array}{l}\text { Entrada direta para estimativa de modelos conjugados ou de } \\
\text { escolha modal } \\
\text { Entrada indireta para estimativa de modelos de distribuição } \\
\text { agregados }\end{array}$ \\
\hline Dados de terminais & $\begin{array}{l}\text { Entrada direta para estimativa de modelos de escolha do canal de } \\
\text { transporte }\end{array}$ \\
\hline
\end{tabular}

Fonte: Tavasszy e Jong (2014, tradução nossa, adaptado) 
Allen, Browne e Cherrett (2012), por sua vez, revisam 162 estudos relacionados ao transporte urbano rodoviário de cargas em 18 países da Europa, América, Ásia e Oceania nos últimos 50 anos. Os autores consideram que os dados coletados envolvem os seguintes aspectos:

a) geração de fluxo de cargas e de viagens de veículos de cargas pelos estabelecimentos;

b) propósito de viagens e cargas transportadas por cada veículo;

c) padrões de viagens detalhados dos veículos, incluindo aí a roteirização e programação de entregas;

d) dados sobre a frota, velocidades e combustível;

e) origens das viagens dos veículos;

f) atividades de carga e descarga e seu tempo demandado;

g) organização do canal de suprimento;

h) fluxo de tráfego nas vias.

Nos estudos analisados observam-se alguns aspectos similares e outros complementares entre o que os autores consideram como dados requeridos. Por exemplo, Richardson, Ampt e Meyburg (1995) fornecem o tipo de pesquisa na qual os dados são obtidos e, portanto, sob qual foco concentra-se o estudo: do uso do solo, dos movimentos ou do inventário em transportes, dentre outros. Aliás, considera-se que estes são os principais focos sobre coleta de dados apresentados por Ogden (1992), Routhier e Patier (2006), Holguin-Veras et al. (2010), Allen, Browne e Cherrett (2012), Holguín-Veras e Jaller (2014) e Tavasszy e Jong (2014).

A rigor, infere-se que os focos atuais na coleta de dados revelam uma preocupação básica em buscar entender como o TUC opera e impacta no sistema de transporte. Assim análises de percepção e atitudinais dos atores envolvidos no processo de distribuição de carga urbano, e que relacionam as características demográficas e sócio-econômicas de diferentes grupos nas áreas de origem e destino das mercadorias com os fluxos de cargas, soam receber menor atenção. 
Esta impressão encontra respaldo nas revisões de estudos feitas por Allen, Browne e Cherrett (2012). Os autores relatam que os principais propósitos de pesquisas em TUC são: ganhar compreensão sobre as operações de transporte, foco que responde pela maioria dos estudos analisados, e apoiar tomadores de decisão em políticas públicas e desenvolver modelos.

Além da necessidade em compreender como o TUC opera e impacta, percebe-se também que alguns autores têm outros focos distintos, por vezes intercalando dados com os resultados que se esperam de sua coleta. Por exemplo, Ogden (1992) cita áreas que em um momento referem-se aos dados (ex.: sobre os veículos) ou aos resultados que se pode obter com os mesmos (ex.: definição dos principais geradores e corredores).

Routhier e Patier (2006) focalizam os estudos nos estabelecimentos, e buscam informações sobre operações de carregamento, rotas e as características dos produtos transportados. Allen, Browne e Cherrett (2012) por sua vez demonstram que os estudos têm focalizado aspectos similares à Routhier e Patier (2006), e infere-se que parte significativa dos dados sejam contemplados na proposta por Holguín e Jaller (2014).

Holguín-Veras e Jaller (2014), e de certa forma como Ogden (1992) e Routhier e Patier(2006), focalizam a obtenção de dados sobre três atores, embarcadores, transportadores e recebedores, e não deixam claro a necessidade em coletar outros dados sobre o inventário, tais como sobre a frota e terminais de forma abrangente.

Holguín-Veras e Jaller (2014) também não dão ênfase em identificar como ocorre o processo de carregamento de veículos nas empresas, aspecto destacado por Routhier e Patier(2006), e aparentemente considerado por Holguín-Veras e Jaller (2014) como um processo de escolha.

\subsubsection{Categorias de dados em TUC}

A partir das diferentes visões dos especialistas em transportes, torna-se importante efetuar uma síntese das categorias de dados apresentadas, bem como fornecer uma breve descrição dos dados necessários para o planejamento do TUC. 


\section{$\underline{\text { Dados sobre geracão de cargas e de viagens de cargas }}$}

Holguín-Veras e Jaller (2014) citam que os dados sobre a geração de cargas referem-se ao estudo dos padrões de consumo e produção de cargas, onde consumo é entendido como a quantidade de mercadorias sendo recebidas, e produção as quantidades que deixam o estabelecimento.

Para Ogden (1992) a coleta de dados sobre cargas deve ser desagregada por remessa. Ou seja, para cada carga de um mesmo produto que precisa ser movimentado de uma origem para um destino devem ser levantados os seguintes dados:

a) localização das origens-destinos e seus respectivos usos do solo;

b) classificação e tipo do produto (se congelado, líquido,etc.);

c) tamanho da remessa em termos de massa e volume;

d) se a remessa representa carga completa ou fracionada;

e) tipo de unitização (se por pallet, contêiner, solta, etc.);

f) tipo de movimentação (se é manual, por empilhadeira, por guindaste, etc.);

g) propriedade das mercadorias;

h) responsabilidade pelo transporte (embarcador, transportador, etc) e;

i) método de despacho (depósito, telefone, etc).

Os dados sobre a geração de viagens de carga são uma estimativa do número de viagens de veículos de carga necessárias para transportar a carga gerada ou recebida. Trata-se de uma resultante de decisões logísticas tomadas pelas empresas no tocante à escolha do modo de transporte, frequências de entregas, nível de serviço adotado, entre outras (HOLGUíNVERAS; JALLER, 2014).

Para Ogden (1992) os dados sobre o fluxo de veículos de carga são importantes para o planejamento e gerenciamento da infraestrutura viária, já que eles revelam informações sobre as atividades relacionadas ao transporte de cargas, além das características como as variações das viagens durante o dia, direção dos fluxos e tipo de veículo utilizado. 
Ogden (1992) sugere ainda os seguintes campos a serem pesquisados: localização das origens-destinos e respectivos usos do solo, hora do dia e toneladas coletadas ou entregues por cada parada por tipo de mercadoria.

\section{Características econômicas e distribuicão espacial/localizacão dos agentes}

Estes dados servem para caracterizar o comportamento dos atores envolvidos, notadamente embarcadores, transportadores e recebedores de cargas. Para isto há necessidade de se coletar dados sobre o porte do negócio, área do estabelecimento, número de empregados, número e tipo de veículos, políticas de estocagem, horas de operação, vendas, segmento industrial, localização espacial e distribuição dos empreendimentos e seus respectivos fornecedores e clientes, entre outros (HOLGUÍN-VERAS; JALLER, 2014; ROUTHIER; PATIER, 2006).

Infere-se que as informações sobre viagens de carga e veículos, associadas à identificação dos agentes identifiquem os principais geradores e atratores de cargas, aspecto importante levantado por Ogden (1992) para entender o papel destes na economia, tanto por uma abordagem metropolitana ou localizada (um porto, terminal de cargas, área industrial ou corredor de transportes).

\section{Informacões sobre os padrões de fluxo no canal logístico}

Holguín-Veras e Jaller (2014) consideram que o desenvolvimento de modelos de demanda por carga requer uma compreensão básica do funcionamento do sistema que é modelado. Os autores propõem identificar quais são os agentes envolvidos, suas interações e funções, dentre outros. Allen, Browne e Cherrett (2012) sugerem o conhecimento da organização do canal de suprimento, onde define-se o papel e as características dos fornecedores, transportadores e recebedores envolvidos.

\section{$\underline{\text { Rotas de entrega }}$}

Inclui informações sobre a sequência de entregas (roteirização), a localização dos pontos visitados dispostos em mapas, a quantidade de carga transportada, as entregas e coletas 
feitas, com seus respectivos tempos e frequências. Além disso, devem ser coletados dados sobre os fluxos de origem e destino de mercadorias (OD) ao longo da rota, bem como sobre a quantidade de viagens vazias (ALLEN; BROWNE; CHERRETT, 2012; HOLGUÍN-VERAS; JALLER, 2014; ROUTHIER; PATIER, 2006).

\section{Processos de escolha especiais}

Os processos de escolha especiais envolvem as decisões nos estabelecimentos que refletem na definição do modo de transporte, dos horários de entrega (programação), do tempo e frequência das operações de carga e descarga, do tipo de veículo utilizado e das características das mercadorias envolvidas (ALLEN; BROWNE; CHERRETT, 2012; HOLGUÍN-VERAS; JALLER, 2014; ROUTHIER; PATIER, 2006).

\section{Características da malha viária, terminais e frota de veículos}

Este tipo de pesquisa lista os aspectos da rede viária, tais como configuração, descrição das vias e respectivas capacidade, mãos de direção, restrições de acesso, trajetos preferenciais e velocidades médias, além de outros dados necessários para modelar como o fluxo de carga se comporta no sistema de transporte (HOLGUÍN-VERAS; JALLER, 2014; RICHARDSON; AMPT; MEYBURG, 1995).

Ogden (1992), por sua vez, cita a necessidade em identificar os principais corredores de carga dentro de uma região metropolitana, destacando seus pontos de congestionamento e deficiências na configuração e na infraestrutura, os espaços para manobrar e estacionar, dentre outros. Tais corredores devem ser descritos por tipos de mercadorias movendo pelos mesmos, tipos de veículos de carga trafegando e tipo de movimento (se inter e intra urbano, interestadual, etc.).

Richardson, Ampt e Meyburg (1995) listam também a necessidade em identificar de um modo geral os terminais (estações para carga descarga, estacionamento, troca modal, etc.) e veículos com suas características operacionais e níveis de conforto (neste caso, nota-se um foco no transporte de pessoas). 
Para Ogden (1992) é crucial para o planejamento do TUC a descrição geral dos veículos quanto à quantidade, porte (se leve, médio, pesado), configuração (se rígido, semireboque), carroceria (refrigerada, tanque, van, etc.), propriedade (se próprio ou de terceiros) e, por fim, setor em que opera (intra ou interurbano, transporte regional, etc.).

\subsubsection{Quadro resumo das categorias de dados}

Tomando como base os estudos apresentados, considera-se que as categorias e os respectivos dados para compreender e avaliar o impacto do TUC podem ser resumidos conforme indicado no Quadro 2.3. Neste apresenta-se uma relação entre os principais tipos de pesquisas sugeridos por Richardson, Ampt e Meyburg (1995) e considerados focos nos trabalhos dos autores pesquisados, com as categorias e os dados descritos anteriormente. Entende-se que esta organização permite uma visão de quais dados são necessários para estudos em TUC sem perder de vista o tipo ou foco de pesquisa adotado.

Quadro 2.3 - Tipos de pesquisa e dados para TUC

\begin{tabular}{|c|c|c|}
\hline $\begin{array}{l}\text { Tipos de } \\
\text { pesquisa }\end{array}$ & Categorias de dados & Tipos de dados \\
\hline \multirow{2}{*}{ Uso do } & \multirow{2}{*}{$\begin{array}{l}\text { Geração de carga e de } \\
\text { viagens de carga }\end{array}$} & Produção \\
\hline & & Consumo \\
\hline \multirow{13}{*}{$\begin{array}{l}\text { Padrão } \\
\text { de } \\
\text { viagens }\end{array}$} & \multirow{3}{*}{$\begin{array}{c}\text { Características econômicas } \\
\text { e operacionais/localização } \\
\text { dos agentes }\end{array}$} & Embarcadores \\
\hline & & Transportadores \\
\hline & & Recebedores \\
\hline & $\begin{array}{c}\text { Informação dos fluxos } \\
\text { logísticos } \\
\end{array}$ & $\begin{array}{l}\text { Produção e organização do canal de } \\
\text { suprimento }\end{array}$ \\
\hline & \multirow{5}{*}{ Rotas de Entrega } & Seqüência de entrega \\
\hline & & Localização de origens e destinos \\
\hline & & Fluxos OD \\
\hline & & Tempo e frequência de entregas \\
\hline & & Fluxos de carga vazia/carregamento \\
\hline & \multirow{4}{*}{$\begin{array}{c}\text { Processos de escolha } \\
\text { especial }\end{array}$} & Escolha modal \\
\hline & & Programação de entregas \\
\hline & & Operações de carga e descarga \\
\hline & & Atributos do modo \\
\hline \multirow{6}{*}{ Inventário } & \multirow{4}{*}{$\begin{array}{c}\text { Características da Rede } \\
\text { Viária }\end{array}$} & Tempos de viagens,custos \\
\hline & & Restrições de uso \\
\hline & & Capacidade \\
\hline & & Volumes de tráfego \\
\hline & Terminais & Localização, características \\
\hline & Frota de veículos & Quantidade e características \\
\hline
\end{tabular}




\subsection{COM QUEM COLETAR}

Antes da coleta de dados é importante conhecer sobre os atores participantes do sistema de transporte e como estes podem auxiliar nesta tarefa. Por exemplo, devido à multiplicidade de agentes envolvidos e cada um focalizando os aspectos inerentes a seus negócios, nenhum deles possui informações completas sobre o funcionamento do sistema de transporte (HOLGUÍN-VERAS; JALLER, 2014) (ver Quadro 2.4):

a) os agentes que produzem e embarcam a carga em pontos de suprimento, tipicamente têm informações sobre a carga, porém não possuem a visão completa sobre o processo de entrega das mercadorias quando estas deixam suas instalações;

b) transportadores têm informações sobre o processo de entrega, porém nem sempre estão conscientes sobre o valor e o tipo de mercadoria que transportam;

c) agências governamentais de transporte têm informações sobre o uso do solo e o tráfego na rede viária, porém conhecem pouco sobre o fluxo de cargas em suas jurisdições.

Quadro 2.4 -Visões parciais dos agentes sobre o sistema de transporte

\begin{tabular}{|c|c|c|c|c|c|}
\hline Geração de carga & $\begin{array}{l}\text { Embarca- } \\
\text { dores } \\
\text { Produtores }\end{array}$ & $\begin{array}{c}\text { Transporta } \\
\text {-dores }\end{array}$ & $\begin{array}{l}\text { Centros de } \\
\text { Distribuição, } \\
\text { Armazéns }\end{array}$ & $\begin{array}{l}\text { Consumidor } \\
\text { es de carga, } \\
\text { recebedores }\end{array}$ & $\begin{array}{l}\text { Agências de } \\
\text { transportes }\end{array}$ \\
\hline Quantidade de carga & $\operatorname{Sim}(1)$ & $\operatorname{Sim}(1)$ & $\operatorname{Sim}(1)$ & $\operatorname{Sim}(2)$ & Não \\
\hline $\begin{array}{l}\text { Número de viagens } \\
\text { veículos carregados }\end{array}$ & $\operatorname{Sim}(1)$ & $\operatorname{Sim}(1)$ & $\operatorname{Sim}(1)$ & $\begin{array}{l}\text { Nem } \\
\text { sempre }\end{array}$ & \multirow{2}{*}{$\begin{array}{l}\text { Nos links chave } \\
\text { (sem distinção entre } \\
\text { carregados e vazios) }\end{array}$} \\
\hline $\begin{array}{l}\text { Número de viagens } \\
\text { veículos vazios }\end{array}$ & Não & $\operatorname{Sim}(1)$ & Não & Não & \\
\hline $\begin{array}{l}\text { Número e freqüencia } \\
\text { de entregas }\end{array}$ & $\operatorname{Sim}(1)$ & $\operatorname{Sim}(1)$ & $\operatorname{Sim}(1)$ & $\operatorname{Sim}(2)$ & Não \\
\hline Tipo de mercadoria & $\operatorname{Sim}(1)$ & $\begin{array}{l}\text { Nem } \\
\text { sempre }\end{array}$ & $\operatorname{Sim}(1)$ & $\operatorname{Sim}(2)$ & $\begin{array}{l}\text { Em algumas portas } \\
\text { de entrega }\end{array}$ \\
\hline Tamanho da remessa & $\operatorname{Sim}(1)$ & $\operatorname{Sim}(1)$ & $\operatorname{Sim}(1)$ & $\operatorname{Sim}(2)$ & Não \\
\hline Valor da carga & $\operatorname{Sim}(1)$ & $\begin{array}{l}\text { Nem } \\
\text { sempre }\end{array}$ & $\begin{array}{l}\text { Nem } \\
\text { Sempre }\end{array}$ & $\operatorname{Sim}(2)$ & $\begin{array}{l}\text { Em alguns pontos de } \\
\text { entrada }\end{array}$ \\
\hline Padrão de uso do solo & $\operatorname{Sim}(1)$ & $\operatorname{Sim}(1)$ & $\operatorname{Sim}(1)$ & $\operatorname{Sim}(1)$ & Todos \\
\hline
\end{tabular}

Notas: (1) Somente da carga que o agente manipula , (2) Para toda carga que recebem

Fonte: Holguín-Veras e Jaller (2014, tradução nossa) 
Segundo Holguín-Veras e Jaller (2014) estas capacidades limitadas têm implicações diretas nos esforços de coleta de dados, pois as pesquisas que obtêm informações dos participantes do sistema de transporte são capazes de capturar apenas informações parciais. Neste cenário, NCFRP (2012) pontua que embarcadores e recebedores são os que estão em posição melhor para fornecer uma visão mais completa sobre o sistema de transporte, e que a coleta de dados nestes estabelecimentos pode gerar modelos mais acurados.

Por outro lado, Santos e Sánchez-Díaz (2015) ao realizarem uma pesquisa com transportadores de carga fracionada (LTL), afirmam que os mesmos podem fornecer informações sobre seus embarcadores e recebedores e, principalmente, das operações de transporte no meio urbano. Por exemplo, afirmar que os transportadores nem sempre conhecem sobre a mercadoria sobre a qual transportam é algo questionável, pois os mesmos incorrem em riscos (assaltos, danos) e calculam o próprio frete baseado nas avaliações dos produtos, tais como valor, peso, risco de perecibilidade ou avarias, dificuldade para coletar, carregar e entregar (NTC, 2001). Além disso, há os transportadores que são os próprios embarcadores ou recebedores da mercadoria, caso do setor de distribuidores de bebidas, por exemplo (SANTOS, 2008).

No contexto do planejamento do TUC, conclui-se ser interessante coletar os dados sobre viagens de cargas nos estabelecimentos com maior representatividade na geração e atração de cargas em termos da quantidade de entregas ou despachos, peso ou valor das mercadorias, conforme o ponto de interesse no estudo. No tocante às informações sobre rotas, uma orientação é coletar os dados nos transportadores, pois são estes que executam a operação (SANTOS; SÁNCHEZ-DÍAZ, 2015).

\subsection{COMO COLETAR}

Os diferentes tipos de pesquisa se utilizam de um grupo de métodos que são os meios utilizados para obter os dados. Geralmente estes métodos são utilizados em conjunto, e com diferentes tipos de instrumentos, tais como questionários pré-estruturados, diários de viagens, GPS, etc., para a realização de pesquisas em diferentes alvos amostrais (HOLGUÍN-VERAS; JALLER, 2014) ou técnicas de pesquisas (ALLEN; BROWNE; CHERRETT, 2012). 
Neste contexto, a primeira decisão quanto ao método de pesquisa em transportes é sua dimensão temporal. Este pode se caracterizar por pesquisas transversais, que buscam medir a resposta a uma mudança incremental no sistema de transporte em um determinado período, ou por séries temporais ou pesquisas longitudinais que, por sua vez, podem se dividir em pesquisas em painel (mantém os mesmos indivíduos pesquisados ao longo do tempo) ou pesquisas transversais sucessivas (mesma amostra da população, porém com indivíduos que variam durante o período analisado) (ORTÚZAR; WILLUMSEN, 2011; RICHARDSON; AMPT; MEYBURG, 1995).

Estas dimensão temporal, independentemente de seu uso em modelos longitudinais, supre também a necessidade de um contínuo processo de coleta de dados de modo a capturar variações sazonais e assim sua influência na demanda por transportes. Além disso, permite monitorar o comportamento do usuário sobre intervenções no sistema de transporte (ORTÚZAR; WILLUMSEN, 2011, p. 76).

Richardson, Ampt e Meyburg (1995) afirmam ainda que, após decidir sobre seus aspectos temporais, os métodos de pesquisas em transportes podem ser enquadrados em 6 grupos: as pesquisas observacionais, de auto-preenchimento, por telefone, de interceptação e as realizadas no local do estudo por meio de entrevistas em domicílios ou empresas, e as documentais.

\section{Pesquisas observacionais}

Para Richardson, Ampt e Meyburg (1995, p. 44) estas pesquisas podem ser diretas e indiretas. Nas pesquisas diretas ocorrem as pesquisas de inventário em transportes, que utilizam recursos como vídeos, imagens digitais ou tecnologias embarcadas em veículos. Os autores enquadram neste grupo as contagens de tráfego (no cordão externo ou linhas de contorno interno), de desempenho do sistema de transporte (de tempo de viagens, atrasos em interseções), de rastreamento de viagens e de contagens de classe de veículos. Com exceção às pesquisas de inventários, as demais requerem um cuidado quanto à coleta de amostras tendenciosas. 
Allen, Browne e Cherrett (2012) listam as pesquisas observacionais diretas em três categorias: feitas pessoalmente, que utilizam imagens gravadas em vídeos e as que coletam dados automaticamente por meio de equipamentos como GPS nos veículos, ou laços indutivos instalados nas vias.

Nas pesquisas observacionais indiretas busca-se padrões de uso de veículos, informações sobre vendas de combustível ou outros indicadores econômicos, resíduos de acidentes e marcas de frenagem indicando locais de maior risco. As pesquisas observacionais têm sido utilizadas comumente para validar dados de pesquisas com entrevistas ou de autopreenchimento, e as de linhas de contorno para validar as pesquisas de origem-destino de viagens (RICHARDSON; AMPT; MEYBURG, 1995).

\section{$\underline{\text { Pesquisas de auto-preenchimento }}$}

Richardson, Ampt e Meyburg (1995) informam que este método é aplicado junto a domicílios, estabelecimentos e motoristas, e é um dos mais utilizados em transportes. Tem a vantagem de menores custo, possibilidade de maior abrangência, menores vieses pela interferência do entrevistador e, em alguns casos, maior tempo para o respondente preparar as respostas. Porém este método apresenta as seguintes desvantagens: menores taxas de retorno, entre 20 e $55 \%$, riscos do respondente não ter o perfil desejado para a resposta, e não permitem respostas espontâneas, o que dificulta sua aplicação em pesquisas comportamentais.

Allen, Browne e Cherrett (2012) elencam três opções de auto-preenchimento usualmente utilizadas em transportes:

a) o uso de fax, correio ou email pelos quais o questionário é enviado para os respondentes que, por sua vez, os completam e retornam;

b) o uso dos recursos anteriores ou internet onde há um telefonema inicial e um final para buscar o de acordo do respondente e apoiar a conclusão da pesquisa;

c) a visita ao respondente para buscar o de acordo com a pesquisa e deixar o questionário, que é preenchido e recolhido pelo pesquisador em data posterior. 


\section{Pesquisas por telefone}

As pesquisas por telefone possuem vantagens como abrangência e custos menores que as entrevistas in loco, podem ser assistidas por computador (CATI - computer assisted telephone interviews), que lê as questões para o respondente teclar as respostas, são ideais para validar dúvidas em respostas mal preenchidas, para contatos com empresas (HOLGUÍN-VERAS; JALLER, 2014; RICHARDSON; AMPT; MEYBURG, 1995) e, infere-se com consumidores.

Porém, este método apresenta desvantagens como a dificuldade em encontrar um respondente no local, a competição com outros tipos de ações de marketing que exploram este canal, o viés que pode ocorrer em função do perfil inadequado das pessoas que estejam no local para responder à pesquisa e a falta de contato visual (RICHARDSON; AMPT; MEYBURG, 1995).

\section{$\underline{\text { Pesquisas de interceptação }}$}

As pesquisas de interceptação ocorrem quando as pessoas são abordadas durante a execução de uma atividade (transportando cargas, indo ao trabalho), no que Allen, Browne e Cherrett (2012) apontam como um tipo de pesquisa "cara a cara". Estas pesquisas são realizadas a bordo de veículos, em linhas de cordão nas vias, em shopping centers, etc. e, portanto, exigem algum contato com o entrevistado. As alternativas sugeridas pelos autores para pesquisas de interceptação são:

a) abordagem e posterior envio do questionário;

b) abordagem e preenchimento no mesmo momento;

c) uma terceira alternativa que combina ambas, sendo a primeira com uma etapa de questionários com respostas mais curtas e a seguinte como complemento da primeira;

d) pesquisas nas vias - com respostas por carta paga - onde os motoristas podem ser abordados em paradas naturais (semáforos, pedágios) ou serem induzidos (postos de polícia rodoviária) e;

e) entrevistas nas vias. 


\section{Pesquisas in loco}

São as pesquisas no local do estudo, e ocorrem essencialmente por meio de entrevistas em domicílios ou empresas. Apresentam como vantagens as altas taxas de retorno das respostas (entre $75 \%$ e $85 \%$ ), flexibilidade na obtenção de diferentes tipos de respostas, a presença do pesquisador pode eliminar dúvidas do respondente, são mais apropriadas para pesquisas atitudinais, ou quando há questões mais complexas para serem respondidas. As principais desvantagens são: apresentam dificuldade em manter o interesse do respondente, são de custo maior e não apropriadas em obter dados reais quando estes não estão disponíveis (RICHARDSON; AMPT; MEYBURG, 1995).

Para Ortúzar e Willumsen (2011, p. 74) os dados obtidos em pesquisas de estabelecimentos provêem boas informações para estimar geração de viagens, escolha modal e sobre a extensão das viagens na cidade, elemento importante para a estimação de modelos de geração de viagens.

Richardson, Ampt e Meyburg (1995) relatam que as pesquisas no local do estudo podem ocorrer em grupos e terem como alvo as entrevistas em profundidade. No caso das entrevistas em grupos, busca-se obter respostas a partir da interação entre os entrevistados selecionados a partir de critérios pré-definidos, podem ser gravadas, sendo mais qualitativas e menos apropriadas quando se necessita obter significância estatística. As entrevistas em profundidade tentam capturar aspectos não revelados em entrevistas estruturadas ou semi-estruturadas, podendo ser individuais ou em grupo (neste caso podem ser auxiliadas por jogos interativos que simulam a situação real para os entrevistados responderem por meio de alternativas).

\section{$\underline{\text { Pesquisas documentais }}$}

Trata-se da busca por informações em documentos (publicados ou não) ou em bases de dados que venham a complementar informações e/ou orientar o desenho de uma dada pesquisa. Cuidados devem ser tomados com relação às definições, procedimentos de coleta e tratamento dos dados, seus propósitos e os resultados obtidos nestes documentos de modo a validar a consistência das informações. 
Podem prover informações sobre o sistema de inventário em transportes (mapas das vias, fotos aéreas das moradias e estabelecimentos e sua localização) que podem auxiliar na definição de amostras, podendo ser a unidade de pesquisa (fornecedora de informações) ou seu próprio objeto (quando se pesquisa quais tipos de profissionais em transporte lêem determinada publicação) (RICHARDSON; AMPT; MEYBURG, 1995). Incluem-se neste método também as pesquisas em bases de dados públicas de organismos governamentais (ROUTHIER; PATIER, 2006; TAVASSZY; JONG, 2014).

\subsection{ONDE COLETAR}

Richardson, Ampt e Meyburg (1995) relatam que, em geral, os métodos e tipos de pesquisas apresentados se inter-relacionam em um processo de planejamento em transportes. Porém, nota-se na literatura sobre o planejamento em transportes um foco nas entrevistas em domicílios, que em síntese se traduz em um forte viés para a análise do transporte de passageiros (BRUTON, 1979; MELLO, 1975; ORTÚZAR; WILLUMSEN, 2011; RICHARDSON; AMPT; MEYBURG, 1995).

Apesar de diversos autores propagarem a necessidade de uma visão sistêmica dos transportes, há pouca ênfase em pesquisas para o transporte urbano de cargas, provavelmente por considerarem uma maior importância do transporte de pessoas, ou pela complexidade em obter dados em TUC, ou ambos os fatores. Assim, torna-se importante observar como os métodos e técnicas de pesquisas são utilizados e inter-relacionados também com a visão de autores que estudam o transporte urbano de cargas.

Routhier e Patier (2006) fazem uma revisão sobre as fontes e tipos de dados coletados para o estudo do transporte urbano de cargas na França. Os autores consideram que as pesquisas nacionais pelos órgãos de governo têm focalizado dados para o transporte regional, sendo difícil utilizar tais dados para estudos no meio urbano. Para os autores as principais fontes de dados e pesquisas que podem ser utilizadas para o TUC envolvem as realizadas pelo setor público: as de uso do solo que se baseiam nos registros de empresas e que descrevem suas atividades, localização, número de empregados, etc.; os registros de licenciamento de veículos, as pesquisas com transportadores de carga; as contagens de tráfego por meio de laços indutivos nas vias e; os dados sobre acidentes. 
Ainda Routhier e Patier (2006) apontam que as pesquisas para o TUC no contexto francês são ocasionais, vem sendo cada vez menos realizadas, e baseiam-se em dados coletados junto a estabelecimentos, tais como sobre o fluxo de cargas que estes geram, com motoristas, ou utilizando dados de GPS instalados em veículos de cargas. Os autores citam ainda pesquisas em domicílios sobre hábitos de compra pela internet e as observacionais junto à polos geradores de tráfego.

Holguin-Veras et al. (2010) efetuam uma abrangente revisão de diferentes abordagens e citam diferentes métodos de coleta de dados em transporte de cargas, agrupando-os de acordo com o que eles definem como alvo amostral: tendo como bases estabelecimentos embarcadores, transportadores e recebedores; por meio de pesquisas que interceptam os veículos; nos próprios veículos ou; acompanhando o fluxo da carga no canal logístico.

Allen, Browne e Cherrett (2012) ao invés de alvo amostral definem os focos dos estudos como técnicas de pesquisa em 12 grupos: pesquisas em estabelecimentos, operadores de transporte e embarcadores, de observação dos veículos, sobre estacionamentos, com motoristas, de fluxo de cargas, em rodovias, diários de viagem de veículos, com GPS, com prestadores de serviço e contagens de tráfego.

O que se observa de Holguin-Veras et al. (2010) e Allen, Browne e Cherrett (2012) são similaridades e de modo a prover uma explicação destes alvos amostrais, estes são consolidados e explicados a seguir a partir das referências apresentadas.

\section{$\underline{\text { Pesquisas baseadas em estabelecimentos }}$}

Neste tipo de pesquisa o alvo são os estabelecimentos de origens e destinos intermediários ou finais de cargas, tais como indústrias, armazéns, centros de distribuição, transportadoras, etc. Envolvem principalmente os estabelecimentos de embarcadores, transportadores e recebedores de cargas e os entrevistados geralmente são os proprietários, gerentes de frota ou operadores.

Estas pesquisas fornecem informações relevantes sobre a geração e características das cargas e viagens de e para os respectivos estabelecimentos, análises de tempos e descrição 
dos processos relacionados com as atividades de transportes (coleta, entrega, carga e descarga,etc.) e o uso de facilidades, bem como sobre os modos de transportes utilizados.

Os métodos comumente utilizados são entrevistas presenciais ou por telefone, o uso de auto preenchimento por cartas via correios ou mensagens via internet, com suas vantagens e desvantagens. Um exemplo de pesquisa com estabelecimentos realizada nos Estados Unidos com embarcadores, e sem paralelo conhecido no Brasil, é a de fluxo de mercadorias, CFS (de Commodity Flow Survey).

Segundo Holguín-Veras et al. (2010, p. 20), "a pesquisa com transportadores é a mais difundida possivelmente pela facilidade em identificar o público-alvo feita por meio de registros de veículos". Sobre este aspecto, porém, cabe reforçar que apesar de os registros de veículos serem coletados de órgãos públicos relacionados (no caso do Brasil, os Detrans), o fato é que parcela importante destes tipicamente não é registrada nos locais onde circulam.

\section{$\underline{\text { Pesquisas de interceptação de viagens }}$}

Este tipo de pesquisa focaliza as viagens dos veículos e utiliza o método direto. Toma-se uma amostra dos usuários das vias dos quais se solicita responder um questionário aplicado por um pesquisador. Um exemplo são entrevistas com motoristas em rodovias, seja nos acostamentos, postos de polícia rodoviária onde os policiais auxiliam na parada do veículo, ou em pontos de paradas espontâneas, como postos de combustíveis.

Para Holguín-Veras et al. (2010) os pontos fortes deste tipo de pesquisa são a confiabilidade dos dados, alta taxa de respostas se comparada com pesquisas por telefone ou correio, e uma boa representação estatística do fluxo de veículos na área em estudo. Por outro lado, devido à dificuldade em encontrar locais apropriados para interromper as viagens, tal limitação pode produzir amostragens enviesadas. Há outros pontos negativos: há potencial de a pesquisa causar uma interrupção no tráfego; a captura de informações ocorre apenas no local onde há as entrevistas; não são apropriadas para coletar dados de viagens internas devido à complexidade das viagens encadeadas. Por exemplo, nas pesquisas de interceptação de viagens Bruton (1979, p. 41) orienta indicar como origem e 
destino os pontos diametralmente opostos, porém Holguín-Veras et al. (2010) afirmam que este tipo de pesquisa não é capaz de coletar informações sobre rotas, o que faz sentido.

As informações geralmente coletadas são: origem, destino e propósito da viagem, padrões de rotas, tipo de mercadoria, peso e características da carga e veículo, informações sobre embarcadores, recebedores e da própria transportadora, etc. Para Ortúzar e Willumsen (2011, p. 83) estas pesquisas são úteis para complementar, validar e ampliar a compreensão das viagens e para complementar os dados de pesquisas em domicílios e estabelecimentos.

\section{$\underline{\text { Pesquisas no cordão externo }}^{6}$}

Pesquisas dos movimentos que cruzam o cordão externo são consideradas como o único método satisfatório para determinação das origens e destinos dos movimentos diretos e externos-internos. Este pode ainda tratar dos movimentos internos-externos, e utilizar entrevistas em rodovias pela interceptação de viagens, ou a entrega de cartas aos motoristas para preenchimento posterior com reenvio pago. Os veículos que cruzam o cordão (fronteira) especificado são as unidades amostrais, e os dados coletados são basicamente os mesmos coletados em pesquisas de interceptação de viagens sendo que, no caso de cartões, pode-se agregar um apelo à cooperação para seu preenchimento (BRUTON, 1979, p. 39).

Os dados coletados fornecem informações para o desenvolvimento de matrizes origemdestino de viagens, permitem a análise da distribuição de peso de mercadorias por classes de veículos, e o estudo de aspectos como cargas vazias (BEAGAN; FISCHER; KUPPAM, 2007). Para Ortúzar e Willumsen (2011, p. 74) estas pesquisas são úteis para identificar viagens de não residentes, complementando as pesquisas in loco.

Holguín-Veras et al. (2010) citam que uma alternativa para causar menor interrupção no tráfego ao selecionar a amostra é coletar as placas dos veículos que passam pelo cordão externo, com posterior coleta dos dados do transportador via informações públicas e, em seguida, envio de cartas para preenchimento. A coleta de placas pode ser feita por câmeras, manualmente, por fotos, etc.

\footnotetext{
${ }^{6}$ Sobre a definição de cordão externo e movimentos ver seção 2.6 (p.38) e Figura 2.2 (p.45).
} 
Porém, a desvantagem dos métodos que utilizam tais cartas é o espaço de tempo entre a abordagem do viajante e o preenchimento do questionário. Isto causa baixa taxa de retorno de respostas ${ }^{7}$ e altas taxas de erros nas respostas que, por sua vez, podem causar viés na amostra. Além disso, o envio de correspondências com dados errados podem causar publicidade negativa para a pesquisa e, mesmo com dados corretos, invasão de privacidade (MILLER et al. ${ }^{8}$,1993apud HOLGUIN-VERAS et al, 2010, p. 22).

Por outro lado, Bruton (1979, p. 39) cita um exemplo com $72 \%$ de respostas de uma pesquisa acompanhada por intensa campanha de conscientização. Ortúzar e Willumsen (2011, p. 85) orientam reduzir o número de questões para obter melhores taxas e sugerem coletar dados como ocupação da carga, origem, destino e propósito da viagem, bem como o modo utilizado.

\section{$\underline{\text { Pesquisas de diário de viagens (veículos) }}$}

As unidades amostrais destas pesquisas sãos os veículos, dos quais se coletam informações sobre suas características e de suas operações com cargas (ALLEN; BROWNE; CHERRETT, 2012; HOLGUIN-VERAS et al., 2010). Assim são coletados dados como o número de registro do veículo, nome ou endereço da empresa ou proprietários (BRUTON, 1979,p. 46) e informações sobre as viagens realizadas. Neste caso, a abordagem básica é selecionar uma amostra representativa de veículos operando em determinada região na qual os motoristas preenchem relatórios geralmente durante um determinado período - em geral, $24 \mathrm{~h}$ - sobre origens e destinos, quilometragem rodada, rota percorrida, tempos de viagens, mercadoria transportada, tamanho dos embarques, tipo do veículo, uso do solo, tipo de atividade no final de cada viagem, etc. (BEAGAN; FISCHER; KUPPAM, 2007).

Uma alternativa ao diário de viagens é o uso de GPS inserido no veículo e combinado com sistemas de informação geográfica (GIS - GeographicalInformation Systems) tais como os mapas georreferenciados. Estes podem complementar as informações ao permitir rastrear o posicionamento do início e fim das viagens, seu trajeto, distâncias e tempos de operação.

\footnotetext{
${ }^{7}$ Bruton (1979, p. 39) cita que usualmente as taxas de retorno dos questionários variam de $10 \%$ a $50 \%$, sendo que as taxas mais baixas são para veículos comerciais e de viajantes noturnos.

${ }^{8}$ Miller, K. S., T. N. Harvey, P. W. Shuldiner and C. W. Ho (1993). "Using Video Technology to Conduct 1991 Boston Region External Cordon Survey." TransportationResearch Record 1412: 46-56.
} 
Além dos métodos listados, Holguín-Veras et al. (2010) citam a obtenção de informações por meio de pesquisas documentais, tais como dos registros de licenciamento de placas de veículos, ou observacionais indiretas pela utilização de sistemas inteligentes de transporte (ITS - Intelligent Transportation System), tais como sistemas de posicionamento global (GPS -Global Positioning System) ou de rastreamento de veículos.

Tais recursos, por sua vez, associados com informações sobre o uso do solo podem fornecer informações sobre as atividades no fim de cada viagem. Porém, notadamente o uso de GPS apresenta limitações, pois não permite especificar as quantidades de cargas entregues ou recolhidas. Além disso, o uso destes sistemas com ITS são caros, o que limita a cobertura nas análises.

As principais aplicações das pesquisas de diários de viagens são a compreensão da geração e encadeamento de viagens e da rota percorrida pelos veículos, associada com as características dos veículos, das remessas e das atividades envolvidas.

Porém, Beagan, Fischer e Kuppam (2007) afirmam que, além do custo, em tais pesquisas há uma rejeição dos transportadores por dificultar, e difundir informações sigilosas, sobre suas operações. Além disso, citam que a definição da amostra também é difícil, pois registros públicos de veículos ou de transportadores, geralmente utilizados para traçá-la, são imprecisos quantos aos veículos e empresas que realmente circulam na região.

\section{$\underline{\text { Pesquisas baseadas em rotas (cadeia de suprimentos) }}$}

Holguin-Veras et al. (2010) classificam este tipo de pesquisa como as que coletam dados ao longo da cadeia de suprimentos e que são geralmente vinculadas a pesquisas com transportadores. Os autores citam como exemplo as pesquisas longitudinais onde embarques individuais são rastreados ao longo da cadeia de suprimentos e fornecem uma abrangente descrição do fluxo das mercadorias porta a porta, desde o embarcador até o consumidor final. Outras informações relevantes são obtidas, tais como as características dos agentes participantes, os aspectos que influenciam no tamanho do embarque e na escolha modal. Tais pesquisas são estruturadas em três níveis: 
a) do estabelecimento, onde são realizadas pré-entrevistas com questionários para obter informações sobre as características econômicas e logísticas da indústria/embarcador, tais como frota, políticas de estocagem, relações de parceiros comerciais, infraestrutura de transporte, restrições de entrega, sistemas de informação utilizados, etc.;

b) do embarque, em que é aplicado questionário sobre os embarques mais recentes selecionados aleatoriamente. As perguntas se direcionam para as características físicas e econômicas dos embarques, tais como tipo de mercadoria, valor, peso, destino, natureza do cliente, tempo de partida e configuração do pedido, termos comerciais de troca, etc.;

c) físico ou organizacional do canal de transporte, onde questionários "tipo perna" são preenchidos via entrevistas ou por telefone e obtidas informações sobre as características de cada operador no canal logístico, em cada subetapa do transporte. São obtidos dados sobre as características econômicas do operador, do serviço oferecido, sobre a divisão de responsabilidades entre operadores e das relações entre eles. Também são obtidas informações sobre o preço e condições de chegada da mercadoria pelo recebedor.

O ponto forte destas pesquisas é fornecer informações sobre a organização do canal logístico. Porém, são pesquisas caras, muitas vezes requerem desenhos específicos e, segundo Holguin-Veras et al. (2010), o orçamento pode ser o maior limitador.

\section{Contagem de veículos por classes}

Consiste na contagem do tráfego de veículos de carga classificados segundo um sistema pré-definido, como a da resolução do Conselho Nacional de Trânsito brasileiro ${ }^{9}$, que estabelece as dimensões e limites de pesos dos veículos de carga. Trata-se de uma pesquisa de observação utilizada para avaliar o volume de tráfego e congestionamentos, diferenciando os veículos entre automóveis e caminhões. Bruton (1979, p. 43) a define como contagens na linha de controle dos veículos que cruzam o cordão interno, sugerindo que se divida a área do estudo em partes iguais e que esta linha não passe pela área central do estudo.

\footnotetext{
${ }^{9}$ Resolução CONTRAN número 210 de 2006, ou do artigo 96 do Código de Trânsito Brasileiro - CTB
} 
Beagan, Fischer e Kuppam (2007) citam que este tipo de pesquisa é útil principalmente para: calibração e validação de modelos como, por exemplo, matrizes origem-destino; levantamento da distribuição do tráfego durante o dia; desenvolvimento de modelos de geração de viagens e; com uma suficiente cobertura geográfica, identificação dos principais corredores de tráfego, dentre outros.

Em geral as contagens são feitas em períodos específicos, tais como os de pico e evita-se contagens noturnas pelas dificuldades inerentes em observar os veículos. De acordo com Holguin-Veras et al. (2010), os principais métodos de contagem de volumes de tráfego são o manual, feita meio de um observador treinado, ou utilizando sistemas automatizados como o classificador automático de veículos, AVC (Automatic Vehicle Classifier).

Na contagem manual pode-se contar com vídeos pré-gravados de imagens de tráfego cuja vantagem é poder revisar os dados. No caso de AVC utiliza-se laços indutivos, vídeo câmeras, como as de reconhecimento de caracteres, OCR (Optical Character Recognition), ou outros tipos de detectores que, individualmente e automaticamente contam e classificam os veículos por eixo ou por comprimento. Allen, Browne e Cherrett (2012) listam ainda as contagens de veículos em estabelecimentos e locais para estacionar, cujos objetivos são avaliar o uso do solo ou as operações de carga e descarga.

Conjugados, os sistemas citados envolvem a técnica WIM (weight in motion) que permite também classificar os veículos por classes de peso e velocidade, conforme o sistema padrão utilizado. Porém, este tipo de recurso é caro e as informações se degradam durante os congestionamentos devido à dificuldade em estimar as velocidades dos veículos (COIFMAM e KIM ${ }^{10}$, 2009apud HOLGUÍN-VERAS et al., 2010).

Ainda, segundo Holguin-Veras et al. (2010), os métodos de classificação baseados em vídeo câmeras estão sujeitas a erros devido a sombras, bloqueio por veículos maiores, ângulos de câmera e condições climáticas. Além disso, as pesquisas são limitadas aos locais onde a tecnologia está instalada e podem ocorrer erros quando da mudança de um sistema de classificação. Exemplo: na conversão de um sistema que classifica os veículos

\footnotetext{
${ }^{10}$ Coifman, B. and S. B. Kim (2009). "Speed Estimation and Length Based Vehicle Classification from Freeway Single-Loop Detectors." TransportationResearchPart C 17: 249-264.
} 
por eixo para outro que tem por referência o seu comprimento ou peso. Uma comparação entre as diferentes técnicas de classificação de veículos apresentadas é dada no Quadro 2.5.

Quadro 2.5 - Comparação entre as técnicas de classificação de veículos

\begin{tabular}{|c|c|c|c|c|c|}
\hline \multirow{2}{*}{ Tecnologia } & \multicolumn{3}{|c|}{ Tipos de dados para classificação de veículos } & \multicolumn{2}{|c|}{ Prós e Contras } \\
\hline & Classes & Qtde eixos & Comprimento & Vantagens & Desvantagens \\
\hline $\begin{array}{c}\text { Observação } \\
\text { manual /vídeos }\end{array}$ & $\mathrm{x}$ & $\mathrm{x}$ & $\mathrm{X}$ & $\begin{array}{l}\text { Poder obter } \\
\text { classificações } \\
\text { detalhadas }\end{array}$ & $\begin{array}{l}\text { Consome tempo e } \\
\text { recursos; pode ser } \\
\text { aplicada em curtos } \\
\text { períodos e áreas limitadas }\end{array}$ \\
\hline $\begin{array}{c}\text { Tubos } \\
\text { pneumáticos }\end{array}$ & & $\mathrm{x}$ & & $\begin{array}{l}\text { Baixo custo; coleta } \\
\text { contínua de dados } \\
\text { com classificação } \\
\text { automática; } \\
\text { portabilidade }\end{array}$ & $\begin{array}{c}\text { Detecta apenas } \\
\text { quantidade de eixos; } \\
\text { erros em altos volumes } \\
\text { de tráfego ou segmentos } \\
\text { com alta velocidade }\end{array}$ \\
\hline Vídeo câmeras & & & $\mathrm{x}$ & $\begin{array}{l}\text { Coleta contínua de } \\
\text { dados com } \\
\text { classificação } \\
\text { automática }\end{array}$ & $\begin{array}{c}\text { Detecta apenas o } \\
\text { comprimento do veículo; } \\
\text { sujeita a erros devido a } \\
\text { sombras, clima adverso, } \\
\text { bloqueios de imagem ou } \\
\text { ângulo da câmera }\end{array}$ \\
\hline $\begin{array}{l}\text { Laços indutivos, } \\
\text { sensores } \\
\text { magnéticos /outros } \\
\text { de pavimento }\end{array}$ & & & $\mathrm{x}$ & $\begin{array}{l}\text { Coleta contínua de } \\
\text { dados com } \\
\text { classificação } \\
\text { automática }\end{array}$ & $\begin{array}{c}\text { Detecta apenas o } \\
\text { comprimento do veículo; } \\
\text { performance cai durante } \\
\text { congestionamentos }\end{array}$ \\
\hline WIM & $\mathrm{x}$ & $\mathrm{x}$ & $\mathrm{x}$ & $\begin{array}{l}\text { Coleta contínua de } \\
\text { dados com } \\
\text { classificação } \\
\text { automática }\end{array}$ & $\begin{array}{l}\text { Instalação completa tem } \\
\text { custo alto; limitação de } \\
\text { locais para aplicação }\end{array}$ \\
\hline
\end{tabular}

Fonte: Holguín-Veras et al. (2010) - Tradução nossa, adaptado

\subsection{ETAPAS PARA O PLANEJAMENTO DA COLETA}

A coleta, tratamento e disponibilização de bases de dados têm sido um dos principais desafios dos analistas e planejadores de transporte, pois demanda esforço e tempo, além de recursos humanos e financeiros consideráveis, muitas vezes escassos. Por essa razão, esse processo exige um planejamento em etapas de forma a obtê-los de modo rápido e o mais eficiente quanto possível (BRUTON,1979, p.26). Da análise das referências bibliográficas, conclui-se que a quantidade e os detalhes dos dados variam conforme o escopo do estudo a ser realizado, porém verifica-se também que as etapas do planejamento da coleta de dados em transporte urbano são estruturadas sob uma sequência básica (BRUTON, 1979; MELLO, 1975; ORTÚZAR; WILLUMSEN, 2011), e envolvem: 

a) a definição da área de estudo;
b) a subdivisão da área de estudo em zonas de tráfego;
c) a definiçãa dos padrões de viagens em quatro movimentos básicos;
d) a coleta dos dados utilizando diferentes métodos e técnicas de pesquisa considerados mais apropriados a cada um dos movimentos citados;
e) a avaliação da exatidão dos dados e;
f) a análise dos dados.

Da sequência proposta, do exposto pelos diferentes autores que tratam do transporte de cargas, e considerando a introdução de uma base de dados extraída de documentos eletrônicos, nota-se a necessidade em efetuar algumas alterações para o caso do TUC:

a) devido à pouca compreensão do transporte urbano de cargas, torna-se necessário caracterizá-lo antes da coleta de dados, no que Tedesco (2008) apresenta como análise da estrutura semântica, dos elementos de representação e dos participantes do objeto de estudo;

b) a análise por zona de trafego impõe uma perda significativa das informações sobre viagens encadeadas comumente realizadas para entregas e coletas de cargas no meio urbano; por isso a etapa de "subdivisão da área de estudo em zonas de tráfego" é renomeada para "definição do nível de desagregação dos dados";

c) as etapas de avaliação da exatidão e análise dos dados devem ser realizadas após a etapa que trata da metodologia de obtenção dos dados de documentos fiscais eletrônicos;

Diante do exposto, propõe-se as seguintes etapas para o planejamento da coleta de dados em estudos sobre o transporte urbano de cargas:

a definição da área de estudo que traz os critérios para a limitação geográfica das análises;

a caracterização do objeto de estudo, no caso o transporte urbano de cargas;

a definiçãa do nível de desagregação dos dados, necessários para compreender os movimentos de carga urbanos; 
$>$ a definição dos padrões de viagens em quatro movimentos básicos para orientar a coleta dos dados;

$>$ a coleta e inter-relação dos dados utilizando dados de documentos fiscais eletrônicos, do cadastro de contribuintes e de fontes de dados georreferenciados;

$>$ a coleta de dados complementares por meio de diferentes métodos e técnicas de pesquisa;

a validação dos dados extraídos com dados complementares junto a órgãos públicos e privados utilizando os métodos de pesquisa tradicionais;

a análise dos dados obtidos.

Vale ressaltar que a coleta de dados de documentos fiscais eletrônicos, dos dados complementares e a validação dos dados são tratados no Capítulo 3 por sua vinculação com a metodologia alternativa de obtenção de dados proposta. A análise dos dados é realizada por meio de uma aplicação no Distrito Federal no Capítulo 4.

\subsection{DEFINIÇÃO DA ÁREA DE ESTUDO}

No contexto do planejamento de transportes, a definição da área de estudo significa delimitar a área, os limites físico-geográficos do ambiente a ser estudado que, em resumo, significa estabelecer um limite denominado cordão externo ou linha de contorno. Assim, a área dentro deste cordão é pesquisada intensivamente, analisando-se o uso do solo presente e futuro, e obtém-se dados sobre os padrões de viagem por meio de pesquisas de origemdestino (BRUTON, 1979; MELLO, 1975; ORTÚZAR; WILLUMSEN, 2011).

Ortúzar e Willumsen(2011, p. 72), por sua vez, pontuam que a dimensão da área de estudo é influenciada pelo horizonte dos planejamentos, sendo maiores para os estratégicos com horizonte de 20 anos e menores para os táticos, de base anual. Os autores afirmam que não há uma regra para estabelecê-la e que tal definição depende do contexto de cada projeto.

Porém, ao se definir a área de estudo Bruton (1979, p.27) sugere três critérios principais: 
a) O cordão externo é traçado de modo a conter a área onde ocorre a grande maioria das viagens de uma área urbana;

b) O cordão externo deve conter as áreas que serão desenvolvidas dentro do horizonte de planejamento definido;

c) O cordão externo deve ser contínuo e uniforme, deve cruzar e ser canalizado para um número pequeno de vias e onde seja seguro efetuar pesquisas.

Bruton (1979, p.27) ainda sugere que se pode analisar gráficos de dispersão da população como apoio à definição do cordão externo, especialmente em áreas mais complexas e conurbadas. Para o TUC, pode-se inferir que utilizar gráficos de dispersão dos despachos e entregas de mercadorias é uma alternativa viável pela metodologia que utiliza dados de documentos fiscais eletrônicos. No mais, considera-se que os critérios apontados para a definição da área de estudo por um cordão externo encontra respaldo na literatura sobre o TUC, e pode envolver desde uma região metropolitana, um corredor de transporte ou uma área específica, como um porto, área industrial ou determinada empresa (OGDEN, 1992).

\subsection{CARACTERIZAÇÃO DO OBJETO DE ESTUDO}

Os estudos do transporte urbano de cargas têm avançado de modo recente (ALLEN; BROWNE; CHERRETT, 2012; ANAND et al., 2012; QUACK; VAN DUIN; VISSER, 2008). Para Holguín-Veras et al. (2014c), apesar desta atividade ter uma contribuição decisiva para a economia, seu funcionamento é pouco compreendido devido, além da dificuldade na coleta de dados, à complexidade dos elementos que o compõem. Neste sentido, considera-se fundamental uma caracterização conceitual do TUC que permita balizar os estudos sobre o tema.

De um modo geral, a caracterização do objeto de estudo significa definir a sua estrutura semântica, os equipamentos, a infraestrutura, a estrutura normativa (leis, regulamentações), a estrutura funcional (como os elementos físicos são organizados), a estrutura de produção ou cadeia produtiva, a estrutura de gestão e a estrutura político-institucional, e como os atores dividem as responsabilidades e competências acerca do funcionamento, produção e manutenção do sistema de transporte (TEDESCO, 2008). 
Neste sentido, alguns dos aspectos listados são selecionados e expressos sinteticamente como segue. Mais detalhes sobre os mesmos estão no Apêndice A deste trabalho. A proposta é que conceitos sobre o TUC fiquem claros e permitam tratar os dados de modo apropriado para interpretar os movimentos de mercadorias no espaço urbano.

\section{Definicão e diferencas do TUC para o transporte de pessoas}

NCFRP (2012) e Ogden (1992) deixam claro que os estudos sobre transporte urbano de cargas têm adotado conceitos baseados no transporte de pessoas, ignorando suas diferenças. O que se observa é que isto tem levado a interpretações não realísticas dos movimentos de carga urbano. Dentre as diferenças apontadas destacam-se:

a) o tomador de decisão no transporte de pessoas são os indivíduos que realizam as viagens; no TUC o principal tomador de decisão é a empresa e, infere-se, também os consumidores pela sua alta participação nos movimentos de carga urbanos;

b) no transporte de passageiros há uma relação direta entre a geração de demanda (viagens de passageiros) e a de viagens de veículos; no TUC a geração de demanda por cargas (ex.: toneladas de mercadorias) não é direta com a geração de viagens de veículos com carga.

\section{Viagens encadeadas, paradas e entregas}

Um conceito importante é o de viagens encadeadas em TUC, que na Figura 2.1 é representado pela sequência HB-S1-S2-S3-HB.

Figura 2.1 - Viagens versus origem e destino de cargas

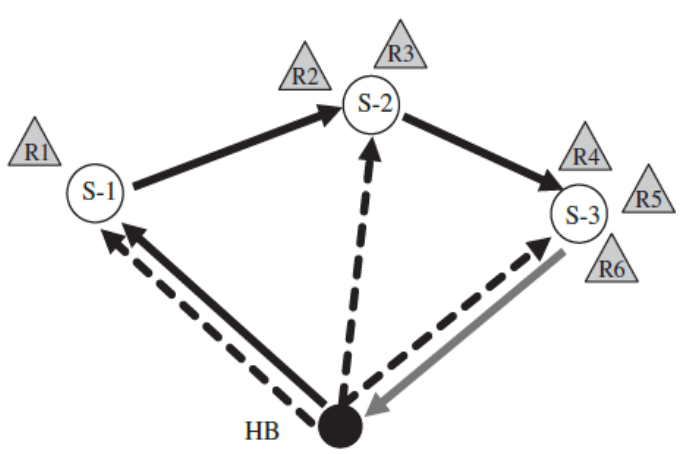

Fonte: Holguin Veras et al. (2013, tradução nossa, adaptado)
Legenda:

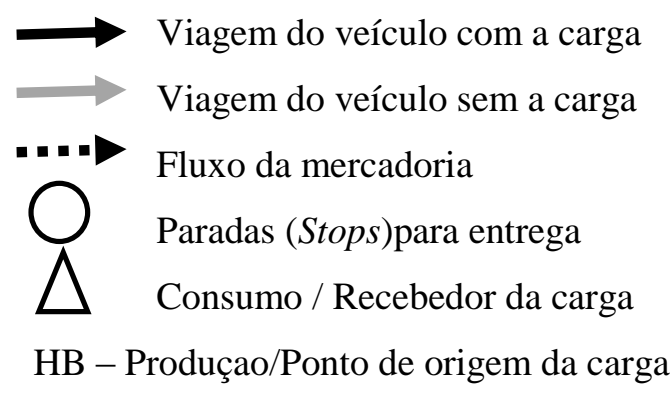


Da Figura 2.1 são extraídas importantes conclusões:

a) uma "viagem é uma jornada individual com certo propósito entre dois pontos por um meio específico de transporte" e indica que qualquer parada, excluídas as de motivo secundário (acidentes, congestionamentos), marca o início de uma nova viagem (MELLO, 1975, p. 47);

b) uma rota de entrega urbana pode ser feita com várias viagens individuais, também denominadas de viagens encadeadas;

c) cada ponto de parada pode ser utilizado para efetuar múltiplas entregas ou despachos que, do ponto de vista de um estabelecimento, não necessariamente representa uma viagem atraída/gerada;

d) as entregas urbanas feitas por meio de viagens encadeadas com múltiplas paradas tem uma participação expressiva nos movimentos de carga urbanos, e são realizadas por diversos segmentos de atividades (HOLGUÍN-VERAS et al., 2013);

e) rotas geram viagens com carga e outras vazias (viagem S3-HB da Figura 2.1), que necessitam ser consideradas;

f) o fluxo da mercadoria raramente coincide com a direção do fluxo das viagens, ou seja, as origens e destinos das viagens raramente refletem a relação de demanda e suprimento.

\section{Geração e atracão de cargas e viagens}

NCFRP (2012) e Holguín-Veras et al. (2014c) consideram importante compreender as diferenças entre geração ou atração de cargas (GC, AC) e geração ou atração de viagens com carga (GVC, AVC). GC/AC se referem à estimativa da quantidade de cargas produzidas e atraídas para determinada zona ou local, e é medida geralmente por peso (toneladas) ou volume (metros cúbicos). GVC/AVC são medidas pelo número de viagens de veículos ou entregas necessárias para transportar as cargas geradas e atraídas. Estes aspectos necessitam ser compreendidos para avaliar o impacto da implantação de estabelecimentos sobre a capacidade local para receber cargas e, também, para definir em que sentido se dão os movimentos nos diferentes segmentos de atividades (JALLER; SÁNCHEZ-DÍAZ; HOLGUÍN-VERAS, 2014). 


\section{Escolha do modo de transporte em TUC}

Entre os fatores determinantes para a escolha do modo de transporte estão o frete, a distância a percorrer, etc., porém neste estudo destaca-se a importância do tamanho da remessa da mercadoria (seu peso e volume). Em TUC o modo de transporte típico é o rodoviário, e o processo de escolha do modo de transporte se baseia na definição de políticas de carregamento destes veículos.

\section{$\underline{\text { Atores no TUC }}$}

NCFRP (2012) define os principais atores participantes do TUC da seguinte forma:

a) embarcadores são os que produzem e embarcam a carga diretamente ou por meio de serviços terceirizados;

b) transportadores são os que transportam as mercadorias, podendo ser terceirizados ou privados (que estão vinculados a uma empresa não transportadora);

c) recebedores referem-se aos agentes onde há o destino da carga, podendo ser armazéns, consumidores finais, varejistas, atacadistas, etc. Os recebedores assumem papel importante no comportamento do TUC, pois são quem impõem restrições ao transporte, tais como horário e frequência de entrega, etc. e;

d) consumidores finais, são definidos como recebedores, têm participação expressiva nos destinos de mercadorias e influenciado mudanças significativas nos canais de distribuição por meio das compras por internet.

\section{Fatores de influência no TUC}

É importante observar os fatores que afetam o movimento de cargas, pois a partir destes pode-se identificar dados e análises necessárias para compreender os movimentos de mercadorias no espaço urbano. Dentre eles destacam-se:

a) a localização das fontes de produção de cargas, seus intermediários e mercados finais para determinar as origens e destinos;

b) as variações sazonais e padrões de consumo de produtos, que desempenham um importante fator na demanda por transporte de cargas; 
c) a necessidade em conhecer as características do produto, tais como seu valor, perecibilidade e periculosidade, que induzem a esquemas especiais de transporte e;

d) a frequência de entregas de mercadorias, cujo aumento tende a proporcionar menor produtividade no uso da frota.

\subsection{DEFINIÇÃO DO NÍVEL DE DESAGREGAÇÃO DOS DADOS}

Definida a área de estudo recomenda-se tradicionalmente dividi-la em zonas, de modo a ter uma idéia espacialmente desagregada das origens e destinos das viagens. As definições de zonas comumente adotadas no planejamento de transportes são baseadas em micro regiões definidas pelo IBGE, bairros ou agrupamentos de bairros com características econômicas e sociais semelhantes (MELLO, 1975, p. 49).

De modo a tornar manuseáveis os dados coletados individualmente, este são agrupados em zonas externas (fora da área do cordão externo), e as zonas internas (dentro deste limite) (BRUTON, 1979). Recomenda-se dividir as zonas internas com maior detalhe e as externas ao cordão em menor nível de detalhe (zonas de tamanho maior) (ORTÚZAR; WILLUMSEN, 2011, p. 74).

Porém, este nível de detalhamento das zonas internas para análises do transporte urbano de cargas merece considerações. Ogden(1992) cita que a divisão zonal do fluxo de mercadorias, adotada comumente nos estudos, não reflete a expressiva variação na geração de cargas de locais ou estabelecimentos específicos em vários níveis de magnitude. Outros problemas com a divisão por zona se refletem no contexto da modelagem:

o uso de modelos agregados por zonas [...] tem pouca justificativa teórica das variáveis explanatórias ou da forma funcional das relações; carecem de variáveis importantes como custos de transporte ou medidas relacionadas com o transporte de cargas; falham em satisfazer pressupostos quando usam regressão com mínimos quadrados; frequentemente não levam em conta o fato de que viagens de veículos de carga são organizadas em rotas compostas por múltiplas viagens (SLAVIN $^{11}, 1976$ apud OGDEN, 1992, p. 285).

\footnotetext{
${ }^{11}$ Slavin H. L. (1976) Demand for urban goods vehicle trips. Transportation Research Record 591, pp 32-37.
} 
Ortúzar e Willumsen (2011, p. 73) afirmam que dados para o planejamento de transportes devem possuir uma série de características ideais, dentre estas destaca-se a alta qualidade para serem utilizados em níveis desagregados. Enfim, considera-se que o planejamento do transporte urbano de cargas requer dados desagregados para interpretar o fluxo de viagens notadamente baseado em rotas. Ao se agregar os dados em zonas, perde-se esta informação e, por consequência, a capacidade em avaliar, por exemplo, os movimentos reais de mercadorias, quais espaços urbanos são ocupados para estacionar e efetuar as diversas paradas e entregas urbanas.

Neste sentido ao invés da divisão por zonas propõe-se definir o nível de desagregação desejado, podendo ser este por CEP (HOLGUIN-VERAS et al., 2010), pontos de parada (SANTOS, 2008), estabelecimento ou outro (uma área, por exemplo), de modo que este atenda aos requisitos necessários para interpretar os movimentos das viagens com carga no meio urbano. No contexto deste estudo e por limitação do sigilo fiscal, adota-se como suficiente interpretar as informações por CEP quando são identificados os endereços dos destinos, e em termos gerais (agregados) quando não.

\subsection{MOVIMENTOS PADRÃO DE VIAGENS}

Nesta etapa classificam-se os padrões de viagens segundo o seu sentido em relação ao cordão externo, pois considera-se que estes apresentam características distintas tanto em termos do perfil das cargas (fechadas ou parceladas), dos veículos (maiores ou menores) e do tipo de viagem (diretas ou encadeadas) e, portanto, orientam diferentes procedimentos para coleta de dados. Além disso, espera-se que os diferentes movimentos tenham diferentes participações nos movimentos totais de carga no meio urbano.

Porém, as referências estudadas demonstram uma abordagem focalizada no transporte de pessoas para a definição destes movimentos, pois destacam apenas a importância dos domicílios como origem e destinos dos fluxos, feitos por pessoas residentes e não residentes (BRUTON, 1979; MELLO, 1975; ORTÚZAR; WILLUMSEN, 2011). Como discutido nas seções anteriores, adota-se os estabelecimentos (empresas) como foco de análise do TUC. 
Deste modo e tendo como base o esquema apresentado por Ortúzar e Willumsen (2011, p. 74), propõe-se o estudo do movimento de cargas baseado no esquema da Figura 2.1, onde se destacam os quatro movimentos básicos em transporte em relação ao cordão externo: movimentos externos-externos, externos-internos, internos-externos e internos-internos.

Figura 2.2 - Movimentos padrão de viagens em um sistema de transportes

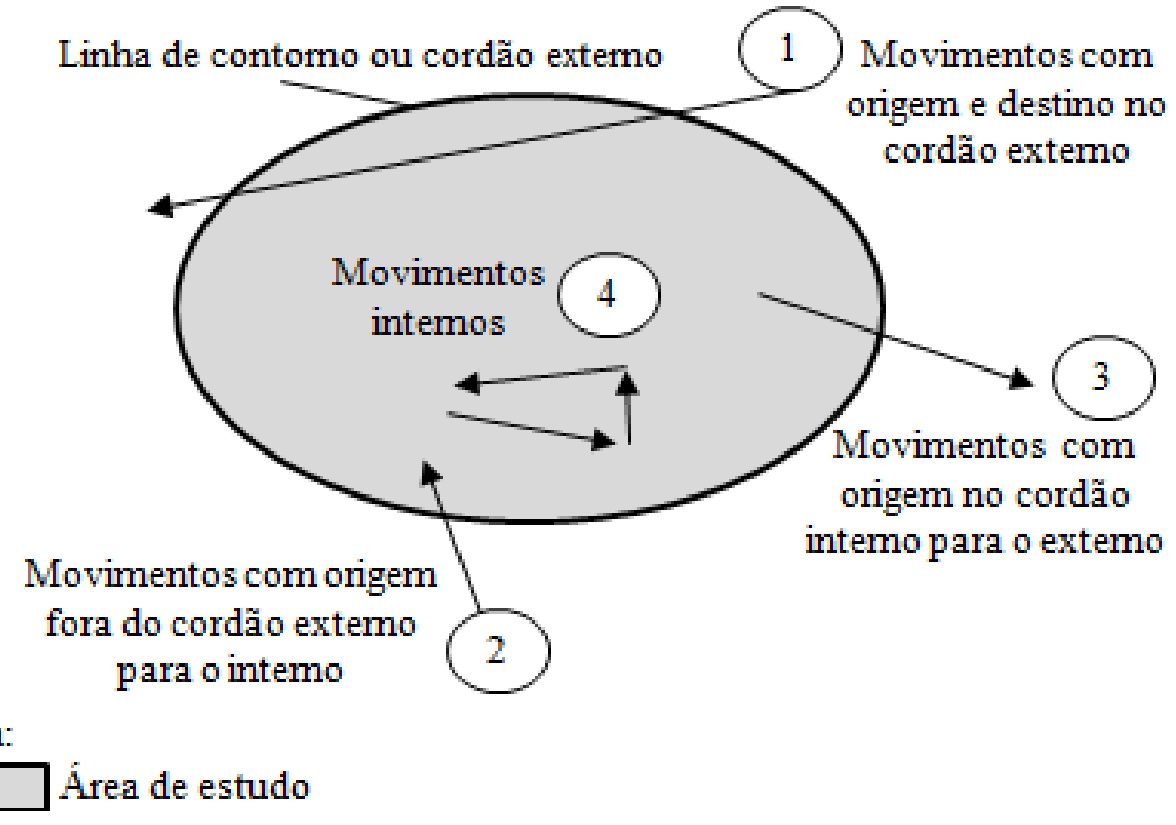

Fonte: Ortúzar e Willumsen (2011, adaptado)

1) Movimentos externos-externos (direto ou de passagem): mesmo podendo ter paradas na área de estudo, estes movimentos têm origem e destinos fora dos limites do cordão externo. Segundo Mello (1975, p. 49) são viagens de longa distância em veículos de maior peso, que causam danos aos pavimentos e redução das capacidades das vias, além do aumento de ruídos. Para Bruton (1979, p. 33) estes movimentos são geralmente pesquisados na linha de contorno;

2) Movimentos externos-internos: origem fora do cordão externo e destino dentro da área de estudo e pesquisados no cordão externo (BRUTON, 1979, p. 33) feitos por residentes e não residentes (ORTÚZAR; WILLUMSEN, 2011, p. 74). No caso de cargas, sugere-se pesquisar as origens externas (estabelecimentos ou regiões) que apresentem impacto significativo no fluxo interno, seja por meio de movimentos diretos (cargas fechadas) ou por viagens encadeadas (rotas); 
3) Movimentos internos-externos: origem dentro da área de estudo e destino fora desta, pesquisados por meio de pesquisa no local do objeto (domicílio ou empresa) ou nos cordões externo e interno (por meio de linha de controle interna) (BRUTON, 1979, p. 33);

4) Movimentos internos: origem e destino dentro da área do cordão externo, concentram o maior volume de tráfego e devem ser estudados com maior detalhe por meio de pesquisas nos domicílios (MELLO, 1975, p. 50) e, sugere-se em estabelecimentos e junto a consumidores finais.

Portanto, espera-se que os movimentos com destino interno, especialmente os de origem interna, tenham maior participação na produção de viagens encadeadas. Devido à sua importância, sugere-se que os dados para o padrão de viagem baseado em rotas possam, em parte, ser obtidos por esta metodologia e complementados por pesquisas em estabelecimentos de origem (internos ou externos) mas que tenham como destino (total ou parcial) o cordão interno. 


\section{METODOLOGIA PARA OBTENÇÃO DOS DADOS DE DFe}

Os estudos sobre o transporte urbano de mercadorias demonstram pouca disponibilidade de dados e/ou o custo elevado de sua obtenção por métodos tradicionais. Por exemplo, pesquisas origem-destino de cargas são caras, difíceis de obter pois, em regra, são confidenciais para quem possui as informações, tais como embarcadores, além de difíceis de manter atualizadas. Por exemplo, Holguín-Veras et al. (2010) apresentam o Quadro 2.6 que lista as principais deficiências em fontes de dados de informação para diferentes categorias de dados. Como é recente e tem referência o contexto dos Estados Unidos, país com tradição na realização de pesquisas em transportes, sua análise permite inferir que o estudo do transporte urbano de cargas num contexto global sofre com limitações em dados fundamentais.

Quadro 3.1- Resumo sobre lacunas de dados

\begin{tabular}{|c|c|c|}
\hline \multirow{2}{*}{$\begin{array}{l}\text { Dados de } \\
\text { geração de carga }\end{array}$} & Produção & \multirow{2}{*}{$\begin{array}{l}\text { Fontes que poderiam prover informações sobre produção e } \\
\text { consumo não foram identificadas. Microdados de CFS que } \\
\text { poderiam ser utilizados são de acesso restrito. }\end{array}$} \\
\hline & Consumo & \\
\hline \multirow{4}{*}{$\begin{array}{l}\text { Rotas de } \\
\text { Entrega }\end{array}$} & Seqüência & $\begin{array}{l}\text { Somente dados de GPS de transportadores privados podem } \\
\text { prover bons dados }\end{array}$ \\
\hline & Localização & Baixo nível de detalhe sobre localizações \\
\hline & Fluxos OD & $\begin{array}{|llll|}\begin{array}{l}\text { Algumas fontes identificadas mas com informações } \\
\text { incompletas }\end{array} & & \\
\end{array}$ \\
\hline & Fluxos de carga vazia & Fontes de informação não identificadas \\
\hline \multirow{3}{*}{$\begin{array}{l}\text { Características } \\
\text { econômicas dos } \\
\text { agentes }\end{array}$} & Embarcadores & \multirow{3}{*}{$\begin{array}{l}\text { Algumas fontes identificadas que podem prover este tipo de } \\
\text { informação, mas sem uma representação completa. Os } \\
\text { dados não tem informações extra sobre outras categorias }\end{array}$} \\
\hline & Transportadores & \\
\hline & Recebedores & \\
\hline \multirow{3}{*}{$\begin{array}{c}\text { Distribuição } \\
\text { espacial / } \\
\text { localização dos } \\
\text { agentes }\end{array}$} & Embarcadores & \multirow{3}{*}{$\begin{array}{l}\text { Algumas fontes identificadas que podem prover este tipo de } \\
\text { informação, mas sem uma representação completa. Os } \\
\text { dados não tem informações extra sobre outras categorias }\end{array}$} \\
\hline & Transportadores & \\
\hline & Recebedores & \\
\hline \multirow{4}{*}{$\begin{array}{l}\text { Características } \\
\text { da Rede Viária }\end{array}$} & Tempos de viagens, custos & \multirow{4}{*}{$\begin{array}{l}\text { Somente baixo nível de detalhe sobre estas categorias foi } \\
\text { identicado entre diferentes fontes }\end{array}$} \\
\hline & Restrições de uso & \\
\hline & Capacidade & \\
\hline & Volumes de tráfego & \\
\hline \multirow{3}{*}{$\begin{array}{l}\text { Processos de } \\
\text { escolha especial }\end{array}$} & Escolha modal & Sem informação sobre escolha modal \\
\hline & Tempo de entrega & Baixo nível de detalhe sobre tempo de entrega \\
\hline & Atributos do modo & Algum nível de detalhe sobre atributos do modo utilizado \\
\hline \multirow{3}{*}{$\begin{array}{l}\text { Outros dados } \\
\text { econômicos }\end{array}$} & Funções de produção & Fontes de informação não identificadas \\
\hline & Funções de demanda & Fontes de informação não identificadas \\
\hline & Coeficientes Entrada/Saída & Bom nível de detalhe em pesquisas realizadas nos EUA \\
\hline
\end{tabular}

Fonte: Holguín-Veras et al. (2010, tradução nossa, adaptado) 
Da análise do Quadro 2.6 verifica-se que as fontes de dados ou não são identificadas, quando identificadas fornecem informações restritas ou incompletas, ou então estão dispersas entre diferentes atores com visões parciais do sistema de transporte urbano de cargas. Neste contexto, resta aos pesquisadores duas abordagens: desenvolver um método com os dados disponíveis, muitas vezes secundários, ou coletá-los de forma direta, o que é proibitivamente caro. Além disso, é preciso considerar se os estabelecimentos irão fornecer as informações (AMBITE et al., 2003; GIULIANO et al., 2010; GONZÁLEZCALDERÓN; HOLGUÍN-VERAS, 2014; TAVASSZY; JONG, 2014).

Alternativas para a coleta de dados em TUC vem sendo buscadas, tais como a busca por parcerias incentivada pelo "Guia de Partilha de Dados em Transporte de Cargas" (NCFRP, 2013). Porém, mesmo neste caso, demonstra-se que as empresas são relutantes em fornecer informações muitas vezes sigilosas. Por exemplo, baseando-se nesta proposta, Cruz-Ross et al. (2014) contatam 493 companhias, que culmina em uma pesquisa online com 32 empresas propensas a formar parcerias para partilhar dados e apoiar os estudos para identificar suas necessidades e preocupações. Destas 32, apenas 3 fornecem dados amostrais, e 22 relatam o temor de que suas informações sejam mal utilizadas em um contexto de competição de mercado.

Giuliano et al. (2010) propõem um método para modelagem do fluxo de cargas intrametropolitano que objetiva criar um sistema automatizado de planejamento e análise do fluxo de cargas utilizando dados secundários provenientes de diversas fontes, tais como internet e agências governamentais, pesquisas de fluxo de mercadorias e dados de emprego em determinadas regiões. Porém, os autores citam a dificuldade em obter consistência nas informações provenientes de fontes diferentes, geralmente com diferentes escalas de medida, o que tomou a maior parte do tempo do estudo.

Allen, Browne e Cherrett (2012), em sua revisão de 162 estudos relacionados ao transporte urbano rodoviário de cargas, identificam os principais métodos utilizados para coleta de dados em TUC nos últimos 50 anos. Para os autores há duas opções: auto-preenchimento dos questionários pelo respondente ou a realização de entrevistas e sendo que, e em alguns casos, o uso de auto-preenchimento ocorreu pela inviabilidade da entrevista. De qualquer forma, os autores apontam que em 96 pesquisas onde foi possível identificar o método 
utilizado, 49 são feitas por meio de entrevistas, 31 por meio do auto-preenchimento e 16 utilizam ambos. Enfim, o caro método por meio de entrevistas ainda prevalece.

Por outro lado, e apesar da literatura estudada sobre coleta de dados para o planejamento em transportes contemplar um período de avanço significativo na digitalização dos dados, de Richardson, Ampt e Meyburg (1995) a Holguín-Veras (2014), não se nota uma preocupação em explorar os métodos documentais. Porém, segundo Tavasszy (2014, p. 243) a captura de dados em meio digital das operações em transportes vem crescendo sensivelmente, seja por meio de recursos na internet ou por meio de sistemas de gerenciamento e, diga-se, por meio da digitalização das transações comerciais.

Tavasszy (2014) relata ainda que os bancos de dados digitais tendem a ser um repositório significativo de informações a baixo custo, abrangência e detalhamento, os big data. Ainda, o autor considera que o principal desafio é acompanhar a evolução destes bancos de dados em meio digital, que podem revolucionar a forma de compreender o transporte urbano de cargas. Entende-se que esta se trata de uma visão interessante, alinhada com o que se propõe nesse estudo.

Além de buscar avançar na coleta dos dados, também é importante relatar que os trabalhos que tratam do planejamento de transportes, apesar de contemplar as viagens de veículos comerciais, segue um foco enviesado para o transporte de pessoas e, em alguns casos, não apropriado para compreender os movimentos de cargas. É preciso incorporar e integrar os diferentes temas em uma abordagem única. Pode-se concluir que o planejamento de transportes, que pretenda contemplar o transporte urbano de cargas, necessita tratá-lo com suas especificidades sob pena de não refletir o seu real impacto no espaço urbano.

Neste contexto, a proposta portanto é, por meio de um método documental e atendendo às características específicas do TUC, explorar o banco de dados da nota fiscal eletrônica que, paradoxalmente, recebe informações sigilosas de modo obrigatório das empresas e, ao mesmo tempo, cria um repositório de dados valioso que: pode ser explorado preservando o sigilo fiscal e; trazer informações importantes para o avanço dos estudos do TUC.

Por conseguinte, este capítulo apresenta a metodologia desenvolvida para a obtenção dos dados de documentos fiscais eletrônicos (DFe), tratados neste estudo como os dados da 
nota fiscal eletrônica (NFe) e do cadastro fiscal de contribuintes do Distrito Federal. Seu principal objetivo é criar uma base de dados que permita apoiar as diferentes modelagens e análises requeridas para o planejamento do transporte urbano de cargas. A metodologia está baseada nos estudos sobre o TUC, em pesquisas realizadas com distribuidoras de bebidas (SANTOS, 2008) e transportadoras de carga fracionada (SANTOS; SÁNCHEZDÍAZ, 2015). Alguns aspectos relevantes identificados nos estudos e utilizados para modelar a obtenção dos dados de DFe são:

a) separação dos fluxos de notas fiscais entre internos (de, para, entre o Distrito Federal) e externos (relativos a outros estados ou países) (BRUTON, 1979; MELLO, 1975; OGDEN, 1992; ORTÚZAR; WILLUMSEN, 2011);

b) separação dos dados entre pessoa física e jurídica, no intuito de detectar entregas para consumidores finais, e uso de CFOP para determinar se a compra pode ser identificada pelo canal internet (COMI et al., 2012);

c) uso do campo nome da transportadora da NFe buscando identificá-las como intermediárias no fluxo de cargas urbanas (JALLER; SÁNCHEZ-DÍAZ; HOLGUÍN-VERAS, 2014);

d) uso do campo placa da NFe para relacionar os dados dos veículos que transportam as mercadorias com os registrados no cadastro fiscal do Distrito Federal;

e) identificação georreferenciada das origens e destinos (HOLGUÍN-VERAS; JALLER, 2014; HOLGUIN-VERAS et al., 2010) por CEP ${ }^{12}$;

f) a necessidade de agrupamento de notas fiscais como uma entrega ou remessa na situação em que há coincidência entre emitente, destinatário e data de emissão da NFe (SANTOS; SÁNCHEZ-DÍAZ, 2015; SANTOS, 2008).

\subsection{FONTES UTILIZADAS PARA A EXTRAÇÃO DOS DADOS}

Os agentes econômicos que realizam transações com mercadorias e/ou prestações de serviços, como o caso dos operadores de transporte, são obrigados pela lei brasileira a emitir um documento fiscal com os seguintes dados: número do cadastro fiscal; endereços do emitente/prestador do serviço e do destinatário/contratante do serviço e; o valor e a

\footnotetext{
${ }^{12}$ Durante as entrevistas para Santos e Sánchez-Díaz (2015), os 23 gerentes de transportadoras consideram CEP um nível desagregado suficiente para servir como pontos de parada na roteirização de entregas.
} 
descrição das mercadorias. Esses dados devem ser preenchidos corretamente pelo emitente da nota fiscal, porque são os que servem para o cálculo do imposto que ampara a transação e porque, caso existam inconsistências nos mesmos, o contribuinte do imposto fica sujeito a multas por descumprimento de obrigação acessória e/ou por sonegação fiscal.

Obrigação acessória conforme o parágrafo segundo do artigo 113 do código tributário nacional brasileiro (CTN, 2012, p. 22) é: "A obrigação [...] decorrente da legislação tributária e tem por objeto as prestações, positivas ou negativas, nela previstas no interesse da arrecadação ou da fiscalização dos tributos". Entende-se como obrigação acessória aquela em que o contribuinte deve, por lei, emitir e exigir a nota fiscal, transmitir estas informações ao destinatário ou ao emitente, contabilizar e disponibilizar as informações da nota fiscal registrada ao fisco.

Dessa forma, os dados dos documentos fiscais espelham uma situação muito próxima do real dessas transações e geram um fluxo de dados significativos. Com o advento dos documentos fiscais eletrônicos, de processos e de tecnologias da informação que possibilitam com rapidez a coleta, tratamento e análise dos dados dessas transações a um baixo custo, tornou-se viável uma série de iniciativas que estão mudando o cenário das fiscalizações do trânsito de mercadorias e das prestações de serviços de transporte, em todos os diferentes modos, em nível urbano e regional no Brasil.

Os documentos fiscais eletrônicos são produto de uma série de iniciativas englobadas no sistema público de escrituração digital - SPED (SPED, 2015), instituído pelo governo federal brasileiro por meio do decreto 6.022 de 22 de janeiro de 2007. Em linhas gerais, o projeto SPED consiste:

$\mathrm{Na}$ modernização do cumprimento das obrigações acessórias, transmitidas pelos contribuintes às administrações tributárias e aos órgãos fiscalizadores, utilizando-se da certificação digital para fins de assinatura dos documentos eletrônicos, garantindo assim a validade jurídica dos mesmos apenas na sua forma digital (SPED, 2015).

Esse sistema é coordenado pela Receita Federal do Brasil e CONFAZ (Conselho Nacional de Política Fazendária). O desenvolvimento de novas soluções e disseminação de 
informações é realizado constantemente por meio dos encontros nacionais de coordenadores e administradores tributários estaduais - ENCAT (ENCAT, 2015). O projeto SPED envolve ações integradas das administrações tributárias nas três esferas de governo (federal, estadual e municipal), além de parcerias com empresas, órgãos públicos, bancos, associações de classe, etc. (SPED, 2015).

Os principais documentos digitalizados no interesse do transporte de cargas são a Nota Fiscal Eletrônica (NFe), o Conhecimento de Transporte Eletrônico (CTe) e o Manifesto Eletrônico de Documentos Fiscais (MDFe). Estes dois últimos não são utilizados neste trabalho pois ainda não estão disponíveis no banco de dados da secretaria de fazenda do DF. Mais informações sobre os mesmos estão em CTE (2015) e MDFE (2015).

Cada estado brasileiro tem disponível um banco de dados das NFe's relativo às operações que dele se origina e/ou a que ele se destina, mesmo que de modo intermediário (ex.: exportação por um porto ou aeroporto). Esse banco de dados da secretaria de fazenda estadual é o objeto de trabalho dessa pesquisa. Existe também uma base nacional que, mediante convênio pode ser acessada, mas que não faz parte do escopo deste estudo.

O banco de dados das NFe's traz uma série de informações interessantes para estudos em transportes de cargas. Para o caso deste trabalho são escolhidos apenas certos grupos de dados que se acredita serem relevantes para o planejamento do TUC, com a ressalva de que alguns desses apresentam inconsistências e algumas lacunas, tais como:

a) falta de uniformização na descrição de endereços dos destinos por serem registrados por diferentes emitentes em diversos períodos. Observa-se que a descrição textual é precisa, porém é difícil utilizá-la como referência em um banco de dados;

b) CEP's identificados com diferentes números de dígitos ou até mesmo com valores genéricos, tais como, por exemplo, 74000-000, 74000 ao invés de 74.351-014, o que dificulta localizar e georreferenciar diversos destinos;

c) os códigos de atividades das empresas que efetuam a transação comercial geralmente não são informados na $\mathrm{NFe}$, pois estas informações são obrigatórias apenas quando o emitente possui cadastro no município de origem e em determinadas operações (MANUAL-NFE, 2012); 
d) volume, peso das mercadorias e dados do transportador são imprecisos. Na análise de 408.000 NFe's, cerca de 30\% das notas apresentam inconsistência nesses campos, devido principalmente ao fato de o emissor não ser passível de multa pela ausência de tais informações. Isto não acontece com os campos destinados ao cálculo do imposto (quantidade e valor das mercadorias) e dados do emitente/destinatário da transação, tais como endereço, inscrições estaduais e CNPJ (cadastro nacional de pessoa jurídica);

e) a NFe não fornece dados sobre o cadastro de veículos e a área do estabelecimento de origem ou destino.

Para suprir essas imprecisões e lacunas de informações da NFe utiliza-se o banco de dados do cadastro fiscal de contribuintes da Secretaria de Fazenda do Distrito Federal. Isto porque a inserção dos dados no cadastro fiscal é um processo burocrático mais rígido, os dados são fornecidos de uma única fonte, de forma mais precisa e é um tipo de registro que existe em todos os estados brasileiros. No caso desse estudo as informações utilizadas para complementar os dados da NFe são: endereços, código de atividade econômica, cadastro de veículos e área construída dos estabelecimentos com registro no Distrito Federal.

Outro banco de dados utilizado e que é relevante para propósito do trabalho é o código do CEP georreferenciado, informação vendida por diversas empresas, entre elas os CORREIOS $^{13}$. No caso deste estudo, utilizam-se as informações fornecidas pela Companhia de Saneamento Ambiental do Distrito Federal, a CAESB ${ }^{14}$.

\subsubsection{Nota Fiscal eletrônica - NFe}

A Nota Fiscal Eletrônica (NFe), acessível no portal da NFe (NFE, 2015), é desenvolvida de forma integrada pelas Secretarias de Fazenda dos Estados e a Secretaria da Receita Federal do Brasil, a partir da assinatura do Protocolo ENAT 03/2005 (ENAT, 2015), que atribui ao Encontro Nacional de Coordenadores e Administradores Tributários Estaduais (ENCAT, 2015) a coordenação e a responsabilidade pelo seu desenvolvimento e implantação.

\footnotetext{
13 CORREIOS: http://www.correios.com.br/

${ }^{14}$ CAESB: http://www.caesb.df.gov.br/
} 
Para instituir a NFe foi celebrado o Ajuste SINIEF 07/05(SINIEF, 1970), pelos Estados, Distrito Federal e Ministério da Fazenda, juntamente com a legislação complementar contida no Ato da Comissão Técnica Permanente do ICMS, COTEPE 72/05, de 22/12/2005 (NFE, 2015).

NFE(2015) define a Nota Fiscal Eletrônica como:
um documento de existência exclusivamente digital, emitido e armazenado eletronicamente, com o intuito de documentar uma operação de circulação de mercadorias ou prestação de serviços (grifo nosso), cuja validade jurídica é garantida por duas condições necessárias: a assinatura digital do emitente e a autorização de uso fornecida pela administração tributária do domicílio do contribuinte.

Para se ter uma dimensão do rol de informações envolvidas, vale destacar que até 7/6/2015 haviam sido autorizadas mais de 11 bilhões de NFe envolvendo cerca de 1,2 milhões de emissores (NFE, 2015) E expressando o fluxo de mercadorias de uma forma desagregada. As NFe's contêm ricas informações para o planejamento de transporte de carga como, por exemplo:

a) a localização da origem e destino de cada transação que pode ser vinculada pelo CEP e números do Cadastro Nacional de Pessoa Jurídica (CNPJ) ou Pessoa Física (CPF) dos emitentes e destinatários das mercadorias;

b) a descrição das mercadorias via nomenclatura comum do Mercosul (NCM, 2014);

c) o tipo de operação fiscal por meio do código fiscal de operações e prestações (CFOP, 2014);

d) o volume e peso das mercadorias relacionadas que, após terem seus dados tratados, fornecem uma base de informações considerável.

De modo a proporcionar uma visão mais clara sobre como os dados da NFe são gerados e organizados, são desenvolvidos os dois tópicos seguintes: Fluxo operacional da NFe e Organização dos dados. 


\section{Fluxo Operacional da NFe}

O fluxo operacional da NFe, representado na Figura 3.1, descreve como seus dados são gerados e armazenados, quais agentes e responsabilidades estão envolvidos quando um documento eletrônico é emitido e, como são gerenciados os aspectos relacionados com sua integridade e as contingências do processo.

Figura 3.1 - Fluxo Operacional da NFe

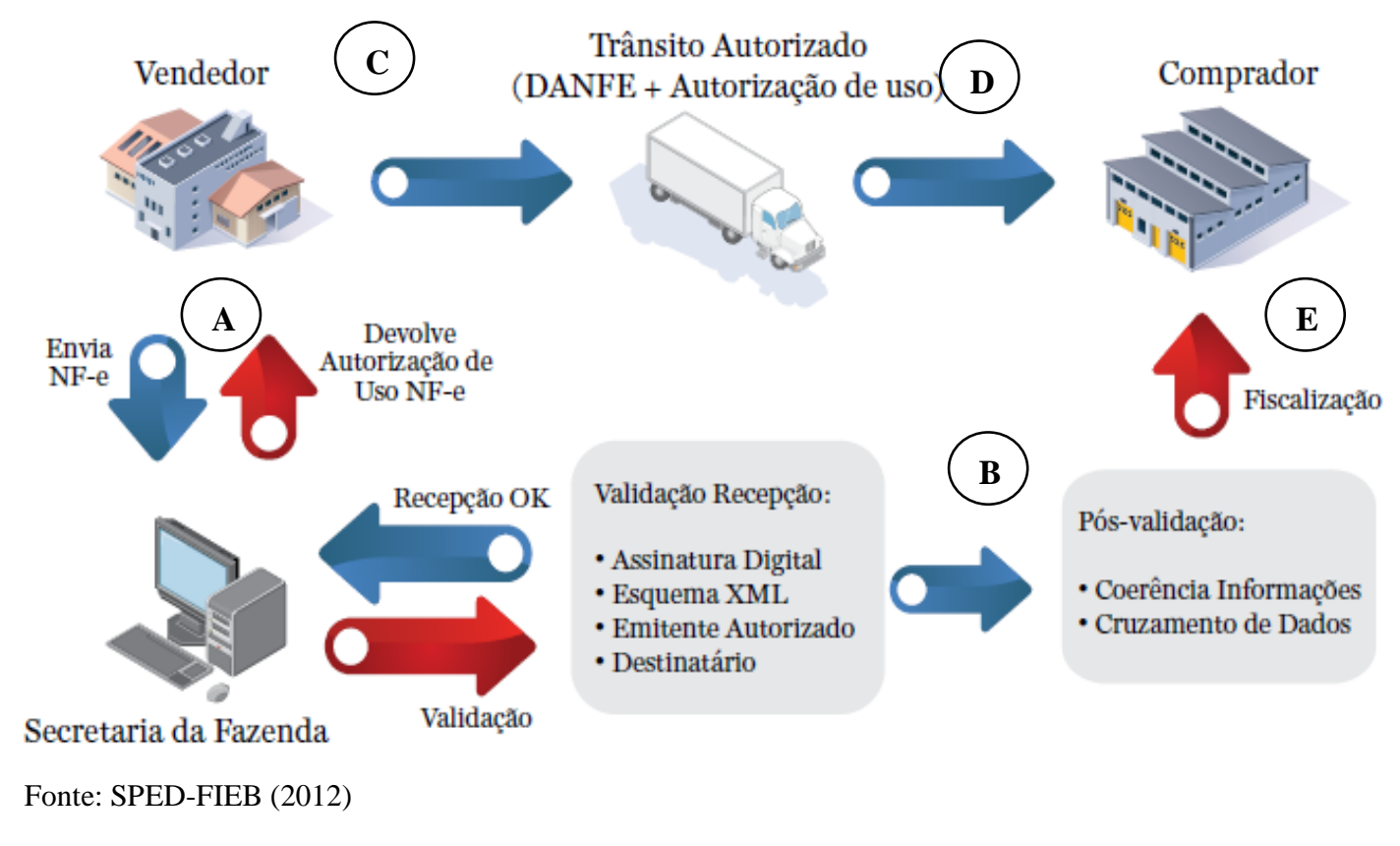

Etapa A: O vendedor (ou emissor do documento fiscal eletrônico) gera um arquivo digital contendo as informações da transação comercial e o assina digitalmente, transmitindo-o para a secretaria de fazenda (SEFAZ) ao qual está sob jurisdição. A SEFAZ recebe e valida o documento seguindo uma série de regras do manual do contribuinte (MANUAL-NFE, 2012). Uma delas é a assinatura digital que garante a autoria e integridade do documento. Assim que a SEFAZ autoriza o uso, o documento torna-se apto a acobertar a operação para a qual foi emitido.

Etapa B: Após a autorização ou denegação, a NFe é armazenada no site da receitas federal e da respectiva receita estadual. Qualquer pessoa que tenha acesso à chave de identificação do documento eletrônico pode consultá-lo na web (NFE, 2015). Esta chave de identificação é um conjunto de 44 números, também expressos em código de barras. 
Etapa C: Uma vez que o arquivo eletrônico é gerado, um documento auxiliar é impresso em papel para acompanhar o trânsito da mercadoria. No caso da NFe denominase documento auxiliar da nota fiscal eletrônica, DANFE ${ }^{15}$.

Etapa D: O emitente da NFe deve fazer chegar o arquivo eletrônico até o recebedor da mercadoria ou serviço, que deve aceitar e fazer a devida contabilização.

Etapa E: As fiscalizações tributárias, de posse das informações dos documentos fiscais eletrônicos, armazenam e cruzam os dados para detectar indícios de sonegação e, consequentemente, iniciar procedimentos como conferência física de cargas e auditorias em empresas. Trata-se de um processo sistemático de validação das informações.

Todo o fluxo descrito acima é dinâmico e ocorre em ambiente web. No caso de alguma interrupção nesse canal de comunicação surge o processo denominado contingência: a NFe é emitida no ambiente de serviços assíncronos (Figura 3.2), ela passa a fluir em modo não sincronizado e, posteriormente, é retomada na internet de modo a não interromper a logística interna das empresas.

Figura 3.2 - Arquitetura de comunicação da $\mathrm{Ne}$

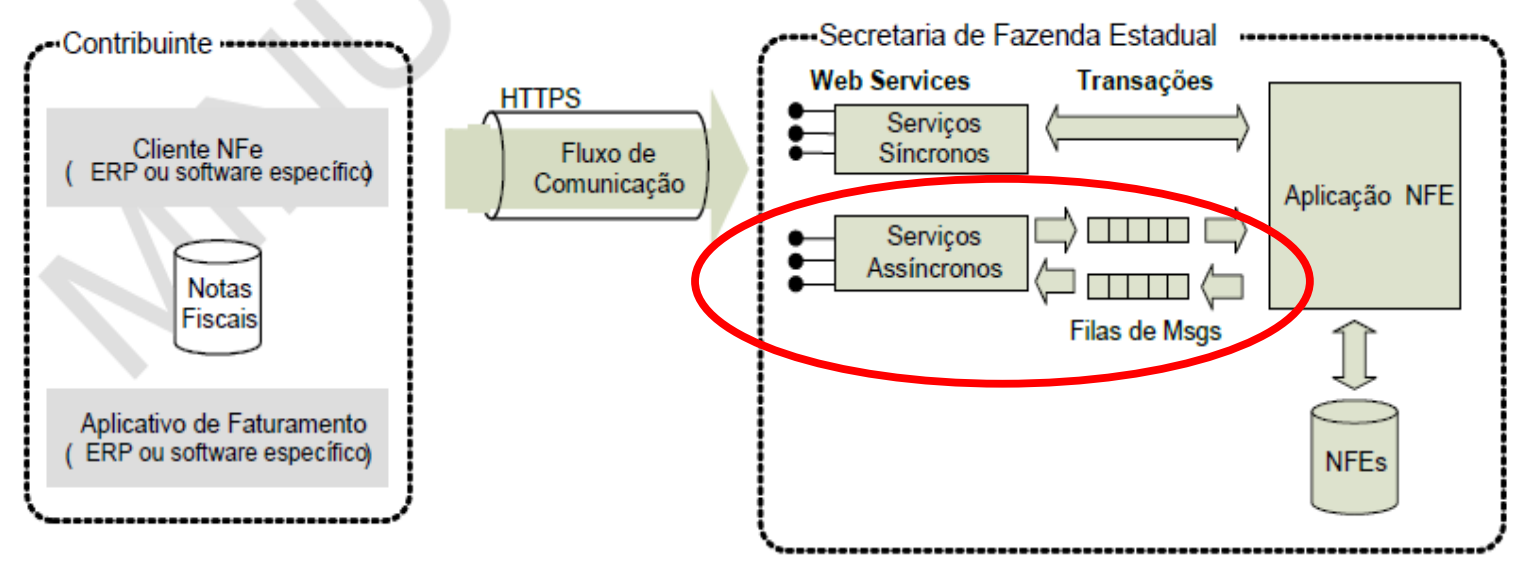

Fonte: Manual-NFe (2012)

\footnotetext{
${ }^{15}$ O DANFE é um recurso para permitir uma transição entre a cultura do papel e a eletrônica e facilitar a fiscalização tributária nas barreiras fiscais nos estados. É importante ter claro que o documento válido é o eletrônico. Um exemplo do DANFE encontra-se na Figura A.1 do Anexo A.
} 


\section{Organizacão dos dados na NFe}

Os dados da NFe são organizados sob o conceito de Schema XML com hierarquia de campos, e sua compreensão é útil e necessária para orientar a manipulação dos dados. Segue uma breve explicação sobre estes conceitos.

Schema XML: É a linguagem de programação que define o conteúdo do documento eletrônico e a sua organização. No exemplo da Figura 3.3, o grupo de informações da NFe (infNFe) se vincula hierarquicamente com o grupo do detalhamento dos tipos de produtos e impostos da NFe (det), que se vincula ao grupo de informações dos produtos (prod), e este com as informações sobre produtos específicos na NFe (medicamentos, armas, etc.).

Figura 3.3 - Diagrama do Schema XML dos grupos de informações da NFe

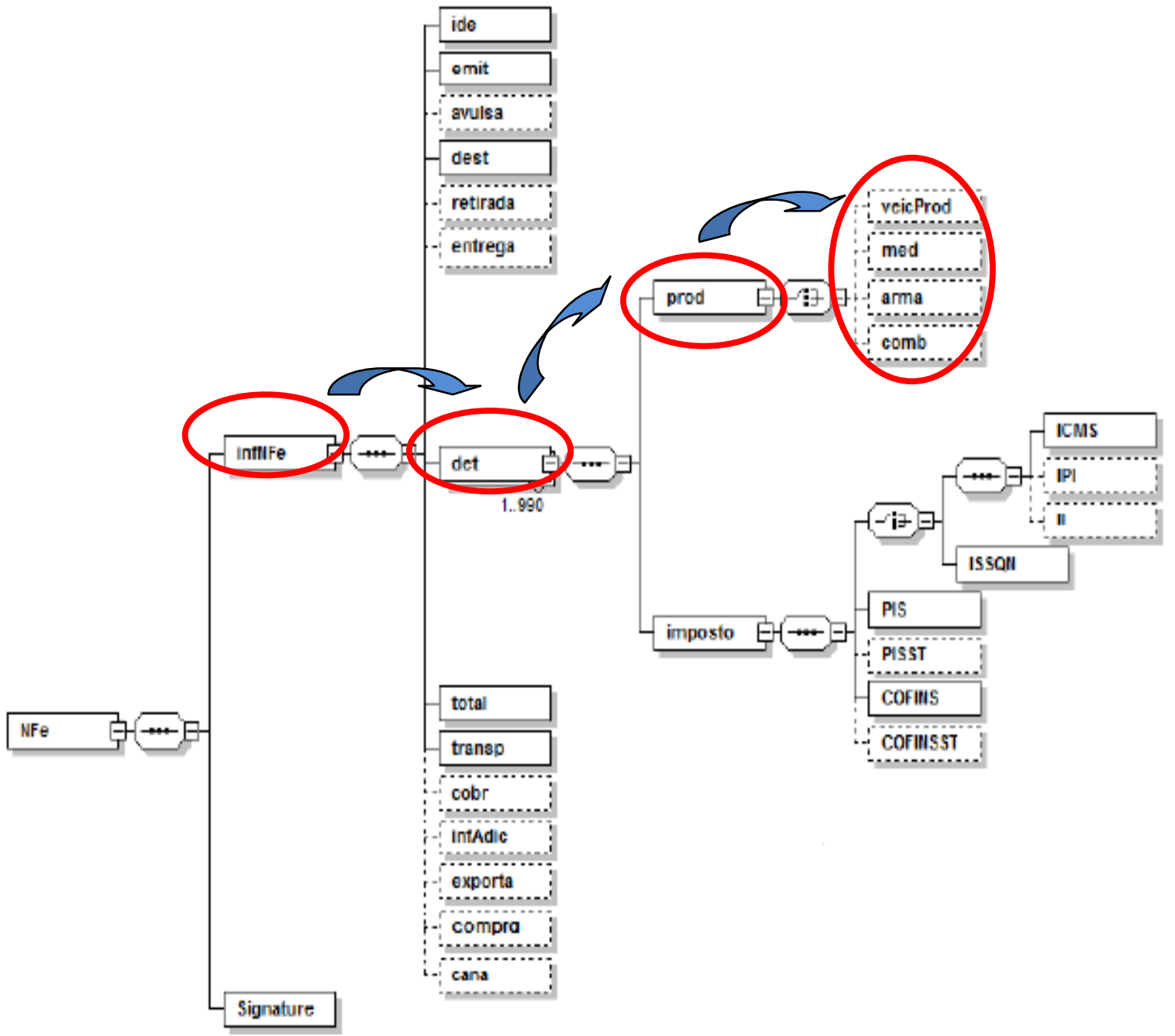

Fonte: Manual-NFe (2012) 
Coluna campo: Contém os nomes padronizados dos diferentes campos, como por exemplo, a IE (inscrição estadual do contribuinte junto às secretarias de fazenda). A diferenciação dos campos é realizada com a identificação de qual grupo do Schema XML os mesmos fazem parte. Os grupos de informações estão destacados com linhas em tom escuro no Quadro 3.2, que também mostra os campos da NFe.

\subsubsection{Cadastro Fiscal de Contribuintes do Distrito Federal}

O cadastro fiscal do Distrito Federal conta com cerca de 200.000 registros de contribuintes ativos, sendo 184.581 pessoas jurídicas, das quais 3.213 empresas possuem matriz em outros estados e 14.629 pessoas físicas registradas, essencialmente ambulantes e feirantes. Como comentado anteriormente, os campos disponíveis na NFe carecem de uma descrição da atividade econômica (CNAE) do destinatário da mercadoria, e também do emitente da NFe quando sua inscrição municipal não é informada (MANUAL-NFE, 2012). O cadastro fiscal no estado de destino supre parte desta carência e, além disso, fornece informações para validação do CEP, da área do imóvel do contribuinte do DF e do cadastro de veículos, úteis ao planejamento do transporte de cargas.

\subsection{SELEÇÃO DOS CAMPOS DA NFE E DO CADASTRO FISCAL}

Neste item são apresentados os campos selecionados dos documentos fiscais eletrônicos como pertinentes para o estudo do planejamento do transporte de carga. No total foram selecionados 25 campos da NFe mostrados no Quadro 3.2 e cujo detalhamento é feito a seguir para aqueles em que a descrição não é considerada auto-explicativa.

O campo Id possui uma chave de 44 números que permite a consulta da $\mathrm{NFe}$ no portal da NFe (NFE, 2015). Sua configuração pode ser consultada em MANUALNFE (2012).

tpNF é o tipo da NFe, sendo normalmente emitida com código 1, de saída, onde o emitente é o local de origem da mercadoria e o destinatário o destino. Porém, notas fiscais com tpNF=0 são de entrada, e neste caso, o local do emitente passa a ser o destino da mercadoria e do destinatário a origem. Isto é um aspecto fundamental para expressar a direção do fluxo da carga e é utilizado no trato dos dados da NFe. 
Quadro 3.2 - Campos selecionados da NFe

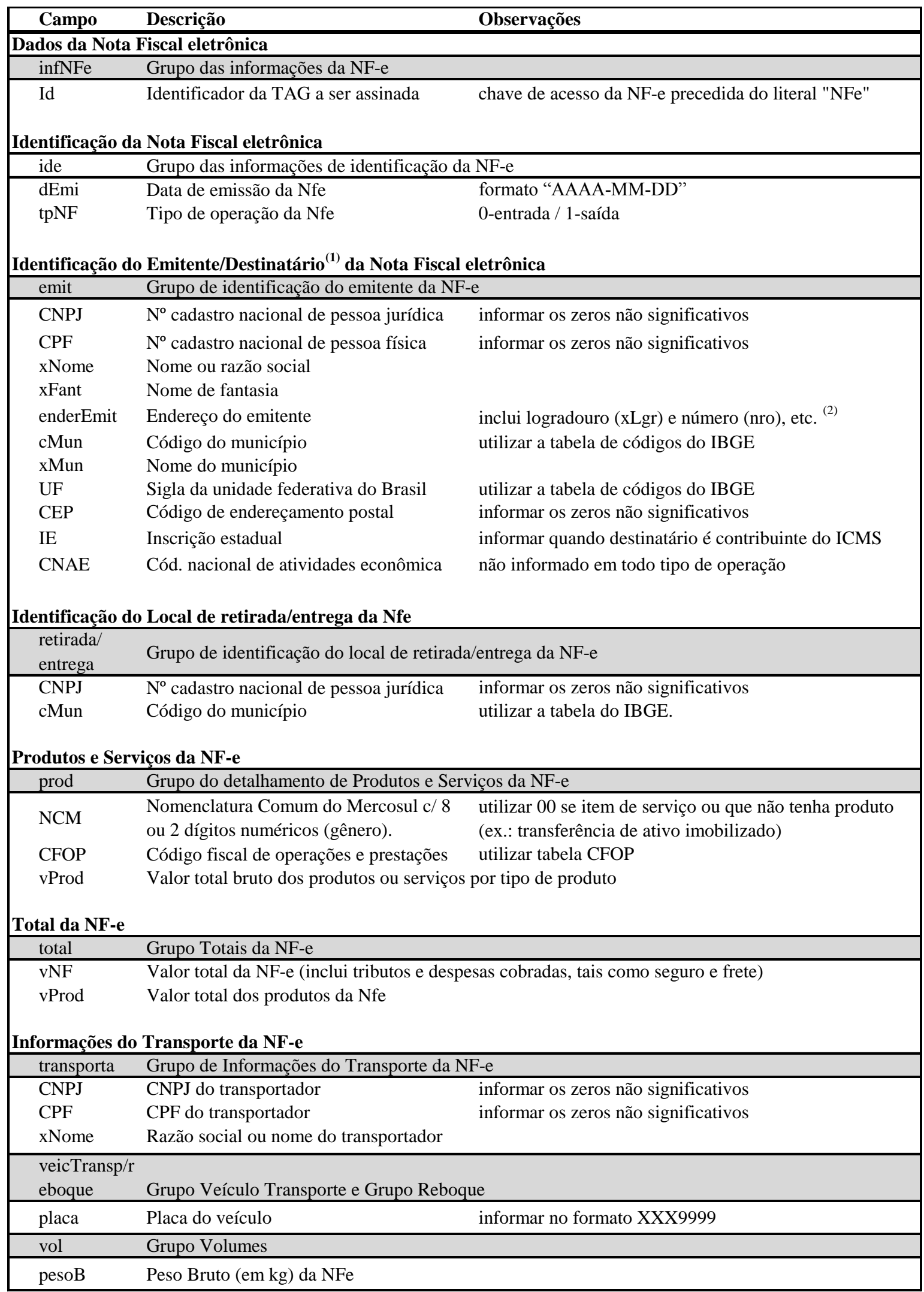

Notas: (1) Dados iguais para o destinatário.Grupo emit torna-se dest e o campo enderEmit torna-se enderDest

(2) Inclui ainda o bairro (xBairro) e complemento $(\mathrm{xCpl})$

Fonte: Manual-NFe (2012, adaptado) - versão 5.0 do Manual da NFe 
cMun é o código dos municípios brasileiros fornecido pelo IBGE e formado por sete dígitos, dos quais os dois primeiros indicam a Unidade Federativa. Esta tabela não é listada por ser extensa, mas pode ser consultada em http://www.sped.fazenda.gov.br.

- UF indica o código da Unidade Federativa do Brasil fornecido pelo IBGE e formado por dois dígitos indicados no Quadro 3.3.

Quadro 3.3 - Códigos das unidades federativas do Brasil conforme padrão IBGE

\begin{tabular}{|l|l|l|l|l|}
\hline Região Norte & Região Nordeste & Região Sudeste & Região Sul & Região Centro-Oeste \\
\hline 11- Rondônia & 21 - Maranhão & 31 - Minas Gerais & 41 - Paraná & 50 - Mato Grosso do \\
12- Acre & 22 - Piauí & 32 - Espírito Santo & 42 - Santa Catarina & Sul \\
13 - Amazonas & 23 - Ceará & 33 - Rio de Janeiro & 43 - Rio Grande do & 51 - Mato Grosso \\
14 - Roraima & 24 - Rio Grande & 35 - São Paulo & Sul & 52 - Goiás \\
15 - Pará & do Norte & & 53 - Distrito Federal \\
16 - Amazonas & 25 - Paraíba & & & \\
17 - Tocantins & 26 - Pernambuco & & & \\
27 - Alagoas & 28 - Sergipe & & & \\
& 29 - Bahia & & & \\
\hline
\end{tabular}

Fonte: Manual-NFe (2012)

> CNAE é o instrumento de padronização nacional dos códigos de atividade econômica utilizados pelas administrações tributária do Brasil. Pode ser consultada em CNAE (2015). Aplica-se a todos os agentes produtores de bens e serviços, empresas privadas, públicas ou agrícolas, organismos públicos, instituições sem fins lucrativos e pessoas físicas, com uma lista de mais de 600 itens. A CNAE é elaborada sob a coordenação da Secretaria da Receita Federal, com orientação técnica do IBGE e participação de representantes da União, dos Estados e dos Municípios que atuam na Comissão Nacional de Classificação - CONCLA. A tabela de códigos e denominações da CNAE conta com 07 dígitos a ser informado na Ficha Cadastral de Pessoa Jurídica (FCPJ) que alimenta o Cadastro Nacional de Pessoa Jurídica (CNPJ).

NCM contém uma lista extensa com cerca de 14.000 códigos de produtos (NCM, 2014). Esta lista completa contém 8 dígitos, porém há o NCM gênero com dois 
dígitos que resume as categorias em 99 grupos mercadorias, e que é utilizado neste trabalho por viabilizar a interpretação dos dados.

CFOP é o código fiscal de operações e de prestações das entradas de mercadorias e bens e da aquisição de serviços. Possui um conjunto numérico de 4 dígitos que identifica a natureza de circulação da mercadoria ou da prestação de serviço de transportes e deve ser indicado nos documentos fiscais (CFOP, 2014).

\section{Selecão dos Dados do Cadastro Fiscal de Contribuintes do Distrito Federal}

Os campos selecionados do cadastro fiscal do Distrito Federal são mostrados no Quadro 3.4. Da mesma forma que para os campos da NFe, abaixo são detalhados apenas aqueles em que a descrição no Quadro 3.4 não é autoexplicativa ou porque necessita de alguma complementação.

Quadro 3.4 - Dados do Cadastro Fiscal do Distrito Federal

\begin{tabular}{|ll|}
\hline Campo & Descrição \\
\hline Inscricao & número do contribuinte no cadastro fiscal do Distrito Federal (CFDF) \\
Nome_Razao & razão social \\
Nome_Fantasia & nome de fantasia \\
CPFCNPJ & CPF ou CNPJ do contribuinte \\
Tipo_Pessoa & F= pessoa física, J=pessoa jurídica \\
Desc_Situacao & se contribuinte ativo, baixado, cancelado, suspenso, etc. \\
CEP & código de endereçamento postal \\
Desc_Atvd_ICMS & código de mesma natureza do CNAE no Distrito Federal \\
Desc_Atvd_ISS & código de mesma natureza do CNAE no Distrito Federal \\
Inscricao_Imovel & código de inscrição do imóvel para vínculo de área \\
area_habite-se I & area construída e/ou do terreno do imóvel \\
codigo do veículo & número de registro do veículo vinculado ao CPF ou CNPJ do proprietário \\
tipo veiculo & se empresa tem veículo e seu tipo: automóvel, caminhão, motocicleta,etc \\
\hline
\end{tabular}

O campo Inscricao refere-se ao campo IE (ver Quadro 3.2) da NFe e é denominado CFDF (Cadastro Fiscal do Distrito Federal) no Distrito Federal. Vale destacar que a conexão dos dados do CFDF com os da NFe é feita por meio dos números do CNPJ, CPF ou da inscrição do emitente ou do destinatário da mercadoria localizado no Distrito Federal.

O campo Desc_Situação descreve se a empresa ainda opera, podendo ser ativa ou suspensa. São as situações utilizadas nesse estudo. Os campos Inscricao_Imovel e código do veículo servem para relacionar a área ou veículos registrados no CFDF com os dados do contribuinte. 


\subsection{FERRAMENTA DE EXTRAÇÃO: SOFTWARE QLIKVIEW}

Este item trata das principais características do software utilizado neste trabalho, o QlikView ${ }^{\circledR}(\mathrm{QV})$. O objetivo desta seção é facilitar a compreensão dos processos de extração, tratamento e apresentação dos dados utilizados no estudo. Segundo QLIKVIEW (2011b) trata-se de um software de inteligência em negócios (BI - de business inteligence) orientado ao usuário. O QlikView (QV) trabalha com bases de dados de grande porte, os denominados big data, em diferentes formatos como SQL Server, Oracle, arquivos do Excel, XML, texto e até aplicativos corporativos, permitindo associações entre dados de modo a suportar decisões corporativas.

O software QlikView é utilizado pela Secretaria de Fazenda do Distrito Federal para análises da própria arrecadação e, para isto, conta com dois servidores que possuem 1 Terabyte de memória RAM, recurso significativamente consumido por este aplicativo e que necessita ser avaliado quando do seu uso. Para se ter uma dimensão desta característica, a extração dos dados da NFe para este trabalho tomou duas horas e meia mesmo utilizando este 1 Terabyte da memória RAM do servidor.

No caso deste estudo, o QV é utilizado para criar associações entre as tabelas de dados dos documentos fiscais eletrônicos, do cadastro fiscal do Distrito Federal e de CEP's georreferenciados, dentre outros, para gerar um banco com informações úteis na análise do transporte de cargas. Acrescenta-se que QV possui recursos que permitem explorar bases de dados em provedores de informação como, por exemplo, associar os dados georreferenciados e apresentá-los em mapas do googlemaps, sem custos.

Para criar um documento no QlikView é necessário desenvolver o chamado script (ver Figura 3.4), que nada mais é do que um roteiro onde se seleciona onde e quais dados são extraídos, como serão tratados, relacionados e disponibilizados. Assim que o script é concluído, carregam-se os dados para serem organizados nos chamados painéis, onde as informações são exibidas e analisadas por meio dos chamados objetos e pastas. Vale salientar que o QV não é uma base de dados tradicional, ou seja, não é possível incluir ou alterar dados na base de dados de origem (QLIVIEW, 2015) 
Para proporcionar uma melhor compreensão do software, alguns termos e recursos utilizados são apresentados: o termo chave de associação entre tabelas, as principais extensões de arquivos utilizadas pelo QV e o painel de análise dos dados, simplesmente denominado painel.

Figura 3.4 - Fluxo de dados em um trabalho com QlikView

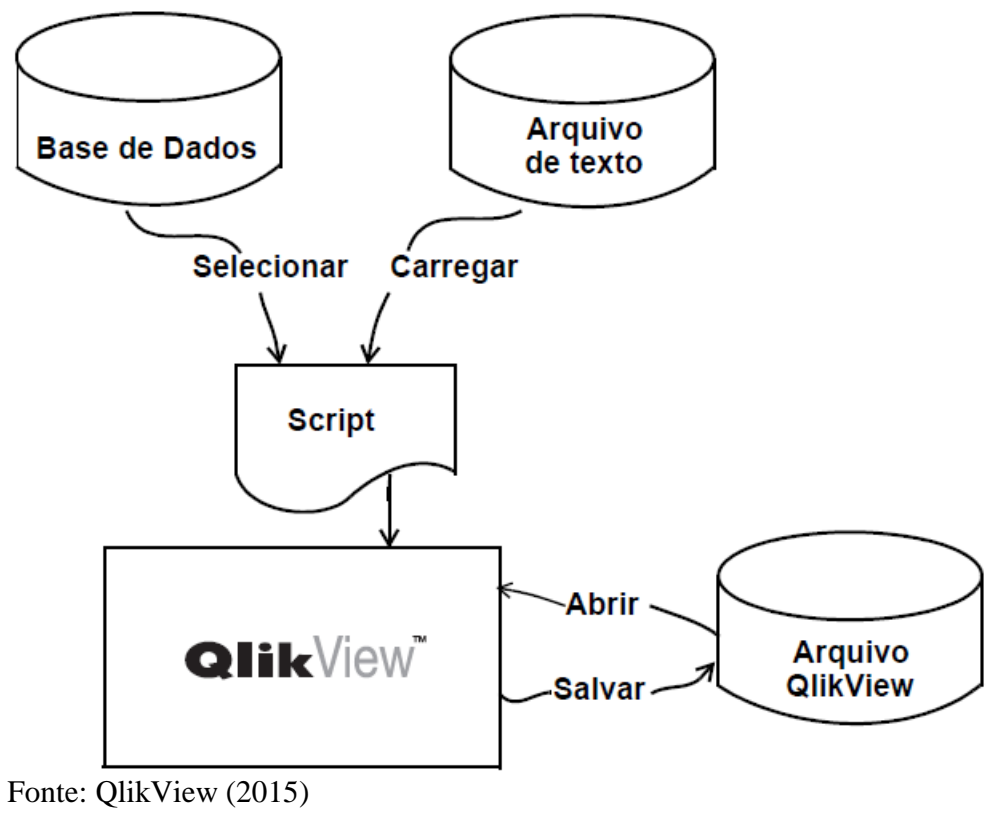

\section{Chave de associacão entre tabela}

Chave de associação, campo-chave ou chave é o campo que conecta duas ou mais tabelas com informações na coluna em comum. A Figura 3.5 destaca, por exemplo, que as tabelas País e Cliente são associadas pelo campo País e as tabelas Cliente e Transação pelo campo ID_Cliente. Nestes casos, País e ID_Cliente são denominados chaves ${ }^{16}$.

Assim, é importante ressaltar que o QV faz associações automáticas por meio de nomes dos campos iguais entre diferentes tabelas e, para isto, conta inclusive com letras maiúsculas e minúsculas (case sensitive) para reconhecê-los. Por isto, é importante ter um cuidado maior com nomes de campos, sendo estes muitas vezes renomeados durante a elaboração do script para servir de chave ou para evitar associações indesejadas.

\footnotetext{
${ }^{16}$ O campo Id da nota fiscal eletrônica possui coincidentemente o nome chave. Por isto, para evitar erros de interpretação, a Id é tratada neste estudo como chave da NFe que, em alguns casos, será usada como chave de associação do QV. Na maioria dos casos, a chave de associação das tabelas da NFe será o campo COD_INFNFE detalhado na metodologia de extração dos dados.
} 
Figura 3.5 - Exemplo de associações de tabelas no QlikView

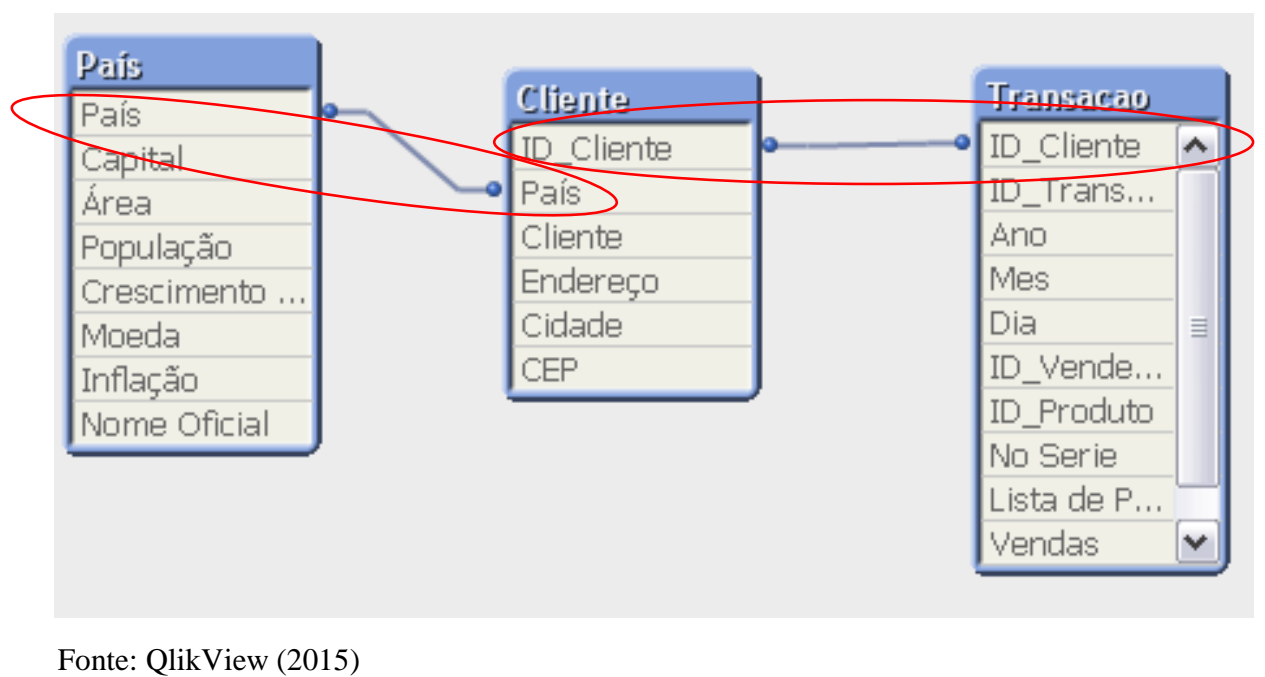

\section{Principais extensões de arquivos utilizadas}

Segundo QLIKVIEW(2011a) a extensão QVD - de QlikView Data- é um arquivo que contém uma tabela de dados que pode ser gravado e lido apenas pelo QlikView. O formato de arquivo é otimizado para agilização na leitura de dados de um script do software e, ao mesmo tempo, é compacto. Por exemplo, a leitura de dados de um arquivo em QVD é geralmente de 10 a 100 vezes mais rápida do que a leitura de outras fontes de dados. Assim, como é demonstrada na etapa metodologia, a estratégia mais utilizada é converter arquivos para este tipo de extensão visando reduzir tempo de processamento.

A extensão QVO - de QlikView Output - é do arquivo de exportação para ser utilizado em outros formatos, como excel, HTML, XML.

Extensão QVW, de QlikView Worksheet - é a utilizada pelo painel, relatórios e o script.

\section{Painel do QlikView}

Um painel nada mais é do que a seleção e organização dos dados extraídos por meio dos denominados objetos e pastas. Nele, o QlikView apresenta diversos recursos não somente para estabelecer relações entre bancos de dados, mas que também facilitam a análise dos resultados. Seguem explicações de alguns itens mostrados na Figura 3.8: 
a) permite a criação de diferentes pastas (abas) possibilitando analisá-las de modo interligado ou desconectado, ou seja, uma alteração, filtro em uma pasta pode ou não produzir alterações nas demais.

b) apresenta diversos tipos de gráficos (de barra, de pizza,etc.), tabelas simples, de seleção múltipla e dinâmicas, listas de dados, objetos de pesquisa para consultar dados, caixas de estatísticas que permitem contar, extrair médias, desvios padrão, quantidade de dados nulos ou faltantes, etc., denominados objetos de pasta;

c) possui recursos que auxiliam no controle de quais campos estão selecionados (que passam a ter a cor verde, vide Figura 3.6); estas seleções podem ser armazenadas pelo programa por meio do marcador de seleções (Figura 3.7), o que permite reverter a seleções de interesse com maior rapidez, um aspecto fundamental quando se analisa um banco de dados de grande porte com diversas variáveis em análise.

Figura 3.6 - Exemplo de comando controlador de seleções no QlikView

\begin{tabular}{|c|c|c|c|}
\hline Seleçö & & & $=$ \\
\hline Campos & & Valores & \\
\hline País & 0 & Monaco & \\
\hline Cliente & 0 & Captain Cook's Surfing School & \\
\hline
\end{tabular}

Fonte: QlikView (2011)

Figura 3.7 - Exemplo de comando marcador no QlikView

\begin{tabular}{l} 
Incluir Marcador \\
Nome do Marcador: \\
\hline $7 / 5 / 10-1$ \\
$\square$ Fazer este marcador um marcador de documento \\
$\square$ Compartihar Marcador com Outros Usuários \\
$\square$ Incluir Seleções em Marcador \\
$\square$ Aplicar o marcador sobre a seleção atual \\
$\square$ Incluir Situação do Layout \\
$\square$ Incluir Posiçốes de Deslizamento \\
$\square$ Incluir Valores de Campo de Entrada \\
Texto de informações: \\
$\square$ Mensagem Pop-up \\
$\square$ CK
\end{tabular}

Fonte: QlikView (2011) 
Figura 3.8 - Exemplo de painel do software QlikView

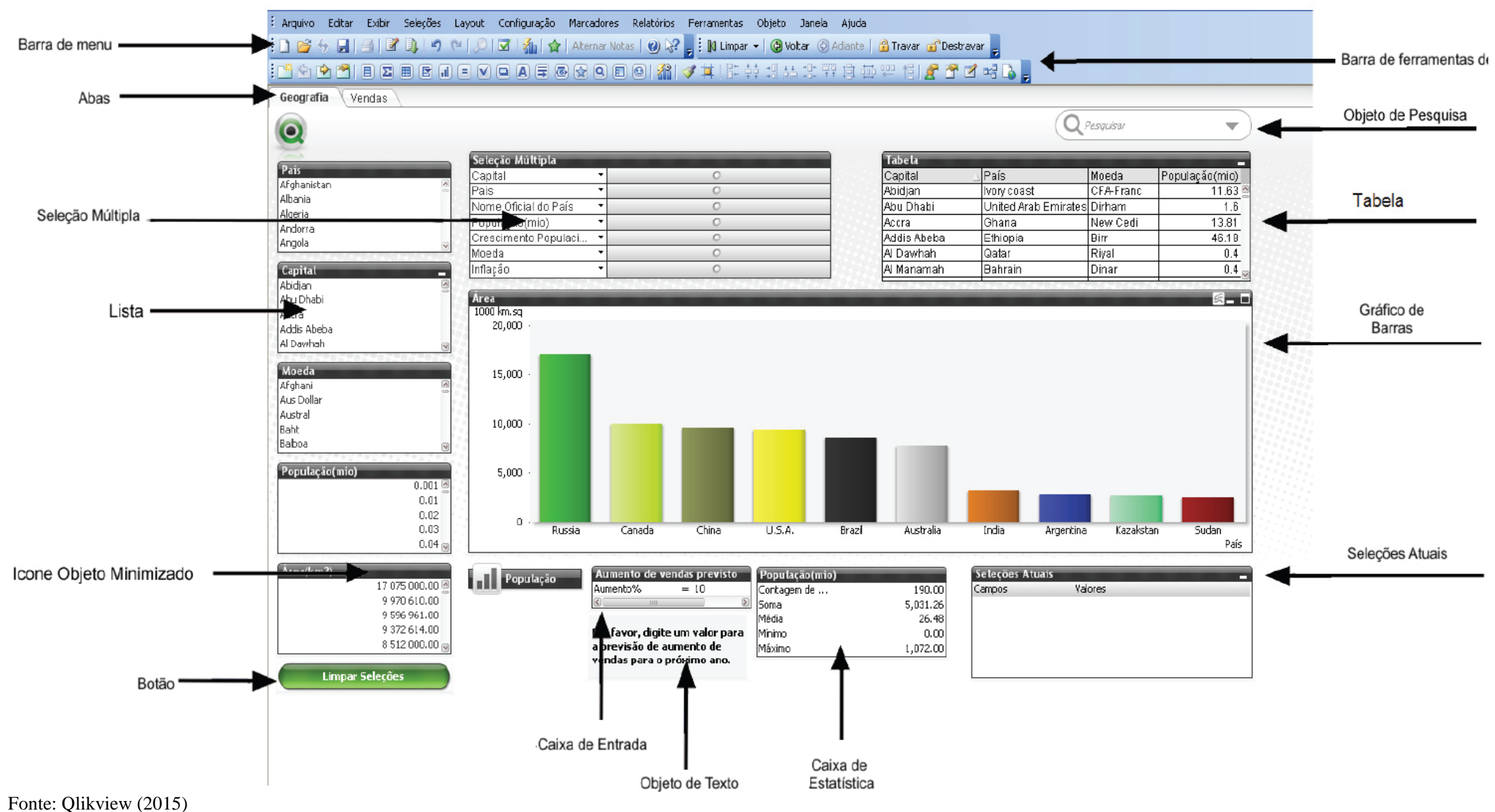




\subsection{FLUXOGRAMA PARA EXTRAÇÃO DOS DADOS}

O fluxograma da Figura 3.9 demonstra a sequência de ações para extrair, tratar e disponibilizar os dados dos documentos fiscais eletrônicos no painel. Estas ações são organizadas em três etapas: Etapa 1 de extração dos dados da base da Secretaria de Fazenda do Rio Grande do Sul; Etapa 2 de geração de um arquivo com extensão QVD com os dados extraídos das notas fiscais eletrônicas e; Etapa 3 de integração dos dados extraídos do cadastro fiscal do Distrito Federal e elaboração do painel.

Figura 3.9 - Fluxograma para obtenção dos dados da NFe

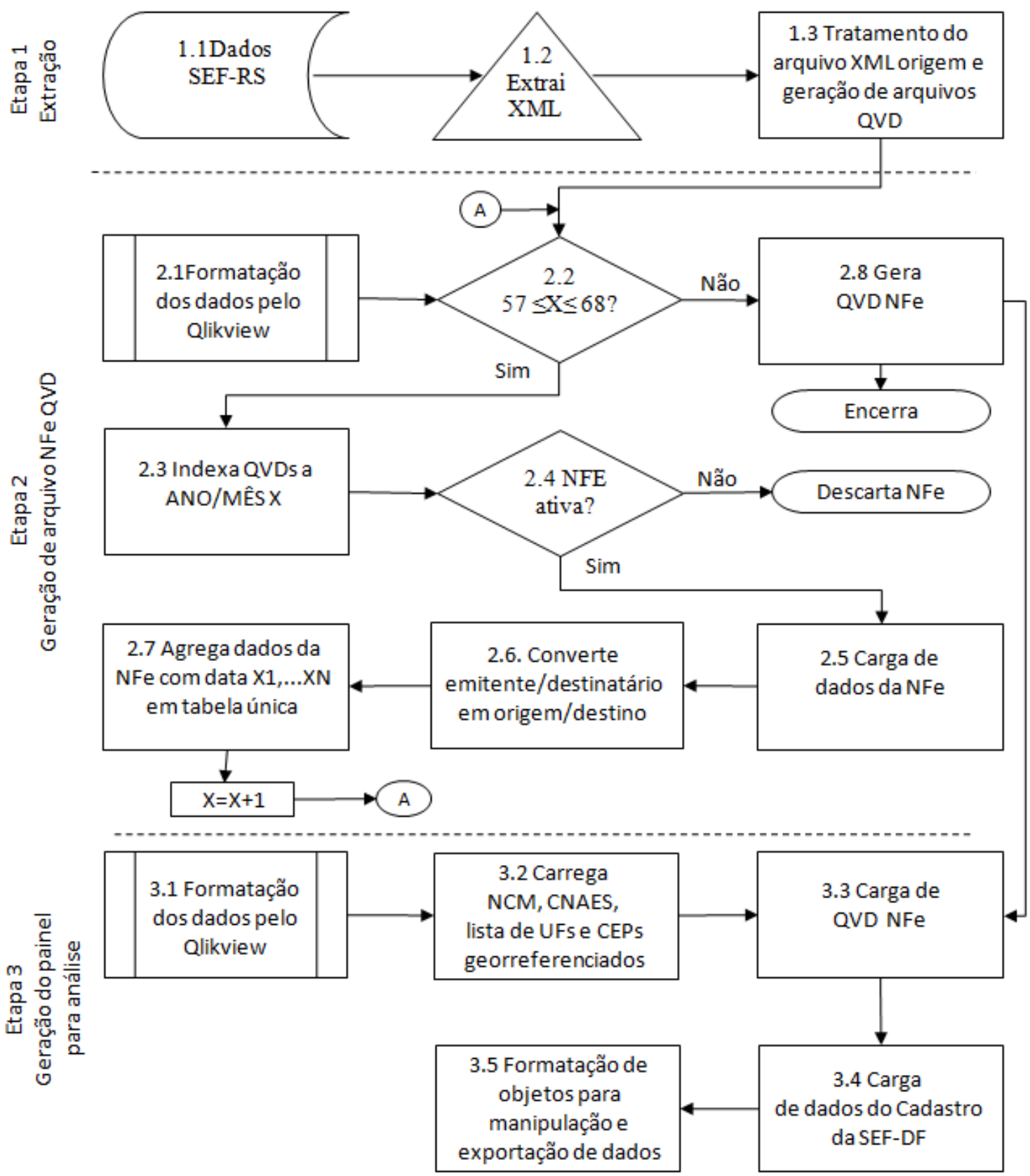


De modo a facilitar a leitura, as ações relacionadas no fluxograma são divididas em subetapas classificadas com um primeiro número que indica à qual etapa pertence, e um segundo número que indica a sequência adotada na etapa. Ainda, quando considerado necessário e de modo a permitir um melhor acompanhamento do fluxograma, são feitos pequenos recortes da etapa na Figura 3.9 com destaque da subetapa descrita.

\subsubsection{Etapa 1 - Extração dos dados da NFe}

Esta etapa consiste em receber os arquivos da NFe que são armazenados no banco de dados da NFe da Secretaria de Fazenda do Rio Grande do Sul, que faz este tipo de serviço para o Distrito Federal e outros sete estados. Esses são convertidos em arquivos para uso no QlikView, de extensão QVD. Esse procedimento é feito em três subetapas.

\section{Subetapa 1.1 - Dados SEF-RS}

Os dados gerados da NFe são armazenados em um banco de dados administrado pela Secretaria de Fazenda do Rio Grande do Sul (SEF-RS) que centraliza os dados do Distrito Federal. Uma NFe somente é autorizada e armazenada se atende critérios de preenchimento e tem a assinatura digital do emissor validada.

\section{Subetapa 1.2 - Extracão dos arquivos XML}

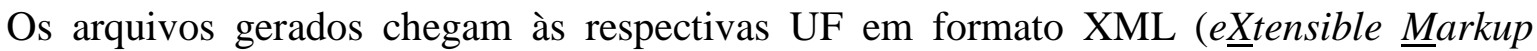
Language). Os dados são extraídos online pela secretaria de fazenda quando a NFe contém a indicação da respectiva unidade federativa nos campos: UF do emitente ou destinatário da NFe, do local de retirada ou entrega da mercadoria.

\section{Subetapa 1.3 - Tratamento do arquivo XML origem e geracão de arquivos QVD}

Os dados extraídos são novamente validados pela SEF-DF e procedimentos internos os organizam para uso. No caso do software QlikView, esses dados são tratados, organizados por pastas e compactados quando convertidos para extensão QVD. Estes arquivos são denominados arquivos QVD originais, e os utilizados nesse estudo com seus respectivos campos são apresentados no Quadro 3.7 da subetapa 2.3. 


\subsubsection{Etapa 2 - Geração do arquivo NFe.QVD}

Na etapa 2 são extraídos os dados da NFe de interesse deste estudo e gerado um arquivo em extensão QVD - NFe.QVD que, na etapa 3, é associado com os dados do cadastro fiscal e de CEP's georreferenciados. Trata-se de uma rotina com oito subetapas.

\section{Subetapa 2.1 - Formatação dos dados pelo QlikView}

Ajusta-se os formatos de data, hora, moeda, separadores de milhar e decimais, além dos números e respectivas siglas dos estados brasileiros conforme nomenclatura IBGE de acordo com os padrões da NFe (Quadro 3.5).

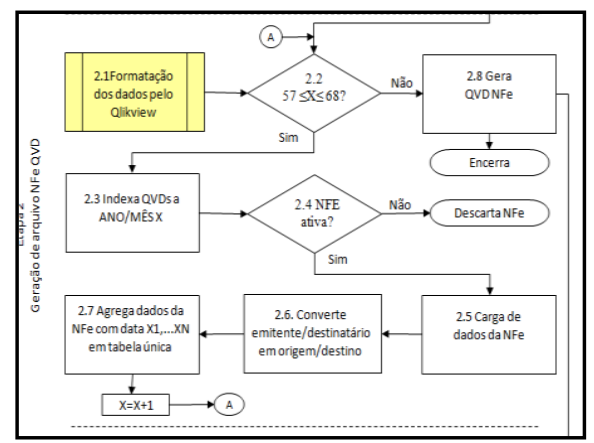

Quadro 3.5 - Formatos de dados na NFe

\begin{tabular}{|ll|}
\hline Item & Configuração \\
\hline Separador de milhar & Uso de ponto “.” \\
Separador de decimal & Uso de vírgula “,” \\
Formato monetário & $\mathrm{R} \$ \# . \# \# 0,00 ;-\mathrm{R} \$ \# . \# \# 0,00$ \\
Formato de horas & hh.mm.ss \\
Formato de data (dia/mês/ano) & DD/MM/YYYY \\
Nome de meses & jan;fev;mar;abr;mai;jun;jul;ago;set;out;nov;dez \\
Dias da semana & seg;ter;qua;qui;sex;sab;dom \\
\hline
\end{tabular}

\section{Subetapa 2.2 - Especificacão do período de análise}

Baseando-se na data de emissão da NFe, esta etapa especifica para o QV quais períodos de ano e mês são extraídos. Dois formatos são utilizados (ver Quadro 3.6), um numérico (coluna AnoMesDir) para comunicação com o banco de dados e outro em texto (coluna AnoMesTxt) para uso do QV na

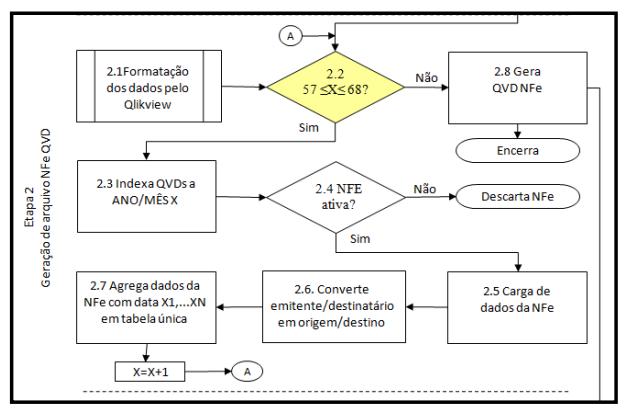
exportação de dados. 
A numeração identificada pela letra $X$ expressa a partição dos arquivos da $\mathrm{NFe}$ no Distrito Federal por mês desde seu início em janeiro de 2009 até agosto de 2014. Para este trabalho são utilizados dados de setembro de 2013 (X=57) a agosto de $2014(X=68)$.

Quadro 3.6 - Período de análise para o QlikView

\begin{tabular}{|c|c|c|}
\hline X & AnoMesDir & AnoMesTxt \\
\hline 1 & $2009 \backslash 01$ & 200901 \\
2 & $2009 \backslash 02$ & 200902 \\
$\cdot$ & $\cdot$ & $\cdot$ \\
$\cdot$ & $\cdot$ & $\cdot$ \\
$\cdot$ & $\cdot$ & $\cdot$ \\
66 & $2014 / 06$ & 201406 \\
67 & $2014 / 07$ & 201407 \\
68 & $2014 / 08$ & 201408 \\
\hline
\end{tabular}

\section{Subetapa 2.3 - Indexação dos campos dos arquivos do banco por ano e mês}

Como observado no item anterior, os arquivos originais estão organizados/particionados pela SEF-DF por ano e mês. Dentro de cada arquivo, porém, os dados dos campos não são internamente diferenciados por períodos. Para que o software compreenda esta organização para cada dado, vincula-se os campos utilizados a um

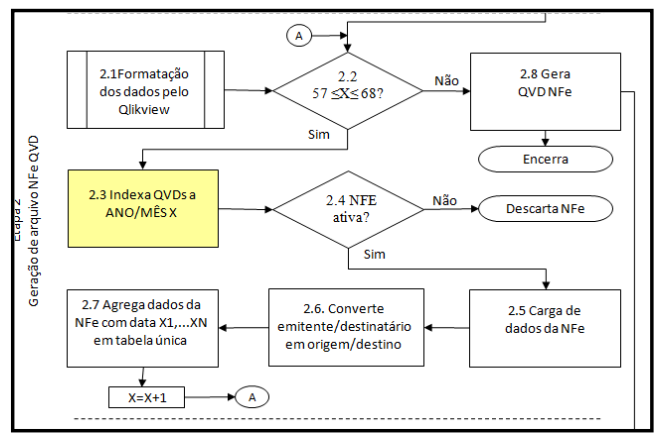
período ano/mês conforme o índice $X$.

Assim, os arquivos QVD originais extraídos na etapa 1 são indexados e renomeados conforme descrito no Quadro 3.7, onde se observa o nome em extensão QVD utilizados neste estudo.

Outro aspecto importante, é que a extração ocorre mês a mês, e não no período todo, o que agiliza o processamento dos dados e garante que, em caso de algum problema durante a extração, não se tenha que reiniciar a extração para o período todo, mas apenas para o que ainda não foi extraído. 
Quadro 3.7 - Arquivos QVD utilizados e gerados

\begin{tabular}{|c|c|c|c|}
\hline \multirow{2}{*}{$\begin{array}{l}\text { Arquivos .qvd } \\
\text { Originais }\end{array}$} & \multicolumn{2}{|c|}{ Campos utilizados } & \multirow{2}{*}{$\begin{array}{c}\text { Arquivos com } \\
\text { campos por } \\
\text { ano e mês } \\
\end{array}$} \\
\hline & Nome & Descrição ou função & \\
\hline NFE_EVENTOS & $\begin{array}{l}\text { COD_DOCUMENTO } \\
\text { COD_SITUACAO }\end{array}$ & $\begin{array}{l}\text { Igual COD_INFNFE (chave) } \\
\text { Se NFe, se ativa, cancelada }\end{array}$ & QvdEventos \\
\hline NFE_PROD & $\begin{array}{l}\text { COD_INFNFE } \\
\text { NCM } \\
\text { CFOP } \\
\text { vProd }^{(1)}\end{array}$ & $\begin{array}{l}\text { Chave de associação de tabelas } \\
\text { Código dos produtos } \\
\text { Código fiscal de operações } \\
\text { Valor dos produtos por NCM }\end{array}$ & QvdProd \\
\hline $\begin{array}{l}\text { NFE_DEST e } \\
\text { NFE_EMIT }\end{array}$ & $\begin{array}{l}\text { COD_INFNFE } \\
\text { CNPJ ou CPF } \\
\text { xFant } \\
\text { xNome } \\
\text { IE } \\
\text { CNAE }\end{array}$ & $\begin{array}{l}\text { Chave de associação de tabelas } \\
\text { Se pessoa jurídica ou física } \\
\text { Nome de fantasia da empresa } \\
\text { Razão social da empresa } \\
\text { Inscrição estadual } \\
\text { Cód. de Atividade Econômica }\end{array}$ & $\begin{array}{l}\text { QvdDest e } \\
\text { QvdEmit }\end{array}$ \\
\hline $\begin{array}{l}\text { NFE_ENDERDEST } \\
\text { e } \\
\text { NFE_ENDEREMIT }\end{array}$ & $\begin{array}{l}\text { COD_INFNFE } \\
\text { UF } \\
\text { CEP } \\
\text { cMun } \\
\text { Outros }\end{array}$ & $\begin{array}{l}\text { Chave de associação de tabelas } \\
\text { Código da UF IBGE } \\
\text { Código de endereçamento postal } \\
\text { Código do município IBGE } \\
\text { Ver nota }\end{array}$ & $\begin{array}{l}\text { QvdEnderDest } \\
\text { e } \\
\text { QvdEnderEmit }\end{array}$ \\
\hline NFE_IDE & $\begin{array}{l}\text { COD_INFNFE } \\
\text { dEmi } \\
\text { tpNF }\end{array}$ & $\begin{array}{l}\text { Chave de associação de tabelas } \\
\text { Data de emissão da NFe } \\
1 \text { se NFe de saída e } 0 \text { de entrada }\end{array}$ & QvdIde \\
\hline NFE_ICMSTOT & $\begin{array}{l}\text { COD_INFNFE } \\
\text { vProd }^{(3)} \\
\text { vNF }\end{array}$ & $\begin{array}{l}\text { Chave de associação de tabelas } \\
\text { Valor total dos produtos na NFe } \\
\text { Valor total da nota fiscal }\end{array}$ & QvdIcmsTot \\
\hline NFE_VOL & $\begin{array}{l}\text { COD_INFNFE } \\
\text { pesoB }\end{array}$ & $\begin{array}{l}\text { Chave de associação de tabelas } \\
\text { Peso bruto }(\mathrm{kg}) \text { da carga na } \mathrm{NFe}\end{array}$ & QvdVol \\
\hline NFE_TRANSPORTA & $\begin{array}{l}\text { COD_INFNFE } \\
\text { CNPJ ou CPF } \\
\text { xNome }\end{array}$ & $\begin{array}{l}\text { Chave de associação de tabelas } \\
\text { Se pessoa jurídica ou física } \\
\text { Nome da transportadora }\end{array}$ & $\begin{array}{l}\text { Qvd } \\
\text { Transportadora }\end{array}$ \\
\hline NFE_INFNFE & $\begin{array}{l}\text { COD_INFNFE } \\
\text { ID }\end{array}$ & $\begin{array}{l}\text { Chave de associação de tabelas } \\
\text { Chave da nota fiscal eletrônica }\end{array}$ & QvdInfNfe \\
\hline
\end{tabular}

Notas: (1) Valor dos produtos separado por tipo de NCM

(2) Inclui outros dados de endereço do emitente ou destinatário: logradouro, bairro, complemento

(3) Valor total dos produtos 


\section{Subetapa 2.4 - Seleção de notas fiscais ativas}

As NFe's sofrem eventos indicando no campo COD_SITUACAO do arquivo QvdEventos se está ativa (situação 100) ou cancelada (101). Estas numerações permanecem vinculadas nos seus históricos e esse trabalho utiliza apenas notas ativas, ou seja, em vigência.

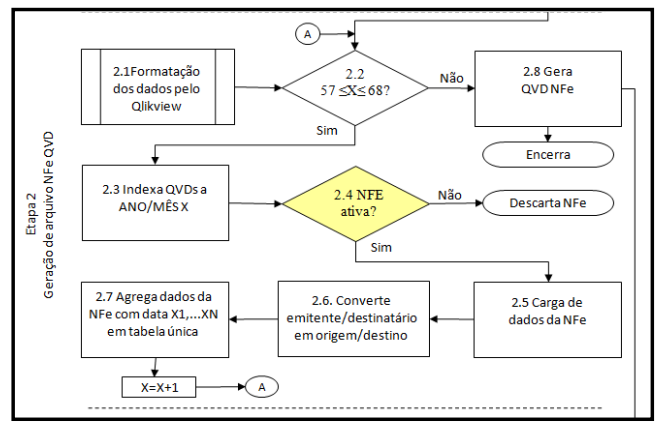

Este filtro norteia todas as cargas posteriores dos demais arquivos da $\mathrm{NFe}$ cujas tabelas de dados são associadas pelo número da chave COD_INFNFE que, apenas no caso do arquivo QvdEventos, tem o nome de campo COD_DOCUMENTO.

\section{Subetapa 2.5 - Carga de dados da NFe}

Excetuando-se o aquivo QvdEventos já carregado na etapa anterior, os demais dados dos campos listados no Quadro 3.7 são carregados conforme a sequência de cima para baixo dos respectivos arquivos. Os valores são carregados, associados e organizados na mesma linha de uma única tabela

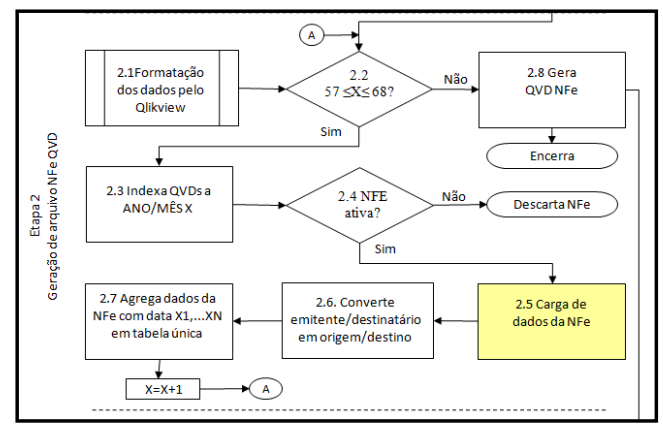
de acordo com o número da chave COD_INFNFE.

Algumas alterações se fazem necessárias neste processo:

a) devido à lista de extensa de códigos NCM (600 tipos) utiliza-se apenas os 2 primeiros dígitos do NCM, campo NCM_GENERO, que engloba 99 grupos de mercadorias;

b) uma mesma NFe pode conter diferentes produtos com distintos gêneros de NCM, o que dificulta classificá-la por tipo de mercadoria. Adota-se como o NCM representativo de uma $\mathrm{NFe}$ aquele cuja soma de valores dos respectivos produtos (soma dos valores do campo VPROD em QvdProd) seja a maior; 
c) o mesmo problema da identificação do NCM ocorre da mesma forma para o campo CFOP. Ocorre que cada CFOP está alinhado a um NCM e adota-se aquele correspondente ao NCM gênero dominante da etapa anterior;

d) as análises relacionadas com os campos CPF ou CNPJ neste trabalho buscam diferenciar se o fluxo de mercadorias ocorre entre empresas ou pessoas físicas. Como CNPJ e CPF são excludentes, ou seja, ou indica um ou outro, cria-se o campo PfPj e utiliza-se o critério: quando o campo CNPJ é nulo, considera-se o dado de PfPj como de pessoa física (PF) , caso contrário, pessoa jurídica (PJ);

e) como se observa no Quadro 3.7, os nomes dos campos que se relacionam com o emitente e destinatário - UF, CEP, CPF ou CNPJ (agora CpfCnpj) - são os mesmos. Isto gera associações automáticas no QV quando estes dados passarem para uma única tabela. Para evitar tal incorreção, todos estes campos são renomeados para CEPEmit (CEP do emitente) ou CEPDest (CEP do destinatário), CpfCnpjEmit, CpfCnpjDest, e assim por diante. O mesmo procedimento é adotado para o campo criado anteriormente PfPj, ou seja, cria-se PfPjEmit e PfPjDest;

f) na carga do arquivo QvdIde as datas contidas no campo dEmi (data de emissão) se apresentam no formato DD/MM/AAAA (dia/mês/ano). Para facilitar análises individualizadas por dia e/ou mês e/ou ano, estes dados são separados em campos distintos, DIA, MÊS, ANO. Ainda, dEmi também é convertido em dia da semana, ou seja, segunda (seg), terça (ter), etc. por meio de um comando interno do QV.É importante salientar que utiliza-se a data de emissão da $\mathrm{NFe}$ visto que não há ainda um registro preciso do recebimento da mesma, e a data de saída é um campo inserido manualmente e considerado não confiável. Além disso, numa amostra de 408.000 registros, em $96 \%$ dos casos a data de saída é ausente ou apontada como igual à data de emissão, por isto não é utilizada. Vale ressaltar, porém, que a data de recebimento pelo destinatário da mercadoria já está sendo utilizada para transações com combustíveis e o projeto da NFe prevê sua disseminação para os demais segmentos de forma gradativa;

g) tendo como chave de conexão o campo COD_INFNFE, são carregados os dados das transportadoras (QvdTransportadora) e, posteriormente, associadas as chaves das NFe's por elas transportadas (QvdInfNfe), permitindo obter relações entre estas e demais dados como produto transportado, emitente e destinatário, placa do 
veículo, data, etc. No entanto, há uma ausência ou imprecisão significativa nos dados de identificação do veículo e da transportadora (razão social). Constata-se que $45 \%$ dos registros possuem falhas neste sentido tornando árdua a tarefa de descobrir a qual transportadora se vincula as NFe's. Trata-se, portanto, de um aspecto importante a ser melhorado no preenchimento da NFe, não somente para fins de estudos em transporte como também para a fiscalização tributária, cujo interesse comum pode favorecer melhorias nesse processo.

\section{Subetapa 2.6 - Discriminação entre origem e destino das mercadorias}

Como detalhado na seção 3.2, o campo tpNF discrimina o tipo da $\mathrm{NFe}$, se é de entrada ou de saída. A $\mathrm{NFe}$ de saída possui código tpNF =1, ou seja, os campos relacionados com emitente, tais como CEP (CEPEmit), coincidem com a origem e os do destinatário com o destino da mercadoria. Porém, o inverso ocorre com a tpNF $=0$, de

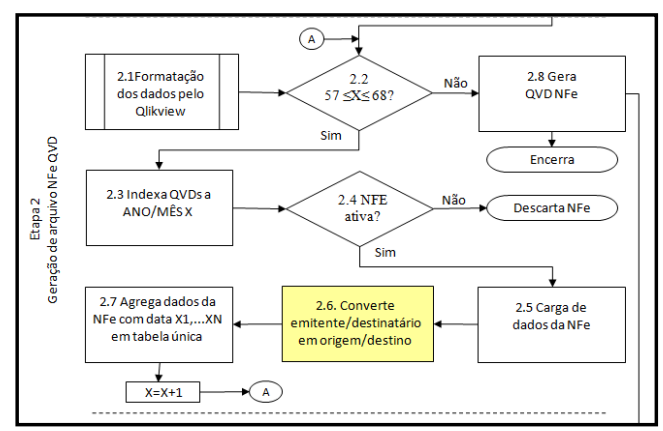
entrada.

Assim, buscando representar as origens e destinos das mercadorias, efetua-se a conversão e se renomeia o final dos campos listados no item "e" da subetapa 2.5 definindo as operações como origem ou destino independentemente do tipo da nota fiscal. Esta caracterização é que fornece os critérios de análise entre origem e destino das mercadorias, seja interna ou externa e que se utiliza no painel do QlikView (Quadro 3.8).

Quadro 3.8 - NFes de entrada e saída e a especificação de origens e destinos

\begin{tabular}{|c|c|c|}
\hline Final campo original & Tipo de NFe & Campo renomeado \\
\hline \multirow{2}{*}{$* * * *$ Emit } & \multirow{2}{*}{$\operatorname{tpNF}=1$ (de saída) } & $* * * *$ Origem \\
\cline { 1 - 1 } & & $* * * * *$ Destino \\
\hline \multirow{2}{*}{$* * * *$ Emit } & \multirow{2}{*}{$\operatorname{tpNF}=0$ (de entrada) } & $* * * *$ Destino \\
\cline { 1 - 1 } & & $* * * *$ Origem \\
\hline
\end{tabular}

Nota: $* * * *$ pode ser CNPJ, CPF, CEP, estado, município, endereço, etc. 


\section{Subetapa 2.7 - Armazena arquivo QVD Data X (de 57 a 68$)$}

Conforme os meses são carregados na rotina, o QlikView agrupa os dados das NFe's ativas e as organiza criando uma única tabela (Tabela 3.1), que serve de base para a próxima etapa.

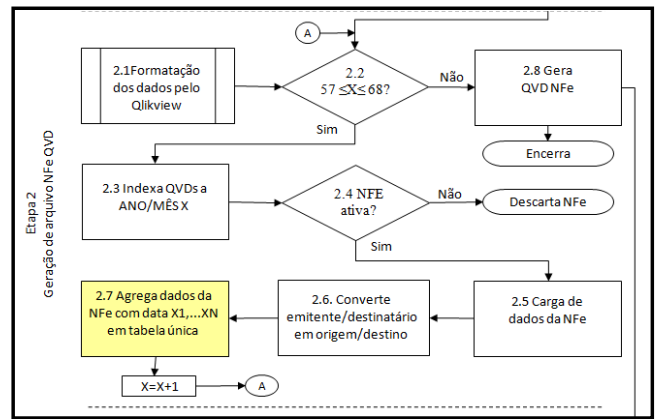

Tabela 3.1 - Dados agregados em tabela pelo QlikView - Ago 2014

\begin{tabular}{rrrrrrrrrr}
\hline Dia & Mês & Ano & $\begin{array}{c}\text { Dia da } \\
\text { semana }\end{array}$ & $\begin{array}{c}\text { NCM } \\
\text { Gênero }\end{array}$ & $\begin{array}{c}\text { Peso } \\
\text { Bruto } \\
(\mathrm{Kg})\end{array}$ & $\begin{array}{c}\text { UF } \\
\text { Origem }\end{array}$ & $\begin{array}{c}\text { UF } \\
\text { Destino }\end{array}$ & $\begin{array}{c}\text { Valor da } \\
\text { Atividade Origem }\end{array}$ & $\begin{array}{c}\text { Nfe } \\
(\mathrm{R} \$)\end{array}$ \\
\hline 1 & ago & 2014 & sex & 02 & 8,50 & DF & DF & Com varej mercad geral, hipermecado & 58,85 \\
1 & ago & 2014 & sex & 02 & 20,00 & DF & DF & Com varej mercad geral, hipermecado & 188,26 \\
1 & ago & 2014 & sex & 02 & 28,00 & DF & DF & Com varej mercad geral, hipermecado & 366,24 \\
1 & ago & 2014 & sex & 02 & 48,78 & DF & DF & Com varej mercad geral, hipermecado & 669,94 \\
1 & ago & 2014 & sex & 02 & 80,00 & DF & DF & Com varej mercad geral, hipermecado & 396,27 \\
1 & ago & 2014 & sex & 02 & 92,16 & DF & DF & Com varej mercad geral, hipermecado & 751,69 \\
1 & ago & 2014 & sex & 02 & 100,00 & DF & DF & Com varej mercad geral, hipermecado 1.127,95 \\
\hline
\end{tabular}

\section{Subetapa 2.8 - Gera arquivo NFE.QVD}

Assim que a rotina encerra o período de análise, o QV armazena o arquivo NFE.QVD que é utilizado na etapa de geração do painel de análise. Sobre esta última etapa comentários adicionais são necessários.

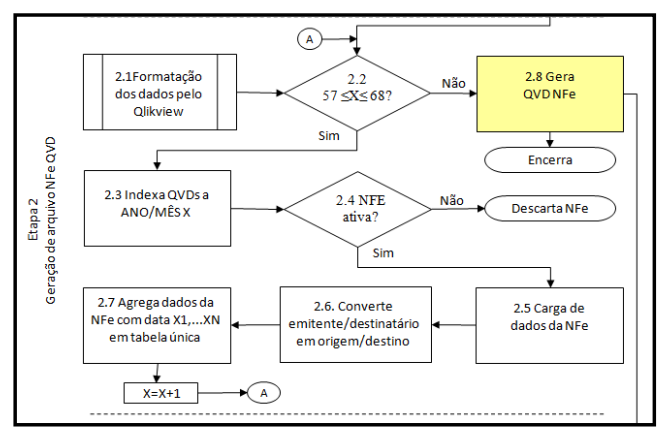

Durante os estudos de Santos e Sánchez-Díaz (2015) verificou-se a existência de remessa de mercadoria com várias NFe's para facilitar a conferência de lotes de entrega ou, até mesmo, para evitar que o cancelamento de uma nota por erros incorra no cancelamento do recebimento da carga toda. Estas remessas são então "desmembradas" em NFes com lotes menores, porém se referem a apenas uma entrega ou despacho. A característica comum destas transações, constata-se, é a mesma data de emissão, de um mesmo emissor, para um mesmo recebedor. 
Assim, o agrupamento por estes critérios é realizado na metodologia de modo a buscar retratar que a quantidade de NFes espelhem a quantidade de entregas ou despachos. Vale salientar que se trata de uma premissa que necessita validações mais acuradas, mas que, para viabilizar o estudo pretendido, é adotada nesta subetapa.

\subsubsection{Etapa 3 - Geração do painel para análise}

O painel é o produto final no uso do QlikView, sendo a interface para as análises. Para sua elaboração utiliza-se o arquivo NFe.QVD e informações contidas no cadastro contribuintes da SEF-DF, além do arquivo de coordenadas para o georreferenciamento dos CEP's de origem e destino das mercadorias. As subetapas relacionadas a esta etapa são descritas a seguir.

\section{Subetapa 3.1 - Preparacão do QV}

Nessa subetapa são feitos os mesmos ajustes descritos na subetapa 2.1 (Quadro 3.5).

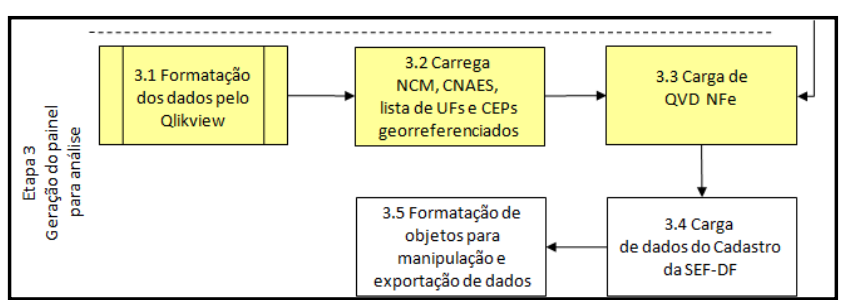

Obs.: quadro menor refere-se às subetapas 3.1, 3.2 e 3.3

\section{Subetapa 3.2 - Carga de tabelas para suporte na manipulacão do painel}

A carga de tabelas para suporte na manipulação do painel são as seguintes:

a) tabela de código de UF IBGE e respectivas siglas para uso em seleções do painel relacionadas como origem e destino das mercadorias, porém agora classificadas como operações internas (Distrito Federal) ou externas (outros estados);

b) planilha contendo números de $\mathrm{CEP}$ com suas respectivas coordenadas geográficas;

c) como não há na NFe uma descrição da atividade econômica do destinatário da mercadoria, utiliza-se como padrão os códigos de atividade econômica do cadastro de contribuintes do Distrito Federal que seguem o padrão CNAE. 


\section{Subetapa 3.3 - Carga de NFe.qvd}

Nesta subetapa é feita a carga do arquivo com extensão QVD contendo as informações das NFe's e gerado na etapa 2.

\section{Subetapa 3.4 - Carga dos dados de cadastro de contribuintes da SEF-DF}

Nesta subetapa são realizados cinco
tratamentos dos dados que serão
associados aos dados das NFe's
carregados anteriormente.

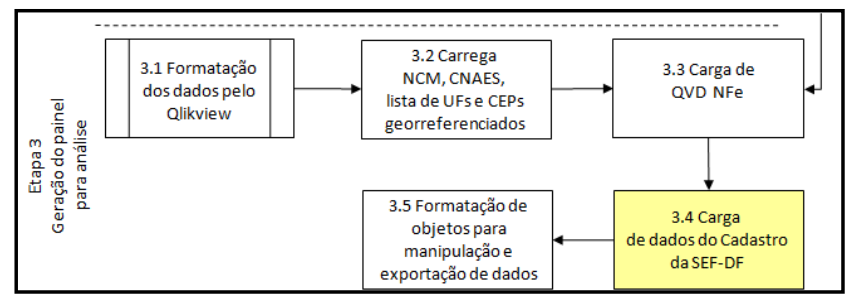

a) como os números de inscrição no cadastro fiscal sofrem alterações durante o tempo para uma mesma empresa (empresas alteram o CNPJ), coleta-se então o CNPJ mais atual;

b) os dados de área construída ou do terreno dos contribuintes são carregados por meio do CNPJ ou CPF;

c) são carregados os dados dos veículos registrados no CNPJ ou CPF do contribuinte, com descrição de modelo, ano e se próprio ou arrendado;

d) são atribuídas as coordenadas (vinculação à base georreferenciada pelo CEP, informação fornecida pela CAESB) aos códigos de atividades pelo CNPJ e separados os dados de cadastro entre origem e destino;

e) são estabelecidas as operações originadas ou destinadas ao DF como internas, e as provenientes de outros estados como externas.

A título de ilustração, a Figura 3.10 apresenta o visualizador de tabelas do QlikView. Este recurso permite orientar quais os campos que estão sendo utilizados como chave de associação entre as tabelas das subetapas 3.2, 3.3 e 3.4. Por exemplo, o campo CpfCnpjOrigem (CPF ou CNPJ da pessoa ou estabelecimento de origem da NFe) relaciona os dados de cadastro do contribuinte de origem (subetapa 3.4) com os dados do arquivo NFe.QVD (da subetapa 3.3 e visualizado como arquivo SomaNFe ${ }^{17}$ na Figura 3.10).

${ }^{17}$ SomaNFe na Figura 3.10 é o nome anterior do arquivo NFe.QVD (nome atual). 
Figura 3.10 - Visualizador de tabelas do painel em QlikView

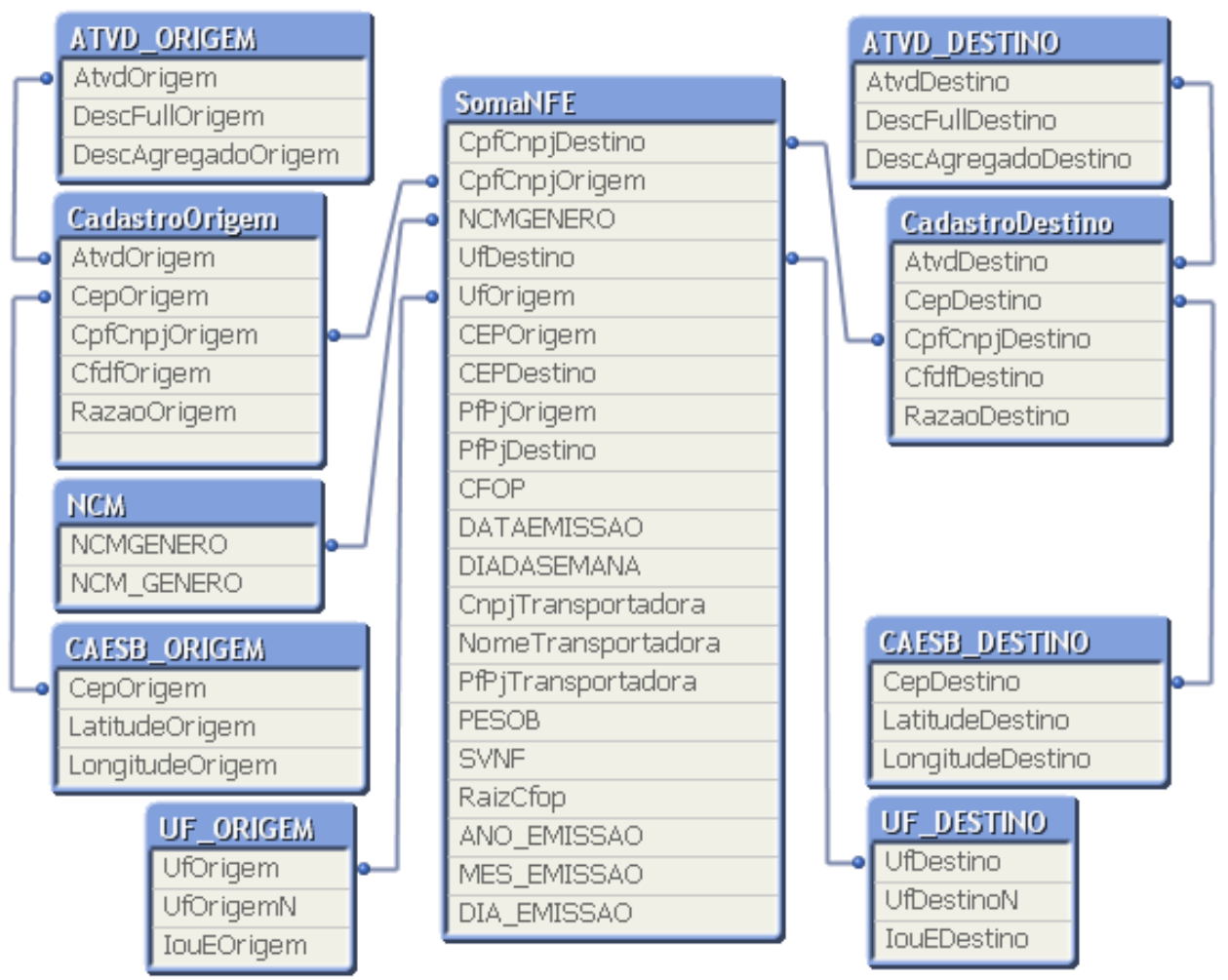

\section{Subetapa 3.5 - Formatacão de objetos para manipulacão e exportacão dos dados}

Para que os dados possam ser visualizados e trabalhados com maior praticidade, há necessidade de formatar os chamados objetos do QlikView. Isso facilita o tratamento e

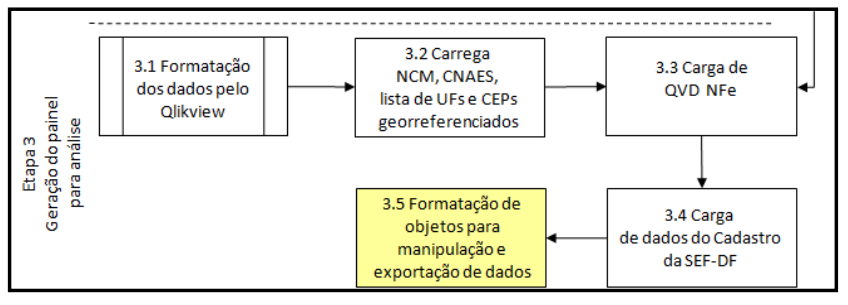
análise dos dados. Para isto é elaborado o painel de análise dos dados, o "painel". O exemplo do painel utilizado nesse estudo é mostrado na Figura 3.11.

Como se pode observar, as análises podem envolver a combinação de diversos campos como NCM, código de atividade e CEP georreferenciados, por dia do mês, da semana, ou por mês. Além disso, permite analisar se uma operação tem origem/destino interno ou externo, por quantidade de notas fiscais, valor ou peso. $\mathrm{O}$ volume das mercadorias não é considerado pois as NFe's apresentam escala de medidas diferentes neste item, tais como metros, peça, caixa, unidade,etc. 
Figura 3.11 - Tela do painel

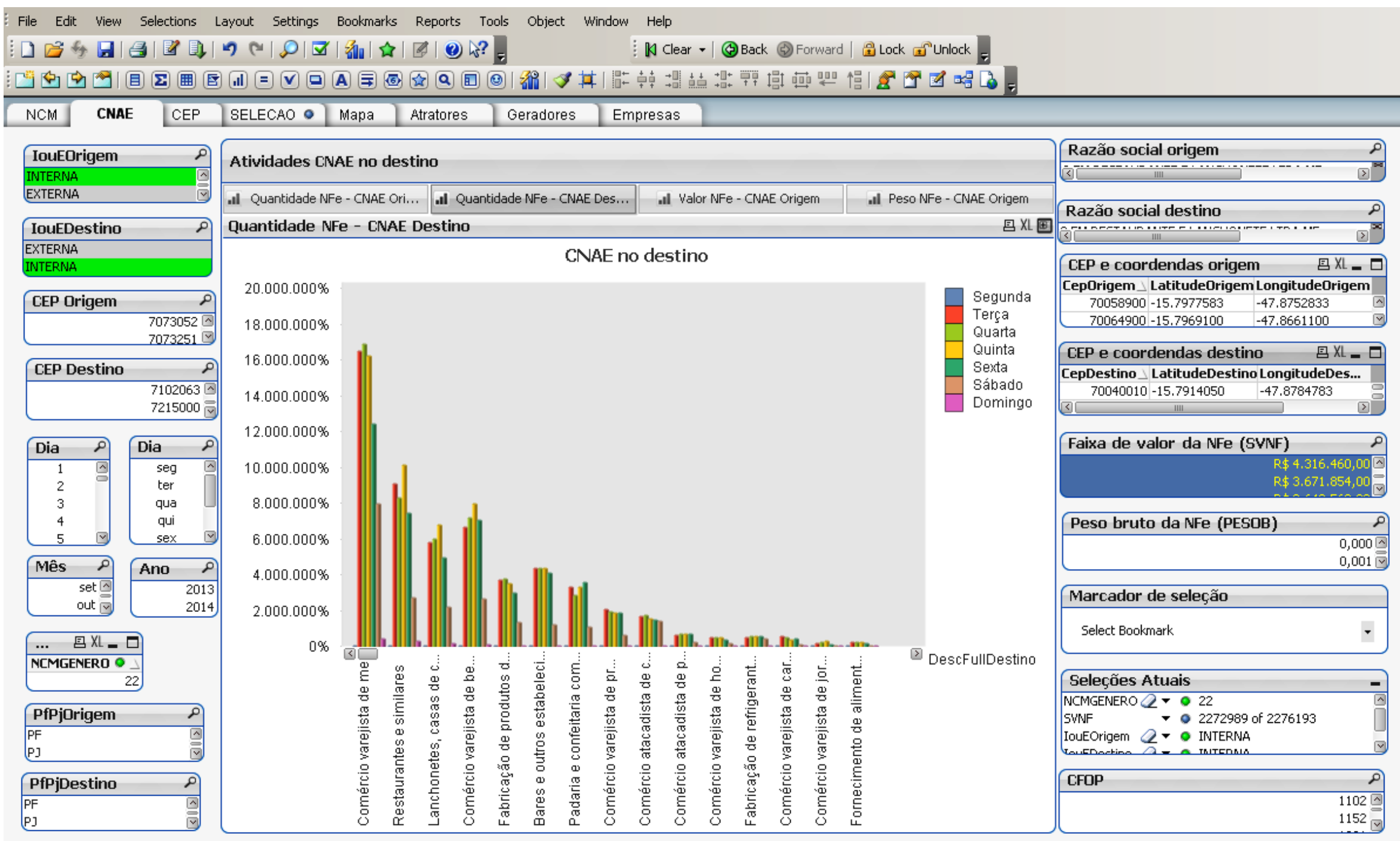




\subsection{DADOS OBTIDOS E PESQUISAS COMPLEMENTARES}

A análise dos dados que podem ser fornecidos pela metodologia permite listar as informações sobre a geração de cargas, de seus agentes com as respectivas características econômicas e dos locais georreferenciados de origem e destino das cargas, vinculados às características dos produtos e às quantidades de remessas, em diferentes períodos. Há também a vinculação das placas dos veículos registrados na SEF-DF com as placas identificadas nas notas fiscais, o que permite associar as entregas e suas cargas às características do modo de transporte utilizado. Por fim, os recursos do QlikView asssociados ao googlemaps permitem também obter dados sobre as distâncias entre as origens e destinos. Verifica-se então que estas informações contribuem para preencher as principais lacunas por dados para modelagem identificadas anteriormente no Quadro 3.1. Esta contribuição é demonstrada no Quadro 3.9.

Quadro 3.9 - Dados providos pela metodologia

\begin{tabular}{|c|c|c|}
\hline Categorias de dados & Tipos de dados & Dados fornecidos pela metodologia de extração dos dados \\
\hline $\begin{array}{l}\text { Informação dos } \\
\text { fluxos logísticos }\end{array}$ & Produção & $\begin{array}{c}\text { Permite rastrear os fluxos de carga do emissor, transportador } \\
\text { e recebedor }\end{array}$ \\
\hline \multirow{4}{*}{$\begin{array}{l}\text { Dados de geração de } \\
\text { carga }\end{array}$} & Produção & \multirow{2}{*}{$\begin{array}{l}\text { Quantidade e tipos de mercadorias por número de } \\
\text { entregas/coletas, valor da transação e peso das mercadorias } \\
\text { desagregados a nível de estabelecimentos. }\end{array}$} \\
\hline & Consumo & \\
\hline & Localização & \multirow{2}{*}{$\begin{array}{c}\text { Indicação georreferenciada das origens (coletas) e destinos } \\
\text { (entregas) por CEP como pontos de parada ou por } \\
\text { estabelecimentos baseadas na data de emissão das Nfe. }\end{array}$} \\
\hline & Fluxos OD & \\
\hline \multirow{3}{*}{$\begin{array}{l}\text { Características } \\
\text { econômicas dos } \\
\text { agentes }\end{array}$} & Embarcadores & \multirow{6}{*}{$\begin{array}{c}\text { Informações georreferenciadas sobre os códigos de atividade } \\
\text { econômica (CNAE), da quantidade de entregas/coletas feitas } \\
\text { e classificação (micro/pequena, regime normal) que auxiliam } \\
\text { na definição do porte das empresas, diferenciação entre } \\
\text { pessoa jurífica e física e das origens e destinos das } \\
\text { mercadorias que, por sua vez, discriminam os embarcadores, } \\
\text { transportadores e recebedores das mercadorias e sua } \\
\text { localização espacial. }\end{array}$} \\
\hline & Transportadores & \\
\hline & Recebedores & \\
\hline \multirow{3}{*}{$\begin{array}{l}\text { Distribuição } \\
\text { espacial / } \\
\text { localização dos } \\
\text { agentes }\end{array}$} & Embarcadores & \\
\hline & Transportadores & \\
\hline & Recebedores & \\
\hline $\begin{array}{l}\text { Características da } \\
\text { Rede Viária }\end{array}$ & Tempos de viagens,custos & $\begin{array}{l}\text { Propõe o uso de dados de custos (tempo de viagem) } \\
\text { fornecidos pelo googlemaps ou então uso de mapas digitais } \\
\text { calibrados fornecidos por empresas fornecedoras ou } \\
\text { relacionadas com softwares de roteirização. }\end{array}$ \\
\hline \multirow{2}{*}{$\begin{array}{l}\text { Processos de } \\
\text { escolha especial }\end{array}$} & Escolha modal & \multirow{2}{*}{$\begin{array}{l}\text { Acessa: dados de veículos de contribuintes registrados no } \\
\text { cadastro fiscal com a descrição de modelo; placas de veículos } \\
\text { na Nfe, com respectiva descrição das características da } \\
\text { mercadoria e do agentes envolvidos na transação. }\end{array}$} \\
\hline & Atributos do modo & \\
\hline \multirow{3}{*}{$\begin{array}{l}\text { Outros dados } \\
\text { econômicos }\end{array}$} & Funções de produção & \multirow{3}{*}{$\begin{array}{l}\text { Permite gerar tabelas de insumo/produto a partir dos valores } \\
\text { das notas fiscais origem e destino por segmento ou empresa }\end{array}$} \\
\hline & Funções de demanda & \\
\hline & Coeficientes insumo/produto & \\
\hline
\end{tabular}

Fonte: Elaborado pelo autor (2015) com base em Holguín-Veras et al. (2010) 
Além desta contribuição e tomando como referência o Quadro 2.1, verifica-se que a metodologia pode contribuir também para a elaboração de diferentes modelos com as informações destacadas em tom escuro no Quadro 3.10. Uma das possibilidades é a elaboração de modelos de geração e de matrizes origem-destino de cargas para aplicação em modelos de quatro etapas (OGDEN, 1992; TAVASSZY; JONG, 2014).

Outro potencial da metodologia é a obtenção de dados dos fluxos de cargas por estabelecimentos de origem e destino, base para os modelos indicados para simulação de viagens encadeadas (COMI; DONNELLY; RUSSO, 2014; COMI et al., 2012; ROORDA et al., 2010; TANIGUCHI; THOMPSON; YAMADA, 2014).

Quadro 3.10 - Dados da metodologia e modelagens em TUC

\begin{tabular}{|c|c|c|c|c|c|c|c|c|c|c|c|c|}
\hline \multirow{2}{*}{$\begin{array}{c}\text { Categorias de } \\
\text { dados }\end{array}$} & \multirow{2}{*}{ Tipos de dados } & \multicolumn{11}{|c|}{ Modelos para o transporte urbano de cargas } \\
\hline & & GC & $\mathrm{GVC}$ & DIST & EM & IP & VV & EEP & MS & MSh & EEP & OD \\
\hline $\begin{array}{l}\text { Informação dos } \\
\text { fluxos logísticos }\end{array}$ & Produção & & & $\mathrm{X}$ & & $\mathrm{X}$ & & $\mathrm{X}$ & $\mathrm{X}$ & $\mathrm{X}$ & $\mathrm{X}$ & \\
\hline \multirow{2}{*}{$\begin{array}{c}\text { Dados de geração } \\
\text { de carga }\end{array}$} & Produção & $\mathrm{X}$ & & & & $\mathrm{X}$ & & & $\mathrm{X}$ & $\mathrm{X}$ & $\mathrm{X}$ & $\bar{X}$ \\
\hline & Consumo & $\mathrm{X}$ & & & & $\mathrm{X}$ & & & $\mathrm{X}$ & $\mathrm{X}$ & $\mathrm{X}$ & $\bar{X}$ \\
\hline \multirow{4}{*}{ Rotas de Entrega } & Seqüência & & & & & & & & $\mathrm{X}$ & $\mathrm{X}$ & $\mathrm{X}$ & \\
\hline & Localização & & & & & & & & $\mathrm{X}$ & $\mathrm{X}$ & $\mathrm{X}$ & \\
\hline & Fluxos OD & & $\mathrm{X}$ & $\mathrm{X}$ & & $\mathrm{X}$ & $\mathrm{X}$ & & $\mathrm{X}$ & $\mathrm{X}$ & $\mathrm{X}$ & \\
\hline & Fluxos de carga vazia & & $\mathrm{X}$ & & & & $\mathrm{X}$ & & & & & \\
\hline \multirow{3}{*}{$\begin{array}{c}\text { Características } \\
\text { econômicas dos } \\
\text { agentes }\end{array}$} & Embarcadores & $X$ & & & & & & & $\mathrm{X}$ & $\mathrm{X}$ & $\mathrm{X}$ & \\
\hline & Transportadores & $\mathrm{X}$ & & & & & & & $\mathrm{X}$ & $\mathrm{X}$ & $\mathrm{X}$ & \\
\hline & Recebedores & $\mathrm{X}$ & & & & & & & $\mathrm{X}$ & $\mathrm{X}$ & $\mathrm{X}$ & \\
\hline \multirow{3}{*}{$\begin{array}{c}\text { Distribuição } \\
\text { espacial / } \\
\text { localização dos } \\
\text { agentes }\end{array}$} & Embarcadores & $\mathrm{X}$ & & & & & & & $\mathrm{X}$ & $\mathrm{X}$ & $\mathrm{X}$ & \\
\hline & Transportadores & $\mathrm{X}$ & & & & & & & $\mathrm{X}$ & $\mathrm{X}$ & $\mathrm{X}$ & \\
\hline & Recebedores & $\mathrm{X}$ & & & & & & & $\mathrm{X}$ & $\mathrm{X}$ & $\mathrm{X}$ & \\
\hline \multirow{4}{*}{$\begin{array}{c}\text { Características da } \\
\text { Rede Viária }\end{array}$} & Tempos de viagens,custos & & $\mathrm{X}$ & $\bar{X}$ & & $\mathrm{X}$ & $\mathrm{X}$ & & $\mathrm{X}$ & $\mathrm{X}$ & $\bar{X}$ & $\bar{X}$ \\
\hline & Restrições de uso & & $X$ & $\mathrm{X}$ & & $\mathrm{X}$ & $\mathrm{X}$ & & $\mathrm{X}$ & $\mathrm{X}$ & $\mathrm{X}$ & $\mathrm{X}$ \\
\hline & Capacidade & & $\mathrm{X}$ & $\mathrm{X}$ & & $\mathrm{X}$ & $\mathrm{X}$ & & $\mathrm{X}$ & $\mathrm{X}$ & $\mathrm{X}$ & $\mathrm{X}$ \\
\hline & Volumes de tráfego & & & & & & & & & & & $\mathrm{X}$ \\
\hline \multirow{3}{*}{$\begin{array}{c}\text { Processos de } \\
\text { escolha especial }\end{array}$} & Escolha modal & & & & $\mathrm{X}$ & & & & & & & \\
\hline & Tempo de entrega & & & & & & & & & & & \\
\hline & Atributos do modo & & & & $\mathrm{X}$ & & & & & & & \\
\hline \multirow{3}{*}{$\begin{array}{l}\text { Outros dados } \\
\text { econômicos }\end{array}$} & Funções de produção & & & & & & & $\mathrm{X}$ & & & $\mathrm{X}$ & \\
\hline & Funções de demanda & & & & & & & $\mathrm{X}$ & & & $\mathrm{X}$ & \\
\hline & \multicolumn{2}{|l|}{ Coeficientes insumo/produto } & & & & $\mathrm{X}$ & & & & & & \\
\hline
\end{tabular}

Modelos de: geração de cargas (GC), geração de viagens (GVC), distribuição (DIST), escolha modal (EM), insumo/produto (IP), viagens vazias (VV), equilíbrio espacial/preço (EEP), microssimulação: baseado em viagens (MS), microssimulação híbridos: fluxo de cargas e roteirização de veículos (MSh), equilíbrio espacial/preço (EEP), matriz origem/destino (OD); X - Dado pode ser utilizado no modelo.

Fonte: Elaborado pelo autor (2015) com base em Holguín-Veras et al. (2010) 
Por outro lado, da análise do Quadro 3.10 verifica-se que as informações obtidas não abrangem aquelas que dizem respeito às decisões logísticas das empresas, às relacionadas à malha viária, bem como sobre as viagens de veículos de carga. Para as informações sobre decisões logísticas, Tavasszy (2014) recomenda o uso de pesquisas declaradas. No mais, há necessidade de complementar os dados com os métodos e técnicas tradicionais expostos no Capítulo 2, bem como em reconhecer a capacidade limitada dos diferentes atores do TUC em prover estas informações. Em geral, infere-se que há necessidade em complementar os dados sobre:

a) as decisões logísticas com pesquisas em estabelecimentos, colhendo dados sobre os processos de carregamento internos, escolha modal, roteirização e programação de entregas, nível de serviço estabelecido (frequência de entrega, horários de atendimento), etc.;

b) o inventário em pesquisas documentais junto à órgãos públicos e empresas que provêem informações sobre a malha viária (SANTOS, 2008);

c) as viagens de veículos em transportadores, em contagens de tráfego e em pesquisas documentais em órgãos públicos que controlam ou pesquisam sobre o tráfego urbano por meio de radares, câmeras OCR, etc. Estes dados, inclusive, podem ser obtidos e devem servir para validar as estimativas de viagens a serem estudadas.

\subsection{VALIDAÇÃO DOS DADOS OBTIDOS}

Todo levantamento de dados e/ou estruturação de uma base de dados precisa de um tratamento prévio dos dados antes de serem utilizados. Isto é feito para sanar erros de digitação, de inconsistência dos dados ou outros problemas que podem alterar o comportamento normal dos dados. Dentre os erros de digitação observou-se, por exemplo: a digitação de "zeros a mais" nos valores e pesos das mercadorias; os pesos devem ser informados em quilogramas, porém constatou-se o uso de toneladas; há outros campos com significativo número de valores não informados.

Além desses erros ou falhas de preenchimento, os dados também podem apresentar uma distribuição não normal, o que pode requerer análises não paramétricas. Neste sentido, recomenda-se efetuar uma análise de valores extremos e de distribuição dos dados por 
meio de medidas de assimetria, curtose, etc. Como foge ao escopo desta tese tratar deste assunto, recomenda-se Hair Jr et al. (2009) como referência.

Uma vez analisada a consistência da base de dados, passa-se a avaliar a exatidão dos mesmos, comparando-os com valores conhecidos ou obtidos por meio de coleta de dados reais. Uma forma de validação é comparar os valores obtidos com informações prestadas pelos operadores do transporte. (BRUTON, 1979, p. 56).

No caso desse trabalho utiliza-se como referência os dados informados por uma distribuidora de bebidas com alta participação no mercado do Distrito Federal, cujo nome é omitido por questões de sigilo. Este segmento foi escolhido por sua representatividade na quantidade de entregas urbanas realizadas, e por ser uma das empresas com a qual se mantém um canal de contato desde o trabalho de Santos (2008).

Dos dados analisados e informados montou-se a Tabela 3.2. Os dados informados (I) foram a quantidade de entregas realizadas (Q) e destinos (D), que são o número de clientes atendidos no mês de março de 2015, período foi escolhido aleatoriamente pelo distribuidor. Estes valores foram comparados com os obtidos (O) pela metodologia de extração de dados de documentos fiscais eletrônicos. Os resultados demonstram que existe uma aproximação significativa dos dados extraídos com os dados reais da empresa.

Tabela 3.2 - Validação da metodologia de obtenção dos dados - Mar 2015

\begin{tabular}{cccr}
\hline \multirow{2}{*}{ Fontes } & \multicolumn{3}{c}{ Itens } \\
\cline { 2 - 4 } & $\begin{array}{c}\text { Quantidade de } \\
\text { Entregas } \\
(\mathrm{Q})\end{array}$ & $\begin{array}{c}\text { Destinos } \\
\text { (D) }\end{array}$ & $\begin{array}{c}\text { Frequência de } \\
\text { Entrega } \\
=\mathrm{Q} / \mathrm{D} / 4 \text { semanas }\end{array}$ \\
\cline { 2 - 4 } Obtidos $(\mathrm{O})$ & 49.428 & 10.574 & 1,17 \\
Informado $(\mathrm{I})$ & 48.281 & 11.968 & 1,01 \\
I/E & $98 \%$ & $113 \%$ & $86 \%$ \\
\hline
\end{tabular}

Uma segunda verificação, de modo a testar também a validade e o efeito do tratamento dos dados é feita fazendo uma análise comparativa com os dados não agrupados das NFe's. Neste caso, as notas fiscais emitidas pelo mesmo emitente para o mesmo destinatário em um mesmo dia são consideradas separadamente. 
Como se observa na Tabela 3.3, sem o agrupamento das notas fiscais a diferença para os valores informados pela distribuidora salta para mais de 30\%. A explicação para esta diferença é que, segundo informações da empresa, é comum emitirem notas fiscais separadas por tipo de operação para uma mesma entrega (mesmo emitente/destinatário e data de emissão): uma nota para venda da bebida, outra para bonificação da bebida que é uma forma de desconto e, em alguns casos, outra nota para consignação de material promocional, como aluguel de mesas e cadeiras para bares.

Tabela 3.3 - Efeito do agrupamento de Nfe em distribuidora de bebidas - Mar 2015

\begin{tabular}{crrr}
\hline & \multicolumn{3}{c}{ Quantidade de Entregas (*) } \\
\cline { 2 - 4 } Itens & Informado & $\begin{array}{c}\text { Diferença } \\
\text { Estimado x Informado }\end{array}$ & $\begin{array}{c}\text { Diferença } \\
\text { percentual }\end{array}$ \\
\hline Informado pela empresa & 48.281 & & \\
Estimado com agrupamento & 49.428 & 1.147 & $2 \%$ \\
Estimado sem agrupamento & 63.608 & 15.327 & $32 \%$ \\
\hline
\end{tabular}

Portanto, um dos aspectos mais importantes da metodologia, o agrupamento dos dados da $\mathrm{NFe}$, mostra coerência quando se busca traduzir o fluxo de notas fiscais como a quantidade de entregas urbanas. Demonstra-se, portanto, que o uso de documentos fiscais eletrônicos com base na metodologia proposta apresenta uma perspectiva positiva para representar os fluxos de carga no meio urbano.

Essas verificações demonstram a exatidão do método utilizado para extração dos dados das NFe's, já que consegue analisar o universo dos dados do banco de dados da Secretaria de Fazenda do DF para o período em análise. Por fim, fica evidente que coletar dados das notas fiscais puramente e replicar isto em movimentos de cargas tende a falhar. É preciso conhecer sobre como as empresas operam com seus documentos fiscais de modo a interpretar os movimentos reais de entregas. Obviamente há muito para ser explorado nos bancos de dados de documentos fiscais, inclusive para checar se este tratamento se aplica a outros segmentos ou empresas o que, particularmente, acredita-se ser o correto. 


\section{USO DOS DADOS DOS DFe NO DISTRITO FEDERAL}

As informações obtidas dos documentos fiscais eletrônicos (DFe) e organizados no painel fornecem uma visão espacial detalhada dos dados populacionais das transações comerciais com mercadorias, permitindo chegar ao nível mais desagregado por estabelecimento e por origens e destinos urbanos de cargas. Estas características possibilitam obter um rol de dados significativos que, acredita-se, podem ser utilizados em diferentes tipos de análises para o planejamento do TUC.

A utilização coordenada dos dados dos documentos fiscais com os cadastrais, junto com outras fontes de dados georreferenciados permite identificar diferentes possibilidades de análises, como por exemplo: os movimentos padrão de fluxos de cargas por tipo de produtos e de atividades; a posição geográfica dos estabelecimentos e seus ramos de atividades; a quantidade de cargas atraídas e geradas por dia, por estabelecimento e por pessoas físicas; os veículos que saem de uma origem e entregam um determinado tipo de mercadoria para vários destinos; dentre outras.

Obviamente, a proposta neste trabalho não é esgotar todos os tipos de análises que podem ser realizadas com o banco de dados obtido com a extração de dados das diferentes fontes de dados utilizadas, senão apresentar um método de pesquisa documental com dois objetivos: explorar o banco de dados para demonstrar o potencial de uso dos dados do DFe para o planejamento do TUC e, como extensão,efetuar uma análise dos fluxos de cargas em uma área de estudo, no caso o Distrito Federal.

\subsection{TUC NO DISTRITO FEDERAL}

Segundo dados de IBGE (2010), o Distrito Federal conta com uma população de 2,57 milhões de habitantes e densidade populacional de 430 habitantes por quilômetro quadrado, dentre os quais , 97\% das pessoas vivem em áreas urbanas. Tal concentração populacional somada a um deficiente sistema de transporte coletivo tem induzido as pessoas a utilizarem o transporte individual. A título de exemplo, Brasília conta com uma relação de 1,8 habitantes por veículo. (IBGE, 2010; LAMMERS, 2012) 
Somada à alta concentração populacional no espaço urbano, a parte central de Brasília concentra 82\% dos empregos formais do Distrito Federal (TENORIO; JUNIOR, 2009), o que gera uma pressão por espaços nesta região. Para agravar este problema, Lammers (2012) aponta que as políticas públicas existentes são voltadas para expandir a infraestrutura viária e não para gerenciar a demanda por transportes, o que tem incentivado mais ainda o uso do transporte individual.

Em entrevista realizada na Secretaria de Transportes do governo local ${ }^{18}$ verificou-se uma preocupação em resolver problemas relacionados com o deficiente sistema de transporte público coletivo. Outro aspecto relevante observado foi que não há qualquer estudo para analisar o impacto das externalidades negativas do transporte urbano de cargas, assim como medidas que venham a minimizá-las. A única informação provida sobre o setor foi um estudo de contagem de tráfego de cargas realizado nas fronteiras do DF em 2009, mas sem um claro sinal de implementação de políticas públicas voltadas ao TUC.

Este problema não é particular do Distrito Federal, observa-se que é um problema geral em todas as áreas urbanas do Brasil. Como foi comentado no capitulo introdutório dessa tese, a falta de uma base de dados sistemática e confiável dificulta os estudos sobre o TUC, principalmente para realizar um planejamento que ajude a traçar diretrizes e estratégias. A conclusão é que o resultado deste trabalho venha preencher essa lacuna por informações para o referido processo de planejamento.

\subsection{ANÁLISE DO TUC UTILIZANDO DADOS DO DISTRITO FEDERAL}

Tendo como base o referencial teórico estudado, pode-se concluir que o transporte urbano de cargas se caracteriza pela multiplicidade de atores envolvidos, muitas vezes com interesses conflitantes, e por apresentar processos operacionais multifacetados. Diante dessas características, a própria literatura demonstra ser fundamental a liderança do poder público para buscar atender aos interesses sociais, econômicos e financeiros de todos os atores envolvidos, definindo as prioridades e as ações que levem ao desenvolvimento do TUC.

18 Entrevista realizada em fevereiro de 2015 com o subsecretário de mobilidade. 
Muitos fatores são fundamentais para poder se fazer uma análise estratégica no TUC. No entanto, considera-se que um estudo com os dados obtidos por esta metodologia pode auxiliar nessa tarefa por meio das seguintes analises:

análise inicial e tratamento dos dados;

análise dos movimentos padrão dos fluxos de carga;

maiores geradores e atratores de carga;

fatores de Influência no TUC;

dados para modelagem.

Estes grupos de análise são tratados a seguir e, quando aplicável, demonstra-se como gerar os dados a partir dos comandos e recursos disponíveis no painel para efetuar as respectivas análises.

\subsection{ANÁLISE INICIAL E TRATAMENTO DOS DADOS}

Os dados apontam um total de 44.612.926 NFe's transacionadas com o Distrito Federal no período de um ano (setembro de 2013 a agosto de 2014). Porém, ao analisar os valores monetários das NFe's, detecta-se a existência de dados com inconsistências ou valores extremos, possivelmente devido a erros de digitação. As NFe's com valores zerados ou acima de bilhões de reais entram nesta relação. Adotando o critério de quais valores podem expressar razoavelmente uma entrega ou uma carga completa de alto valor,são consideradas nas análises as transações na faixa de 10 reais até 5 milhões de reais. Esta decisão reduz em 2,2\% o tamanho da amostra, dando um total de 43.645.416 NFe's transacionadas, sendo este o valor considerado nas análises.

Considerando o mesmo perfil de erros dos valores, são excluídos os valores extremos dos dados de peso bruto informados nas NFe's. Isto causa uma redução significativa na quantidade de dados, reduzindo ainda mais a amostra para 24.163.169 NFe's. Devido a esta significativa diminuição, o filtro adotado é utilizado para análises onde há a variável peso, e não como restrição para as demais análises (por exemplo: de valor, da quantidade de entregas), pois isto afetaria a consistência dos dados. 
Cabe salientar que, mesmo com o tratamento dos valores das NFe's, os indicadores de curtose $(4.110,02)$, assimetria $(53,17)$ e o gráfico da Figura 4.1 demonstram uma distribuição não normal, elevada e positivamente assimétrica (HAIR JR et al., 2009). Por isto, são utilizados valores de mediana e quartis para as análises estatísticas envolvendo os valores das NFe's.

Figura 4.1 - Distribuição da quantidade por valor de NFe

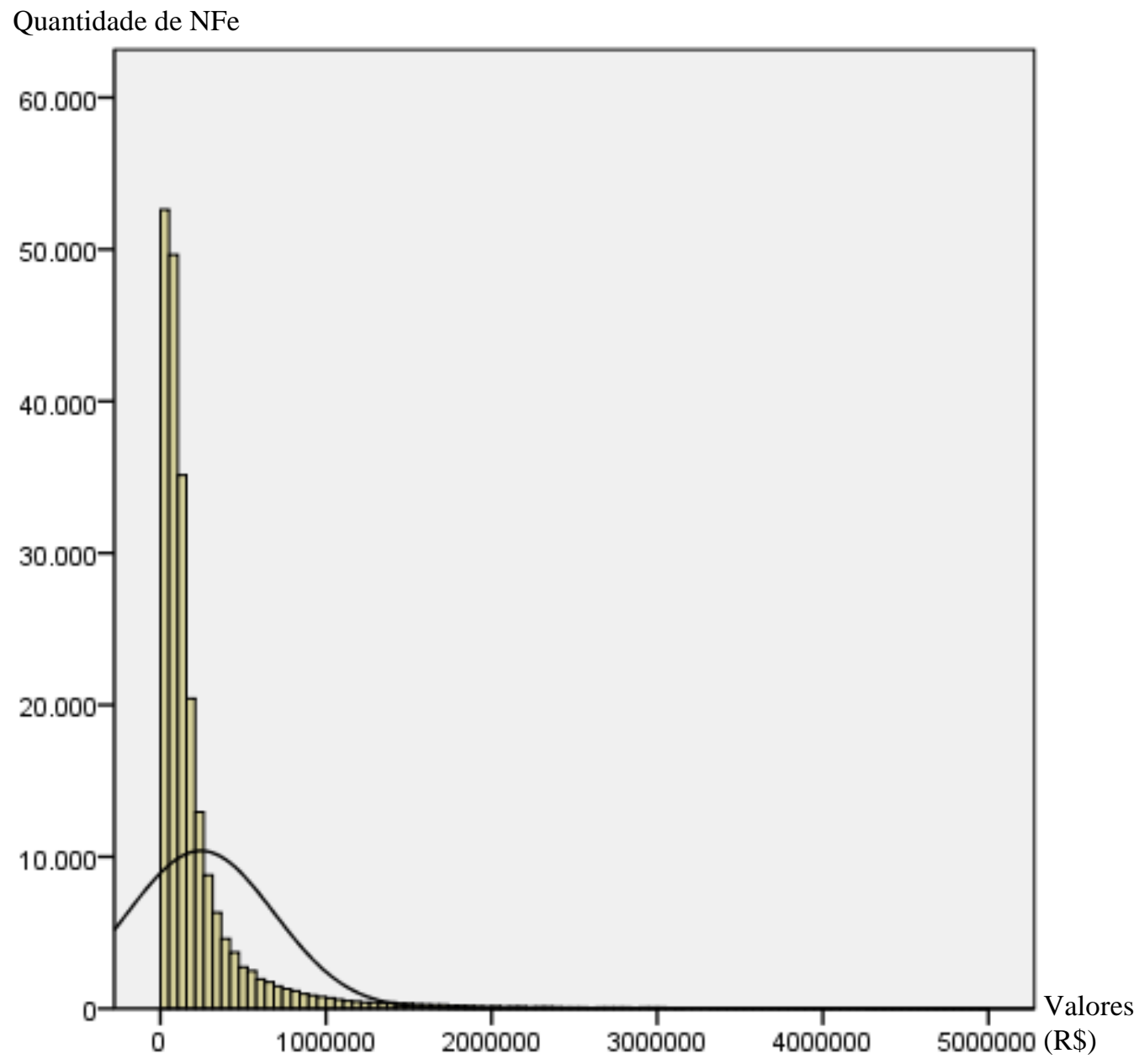

\subsection{MOVIMENTO PADRÃO DOS FLUXOS DE CARGAS}

Um dos fatores fundamentais para poder fazer uma análise estratégica do TUC é a análise dos movimentos padrão dos fluxos de carga que pode ser realizada por meio dos seguintes estudos: 
a) cálculo da participação dos movimentos padrão de NFe's (interno-interno, internoexterno e externo-interno e externo-externo) da quantidade total de NFe's da área em estudo, de modo a verificar possíveis fluxos de cargas prioritários;

b) identificação da participação dos tipos de produtos na geração e atração de fluxos de cargas prioritários, diferenciados por quantidade, peso e valor das NFe's, lembrando que os produtos são o fator de destaque na configuração de diferentes processos de distribuição e, por isto, podem trazer consigo fluxos de cargas interessantes para análise;

c) identificação dos segmentos de atividades que mais geram despachos e atraem entregas, seguindo as análises dos fluxos definidos como prioridade no item a) acima.

Para realizar estes estudos, utilizam-se os objetos do painel IouEOrigem e IouEDestino que referem-se se as operações são de origem ou destino internos (I) ou externos (E) à área de estudo. O cordão externo é definido neste estudo pela unidade federativa, mas também pode ser definido com maior desagregação por municípios, bairros, CEP's ou estabelecimentos.

Selecionada a operação, pode-se segmentar as análises por abas do painel, que possuem tabelas preparadas por produto (aba NCM do painel), atividade econômica do estabelecimento (aba CNAE) ou sua localização por CEP (aba CEP). Além disso, podemse efetuar filtros específicos por produto (objeto NCMGENERO), se o destino ou origem se baseia em uma pessoa física $(\mathrm{PF})$ ou jurídica $(\mathrm{PJ})$.

\subsubsection{Participação dos movimentos padrão das NFe's}

A análise da quantidade e valores de NFe que se originam e/ou se destinam ao Distrito Federal permite obter um panorama dos fluxos de cargas demonstrado na Tabela 4.1 que, por sua vez, mostra alguns aspectos interessantes. Por exemplo, destino interno responde por $85 \%$ das NFe's, sendo que a maior parte $(63 \%)$ tem origem interna, porém outra parte significativa vem de transações com origem externa $(23 \%)$. 
Esta informação demonstra ainda que o Distrito Federal é uma unidade federativa mais importadora (23\%) do que exportadora de mercadorias (15\%), tanto em termos de quantidade como em valor das mercadorias, tornando relevante analisar os fluxos externos que se destinam à área de estudo.

Tabela 4.1 - Quantidade de NFe por origem e destino ${ }^{19}$, Set 2013 - Ago 2014

\begin{tabular}{|c|c|c|c|c|c|c|c|c|}
\hline & & & & & Destino & & & \\
\hline & & Itens & Interna & & Externa & & Total & \\
\hline & & Contagem total & 27.149 .564 & $62 \%$ & 6.391 .509 & $15 \%$ & 33.541 .073 & $77 \%$ \\
\hline & & Soma & 74.314 .361 .223 & $41 \%$ & 34.127 .735 .172 & $19 \%$ & 108.442 .096 .394 & $60 \%$ \\
\hline & & Média & 2.737 & $66 \%$ & 5.340 & $130 \%$ & 3.233 & $78 \%$ \\
\hline & $\stackrel{\pi}{\Xi}$ & Desvio Padrão & 31.852 & $77 \%$ & 41.214 & $100 \%$ & 33.852 & $82 \%$ \\
\hline & $\Xi$ & Máximo & 4.998 .779 & $100 \%$ & 4.995 .685 & $100 \%$ & 4.998 .779 & $100 \%$ \\
\hline & & $25 \%$ & 133 & $90 \%$ & 181 & $123 \%$ & 142 & $96 \%$ \\
\hline & & Mediana & 361 & $89 \%$ & 543 & $134 \%$ & 388 & $96 \%$ \\
\hline & & $75 \%$ & 1.000 & $78 \%$ & 1.945 & $151 \%$ & 1.118 & $87 \%$ \\
\hline & & Contagem total & 10.092 .487 & $23 \%$ & 11.856 & $0 \%$ & 10.104 .343 & $23 \%$ \\
\hline & & Soma & 70.897 .015 .275 & $39 \%$ & 486.854 .183 & $0 \%$ & 71.383 .869 .458 & $40 \%$ \\
\hline 5 & & Média & 7.025 & $170 \%$ & 41.064 & $997 \%$ & 7.065 & $171 \%$ \\
\hline & $\stackrel{\pi}{\tilde{0}}$ & Desvio Padrão & 58.696 & $143 \%$ & 193.735 & $471 \%$ & 59.048 & $144 \%$ \\
\hline & 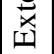 & Máximo & 4.999 .892 & $100 \%$ & 4.989 .259 & $100 \%$ & 4.999 .892 & $100 \%$ \\
\hline & & $25 \%$ & 162 & $110 \%$ & 495 & $335 \%$ & 162 & $110 \%$ \\
\hline & & Mediana & 510 & $126 \%$ & 4.026 & $992 \%$ & 510 & $126 \%$ \\
\hline & & $75 \%$ & 2.145 & $167 \%$ & 31.519 & $2454 \%$ & 2.151 & $167 \%$ \\
\hline & & Contagem total & 37.242 .051 & $85 \%$ & 6.403 .365 & $15 \%$ & 43.645 .416 & $100 \%$ \\
\hline & & Soma & 145.211 .376 .498 & $81 \%$ & 34.614 .589 .355 & $19 \%$ & 179.825 .965 .852 & $100 \%$ \\
\hline & & Média & 3.899 & $95 \%$ & 5.406 & $131 \%$ & 4.120 & $100 \%$ \\
\hline & ఫ్ & Desvio Padrão & 40.950 & $100 \%$ & 42.040 & $102 \%$ & 41.115 & $100 \%$ \\
\hline & $\stackrel{0}{1}$ & Máximo & 4.999 .892 & $100 \%$ & 4.995 .685 & $100 \%$ & 4.999 .892 & $100 \%$ \\
\hline & & $25 \%$ & 140 & $95 \%$ & 182 & $123 \%$ & 147 & $100 \%$ \\
\hline & & Mediana & 390 & $96 \%$ & 544 & $134 \%$ & 406 & $100 \%$ \\
\hline & & $75 \%$ & 1.199 & $93 \%$ & 1.952 & $152 \%$ & 1.285 & $100 \%$ \\
\hline
\end{tabular}

Legenda: Contagem total igual ao total de notas fiscais eletrônicas (NFes) transacionadas com o Distrito Federal de set.2013 a ago.2014; soma, média, desvio padrão e quartis baseados nos valores das Nfes; percentuais (\%) igual à razão valores no quadrante / valores totais

As operações estritamente internas são as de maior proporção e apresentam a menor mediana do valor das mercadorias, $\mathrm{R} \$ 361,00$. Espera-se que este número menor reflita a maior desagregação das cargas neste tipo de operação, possivelmente com maior participação de entregas baseadas em rotas.

${ }^{19}$ Valores em reais. Cotação 1 dólar =2,2625 reais. Fonte: www.economia.uol.com.br/cotacoes em 04/08/2014. 
Origens e destinos externos referem-se a transações para cargas de exportação/importação (via aeroporto) ou às chamadas triangulações comerciais, onde uma mercadoria, por exemplo, é comprada e vendida em outra UF mas passa pelo DF para execução de um serviço (exemplo: concretagem de cimento). Estas NFe's não apresentam origem e destino no DF, porém estão no banco de dados por conterem no campo "local de entrega" o Distrito Federal. Os valores das operações externas apresentam mediana muito acima dos demais movimentos, o que destaca o caráter de cargas com maior valor econômico, porém de impacto reduzido no número de transações no espaço urbano. Assim, por falta de acesso a uma base nacional das NFe's, não se pode estimar quais cargas de passagem, com origem e destinos em outros estados, impactam na malha viária do DF.

As análises das operações internas, e externas para o Distrito Federal se apresentam como interessantes focos de análise, não somente pela participação expressiva nos movimentos de mercadorias, mas também pela expectativa de que se relacionem com entregas mais desagregadas realizadas por meio de viagens encadeadas em rotas.

\subsubsection{Participação dos tipos de mercadorias no fluxo de cargas}

A Figura 4.2 demonstra a quantidade de NFe's emitidas de trinta tipos de produtos para operações de origem e destino internos. Como resultado destaca-se o segmento de bebidas ( $\mathrm{NCM}=22)$ com $14,40 \%$, seguida de materiais elétricos com 7,6\% e, em terceiro, o grupo "Outros" ${ }^{20}$ com 7,0\% de participação. Para operações externas que remetem produtos para o Distrito Federal (Figura 4.3) destacam-se materiais elétricos (10,5\% de participação), cosméticos $(10,2 \%)$, produtos gráficos $(7,3 \%)$ e máquinas $(6,8 \%)$.

Porém, um ponto interessante das operações externas para o DF é a participação de pessoas físicas como destinatárias das mercadorias, que responde por 3.940 .800 entregas, $39 \%$ do total de 10.092.487 (Tabela 4.2). Os principais produtos relacionados com estes movimentos são cosméticos, materiais elétricos e produtos gráficos, que respondem por cerca da metade desses 39\%. Trata-se de uma concentração significativa, o que pode levar a uma avaliação específica desses três segmentos de produtos.

\footnotetext{
${ }^{20}$ Estes são NCM identificados com código 99. Uma análise mais detalhada demonstra se tratarem de vendas de mercadorias por prestadores de serviço (academias, escolas) ou varejistas (comércio de veículos, por exemplo) as pessoas físicas, que correspondem a 1.264.422 NFe, 66,3\% dos destinatários destas transações.
} 
Figura 4.2 - Percentual de NFe por produto, operações internas

Percentual de NFe

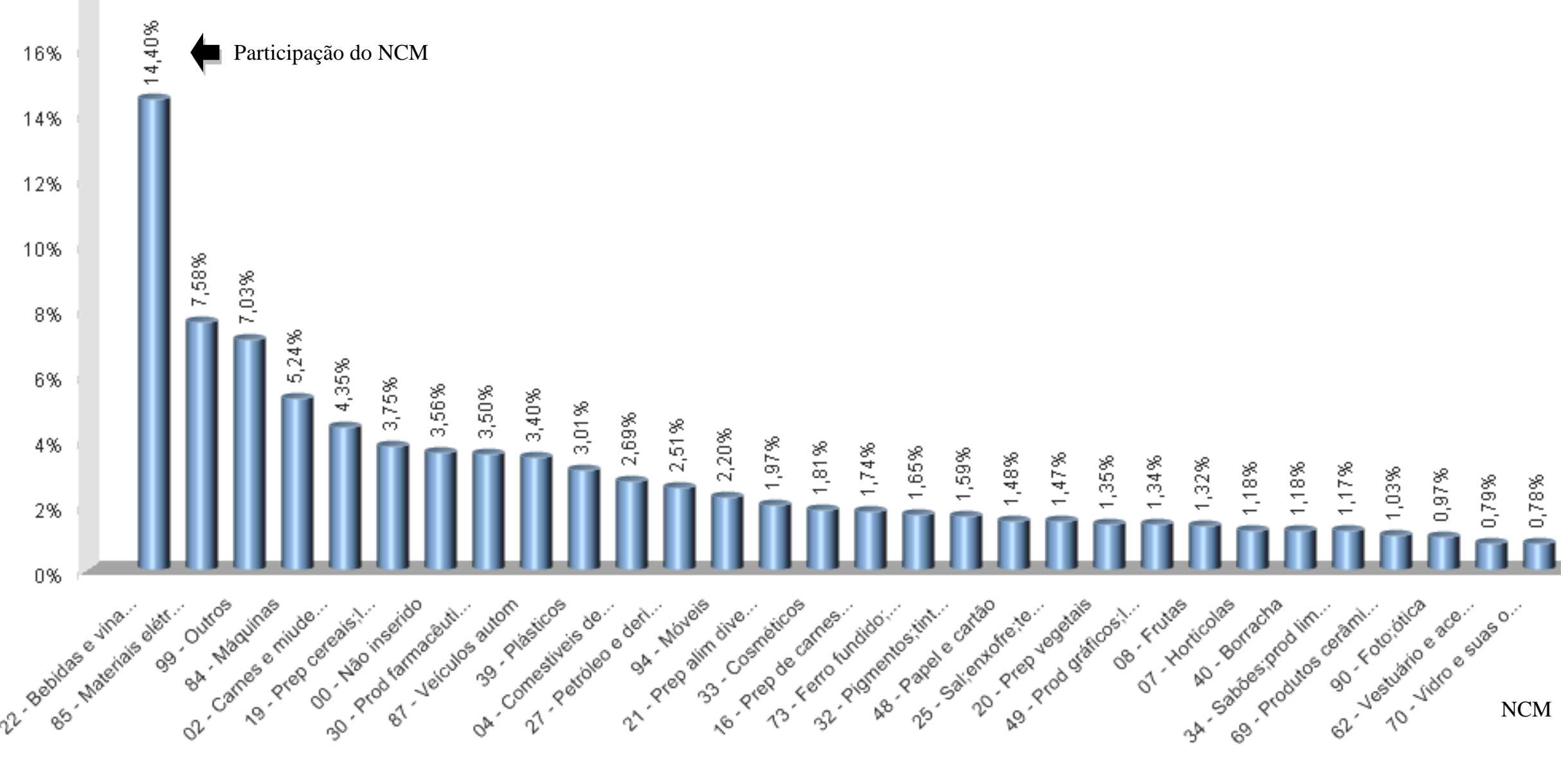


Figura 4.3 - Percentual de NFe por produto, origem externa para DF

Percentual de NFe
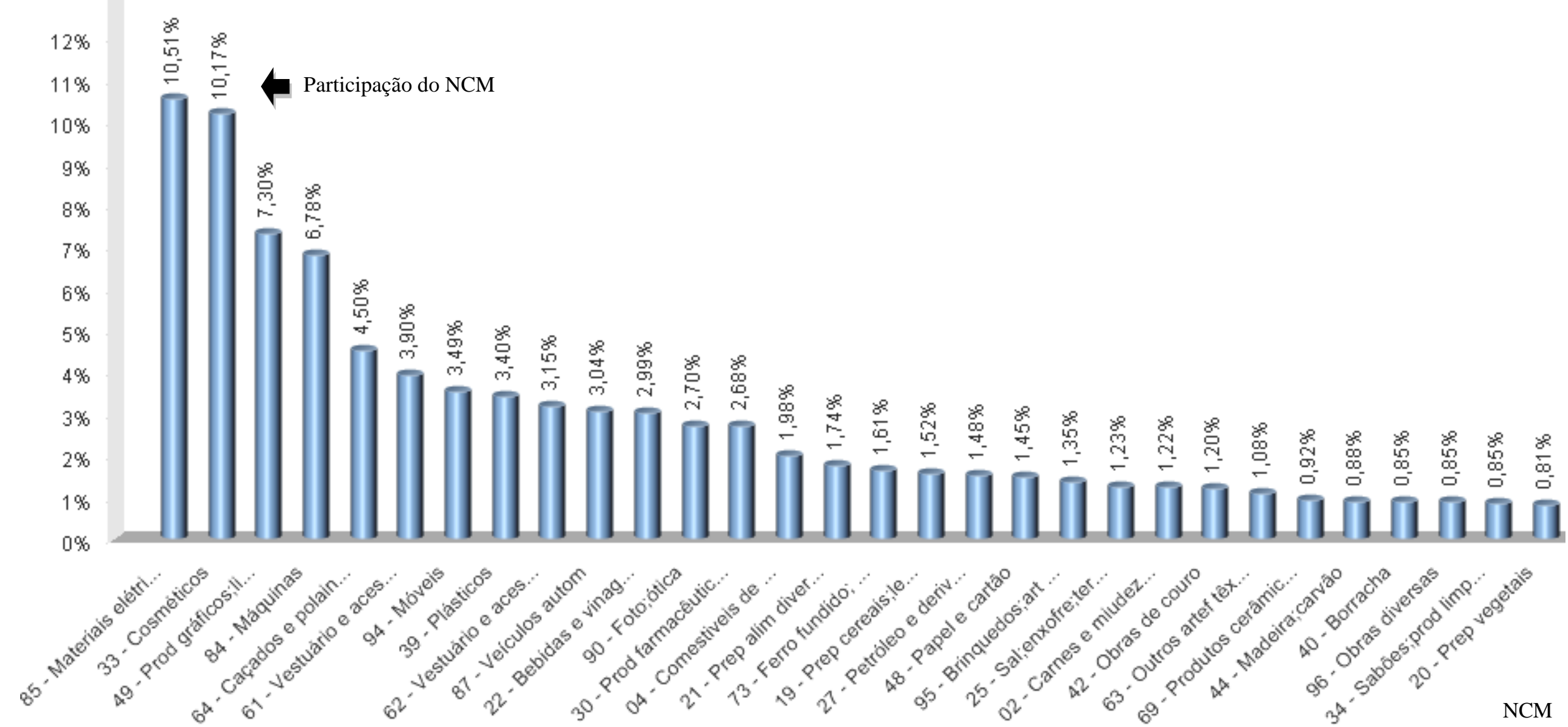
Tabela 4.2 - Entregas por tipo de mercadoria para pessoa física, Set 2013 - Ago 2014

\begin{tabular}{|c|c|c|c|}
\hline Tipo de mercadoria & $\begin{array}{l}\text { Quantidade de } \\
\text { entregas }^{(*)} \\
(\mathrm{QE})\end{array}$ & $\begin{array}{c}\text { QE/total de } \\
\text { entregas } \\
(\%)\end{array}$ & $\begin{array}{l}\text { Participação } \\
\text { acumulada } \\
(\%)\end{array}$ \\
\hline Cosméticos & 894.810 & 22,71 & 22,71 \\
\hline Materiais elétricos & 563.757 & 14,31 & 37,01 \\
\hline Produtos gráficos;livros;jornais & 476.845 & 12,10 & 49,11 \\
\hline Caçados e polainas & 274.165 & 6,96 & 56,07 \\
\hline Máquinas & 248.659 & 6,31 & 62,38 \\
\hline$\ldots$ & $\ldots$ & $\ldots$ & $\ldots$ \\
\hline Total & 3.940 .800 & & 0,00 \\
\hline
\end{tabular}

Também são analisadas as participações do valor e peso dos produtos no total comercializado (Tabela 4.3). No caso dos veículos automotivos, petróleo e derivados e materiais elétricos se destacam com 38,59 \% de participação no valor total das mercadorias comercializadas com destino interno, que é de 145 bilhões de reais.

Tabela 4.3 - Valor comercializado por tipo de mercadoria, Set 2013 - Ago 2014

\begin{tabular}{llrr}
\hline \multicolumn{1}{c}{ Tipo de mercadoria } & \multicolumn{1}{c}{$\begin{array}{c}\text { Valor }^{\left({ }^{*}\right)} \\
(\mathrm{R} \$)\end{array}$} & $\begin{array}{c}\text { Valor/total } \\
(\%)\end{array}$ & $\begin{array}{c}\text { Participação } \\
\text { acumulada } \\
(\%)\end{array}$ \\
\hline Veículos automotivos & 20.438 .181 .498 & 14,07 & 14,07 \\
Petróleo e derivados & 15.637 .367 .904 & 10,77 & 24,84 \\
Materiais elétricos & 10.385 .970 .220 & 7,15 & 32,00 \\
Máquinas & 9.582 .069 .929 & 6,60 & 38,59 \\
Outros & 9.348 .958 .477 & 6,44 & 45,03 \\
Bebidas e vinagres & 8.435 .463 .908 & 5,81 & 50,84 \\
Produtos farmacêuticos & 6.811 .491 .278 & 4,69 & 55,53 \\
\multicolumn{1}{c}{ Total } & 145.211 .376 .498 & 100,00 & $\ldots$ \\
\hline
\end{tabular}

Nota: (*) Destino interno

Para a análise do peso dos produtos efetua-se a restrição do tamanho da amostra exposta na análise inicial dos dados. Nos produtos que tem como destino o Distrito Federal, petróleo e seus derivados também se destacam no peso transportado, seguido por bebidas, terras e, com uma participação interessante, resíduos da indústria alimentícia (Tabela 4.4). Estes grupos de mercadorias respondem por aproximadamente $39 \%$ do peso total que é de 15,1 bilhões de toneladas no período analisado. 
Tabela 4.4 - Peso comercializado por tipo de mercadoria, Set 2013 - Ago 2014

\begin{tabular}{lrrr}
\hline \multicolumn{1}{c}{ Tipo de mercadoria } & $\begin{array}{c}\text { Peso } \\
\text { (ton) }\end{array}$ & $\begin{array}{c}\text { Peso/total } \\
\text { (\%) }\end{array}$ & $\begin{array}{c}\text { Participação } \\
\text { acumulada } \\
\text { (\%) }\end{array}$ \\
\hline Petróleo e derivados & 2.397 .412 & 15,87 & 15,87 \\
Bebidas e vinagres & 1.750 .387 & 11,59 & 27,46 \\
Sal;enxofre;terras & 1.065 .922 & 7,06 & 34,52 \\
Resíduos da indústria alimentícia & 653.137 & 4,32 & 38,84 \\
Carnes e miudezas & 562.128 & 3,72 & 42,56 \\
Cereais & 502.928 & 3,33 & 45,89 \\
Produtos gráficos;livros;jornais & 463.978 & 3,07 & 48,96 \\
Comestíveis de animais & 425.843 & 2,82 & 51,78 \\
Preparações de cereais;leite;pastelaria & 423.227 & 2,80 & 54,59 \\
Produtos farmacêuticos & 422.690 & 2,80 & 57,38 \\
\multicolumn{1}{c}{ Total } & & $\ldots$ & $\ldots$ \\
\hline
\end{tabular}

Nota: Destino interno

A Tabela 4.5 fornece os segmentos com maior peso por remessa para os destinos internos. Verifica-se que as cargas de minérios se destacam, sendo que petróleo e seus derivados, terras, resíduos da indústria alimentícia, cereais e produtos gráficos, além de ter uma participação expressiva no total do peso gerado, também apresentam um peso por remessa expressivo. Por outro lado, bebidas apresentam um peso por remessa menor, o que pode revelar uma distribuição com cargas mais desagregadas.

Tabela 4.5 - Peso por entrega por tipo de mercadoria, Set 2013 - Ago 2014

\begin{tabular}{lr}
\hline \multicolumn{1}{c}{ Tipo de Mercadoria } & $\begin{array}{r}\text { Peso por Entrega } \\
(\mathrm{Kg})\end{array}$ \\
\hline Minérios & 39.627 \\
Níquel e suas obras & 33.094 \\
Sementes & 14.053 \\
Outros produtos de origem animal & 11.300 \\
Petróleo e derivados & 8.079 \\
Cereais & 5.865 \\
Resíduos da indústria alimentícia & 5.052 \\
Sal;enxofre;terras & 4.098 \\
Prod gráficos;livros;jornais & 3.166 \\
Prod farmacêuticos & 2.515 \\
Comestiveis de animais & 733 \\
Preparações de cereais;leite;pastelaria & 634 \\
Carnes e miudezas & 562 \\
Bebidas e vinagres & 561 \\
\hline Nota: Operações com destino interno &
\end{tabular}


Da análise das tabelas anteriores verificam-se movimentos com características específicas nos segmentos de produtos que podem impactar o TUC de modo diferente. Por exemplo, a alta concentração no peso comercializado (total e por remessa) de petróleo e seus derivados, terras, resíduos da indústria alimentícia, cereais e produtos gráficos pode sugerir uma análise sobre o impacto destes segmentos na estrutura viária.

No caso dos movimentos externos para o DF destinados para pessoa física, pode-se avaliar se a entrega está sendo feita em domicílio nos segmentos de cosméticos, materiais elétricos e produtos gráficos, o que sugere um estudo aprofundado de seu impacto no fluxo de tráfego junto a áreas residenciais. Outro destaque é o segmento de bebidas, que possui alta participação no peso total, no valor comercializado (importância econômica) e, principalmente, na quantidade de remessas. Por isto, pode ser avaliado em termos de seu impacto no tráfego urbano e na demanda por espaços para carga e descarga.

\subsubsection{Participação dos tipos de atividades no fluxo de cargas}

Neste item são analisadas as atividades econômicas classificadas no código CNAE para os contribuintes que mais geram despachos e atraem entregas ${ }^{21}$. Mantendo a orientação inicial, são analisadas as operações internas que são desmembradas em atividades de origem ou destino de mercadorias, e as que mais atraem entregas com origem externa, conforme o interesse.

Inicia-se a análise com a participação das atividades que mais geram despachos no DF para entregas internas. Neste caso, analisando a Tabela 4.6 e excetuando os 11,0\% com atividades não identificadas ${ }^{22}$, as demais atividades listadas somam 50,7\% das NFe's emitidas com origem no DF. As quatro atividades que mais despacham mercadorias estão relacionadas com o setor de bebidas (atividades $\mathrm{n}^{\circ} 1 \operatorname{com} 6,25 \%$ e $\mathrm{n}^{\circ} 6 \operatorname{com} 3.27 \%$ ), alimentos (atividades 2 e 3 com 5,62\% e 5,20\%, respectivamente) e setor automotivo (atividade 4 com 4,50\%). Tratam-se de concentrações que se destacam na geração interna de NFe's e que podem ser melhor visualizadas na Figura 4.4.

\footnotetext{
21 A definição de geração ou atração é feita no QlikView por meio do comando "expressões" onde se especifica a análise CNAE origem ou CNAE destino, respectivamente.

${ }^{22}$ Destes $11 \%$ há $42 \%$ pessoas físicas, e o restante para empreendedores individuais.
} 
Tabela 4.6 - Quantidade de despachos por tipo de atividade, Set 2013 - Ago 2014

\begin{tabular}{|c|c|c|c|}
\hline Descrição de Atividades & $\begin{array}{c}\text { Quantidade } \\
\text { de } \\
\text { despachos } \\
\text { (QD) }\end{array}$ & $\begin{array}{c}\mathrm{QD} / \text { total de } \\
\text { despachos } \\
(\%)\end{array}$ & $\begin{array}{c}\text { Participação } \\
\text { acumulada } \\
(\%)\end{array}$ \\
\hline Outros sem cadastro de atividades & 2.990 .680 & 11,02 & \\
\hline 1 Comércio atacadista de cerveja, chope e refrigerante & 1.833 .462 & 6,75 & 6,75 \\
\hline 2 Comércio varejista de mercadorias em geral, com predom produtos alimentícios & 1.526 .942 & 5,62 & 12,37 \\
\hline 3 Comércio atacadista de produtos alimentícios em geral & 1.412 .158 & 5,20 & 17,57 \\
\hline 4 Comércio a varejo de automóveis, camionetas e utilitários novos & 1.222 .789 & 4,50 & 22,07 \\
\hline 5 Comércio varejista de materiais de construção em geral & 921.451 & 3,39 & 25,46 \\
\hline 6 Fabricação de refrigerantes & 888.366 & 3,27 & 28,73 \\
\hline 7 Comércio atacadista de medicamentos e drogas de uso humano & 850.536 & 3,13 & 31,86 \\
\hline 8 Comércio varejista especializado de eletrodomésticos e equipamentos de áudio & 769.358 & 2,83 & 34,69 \\
\hline 9 Comércio por atacado de peças e acessórios novos para veículos automotores & 656.637 & 2,42 & 37,11 \\
\hline 10 Comércio atacadista de aves abatidas e derivados & 510.515 & 1,88 & 38,99 \\
\hline 11 Comércio atacadista de carnes bovinas e suínas e derivados & 494.367 & 1,82 & 40,81 \\
\hline 12 Comércio atacadista de materiais de construção em geral & 438.859 & 1,62 & 42,43 \\
\hline 13 Comércio a varejo de peças e acessórios novos para veículos automotores & 419.345 & 1,54 & 43,97 \\
\hline 14 Comércio atacadista de bebidas não especificadas anteriormente & 378.616 & 1,39 & 45,36 \\
\hline 15 Comércio atacadista de frutas, verduras, raízes, tubérculos, hortaliças & 378.392 & 1,39 & 46,75 \\
\hline 16 Comércio varejista especializado de equipamentos e suprimentos de informática & 374.574 & 1,38 & 48,13 \\
\hline 17 Comércio varejista de produtos farmacêuticos, sem manipulação de fórmulas & 361.739 & 1,33 & 49,46 \\
\hline 18 Comércio atacadista de mercadorias em geral, com predom prod. alimentícios & 335.538 & 1,24 & 50,70 \\
\hline$\cdots$ & $\ldots$ & $\ldots$ & $\ldots$ \\
\hline Total & 27.149 .564 & & 0,00 \\
\hline
\end{tabular}

Nota: Operações internas

Figura 4.4 - Quantidade de despachos por atividade, operações internas

Quantidade de despachos

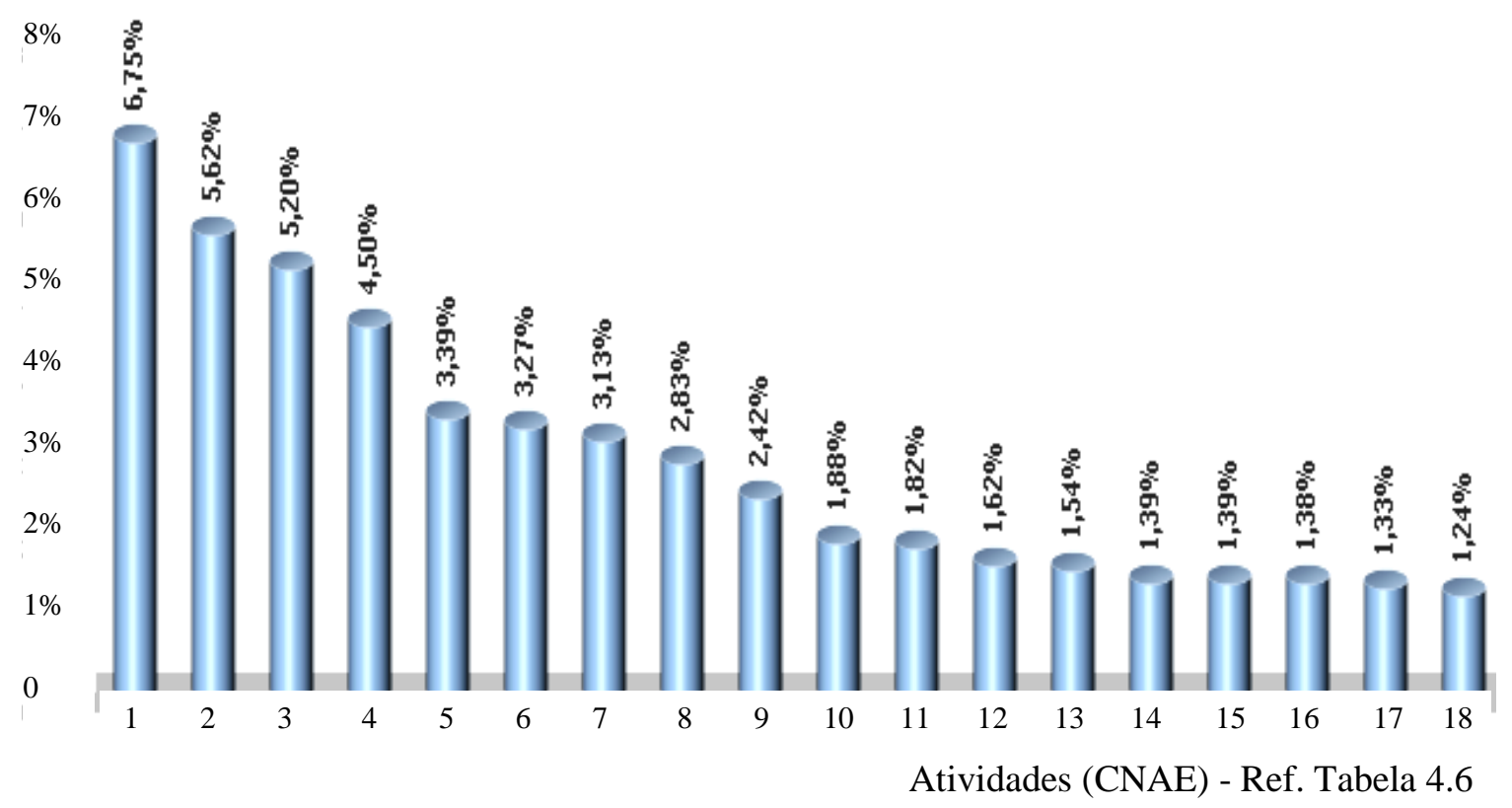


Ainda analisando as operações internas, porém agora focalizando as atividades que atraem entregas no DF, gera-se a Tabela 4.7. Pode ser observado que sem cadastro de atividades atrai 9.830.551 $(36,21 \%)$ das NFe's emitidas. Por meio de uma análise mais detalhada, identificou-se que $72 \%$ destas emissões tem pessoas físicas como destino.

Excetuando-se o grupo sem registro de atividades, verifica-se na Tabela 4.7 que comércio varejista de mercadorias em geral, com predominância de produtos alimentícios que, em última análise, são supermercados, atrai 15,81\% das NFe's emitidas no DF, seguido dos restaurantes e similares $(5,73 \%)$ e comércio varejista de produtos farmacêuticos $(4.60 \%)$. Juntos, estas atividades representam 26,14\% das entregas (atração) em uma concentração que cai sensivelmente para as demais atividades analisadas. Este comportamento é melhor visualizado na Figura 4.5.

Tabela 4.7 - Quantidade de entregas por atividade, Set 2013 - Ago 2014

\begin{tabular}{|c|c|c|c|}
\hline Descrição de Atividades & $\begin{array}{c}\text { Quantidade } \\
\text { de entregas } \\
\text { (QE) }\end{array}$ & $\begin{array}{c}\mathrm{QE} / \text { total } \\
\text { de } \\
\text { entregas } \\
(\%)\end{array}$ & $\begin{array}{c}\text { Participação } \\
\text { acumulada } \\
(\%)\end{array}$ \\
\hline Sem descrição de atividades & 9.830 .551 & 36,21 & \\
\hline 1 Comércio varejista de mercadorias em geral, com predom prod alimentícios & 4.292 .691 & 15,81 & 15,81 \\
\hline 2 Restaurantes e similares & 1.556 .556 & 5,73 & 21,54 \\
\hline 3 Comércio varejista de produtos farmacêuticos, sem manipulação de fórmulas & 1.249 .796 & 4,60 & 26,14 \\
\hline 4 Lanchonetes, casas de chá, de sucos e similares & 810.084 & 2,98 & 29,12 \\
\hline 5 Comércio a varejo de peças e acessórios novos para veículos automotores & 783.141 & 2,88 & 32,00 \\
\hline 6 Fabricação de produtos de padaria e confeitaria com predom prod alimentícios & 536.613 & 1,98 & 33,98 \\
\hline 7 Comércio varejista de materiais de construção em geral & 530.929 & 1,96 & 35,94 \\
\hline 8 Padaria e confeitaria com predominância de revenda & 511.373 & 1,88 & 37,82 \\
\hline 9 Comércio varejista de bebidas & 448.007 & 1,65 & 39,47 \\
\hline 10 Comércio varejista de artigos do vestuário e acessórios & 367.475 & 1,35 & 40,82 \\
\hline 11 Bares e outros estabelecimentos especializados em servir bebidas & 304.078 & 1,12 & 41,94 \\
\hline 12 Comércio varejista de produtos alimentícios em geral & 302.198 & 1,11 & 43,05 \\
\hline 13 Comércio a varejo de automóveis, camionetas e utilitários novos & 258.146 & 0,95 & 44,00 \\
\hline 14 Comércio atacadista de produtos alimentícios em geral & 207.535 & 0,76 & 44,76 \\
\hline 15 Comércio varejista de carnes - açougues & 179.993 & 0,66 & 45,42 \\
\hline 16 Comércio varejista especializado de eletrodomésticos e equip. de áudio & 170.617 & 0,63 & 46,05 \\
\hline 17 Comércio varejista especializado de equip. e suprimentos de informática & 170.592 & 0,63 & 46,68 \\
\hline 18 Comércio varejista de hortifrutigranjeiros & 163.331 & 0,60 & 47,28 \\
\hline 19 Comércio varejista de combustíveis para veículos automotores & 157.759 & 0,58 & 47,86 \\
\hline 20 Comércio varejista de jornais e revistas & 126.935 & 0,47 & 48,33 \\
\hline 21 Comércio varejista de artigos de papelaria & 106.715 & 0,39 & 48,72 \\
\hline 22 Comércio varejista de mat. construção não especificados anteriormente & 106.115 & 0,39 & 49,11 \\
\hline 23 Fornecimento de alimentos preparados preponderantemente para empresas & 106.111 & 0,39 & 49,50 \\
\hline 24 Comércio varejista de calçados & 103.320 & 0,38 & 49,88 \\
\hline 25 Comércio varejista de ferragens e ferramentas & 101.552 & 0,37 & 50,25 \\
\hline ... & ... & ... & ... \\
\hline Totais & 27.149 .564 & & 100,00 \\
\hline
\end{tabular}

Nota: Operações internas 
Figura 4.5 - Quantidade de entregas por atividade, operações internas

Quantidade de entregas

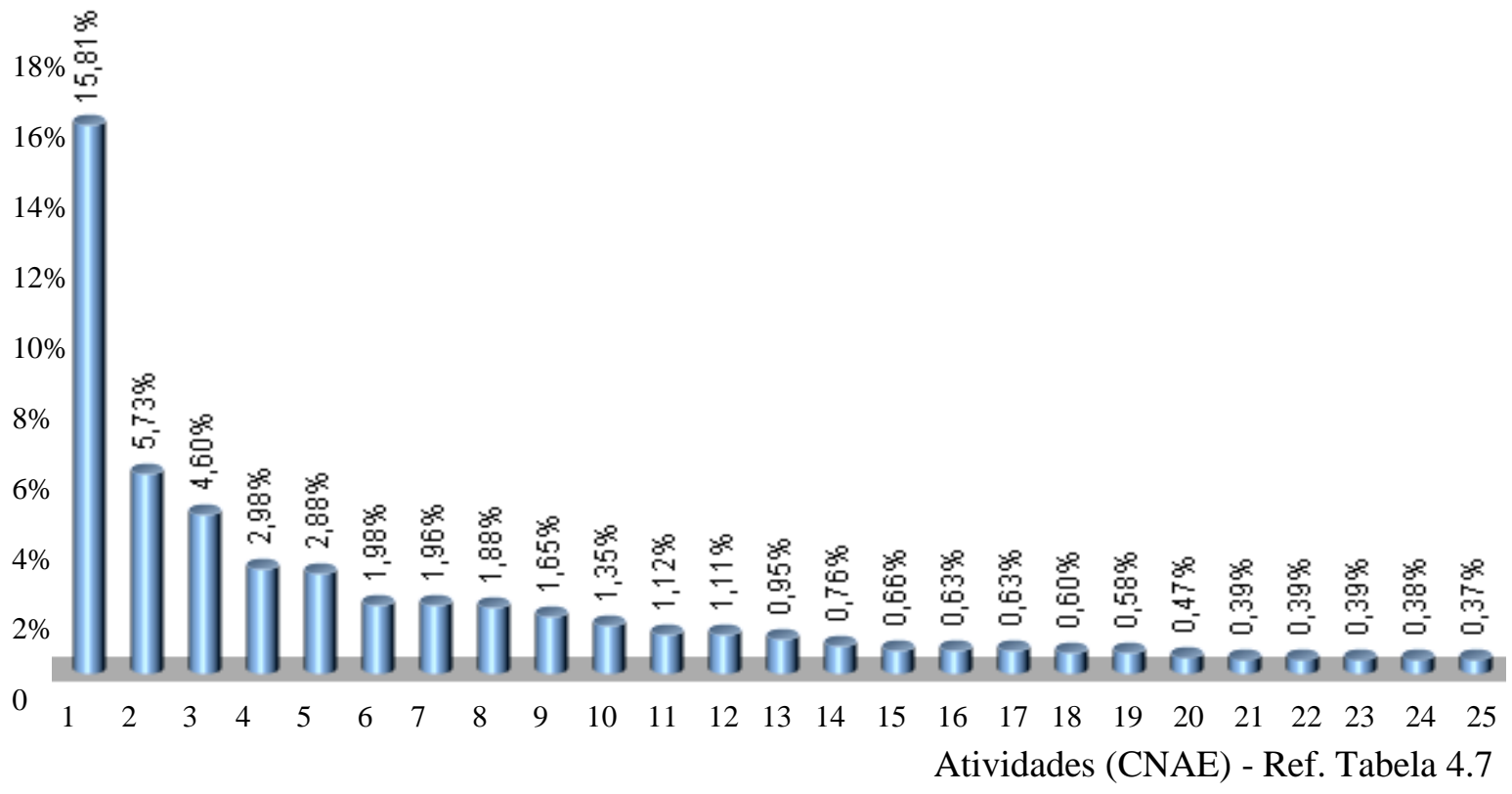

A próxima análise trata das NFe's emitidas em outros estados e são analisadas as atividades que atraem entregas no DF (Tabela 4.8). Neste caso, a participação das atividades que mais atraem entregas muda sensivelmente em relação às operações internas e, com exceção da atividades 1 e 2, as demais apresentam uma participação mais homogênea (Figura 4.6).

Supermercados, por exemplo, que participavam com $15,81 \%$ dos recebimentos nas operações internas, cai para 7,33\% de participação, mas ainda continua como a atividade que mais atrai entregas. Atividades sem identificação, comércio varejista de vestuário, de autopeças e materiais de construção assumem maior destaque. Excetuando as atividades não identificadas, na coluna total acumulado os segmentos representados na Tabela 4.8 representam $36 \%$ das entregas com origem externa destinadas ao DF.

Ainda na Tabela 4.8 destaca-se que as remessas de origem externa estão com 45,20\% das entregas no DF relacionadas com atividades não identificadas. Isto soma 4.561.530 entregas e, destas, 3.779 .549 (83\%) são para pessoa física. Em uma análise mais detalhada, verifica-se que se trata do grupo de pessoas físicas identificado na análise da seção 4.4.2. O aspecto interessante é que a análise das razões sociais dos remetentes indica empresas que atuam com vendas porta-a-porta e internet. 
Tabela 4.8 - Quantidade de entregas por atividade, Set 2013 - Ago 2014

\begin{tabular}{|c|c|c|c|}
\hline Descrição de atividades & $\begin{array}{c}\text { Quantidade } \\
\text { de entregas } \\
\text { (QE) }\end{array}$ & $\begin{array}{c}\mathrm{QE} / \text { total } \\
\text { de } \\
\text { entregas } \\
(\%)\end{array}$ & $\begin{array}{c}\text { Participação } \\
\text { acumulada } \\
(\%)\end{array}$ \\
\hline Sem identificação de atividades & 4.561 .530 & 45,20 & \\
\hline 1 Comércio varejista de mercadorias em geral, com predom prod alimentícios & 739.350 & 7,33 & 7,33 \\
\hline 2 Comércio varejista de artigos do vestuário e acessórios & 406.651 & 4,03 & 11,36 \\
\hline 3 Comércio a varejo de automóveis, camionetas e utilitários novos & 235.919 & 2,34 & 13,70 \\
\hline 4 Comércio varejista de materiais de construção em geral & 212.559 & 2,11 & 15,81 \\
\hline 5 Comércio varejista de calçados & 142.575 & 1,41 & 17,22 \\
\hline 6 Comércio varejista de móveis & 138.397 & 1,37 & 18,59 \\
\hline 7 Comércio varejista de produtos farmacêuticos, sem manipulação de fórmulas & 137.332 & 1,36 & 19,95 \\
\hline 8 Comércio atacadista de produtos alimentícios em geral & 121.045 & 1,20 & 21,15 \\
\hline 9 Comércio varejista especializado de eletrodomésticos e equip de áudio & 117.772 & 1,17 & 22,32 \\
\hline 10 Comércio varejista especializado de equip e suprimentos de informática & 102.764 & 1,02 & 23,34 \\
\hline 11 Restaurantes e similares & 93.741 & 0,93 & 24,27 \\
\hline 12 Comércio varejista de livros & 87.088 & 0,86 & 25,13 \\
\hline 13 Comércio varejista de outros produtos não especificados anteriormente & 83.986 & 0,83 & 25,96 \\
\hline 14 Comércio atacadista de medicamentos e drogas de uso humano & 81.765 & 0,81 & 26,77 \\
\hline 15 Comércio varejista de artigos de óptica & 81.507 & 0,81 & 27,58 \\
\hline 16 Lanchonetes, casas de chá, de sucos e similares & 79.565 & 0,79 & 28,37 \\
\hline 17 Comércio varejista de outros artigos de uso pessoal e doméstico & 69.865 & 0,69 & 29,06 \\
\hline 18 Comércio atacadista de materiais de construção em geral & 65.880 & 0,65 & 29,71 \\
\hline 19 Comércio por atacado de peças e acessórios novos para veículos automotores & 65.553 & 0,65 & 30,36 \\
\hline 20 Comércio a varejo de peças e acessórios novos para veículos automotores & 65.347 & 0,65 & 31,01 \\
\hline 21 Comércio atacadista de frutas, verduras, raízes, tubérculos, hortaliças & 63.318 & 0,63 & 31,64 \\
\hline 22 Comércio varejista de artigos de papelaria & 63.079 & 0,63 & 32,27 \\
\hline 23 Comércio varejista de produtos alimentícios em geral & 62.140 & 0,62 & 32,89 \\
\hline 24 Comércio atacadista de carnes bovinas e suínas e derivados & 60.296 & 0,60 & 33,49 \\
\hline 25 Comércio varejista de cosméticos, produtos de perfumaria e de higiene pessoal & 56.992 & 0,56 & 34,05 \\
\hline 26 Lojas de departamentos ou magazines & 53.223 & 0,53 & 34,58 \\
\hline 27 Comércio varejista de ferragens e ferramentas & 53.040 & 0,53 & 35,11 \\
\hline 28 Transporte rodoviário de carga, exceto produtos perigosos e mudanças & 43.550 & 0,43 & 35,54 \\
\hline 29 Comércio varejista de artigos esportivos & 41.395 & 0,41 & 35,95 \\
\hline- & \multicolumn{3}{|c|}{$\ldots$} \\
\hline Totais & 10.092 .487 & & 100 \\
\hline
\end{tabular}

Nota: Operações externas para o Distrito Federal

Figura 4.6 - Quantidade de entregas por atividade, operações externas para o DF

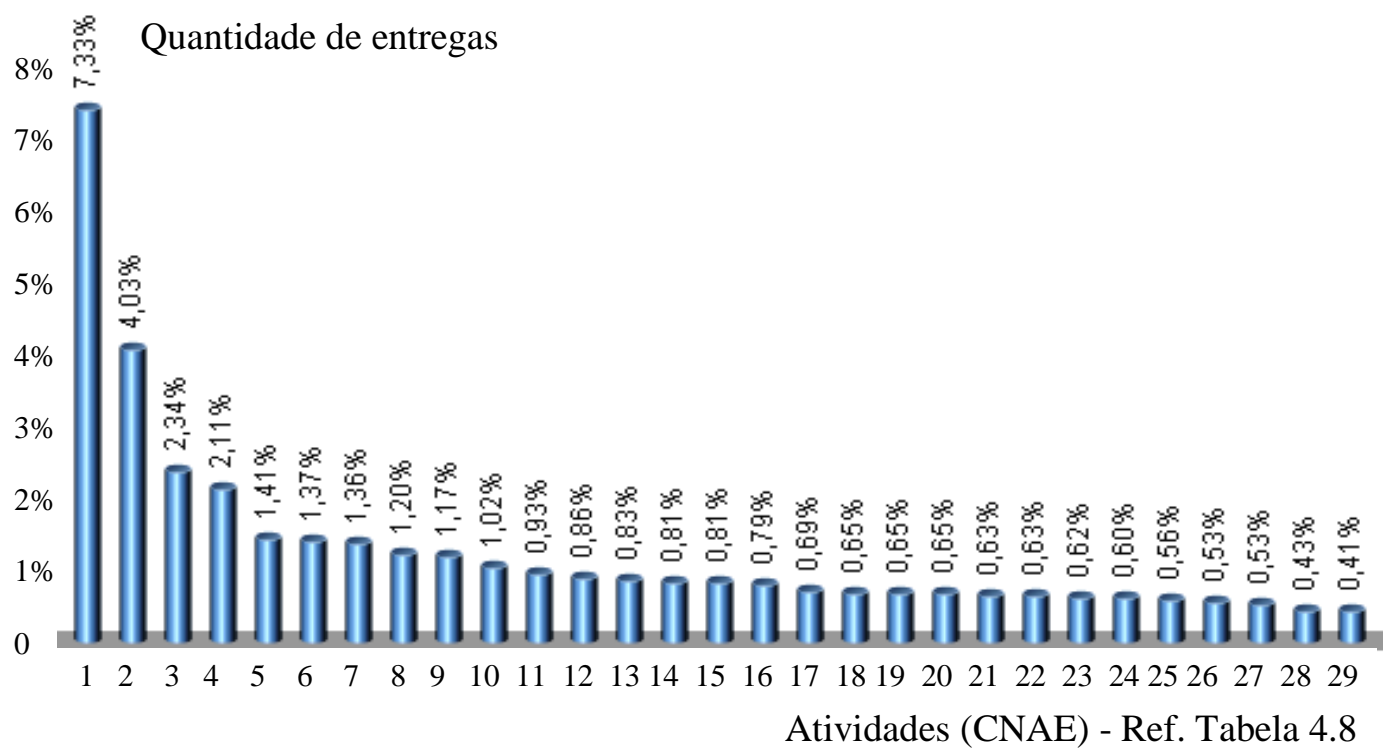


A análise das atividades destaca como geradores os segmentos de bebidas, os supermercados e hipermercados. Como atratores, novamente aparecem supermercados, seguidos de restaurantes e farmácias. Avalia-se então que o segmento de bebidas é um dos maiores geradores internos e o de supermercados opera como o principal atrator (tanto interna como externamente). Estes segmentos mostram elevadas participações nos despachos e entregas de mercadorias. Outro ponto de destaque é a alta participação na quantidade de remessas externas para pessoas físicas no Distrito Federal (39\%) provenientes de vendas por catálogo ou internet. Enfim, os fluxos identificados pelas origens (internas ou externas) com destino interno revelam as principais atividades geradoras e atratoras de NFe's. Infere-se que o maior benefício destas análises é poder traçar focos de estudos sobre em que tipo de movimento estão ocorrendo as entregas e despachos nas atividades. Assim pode-se avaliar de modo mais específico o impacto das atividades no uso do solo e no tráfego urbano.

\subsection{MAIORES GERADORES E ATRATORES DE CARGA}

A identificação dos maiores geradores e atratores de cargas é um aspecto importante para avaliar o impacto das atividades no uso do solo. $\mathrm{Na}$ análise de maiores geradores e atratores de cargas são propostos três tipos de análise: a identificação espacial dos maiores polos geradores e atratores por CEP, a avaliação da intensidade no uso do solo pelas atividades e a caracterização das mesmas como atratoras, geradoras ou intermediárias dos fluxos de cargas.

No estudo dos polos geradores e atratores de cargas o interesse está na identificação e localização geográfica dos CEP's com as maiores participações em atração e geração de cargas. Isto permite visualizar onde se pode traçar focos de ação para estudos mais aprofundados sobre o uso do solo nestes locais.

$\mathrm{Na}$ avaliação da intensidade do uso do solo são destacadas as atividades com maiores movimentos (soma de $\mathrm{NFe}^{\prime}$ emitidas e recebidas), e também que possuem alta concentração destes movimentos em poucas empresas. Acredita-se que estas informações sejam úteis para analisar quão intenso é o uso do solo pelas atividades e até empresas em seus locais de atuação. 
O estudo das atividades geradores ou atratoras envolve o cálculo de suas taxas de geração ou atração de despachos e entregas, respectivamente. O objetivo é caracterizar as atividades como atratoras, geradoras ou intermediárias dos fluxos de cargas como proposto por Jaller, Sánchez-Díaz e Holguín-Veras (2014). Estes cálculos permitem reconhecer o sentido do fluxo de cargas nestas atividades o que, por sua vez, requer planejar diferentes iniciativas que minimizem o impacto das atividades de transporte de cargas.

A identificação dos polos geradores/atratores é feita por meio da seleção da aba de CEP's do painel, os quais são únicos para empreendimentos de maior porte, tais como indústrias, atacadistas, hipermercados, shopping centers, etc. No caso de polos geradores soma-se a quantidade de NFe's origem por CEP, e posteriormente os CEP's são classificados ordem decrescente dos valores somados. Para os polos atratores soma-se a quantidade de NFe's destino (entregas) e o procedimento é o mesmo adotado para os polos geradores.

Para calcular a intensidade do uso do solo, soma-se as quantidades de NFe' emitidas e recebidas por cada atividade. Posteriormente as atividades são classificadas em ordem decrescente destas somas, denominadas movimentos, e os 500 maiores valores são selecionados. Em seguida é feita a contagem de empresas em cada segmento e atribui-se uma taxa de movimentos por empresa.

Para definir as atividades como atratoras e geradoras, soma-se para cada CNAE a quantidade de NFe's de origem e destino no DF. Após as atividades são classificadas ordem decrescente da Equação 1. Assim, atividades com alta relação O/D possuem altas taxas de geração e são denominadas geradoras, ao contrário, possuem altas taxas de atração de cargas e são consideradas atratoras.

$$
\mathrm{O} / \mathrm{D}=\frac{\text { Quantidade de NFe Origem }}{\text { Quantidade de NFe Destino }}
$$

Após as seleções mencionadas são geradas tabelas com a descrição da seleção (CNAE ou CEP), os dados de endereço, das coordenadas geográficas e, em ordem decrescente, dos valores de entregas (atração) e/ou despachos (geração), conforme a análise. Para facilitar as análises dos polos geradores e atratores são apresentados mapas a partir do provedor googlemaps. O QlikView estabelece esta conexão a partir das coordenadas geográficas presentes nas tabelas. 


\subsubsection{Polos geradores e atratores de carga}

As Tabelas 4.9 e 4.10 e as Figuras 4.7 e 4.8 apresentam respectivamente os 36 maiores polos geradores de despachos e atratores de entregas no Distrito Federal. Os dados identificam os CEP's, e as coordenadas geográficas estão vinculadas aleatoriamente aos bairros por sigilo, ou. seja, não podem identificar as empresas visto que nestes casos muitas empresas possuem CEP próprio.

Tabela 4.9 - Maiores polos geradores de despachos por CEP, Set 2013 - Ago2014

\begin{tabular}{|c|c|c|c|c|c|}
\hline CEPs & $\begin{array}{c}\text { Bairros de polos geradores } \\
\text { de depachos no Distrito } \\
\text { Federal }\end{array}$ & Longitude & $\begin{array}{l}\text { Despachos } \\
\text { geradas por } \\
\text { ano (DA) }\end{array}$ & $\begin{array}{c}\text { DA / total de } \\
\text { depachos } \\
\text { gerados no } \\
\text { DF }(\%)\end{array}$ & $\begin{array}{c}\text { Percentual } \\
\text { acumulado } \\
\text { sobre DA } \\
(\%)^{(*)} \\
\end{array}$ \\
\hline 71250210 & Cidade do automóvel & $-15.7900521-47.9793894$ & 1.253 .653 & 4,62 & 4,62 \\
\hline 72035509 & CSG 9 Taguatinga Sul & $-15.8725450-48.0337383$ & 902.669 & 3,32 & 7,94 \\
\hline 71200010 & SIA Trecho 1 & $-15.8135517-47.9667683$ & 596.112 & 2,20 & 10,14 \\
\hline 71200020 & SIA Trecho 2 & $-15.8070483-47.9522567$ & 559.708 & 2,06 & 12,20 \\
\hline 71200030 & SIA Trecho 3 & $-15.8048183-47.9519150$ & 492.614 & 1,81 & 14,01 \\
\hline 72020016 & EQSD 1/13 Taguatinga Sul & $-15.8445409-48.0498146$ & 462.771 & 1,70 & 15,72 \\
\hline 71225500 & STRC Trecho 1 & $-15.7935050-47.9786467$ & 363.994 & 1,34 & 17,06 \\
\hline 71208900 & CEASA & $-15.7980267-47.9496817$ & .784 & 1,25 & 18,31 \\
\hline 70632200 & SAAN Qd 2 & $-15.7637837-47.935426$ & 323.128 & 1,19 & 19,50 \\
\hline 72501100 & Qd AC 101 Santa Maria & $83-48.0418783$ & & 1,11 & 20,61 \\
\hline 71215100 & SGCV Brasília & $-15.8285950-47.9563550$ & 281.250 & 1,04 & 21,65 \\
\hline 70770100 & STN Asa Norte & $-15.7537567-47.8988267$ & 710 & 1,03 & 22,68 \\
\hline 72501970 & Qd AC 101 Santa Maria & $-16.043556-48.0360557$ & 274.474 & 1,01 & 23,69 \\
\hline 72549550 & Polo JK & $-16.0403319-47.9724634$ & & 1,01 & 24,70 \\
\hline 71200970 & Sia Trecho 3 & $-15.803944 \quad-47.957603$ & 371 & 0,89 & 25,59 \\
\hline 70632500 & SAAN Qd 5 & $-15.7582643-47.9339593$ & & 0,85 & 26,44 \\
\hline 72035510 & CSG 10 Taguating & $17-48.0377767$ & 88 & 0,69 & 27,12 \\
\hline 72549555 & Polo JK & $21569-47.9736596$ & .256 & 0,67 & 27,79 \\
\hline 70620100 & SAAN quadra 2 & $37-47.9$ & 300 & 0,66 & 28,45 \\
\hline 72427010 & Ponte Alta Gama & $1896-48.0592455$ & 175.074 & 0,64 & 29,09 \\
\hline 72135200 & Quadra Industrial Tag & $83-48.0787417$ & 502 & 0,62 & 29,71 \\
\hline 71225000 & Setor de Inflamáveis B & $00-47.9715267$ & 729 & 0,60 & 30,30 \\
\hline 71200040 & SIA Trecho 4 & -15.802 & 534 & 0,59 & 30,90 \\
\hline 71988180 & ADE Brasília & $17-48.0$ & & 0,59 & 31,48 \\
\hline 72445010 & Setor Industrial Gama & $7-48$ & & 0,56 & 32,05 \\
\hline 70077900 & SDS, Asa Sul & $-15.7916550-47.8838117$ & 150.958 & 0,56 & 32,60 \\
\hline 72405900 & Setor Leste Industrial Gama & $-16.013644-48.0612314$ & 143.744 & 0,53 & 33,13 \\
\hline 71990720 & ADE Brasília & $2100-48.0021200$ & 139.481 & 0,51 & 33,64 \\
\hline 72110800 & Chácaras Vicente Pires & $-15.7984883-48.0461233$ & 137.176 & 0,51 & 34,15 \\
\hline 73151010 & Fercal & $97133-47.8689633$ & 127.010 & 0,47 & 34,62 \\
\hline 73310200 & Setor de Hotéis I & $-15.6190867-47.6511350$ & & 0,20 & 34,81 \\
\hline 73310970 & Setor de Hotéis Planaltina & $-15.6179733-47.6871683$ & 10.755 & 0,04 & 34,85 \\
\hline 73310660 & Setor Norte Planaltina & $-15.6115617-47.6549667$ & 3.449 & 0,01 & 34,87 \\
\hline 73350308 & Setor Leste Planaltina & $-15.6205467-47.6459033$ & 3.405 & 0,01 & 34,88 \\
\hline 73330142 & Setor Tradicional Planaltina & $-15.6209167-47.6625317$ & 2.318 & 0,01 & 34,89 \\
\hline 73340180 & Setor de Oficinas Planaltina & $-15.6068300-47.6522983$ & 2.303 & 0,01 & 34,90 \\
\hline 1 otal & & & 9.474 .106 & & 34,90 \\
\hline
\end{tabular}

Nota: (*) Total de despachos gerados no DF para operações internas (27.149.564), Set 2013-Ago2014 
$\mathrm{Na}$ análise dos polos geradores verifica-se um número pequeno de distribuidoras de bebidas com participação significativa nas entregas do segmento. No caso de polos atratores, análises detalhadas identificam shopping centers e redes de hipermercados como públicos-alvo. Estes estabelecimentos são facilmente identificáveis por meio do objeto razão social do painel.

Tabela 4.10 - Maiores atratores de entregas por CEP, Set 2013 - Ago 2014

\begin{tabular}{|c|c|c|c|c|c|c|}
\hline CEPs & $\begin{array}{l}\text { Bairros de polos atratores de } \\
\text { entregas no Distrito Federal }\end{array}$ & Latitude & Longitude & $\begin{array}{c}\text { Entregas } \\
\text { por ano } \\
(\text { EA) }\end{array}$ & $\begin{array}{c}\text { EA / total } \\
\text { entregas no } \\
\text { DF }(\%)\end{array}$ & $\begin{array}{c}\text { Percentual } \\
\text { acumulado } \\
\text { sobre EA } \\
(\%)^{(*)}\end{array}$ \\
\hline 72020016 & EQSD 1/13 Taguatinga Sul & -15.8445409 & -48.0498146 & 307.202 & 0,82 & 0,82 \\
\hline 71200010 & SIA Trecho 1 & -15.8135517 & -47.9667683 & 303.487 & 0,81 & 1,64 \\
\hline 70077900 & SDS, Asa Sul & -15.7916550 & -47.8838117 & 238.329 & 0,64 & 2,28 \\
\hline 71200030 & SIA Trecho 3 & -15.8048183 & -47.9519150 & 229.899 & 0,62 & 2,90 \\
\hline 72007750 & Chácaras Vicente Pires & -15.7984883 & -48.0461233 & 200.960 & 0,54 & 3,44 \\
\hline 71219900 & SMAS Brasília & -15.8344267 & -47.9518318 & 197.741 & 0,53 & 3,97 \\
\hline 71215100 & SGCV Brasília & -15.8285950 & -47.9563550 & 193.093 & 0,52 & 4,49 \\
\hline 70300500 & Setor Comercial Sul, Asa Sul & -15.8286467 & -48.0388983 & 166.285 & 0,45 & 4,93 \\
\hline 71200020 & SIA Trecho 2 & -15.8070483 & -47.9522567 & 164.830 & 0,44 & 5,38 \\
\hline 72030100 & Qs 03, Rua 420, Águas Claras & -15.8464915 & -48.0429201 & 164.829 & 0,44 & 5,82 \\
\hline 71225500 & STRC Trecho 1 & -15.7935050 & -47.9786467 & 160.087 & 0,43 & 6,25 \\
\hline 71503504 & SHIN, Lago Norte & -15.7213713 & -47.8857148 & 155.086 & 0,42 & 6,66 \\
\hline 70632200 & SAAN Qd 2 & -15.7637837 & -47.935426 & 149.738 & 0,40 & 7,07 \\
\hline 71250210 & Cidade do automóvel & -15.7900521 & -47.9793894 & 142.328 & 0,38 & 7,45 \\
\hline 71953100 & Qs 3 Epct, Águas Claras & -15.8463385 & -48.0429726 & 127.599 & 0,34 & 7,79 \\
\hline 70770100 & STN Asa Norte & -15.7537567 & -47.8988267 & 127.532 & 0,34 & 8,13 \\
\hline 72215010 & Qnm 01, Ceilândia & -15.8198268 & -48.1071562 & 124.314 & 0,33 & 8,47 \\
\hline 71208900 & CEASA & -15.7980267 & -47.9496817 & 121.768 & 0,33 & 8,79 \\
\hline 70310500 & Galeria dos Estados, Asa Sul & -15.798657 & -47.88552 & 116.360 & 0,31 & 9,11 \\
\hline 73045620 & BR 020, St Industria Sobradinho & -15.6591600 & -47.7992050 & 109.363 & 0,29 & 9,40 \\
\hline 73020414 & Setor Econômico de Sobradinho & -15.6651999 & -47.7941317 & 108.279 & 0,29 & 9,69 \\
\hline 72310300 & QN 502, Samambaia Sul & -15.8835083 & -48.0818200 & 107.453 & 0,29 & 9,98 \\
\hline 70770100 & STN, Asa Norte & -15.7353878 & -47.9051285 & 104.854 & 0,28 & 10,26 \\
\hline 73370100 & Condomínio Arapoanga & -15.6741900 & -47.6512033 & 95.849 & 0,26 & 10,52 \\
\hline 70632100 & SAAN, Qd 1 & -15.7640952 & -47.937272 & 95.556 & 0,26 & 10,77 \\
\hline 70715900 & Brasília Shop & -15.78654 & -47.8895665 & 93.804 & 0,25 & 11,03 \\
\hline 72549550 & Polo JK & -16.0403319 & -47.9724634 & 92.606 & 0,25 & 11,28 \\
\hline 71218900 & Polo Industrial, Guará & -15.830528 & -47.955317 & 90.098 & 0,24 & 11,52 \\
\hline 71936250 & Av Araucárias, Águas Claras & -15.8408911 & -48.0242055 & 88.116 & 0,24 & 11,75 \\
\hline 71215300 & SMAS Brasília & -15.8344267 & -47.9518318 & 87.504 & 0,23 & 11,99 \\
\hline 70390700 & SHIGS, Asa Sul & -15.8286800 & -47.9293150 & 87.448 & 0,23 & 12,22 \\
\hline 71200040 & SIA Trecho 4 & -15.8027850 & -47.9513217 & 83.205 & 0,22 & 12,45 \\
\hline 73010700 & Quadra Central Sobradinho & -15.650787 & -47.7943545 & 77.845 & 0,21 & 12,66 \\
\hline 71225000 & Setor de Inflamáveis Brasília & -15.8037700 & -47.9715267 & 74.251 & 0,20 & 12,86 \\
\hline 71608900 & Aeroporto Intern Brasilia & -15.8743533 & -47.9223700 & 72.792 & 0,20 & 13,05 \\
\hline 70200002 & SCES Trecho 2 & -15.8161503 & -47.8492375 & 71.626 & 0,19 & 13,24 \\
\hline Total & \multicolumn{2}{|l|}{36} & & 4.932 .116 & \multicolumn{2}{|c|}{13,24} \\
\hline
\end{tabular}

Nota: (*) Total de entregas atraídas ao DF de operações externas e internas (37.242.051), Set 2013-Ago2014 
Figura 4.7 - Maiores geradores de despachos por CEP, origem interna

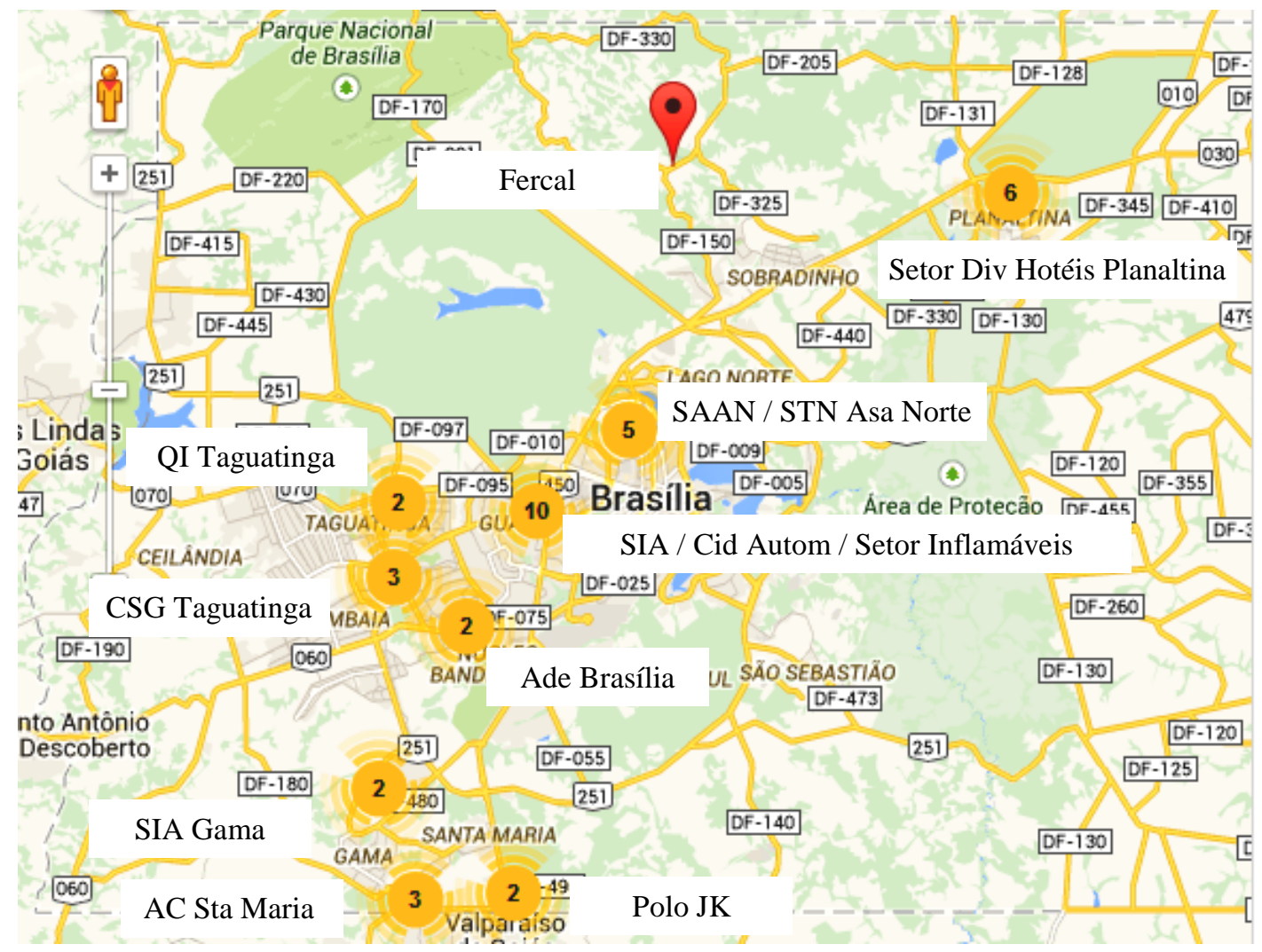

Figura 4.8 - Maiores polos atratores de entregas por CEP, destino interno

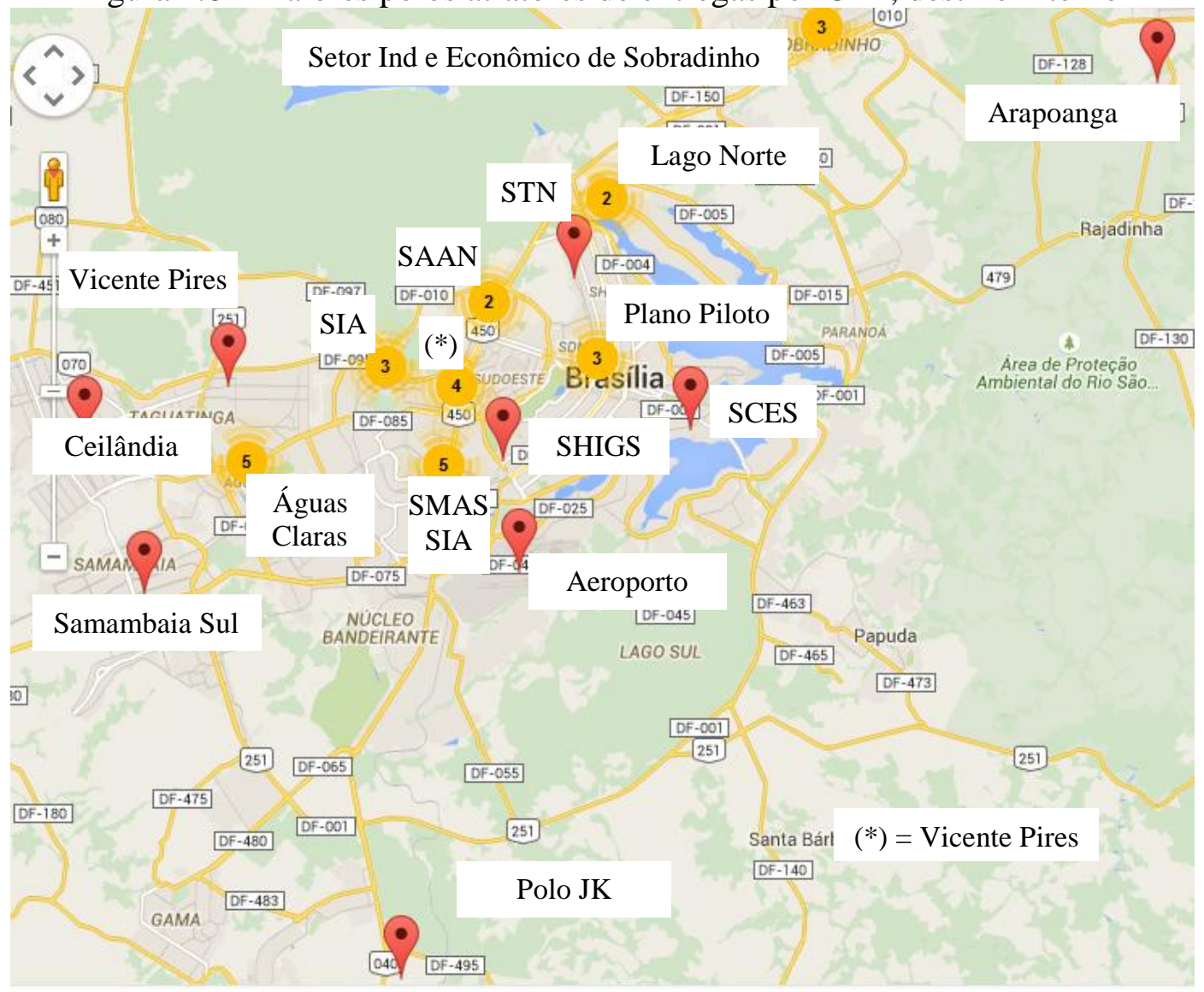


O aspecto interessante do estudo de polos geradores e atratores é a viabilização da visão geral dos mesmos na abrangência do Distrito Federal, e de seus fluxos de entregas e despachos. Trata-se de uma informação populacional para análise do uso do solo, sem a necessidade de se efetuar entrevistas ou outras pesquisas para obter tais informações. Assim, identificar polos geradores e atratores do fluxo de cargas torna-se importante para que gestores e pesquisadores possam definir focos de ação em um processo de planejamento de transportes. Permitem, portanto, abordagens pontuais para o estudo de diferentes projetos.

\subsubsection{Uso do solo}

Na Tabela 4.11 são selecionadas as empresas localizadas no Distrito Federal com maior atração e geração de NFe's em seus segmentos de atividades. Buscando refletir o impacto destes fluxos de mercadorias em seus locais de atuação, são somados os movimentos que estas empresas geram (origem interna) e atraem (de origens externas e internas).

Tabela 4.11 - Atividades com maior movimento de cargas, Set 2013 - Ago 2014

\begin{tabular}{lrrrr}
\hline \multicolumn{1}{c}{ Descrição da atividade econômica } & $\begin{array}{c}\text { Quantidade } \\
\text { de empresas }\end{array}$ & Total NFe & $\begin{array}{c}\text { Total NFe } \\
\text { por empresa }\end{array}$ & O/D \\
\hline Comércio atacadista de cerveja, chope e refrigerante & 5 & 1.910 .209 & 382.042 & 17,0 \\
Fabricação de refrigerantes & 3 & 1.030 .519 & 343.506 & 17,1 \\
Comércio varejista de jornais e revistas & 1 & 139.660 & 139.660 & 1,3 \\
Comércio atacadista de cereais e leguminosas beneficiados, farinhas & 1 & 128.811 & 128.811 & 5,4 \\
Comércio atacadista de pães, bolos, biscoitos e similares & 3 & 365.517 & 121.839 & 3,1 \\
Fabricação de cimento & 2 & 242.101 & 121.051 & 3,1 \\
Comércio varejista de mercad. em geral, com predom. prod. alimentícios & 14 & 1.665 .545 & 118.968 & 2,2 \\
Comércio varejista de outros artigos de uso pessoal e doméstico & 3 & 330.278 & 110.093 & 3,9 \\
Comércio atacadista de aves abatidas e derivados & 6 & 530.331 & 88.389 & 22,4 \\
Fabricação de cervejas e chopes & 2 & 162.678 & 81.339 & 7,6 \\
Comércio atacadista de carnes bovinas e suínas e derivados & 7 & 549.152 & 78.450 & 5,5 \\
Comércio atacadista de bebidas não especificadas anteriormente & 5 & 378.226 & 75.645 & 11,5 \\
Comércio atacadista de cigarros, cigarrilhas e charutos & 3 & 213.194 & 71.065 & 6,8 \\
Comércio atacadista de medicamentos e drogas de uso humano & 12 & 832.829 & 69.402 & 11,0 \\
Comércio varejista de materiais hidráulicos & 2 & 121.763 & 60.882 & 2,4 \\
\hline
\end{tabular}

Pode-se observar que o segmento atacadista e de fabricação de bebidas se destaca consideravelmente, sendo no caso eminentemente gerador (relação O/D alta). Com menor expressão, mas também com um volume significativo por empresa, mesmo tendo uma 
maior quantidade de empresas, destaca-se o comércio varejista de mercadorias em geral com predominância de produtos alimentícios, os supermercados.

\subsubsection{Atividades geradoras e atratoras de cargas}

Com o objetivo de comparar os resultados desse trabalho com as referências fornecidas por Jaller, Sánchez-Díaz e Holguín-Veras (2014), são geradas as Tabelas 4.12 e 4.13 que apresentam as atividades com maior $\operatorname{taxa}^{23}$ de geração ou atração de cargas para os segmentos atacadista e varejista ${ }^{24}$, respectivamente.

Portanto, da Tabela 4.12 verifica-se que atacadistas são eminentemente geradores, com destaque para aves abatidas e cosméticos com participação na emissão de NFes de 4,39\% e $5,8 \%$, respectivamente. Porém, comércio atacadista de bebidas e de medicamentos são geradores, mas também atraem um número importante de cargas. Observa-se também que atacadistas não participam tanto dos valores totais de NFe emitidas quanto os varejistas.

Ou seja, da Tabela 4.13 verifica-se que o segmento varejista é mais atrator (relações O/D menores), sendo destaques vestuário, farmácias e bebidas e supermercados, que participam no segmento varejista como destino em $33,78 \%$ e ainda gera $16,49 \%$ das remessas de cargas. Para uma comparação na cidade Nova Iorque a relação é de que atacadistas geram 4 vezes mais viagens do que varejistas (JALLER; SÁNCHEZ-DÍAZ; HOLGUÍN-VERAS, 2014). No Distrito Federal a relação é de atacadistas gerando 14.858.863 NFes/ano contra 11.514.326 dos varejistas, apenas $30 \%$ a mais em transações.

De qualquer modo, os resultados mostram coerência com as avaliações de Jaller, SánchezDíaz e Holguín-Veras (2014). Enquanto atacadistas apresentam uma taxa O/D de 6,55, ou seja, são mais geradores, varejistas tem 0,77 , são eminentemente atratores. Estas características fornecem os dados de quais atividades e em que sentido de fluxo de cargas pode-se concentrar atenção durante o processo de planejamento, e complementam as análises de geração, atração e de polos geradores realizadas anteriormente.

\footnotetext{
${ }^{23}$ São geradas duas tabelas no QlikView, de geração e atração para posterior cálculo externo

${ }^{24}$ Os termos "atacadista" e "varejista" são selecionados dos campos CNAE no QlikView
} 
Tabela 4.12 - Geradores e atratores no comércio atacadista, Set 2013 - Ago 2014

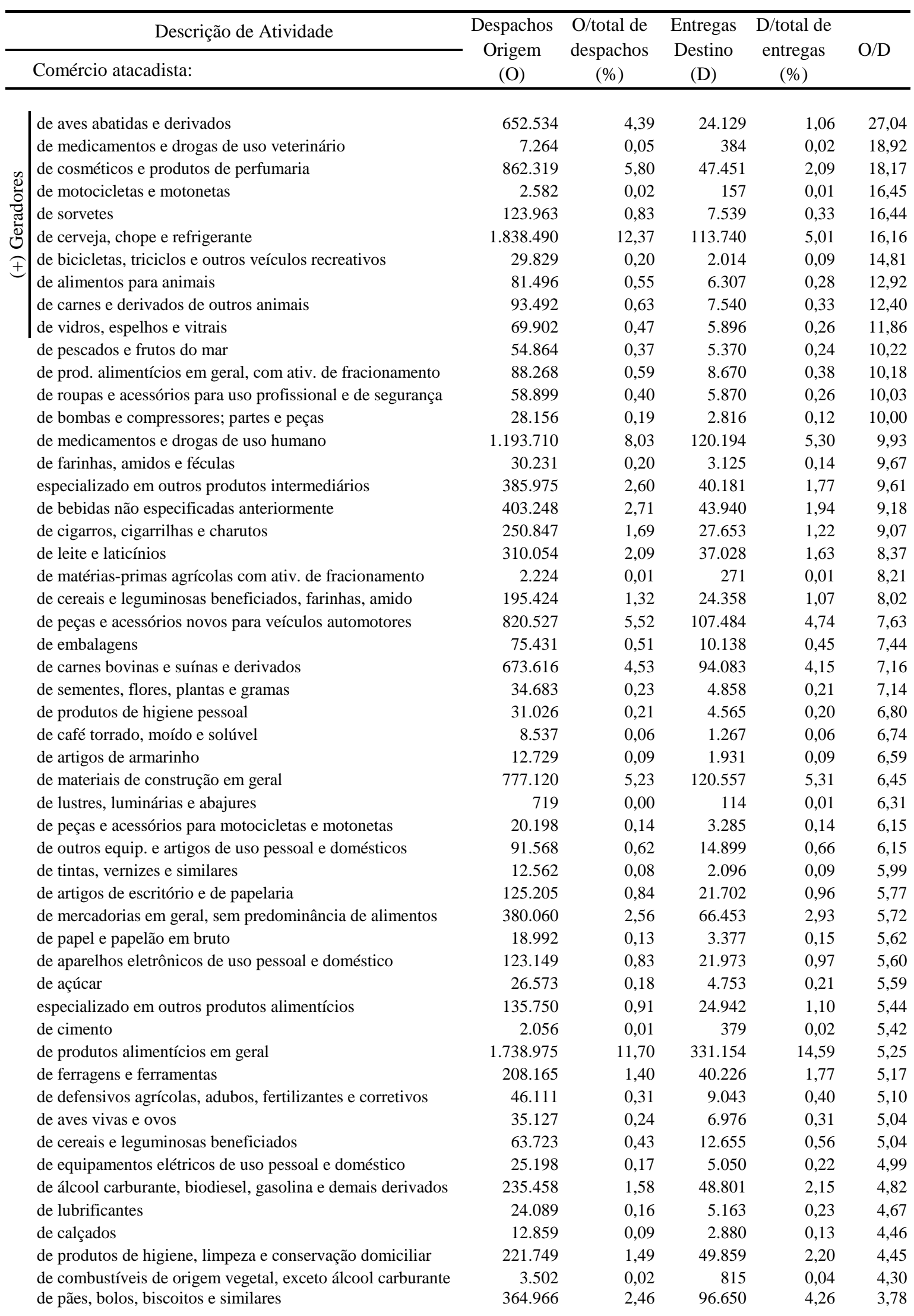

(continua) 
Tabela 4.12 - Geradores e atratores no comércio atacadista, Set 2013 - Ago 2014

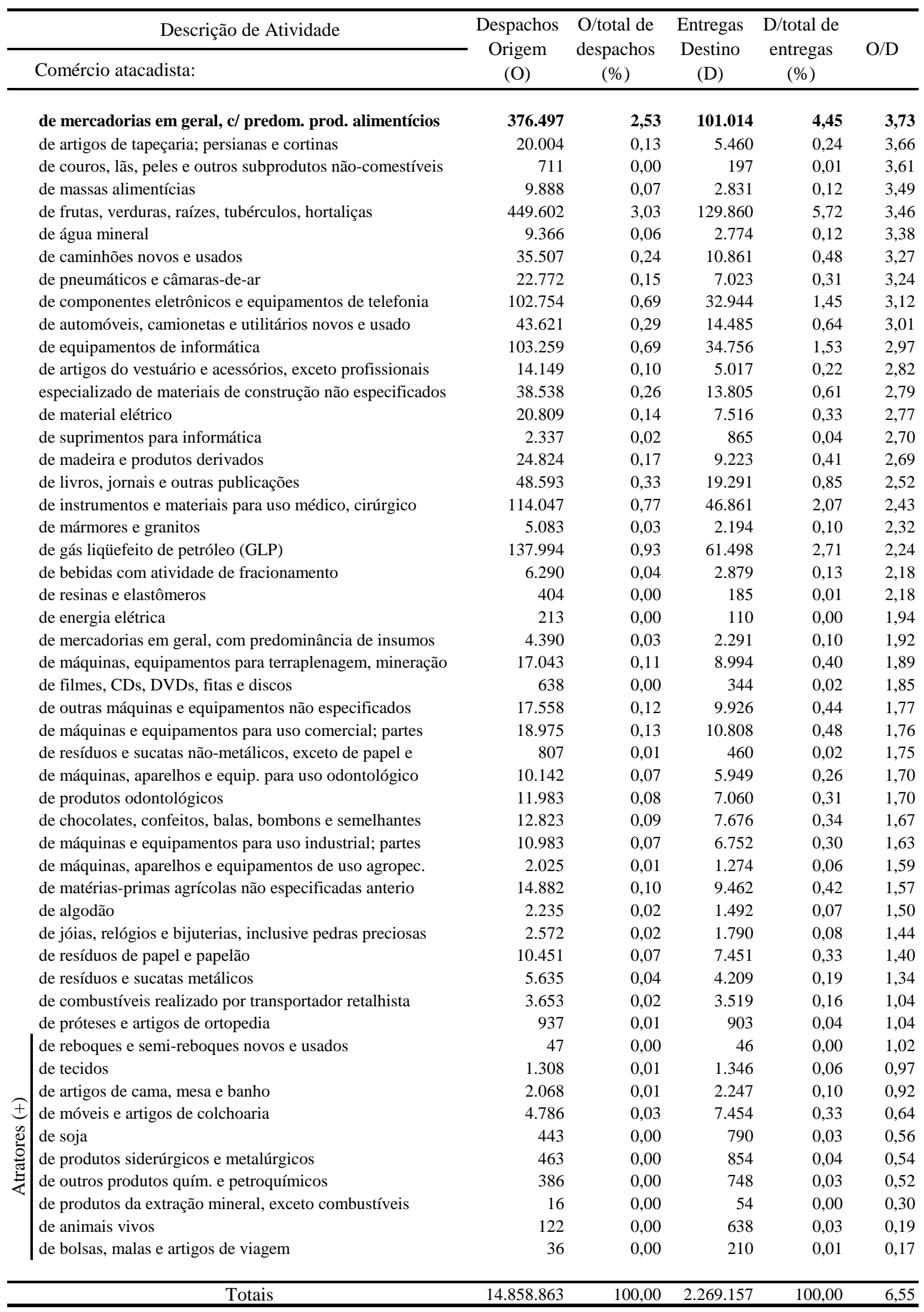

(conclusão) 
Tabela 4.13 - Geradores e atratores comércio varejista, Set 2013 - Ago 2014

\begin{tabular}{|c|c|c|c|c|c|c|}
\hline \multicolumn{2}{|r|}{ Descrição de Atividade } & \multirow{2}{*}{$\begin{array}{c}\text { Despachos } \\
\text { Origem } \\
\text { (O) }\end{array}$} & \multirow{2}{*}{$\begin{array}{c}\text { O/total de } \\
\text { despachos } \\
(\%)\end{array}$} & \multirow{2}{*}{$\begin{array}{l}\text { Entregas } \\
\text { Destino } \\
\text { (D) }\end{array}$} & \multirow{2}{*}{$\begin{array}{c}\mathrm{D} / \text { total de } \\
\text { entregas } \\
(\%)\end{array}$} & \multirow{2}{*}{$\mathrm{O} / \mathrm{D}$} \\
\hline & Comércio varejista: & & & & & \\
\hline \multirow{41}{*}{ 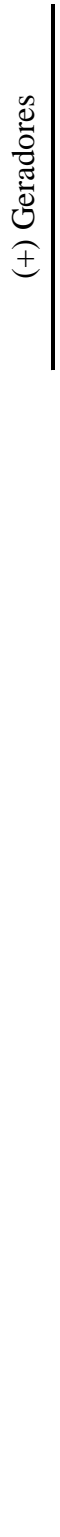 } & de madeira e artefatos & 100.908 & 0,88 & 28.350 & 0,19 & 3,56 \\
\hline & de motocicletas e motonetas novas & 125.247 & 1,09 & 37.773 & 0,25 & 3,32 \\
\hline & especializado de eletrodomésticos e equip. de & 887.790 & 7,71 & 288.574 & 1,94 & 3,08 \\
\hline & de automóveis, camionetas e utilitários novos & 1.352 .833 & 11,75 & 495.105 & 3,32 & 2,73 \\
\hline & de embarcações e outros veículos recreativos; & 21.381 & 0,19 & 9.202 & 0,06 & 2,32 \\
\hline & de artigos fotográficos e para filmagem & 193.346 & 1,68 & 85.073 & 0,57 & 2,27 \\
\hline & de ferragens e ferramentas & 337.888 & 2,93 & 155.344 & 1,04 & 2,18 \\
\hline & especializado de equip. e suprimentos de & 571.915 & 4,97 & 274.204 & $\mathbf{1 , 8 4}$ & 2,09 \\
\hline & de materiais hidráulicos & 100.593 & 0,87 & 49.002 & 0,33 & 2,05 \\
\hline & de outros artigos de uso pessoal e doméstico & 332.051 & 2,88 & 167.844 & 1,13 & 1,98 \\
\hline & de tintas e materiais para pintura & 130.023 & 1,13 & 67.448 & 0,45 & 1,93 \\
\hline & de medicamentos veterinários & 41.599 & 0,36 & 22.199 & 0,15 & 1,87 \\
\hline & de outros produtos não especificados & 333.298 & 2,89 & 179.409 & 1,20 & 1,86 \\
\hline & de equipamentos para escritório & 15.196 & 0,13 & 8.681 & 0,06 & 1,75 \\
\hline & de pneumáticos e câmaras-de-ar & 90.191 & 0,78 & 52.875 & 0,35 & 1,71 \\
\hline & de livros & 311.985 & 2,71 & 183.943 & 1,23 & 1,70 \\
\hline & de artigos médicos e ortopédicos & 79.480 & 0,69 & 46.982 & 0,32 & 1,69 \\
\hline & de produtos saneantes domissanitários & 69.750 & 0,61 & 43.358 & 0,29 & 1,61 \\
\hline & de cal, areia, pedra britada, tijolos e telhas & 27.740 & 0,24 & 18.149 & 0,12 & 1,53 \\
\hline & especializado de equipamentos de telefonia & 104.598 & 0,91 & 72.525 & 0,49 & 1,44 \\
\hline & de materiais de construção não especificados & 209.787 & 1,82 & 145.549 & 0,98 & 1,44 \\
\hline & de materiais de construção em geral & 1.027 .693 & 8,93 & 746.880 & 5,01 & 1,38 \\
\hline & de necas e acescórios novos nara veículos & & & & & 058 \\
\hline & $\begin{array}{l}\text { de peças e acessorios novos para } \\
\text { de automóveis camionetas e util }\end{array}$ & & $\begin{array}{l}4,28 \\
023\end{array}$ & & & 0,58 \\
\hline & de outros artigos usados & $\begin{array}{c}9 \\
4\end{array}$ & 0 & 10 & 1 & 0,025 \\
\hline & de artigos de cama, mesa e banho & 32.355 & $\begin{array}{l}0,02 \\
0,28\end{array}$ & 62.889 & $\begin{array}{l}0,02 \\
0,42\end{array}$ & 0,53 \\
\hline & de bicicletas e triciclos; peças e acessórios & 7.332 & 0,06 & 14.818 & 0,10 & 0,49 \\
\hline & de hortifrutigranjeiros & 85.536 & 0,74 & 184.138 & 1,23 & 0,46 \\
\hline & de peças e acessórios para motocicletas e & 16.135 & 0,14 & 37.067 & 0,25 & 0,44 \\
\hline & de artigos de armarinho & 20.129 & 0,17 & 47.946 & 0,32 & 0,42 \\
\hline & de artigos de tapeçaria, cortinas e persianas & 17.928 & 0,16 & 43.135 & 0,29 & 0,42 \\
\hline & de artigos de caça, pesca e camping & 4.662 & 0,04 & 11.592 & 0,08 & 0,40 \\
\hline & de mercadorias em geral, com predominância & 1.898 .711 & 16,49 & 5.036 .388 & 33,78 & 0,38 \\
\hline & de produtos farmacêuticos, com manipulação & 2.739 & 0,02 & 7.356 & 0,05 & 0,37 \\
\hline & de discos, CDs, DVDs e fitas & 1.767 & 0,02 & 4.977 & 0,03 & 0,36 \\
\hline & de bebidas & 162.383 & 1,41 & 469.725 & 3,15 & 0,35 \\
\hline & de plantas e flores naturais & 9.005 & 0,08 & 27.560 & 0,18 & 0,33 \\
\hline & de doces, balas, bombons e semelhantes & 20.642 & 0,18 & 69.812 & 0,47 & 0,30 \\
\hline & de artigos de colchoaria & 9.877 & 0,09 & 35.376 & 0,24 & 0,28 \\
\hline & de produtos farmacêuticos, sem manipulação & 374.522 & 3,25 & 1.387 .802 & $\mathbf{9 , 3 1}$ & 0,27 \\
\hline & de objetos de arte & 471 & 0,00 & 1.924 & 0,01 & 0,24 \\
\hline \multirow{14}{*}{ 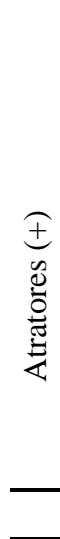 } & de artigos de viagem & 3.842 & 0,03 & 15.833 & 0,11 & 0,24 \\
\hline & de laticínios e frios & 10.008 & 0,09 & 44.256 & 0,30 & 0,23 \\
\hline & de pecas e acessórios usados para veículos & 4.625 & 0,04 & 20.722 & 0,14 & 0,22 \\
\hline & de suvenires, bijuterias e artesanatos & 9.171 & 0,08 & 43.220 & 0,29 & 0,21 \\
\hline & de artigos do vestuário e acessórios & 164.108 & 1,43 & 775.390 & 5,20 & 0,21 \\
\hline & de brinquedos e artigos recreativos & 11.328 & 0,10 & 68.325 & 0,46 & 0,17 \\
\hline & de carnes - açougues & 30.340 & 0,26 & 196.533 & 1,32 & 0,15 \\
\hline & de calçados & 25.950 & 0,23 & 246.172 & 1,65 & 0,11 \\
\hline & de artigos de óptica & 9.454 & 0,08 & 111.691 & 0,75 & 0,08 \\
\hline & de motocicletas e motonetas usadas & 10 & 0,00 & 189 & 0,00 & 0,05 \\
\hline & de mercadorias em lojas de conveniência & 817 & 0,01 & 18.586 & 0,12 & 0,04 \\
\hline & de produtos farmacêuticos homeopáticos & 306 & 0,00 & 9.584 & 0,06 & 0,03 \\
\hline & de antigüidades & 60 & 0,00 & 2.030 & 0,01 & 0,03 \\
\hline & Totais & 11.514 .326 & 100,00 & 14.911 .066 & 100,00 & 0,77 \\
\hline
\end{tabular}


A análise dos maiores geradores e atratores de cargas por esta metodologia identifica quem são e onde estão estes agentes, e demonstra em que sentido e com qual intensidade os fluxos de cargas ocorrem em seus locais de atuação no Distrito Federal. Mais, estas informações estão vinculadas no banco de dados aos produtos comercializados, aos agentes participantes (fornecedores e compradores) e aos períodos de emissão das NFe's. São informações importantes para gestores e pesquisadores definirem focos de ação, analisarem e planejarem políticas de uso do solo.

\subsection{FATORES DE INFLUÊNCIA EM TUC}

Os dados obtidos dos DFe permitem também análises de alguns fatores de influência no TUC que necessitam ser conhecidos de modo a compreender como estes afetam os movimentos de mercadorias no espaço urbano. Entre as análises sugeridas por Novaes (2001) e Ortúzar e Willumsen (2011), e para demonstrar o potencial de análises desta metodologia, são selecionadas:

a) as variações sazonais do fluxo de cargas pelo seu impacto na demanda por transporte de cargas que, por sua vez, permitem identificar picos nos fluxos de cargas e, desta forma, onde há gargalos no uso da infraestrutura de transporte;

b) a localização espacial com as características econômicas dos agentes envolvidos na produção e recebimento de cargas que influenciam na definição dos modos e estratégias de distribuição de mercadorias (ORTÚZAR; WILLUMSEN, 2011);

c) e a análise de frequência de entregas de mercadorias, que segundo Novaes (2001), tende a influenciar na produtividade da frota e, diga-se, permite compreender parte das decisões logísticas sobre políticas de atendimento pelas empresas e, principalmente, em que intensidade estas afetam a ocupação dos espaços urbanos.

Para efetuar estas análises de sazonalidades são geradas tabelas pelo QlikView que contam a quantidade de entregas e despachos de mercadorias, e do seu valor por diferentes períodos, tais como por dia da semana, por mês, etc. Caso exista interesse, é possível segmentar estas análises por produto, atividade econômica, por empresa, CEP, etc. 
A localização espacial dos agentes é realizada pela associação das coordenadas geográficas ao googlemaps. A caracterização econômica dos agentes é feita pela seleção de sua atividade econômica (CNAE) e tipo de registro, se pessoa física pelo CPF, ou jurídica, pelo CNPJ. A vinculação das quantidades de mercadorias (por entrega, valor, peso) é realizadas pela contagem, soma dos valores e pesos das NFe's destinadas ou emitidas pelo agente.

A frequência de entregas é calculada com base na quantidade de entregas de mercadorias por cada destino identificado pelo CNPJ ou CPF, dividida pela quantidade de semanas no período em análise (SANTOS, 2008), o que resulta na Equação 2. A análise de frequência de entregas também pode ser segmentada por empresa, produtos, atividade econômica, CEP, etc., bastando selecionar estes recursos no painel de análise.

$$
\text { Frequência de entrega por semana }{ }^{25} \text { calculada }=\frac{\text { Qtd NFes } / \text { Destinos }}{\text { quantidade de semanas }}
$$

\subsubsection{Sazonalidades}

Para ilustrar a análise de sazonalidade, são produzidos três gráficos com diferentes períodos: anual, com o cálculo de quantidade e valor das NFe's por mês, e mensal e semanal com as quantidades de NFe's transacionadas no Distrito Federal por dia. Os dois primeiros gráficos são gerados com os dados totais de $\mathrm{NFe}$, e o último é gerado para o segmento de bebidas e apenas para as NFe's emitidas. São selecionadas apenas operações internas.

A Figura 4.9 mostra a sazonalidade mensal da quantidade de NFe's transacionadas no DF no período de janeiro de 2010 a dezembro de 2014. Verifica-se que os períodos de maior quantidade de transações são outubro e dezembro, sendo que em agosto há um pico no valor comercializado. Infere-se que este comportamento se deve ao abastecimento das empresas para o período natalino. Tratam-se, portanto, de informações úteis para direcionar as análises para os períodos de maior demanda e avaliar gargalos na infraestrutura disponível para o transporte de cargas.

\footnotetext{
2552 é a quantidade de semanas de setembro de 2013 a agosto de 2014, base da análise.
} 
Figura 4.9 - Sazonalidade mensal das NFe's transacionadas, Jan 2010-Dez2014

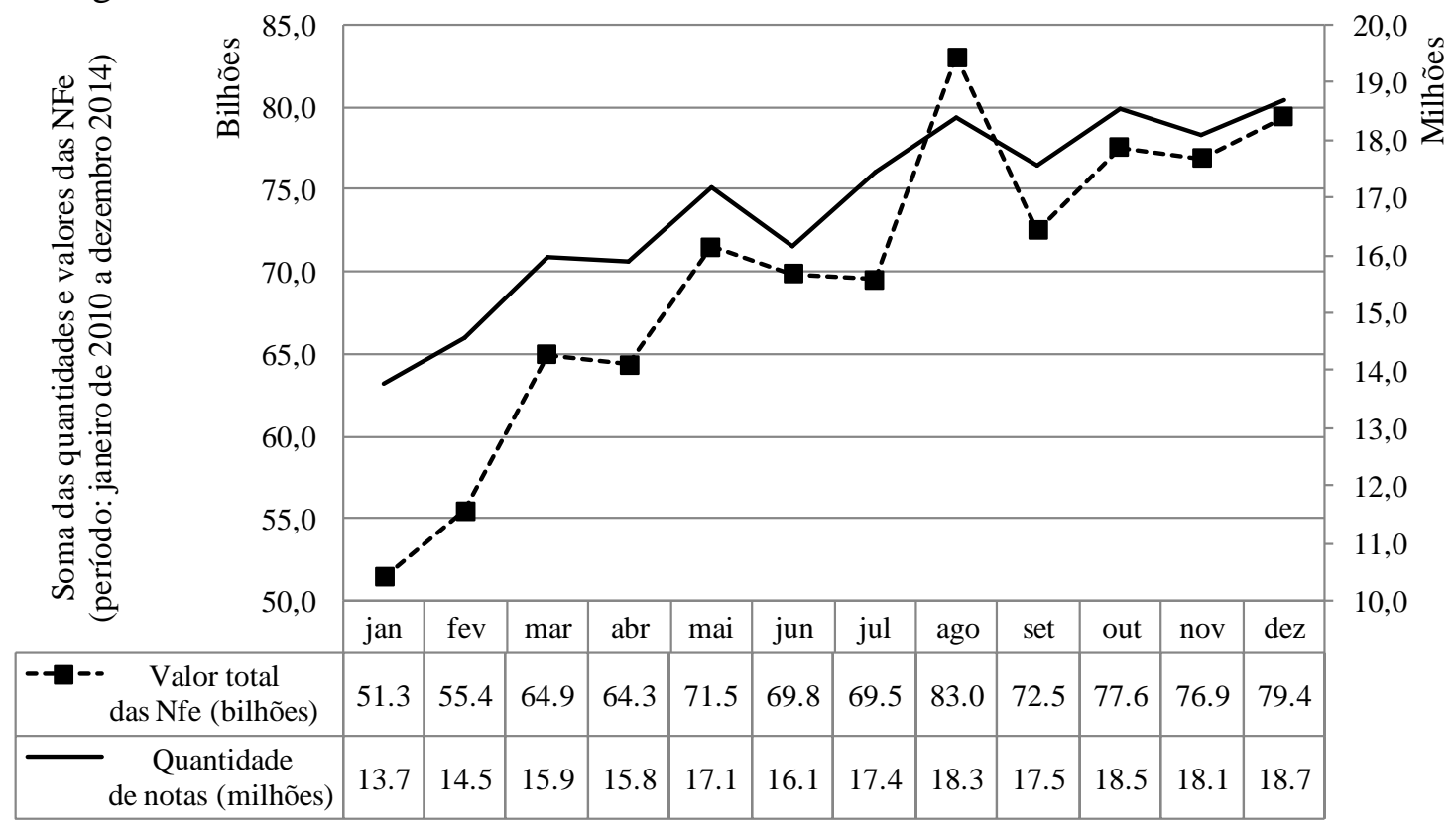

Valores das NFe's atualizados pelo IGPM-FGV

Também é possível destacar a sazonalidade no mês ${ }^{26}$ (Figura 4.10). Uma análise deste tipo pode ser realizada por segmento de atividade ou mercadoria de interesse de modo a capturar comportamentos específicos e, por conseguinte, subsidiar análises mais aprofundadas em termos de planejamento do transporte de cargas. Neste sentido, a Figura 4.11 mostra a análise da sazonalidade diária na semana para bebidas $(\mathrm{NCM}=22)$.

Figura 4.10 - Sazonalidade diária no período mensal por quantidade de NFe

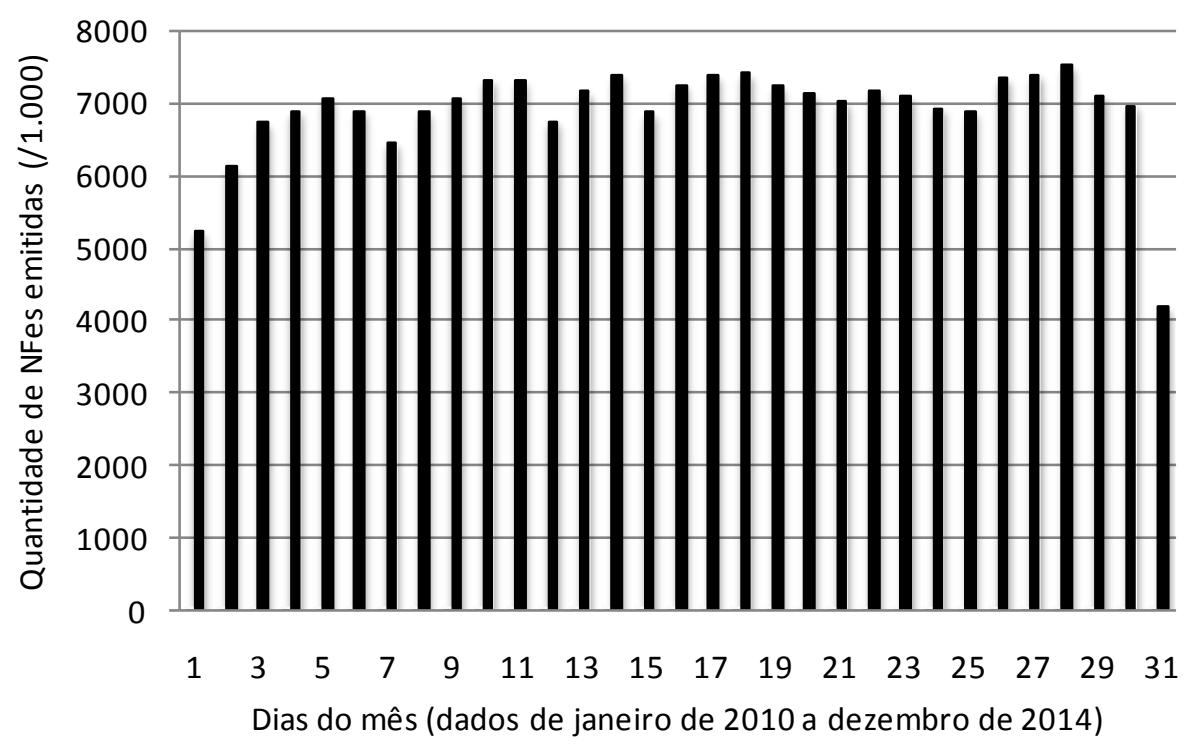

${ }^{26}$ Esta análise é afetada por dias 29,30,31 faltantes em alguns meses. 
Por exemplo, da análise da Figura 4.11 nota-se que na quinta-feira há um volume um pouco maior de NFe's emitidas. Segundo contatos com a área de vendas de duas distribuidoras de bebidas no DF, há uma explicação lógica para isto, pois a emissão de NFe's na quinta-feira significa entrega das mercadorias na sexta-feira. Assim os estabelecimentos se abastecem neste dia que precede o fim de semana, que é o período de maior consumo deste segmento de produto.

Figura 4.11 - Sazonalidade da quantidade de NFe por dia da semana, bebidas

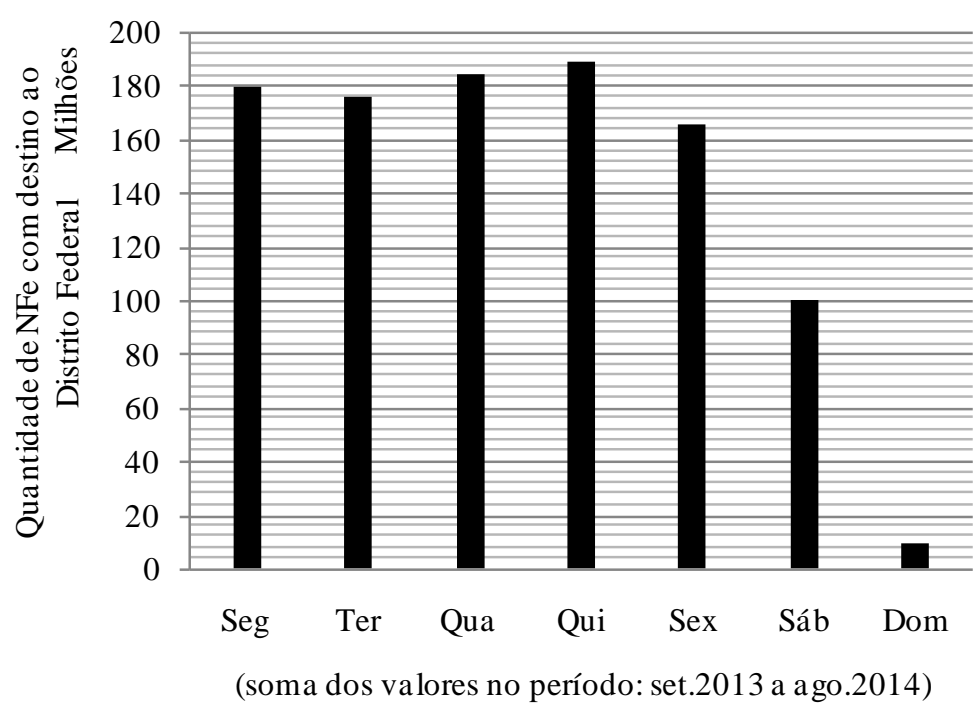

\subsubsection{Frequência de entregas}

Devido à sua importância como maior gerador de entregas e, tendo como base Santos (2008), a frequência de entregas é analisada para os clientes do segmento de bebidas e serve também para reforçar a validação nos dados provenientes das NFe's.

Como se observa na Tabela 4.14, a frequência de entregas por semana das diversas atividades no Distrito Federal é de 1,83 por destino, sendo que os segmentos de comércio varejista de mercadorias em geral, com predominância de produtos alimentícios e panificadoras apresentam valores maiores, próximos a 2,5. Estes resultados demonstram que a análise das frequências de entregas das distribuidoras fornecem informações condizentes com o obtido em Santos (2008), onde as empresas geralmente efetuam visitas de vendas bi-semanais. 
O destaque, porém, vai para comércio atacadista de mercadorias em geral (hipermercados) com ou sem predominância de produtos alimentícios, que possuem frequências de 5,81 e 8,51 , respectivamente. Conclui-se que estas atividades têm recebimento diário de bebidas.

Tabela 4.14 - Frequência de entregas para clientes de bebidas, Set 2013 - Ago 2014

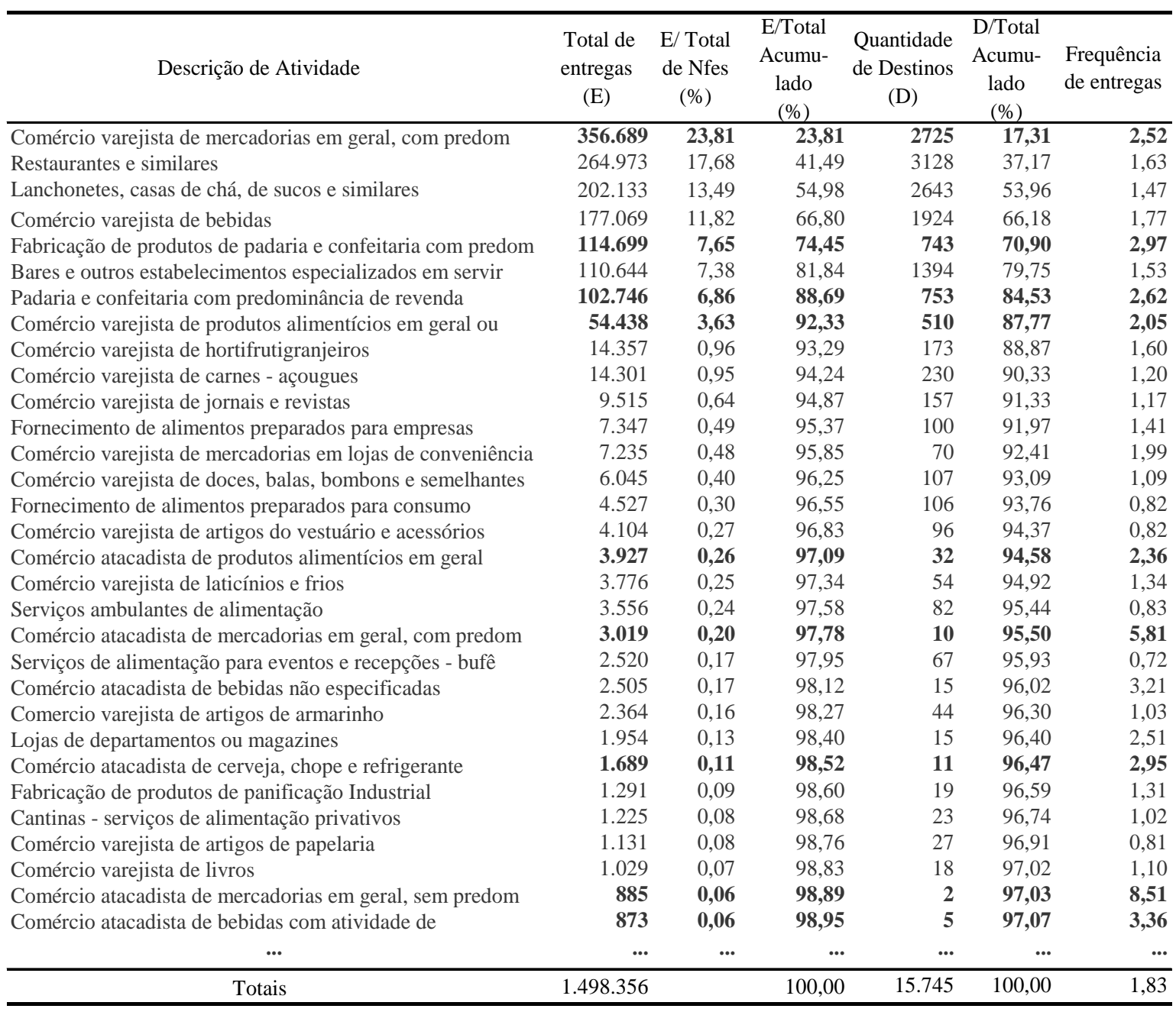

Estes resultados muito próximos aos obtidos por Santos (2008) revelam que a metodologia de obtenção dos dados de DFe permite, por meio de uma pesquisa documental, obter informações que seriam obtidas essencialmente por entrevistas em estabelecimentos ou em interceptação de viagens. Trata-se, portanto, de um salto, pois as pesquisas tradicionais poderiam obter tais informações em bases amostrais e, acredita-se, dificilmente forneceriam uma visão global das frequências de entregas que, em outras palavras, contribui para compreender como as empresas estabelecem suas políticas de atendimento a seus clientes. 


\subsubsection{Localização espacial de agentes}

Como já destacado, o QlikView trabalha com o googlemaps e outros provedores para exibir e manipular informações em mapas georreferenciados. O produto desta associação é visto a seguir e o objetivo é demonstrar o potencial deste trabalho na análise espacial do fluxo de cargas. Isto pode ser feito ainda de modo segmentado, com possibilidade de detalhamento pontual dos locais e quantidades de entregas realizadas ou despachos emitidos.

Para reforçar o potencial que a metodologia oferece, a Figura 7.12 apresenta uma análise segmentada da quantidade de notas fiscais eletrônicas do NCM máquinas, com origem externa para pessoa física no DF no período de setembro de 2013 a agosto de 2014 o que, em última análise, demonstra as compras de computadores e seus acessórios pela internet. Os círculos indicam os locais dos CEP's selecionados. Dentro dos círculos estão indicadas as quantidades de destinos por CEP, porém os recursos do QlikView permitem indicar a quantidade de entregas, os valores e pesos relacionados aos locais selecionados. Da análise da Figura 7.12 verifica-se que as maiores quantidades de destinos estão no plano piloto e em alguns pontos localizados em Taguatinga e Ceilândia (pontos circulados).

Infere-se que estas informações vêm preencher uma lacuna por informações importante, pois a literatura estudada considera que as fontes atuais de informação não fornecem dados precisos e com uma visão completa da localização das origens e destinos das mercadorias. Conforme a literatura aponta, este tipo de dado pode ser obtido essencialmente a partir de pesquisas em veículos, cujas desvantagens, como a aceitação do transportador e seus custos, inviabilizam obter dados de modo abrangente e sistemático.

Portanto, a metodologia proposta apresenta uma contribuição significativa no tocante à localização espacial desagregada, de custo zero, sistemática e abrangente de origens e destinos das mercadorias. Como consequência espera-se que, a partir dos recursos apresentados, se possa avançar significativamente no planejamento de transportes notadamente quanto à elaboração de modelos que necessitam de informações georreferenciadas e desagregadas dos dados de origens e destinos das mercadorias. 
Figura 4.12 - Quantidade de entregas, NCM máquinas, origem externa para PF

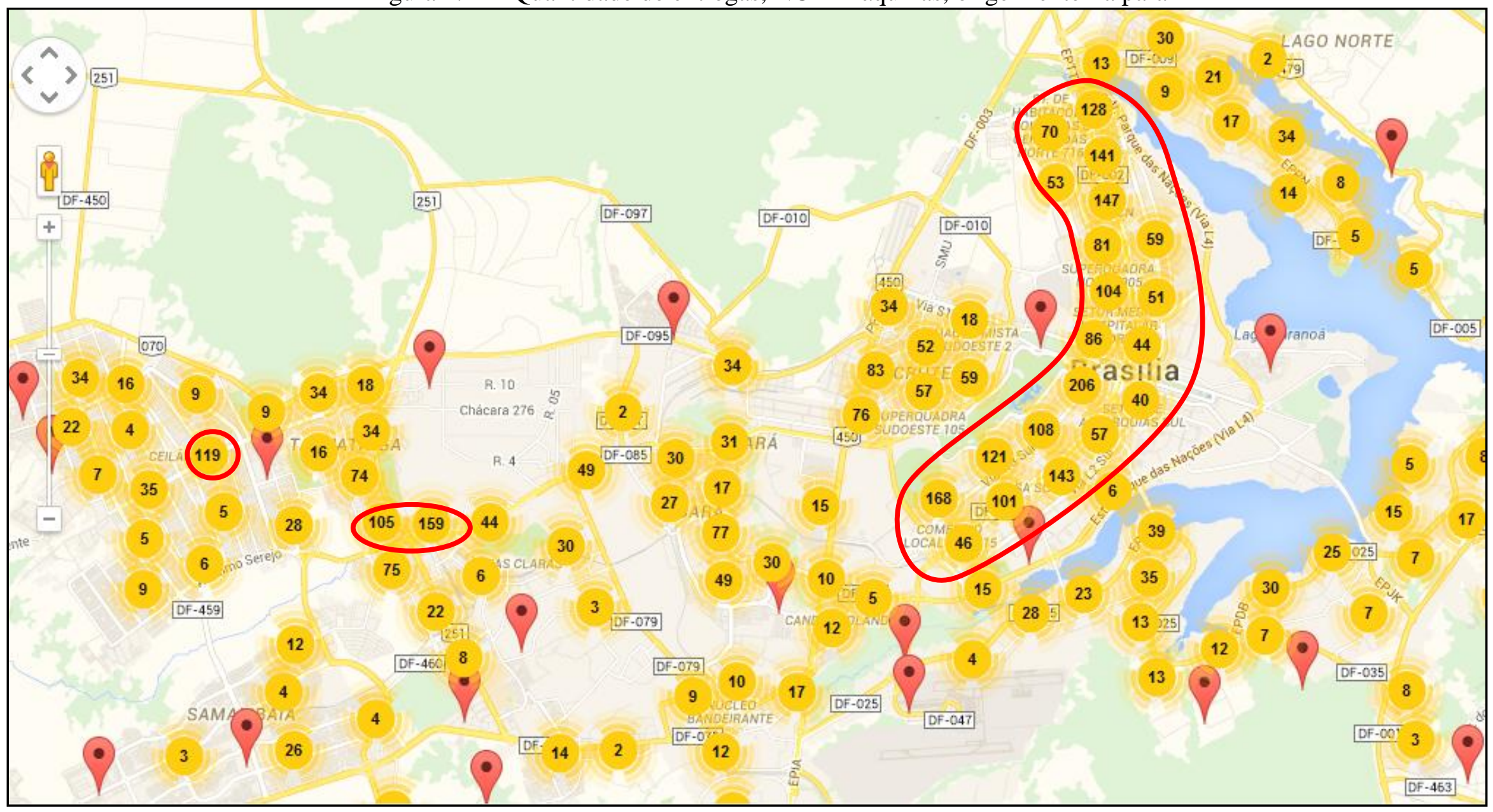




\subsection{DADOS PARA MODELAGEM EM TUC}

A partir das análises anteriores e para demonstrar como a metodologia de obtenção dos dados pode fornecer dados para diferentes tipos de modelagem são apresentados quatro produtos obtidos pela metodologia:

a) uma matriz origem-destino de entregas de mercadorias para os maiores atacadistas de alimentos no Distrito Federal e, paralelamente, a respectiva matriz de distâncias entre as origens e destinos destes atacadistas e seus fornecedores;

b) a análise de fluxo de mercadoria em um canal logístico para o segmento de cosméticos envolvendo remessas externas para pessoas físicas no Distrito Federal;

c) um exemplo de tabela de origem-destino base para roteirização com dados de uma distribuidora de bebidas e;

d) uma tabela de referência para estudos de escolha do modo de transporte também baseada em informações obtidas de uma empresa de bebidas.

Para se chegar às tabelas de matriz de origem e destino de cargas e de roteirização são geradas tabelas dinâmicas no painel especificando as origens e destinos por exemplo, por CEP's, sendo possível segmentar as análises por estabelecimentos, tipo de atividade, período, tipo de produto, dentre outras. Esta geração de tabela dinâmica por CEP é intuitiva, bastando selecionar os campos CEP_Origem nas linhas e CEP_Destino nas colunas das tabelas, e programando a soma dos valores totais (sejam eles, quantidade, valores ou peso das entregas).

A análise de fluxo de mercadorias no canal logístico é feita a partir da seleção e mapeamento dos CNPJ e razões sociais das origens, dos destinos e dos transportadores que se relacionam nas NFe's com os segmentos de produtos de interesse no estudo. A geração da tabela de referência para estudos de escolha modal é feita pela associação das placas dos veículos registrados no cadastro fiscal do Distrito Federal com as placas dos veículos informadas $^{27}$ nas notas fiscais que, por conseguinte, permite relacionar: os dados da remessa da mercadoria, tais como tipo de produto, seu peso, valor e data de emissão da

${ }^{27}$ Foi constatado que em apenas $45 \%$ das NFe's há identificação das placas. 
$\mathrm{NFe}$; a propriedade do veículo e suas características como capacidade e modelo; as origens, destinos e respectivas localizações e descrição das características econômicas dos agentes envolvidos na operação de entrega.

\subsubsection{Matriz OD de entregas}

Uma das peças mais importantes na modelagem em transportes é a matriz origem-destino (HOLGUÍN-VERAS et al., 2001, p. 43). Por meio da metodologia de extração gera-se uma matriz origem-destino (OD) (Tabela 4.15) de entregas ou de cargas com seus valores para todos os CEP's do Distrito Federal, e destes para com os dos demais estados onde ocorrem transações comerciais.

Este tipo de matriz OD é base para a modelagem em modelos de quatro etapas baseados em mercadorias, considerados mais adequados para interpretar os movimentos de veículos com carga no meio urbano (OGDEN, 1992) Isto significa uma mudança significativa em relação aos métodos identificados na literatura estudada, pois apresenta-se como alternativa à realização de pesquisas amostrais e permite maior desagregação do que as análises por zona.

Os valores de referência utilizados nesta análise são a quantidade de notas físcais eletrônicas recebidas (entregas) e emitidas (despachos) para e a partir do Distrito Federal. Assim, a metodologia permitiu gerar uma matriz de origem-destino de entregas e despachos de e para o Distrito Federal em relação aos demais estados, e que conta com 5169 CEP's origem e 8188 CEP's destino. Trata-se de uma tabela de difícil manipulação em um computador comum, e que muitas vezes necessita ser segmentada para viabilizar a análise desejada.

Para restringir o tamanho da matriz e permitir sua representação neste trabalho, são selecionados os 8 maiores CEP's atratores de cargas em termos de número de entregas (destacados em negrito na linha de destinos da Tabela 4.15), considerando o segmento de comércio atacadista de mercadorias em geral, com predominância de produtos alimentícios, os denominados atacadistas de alimentos. 
Os demais CEP's destacados em negrito na coluna de origens da Tabela 4.15 referem-se aos 8 fornecedores destes atacadistas com maior quantidade de despachos gerados. A título de ilustração, esta escolha se baseia na análise da Tabela 4.12 (linha 1-tabela de continuação), onde atacadistas de alimentos ganham destaque como atratores e geradores. Por questões de sigilo, os três algarismos do CEP que identificam o local são omitidos pois esses estabelecimentos geralmente possuem CEP único.

Tabela 4.15 - Matriz OD base para seleção de CEP's, Set 2013 - Ago 2014

\begin{tabular}{c|cccccccccc|c}
\hline O/D & $\mathbf{7 2 2 2 7}$ & $\mathbf{7 2 2 3 7}$ & $\mathbf{7 3 3 8 0}$ & $\mathbf{7 2 4 2 6}$ & $\mathbf{7 2 0 3 5}$ & $\mathbf{7 2 7 0 1}$ & $\mathbf{7 1 9 1 9}$ & $\mathbf{7 1 0 7 0}$ & $\ldots$ & 71572 & $\begin{array}{c}\sum \\
\text { origens }\end{array}$ \\
\hline $\mathbf{7 4 9 8 0}$ & 0 & 0 & 0 & 0 & 5.408 & 0 & 0 & 0 & $\ldots$ & 0 & $\mathbf{5 . 4 0 8}$ \\
$\mathbf{7 2 2 6 5}$ & 0 & 823 & 19 & 20 & 4 & 1.903 & 3 & 138 & $\ldots$ & 0 & $\mathbf{2 . 9 4 5}$ \\
$\mathbf{7 2 0 3 5}$ & 0 & 637 & 822 & 547 & 4 & 0 & 668 & 6 & $\ldots$ & 0 & $\mathbf{2 . 9 3 7}$ \\
$\mathbf{7 2 2 2 7}$ & 80 & 5 & 1.010 & 1.223 & 2 & 0 & 0 & 127 & $\ldots$ & 0 & $\mathbf{2 . 7 3 5}$ \\
$\mathbf{7 1 2 0 8}$ & 122 & 748 & 576 & 378 & 6 & 0 & 231 & 20 & $\ldots$ & 0 & $\mathbf{2 . 4 0 8}$ \\
$\mathbf{7 2 4 0 5}$ & 0 & 0 & 506 & 406 & 0 & 869 & 302 & 0 & $\ldots$ & 0 & $\mathbf{2 . 1 7 8}$ \\
$\mathbf{7 4 9 8 5}$ & 0 & 0 & 0 & 0 & 0 & 3 & 0 & 0 & $\ldots$ & 0 & $\mathbf{2 . 0 7 8}$ \\
$\mathbf{7 1 2 0 5}$ & 20 & 156 & 511 & 375 & 0 & 0 & 0 & 323 & $\ldots$ & 0 & $\mathbf{2 . 0 0 2}$ \\
$\ldots$ & $\ldots$ & $\ldots$ & $\ldots$ & $\ldots$ & $\ldots$ & $\ldots$ & $\ldots$ & $\ldots$ & $\ldots$ & $\ldots$ & $\ldots$ \\
32530 & 0 & 1 & 0 & 0 & 0 & 0 & 0 & 0 & & 0 & $\mathbf{1}$ \\
\hline$\sum$ & $\mathbf{1 5 . 5 8 0}$ & $\mathbf{1 4 . 7 1 1}$ & $\mathbf{1 3 . 1 9 1}$ & $\mathbf{1 0 . 8 9 2}$ & $\mathbf{1 0 . 3 2 1}$ & $\mathbf{6 . 4 3 0}$ & $\mathbf{5 . 4 6 4}$ & $\mathbf{5 . 3 4 2}$ & & $\mathbf{1}$ & $\mathbf{1 0 1 . 0 0 0}$ \\
\hline destinos & & & & & & & & & & & \\
\hline
\end{tabular}

Após a seleção dos CEP's dos 8 maiores atacadistas e dos seus 8 maiores fornecedores, os 16 CEP's resultantes formam a base para a matriz OD que é estruturada em três etapas:

a) primeiro são geradas as matrizes em que os atacadistas são destino e, para isto, são utilizados os filtros do painel IouEDestino para o Distrito Federal, e a Atividade de Destino "comércio atacadista de mercadorias em geral, com predominância de produtos alimentícios";

b) na segunda etapa inverte-se a análise e atribui-se aos atacadistas a origem dos despachos, e os respectivos CEP's de seus fornecedores passam a ser o destino das respectivas remessas; as tabelas geradas nestas duas primeiras etapas são apresentadas na Tabela B.1 do Apêndice B;

c) na terceira etapa as quantidades de entregas atraídas e os despachos gerados para e a partir dos atacadistas de alimentos com seus principais fornecedores sãos somados, gerando o que se denomina de movimentos totais. Estes valores são apresentados na Tabela 4.16. 
Porém, algumas observações para compreender as características dos dados gerados merecem destaque:

a) a matriz gerada (Tabela 4.16) permite observar a quantidade de viagens nos chamados movimentos "intrazonais" representados por CEP's coincidentes que é o caso dos movimentos no CEP 72035 , pois ali se encontram um atacadista e seu respectivo fornecedor. Enfim, este importante tipo de informação não é perdido como ocorre tradicionalmente nas análises de movimentos por zona;

b) o público selecionado gera 25.574 movimentos, atrai 20.529 entregas e gera 4.645 despachos, sendo neste caso aproximadamente 4 vezes mais atrator do que gerador, aspecto coerente com as análises de geração e atração anteriores;

c) esses 8 atacadistas são responsáveis pela atração de $33 \%$ do total de entregas do segmento (101.014 entregas $^{28}$ - ver linha 1 da Tabela 4.12, continuação) um valor representativo expressivo;

d) como a característica do segmento é o recebimento de cargas fechadas (FTL), espera-se que este valor se aproxime da quantidade de viagens de veículos atraídas e geradas.

Para concluir esta análise são extraídos a respectiva matriz de distância e um mapa com as linhas de desejo dos fluxos de cargas obtidos, ambos baseados no googlemaps (Tabela 4.17 e Figura 4.13). São informações importantes, pois apoiam as etapas de distribuição e alocação do tráfego em simulações no modelo de quatro etapas, tais como os efeitos de alterações na malha viária. Aliás, da análise na Figura 4.13 nota-se um fluxo maior de mercadorias (alimentos) provenientes de Goiânia (CEP com início em 74980) e um ponto de concentração destes fluxos na região próxima à Central de Abastecimento de Brasília, CEASA. Portanto, não considerando a previsão, demonstra-se que a metodologia pode suprir informações básicas para modelagem, fazendo o papel de um modelo de geração de matriz origem-destino do fluxo de cargas, base para modelos de quatro etapas baseados em mercadorias.

\footnotetext{
${ }^{28}$ Há uma diferença de 14 viagens a menos na Tabela 6.10 devido à restrição para soma dos valores no excel.
} 
Tabela 4.16 - Matriz OD de entregas de atacadistas, Set 2013 - Ago 2014

\begin{tabular}{|c|c|c|c|c|c|c|c|c|c|c|c|c|c|c|c|c|}
\hline O/D & 71070 & 71205 & 71208 & 71919 & 72035 & 72035 & 72227 & 72227 & 72237 & 72265 & 72405 & 72426 & 72701 & 73380 & 74980 & $\sum$ origens \\
\hline 71070 & - & - & - & - & 1 & - & 3 & - & - & 6 & - & - & - & - & - & 10 \\
\hline 71205 & 323 & - & - & - & - & - & - & 20 & 156 & - & - & 375 & - & 511 & - & 1.385 \\
\hline 71208 & 20 & - & - & 231 & - & 6 & - & 122 & 748 & - & - & 378 & - & 576 & - & 2.081 \\
\hline 71919 & - & - & 65 & - & 13 & 1 & 1 & - & - & 11 & 11 & - & - & - & - & 102 \\
\hline 72035 & 6 & - & - & 668 & - & 4 & - & - & 637 & - & - & 547 & - & 822 & - & 2.684 \\
\hline 72035 & - & - & 44 & 9 & 79 & 146 & 3 & 26 & 81 & 94 & - & 508 & 156 & 699 & 2.547 & 4.392 \\
\hline 72227 & 127 & - & - & - & - & 2 & - & 80 & 5 & - & - & 1.223 & - & 1.010 & - & 2.447 \\
\hline 72227 & - & 18 & 140 & - & 2 & 46 & 6 & - & - & 2 & - & - & - & - & - & 214 \\
\hline 72237 & - & 1 & 59 & - & 66 & 21 & - & - & - & 311 & 5 & - & - & - & - & 463 \\
\hline 72265 & 138 & - & - & 3 & - & 4 & - & - & 823 & - & - & 20 & 1.903 & 19 & - & 2.910 \\
\hline 72405 & - & - & - & 302 & - & - & - & - & - & - & - & 406 & 869 & 506 & - & 2.083 \\
\hline 72426 & - & 12 & 28 & - & 45 & 58 & 15 & - & - & 2 & 7 & - & - & - & - & 167 \\
\hline 72701 & - & - & - & - & - & 79 & - & - & - & 533 & 31 & - & - & - & - & 643 \\
\hline 73380 & - & 2 & 28 & - & 29 & 67 & 30 & - & - & 2 & 27 & - & - & - & - & 185 \\
\hline 74980 & - & - & - & - & - & 5.408 & - & - & - & - & - & - & - & - & - & 5.408 \\
\hline$\sum$ destinos & 614 & 33 & 364 & 1.213 & 235 & 5.842 & 58 & 248 & 2.450 & 961 & 81 & 3.457 & 2.928 & 4.143 & 2.547 & 25.174 \\
\hline
\end{tabular}

Notas: Os CEP 72035 e 72227 parecem duplicados devido à omissão dos três últimos algarismos. São CEP's distintos entre os atacadistas e seus fornecedores. Valores representam quantidade de entregas 
Tabela 4.17 - Matriz de distância de atacadistas de alimentos

\begin{tabular}{|c|c|c|c|c|c|c|c|c|c|c|c|c|c|c|c|c|}
\hline O/D & 71070 & 71205 & 71208 & 71919 & 72035 & 72035 & 72227 & 72227 & 72237 & 72265 & 72405 & 72426 & 72701 & 73380 & 74980 & $\sum$ origens \\
\hline 71070 & & 10 & 10 & 9 & 12 & 13 & 20 & 12 & 11 & 27 & 30 & 32 & 14 & 46 & 210 & 457 \\
\hline 71205 & 9 & & 1 & 13 & 16 & 17 & 20 & 17 & 15 & 27 & 29 & 32 & 14 & 39 & 214 & 463 \\
\hline 71208 & 8 & 1 & & 12 & 16 & 17 & 19 & 16 & 14 & 27 & 29 & 32 & 14 & 39 & 214 & 459 \\
\hline 71919 & 11 & 17 & 14 & & 6 & 6 & 14 & 4 & 4 & 21 & 26 & 27 & 8 & 51 & 203 & 410 \\
\hline 72035 & 18 & 18 & 18 & 6 & & 1 & 18 & 3 & 4 & 25 & 21 & 22 & 12 & 54 & 198 & 417 \\
\hline 72035 & 19 & 19 & 19 & 7 & 1 & & 18 & 4 & 4 & 25 & 21 & 21 & 12 & 55 & 198 & 421 \\
\hline 72227 & 20 & 22 & 22 & 14 & 18 & 18 & & 18 & 18 & 9 & 38 & 39 & 10 & 57 & 213 & 517 \\
\hline 72227 & 16 & 19 & 20 & 4 & 4 & 4 & 17 & & 2 & 25 & 25 & 25 & 11 & 54 & 201 & 428 \\
\hline 72237 & 13 & 18 & 16 & 4 & 4 & 4 & 17 & 2 & & 24 & 24 & 25 & 11 & 53 & 201 & 418 \\
\hline 72265 & 26 & 27 & 28 & 20 & 23 & 23 & 8 & 23 & 23 & & 35 & 35 & 15 & 62 & 211 & 560 \\
\hline 72405 & 30 & 31 & 30 & 28 & 22 & 21 & 40 & 25 & 26 & 51 & & 5 & 34 & 67 & 191 & 601 \\
\hline 72426 & 34 & 34 & 34 & 30 & 24 & 23 & 42 & 27 & 28 & 44 & 5 & & 36 & 70 & 190 & 620 \\
\hline 72701 & 14 & 16 & 16 & 8 & 11 & 12 & 9 & 12 & 12 & 16 & 32 & 32 & & 51 & 209 & 449 \\
\hline 73380 & 49 & 39 & 39 & 52 & 55 & 55 & 57 & 56 & 54 & 64 & 67 & 70 & 51 & & 252 & 959 \\
\hline 74980 & 216 & 216 & 216 & 206 & 199 & 199 & 214 & 202 & 203 & 210 & 191 & 191 & 211 & 252 & & 2.925 \\
\hline$\sum$ destinos & 482 & 487 & 482 & 415 & 411 & 411 & 512 & 422 & 418 & 595 & 573 & 587 & 453 & 950 & 2.905 & 10.104 \\
\hline
\end{tabular}


Figura 4.13 - Linha de desejo dos maiores atacadistas de alimentos no DF

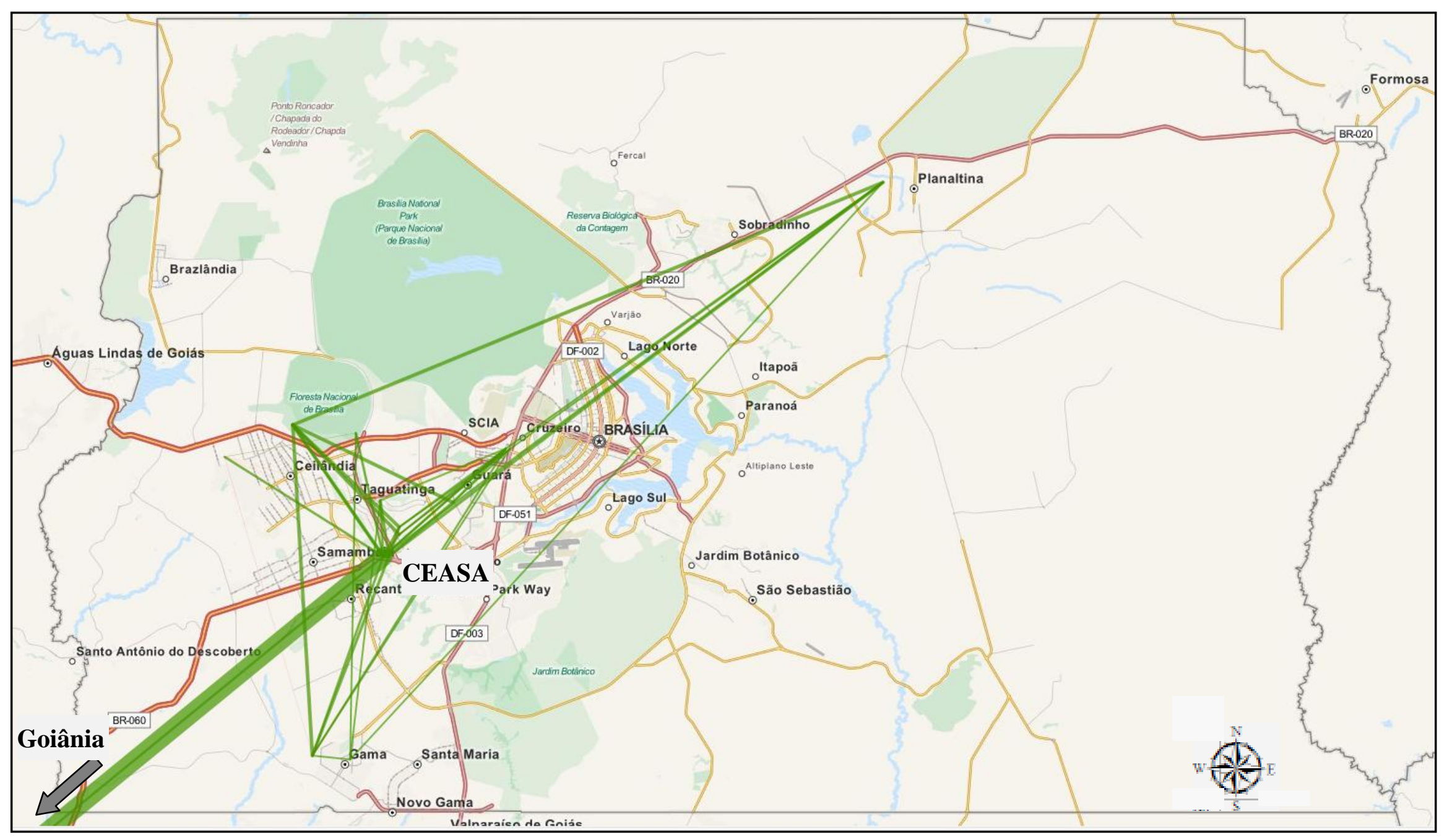

Nota: Linhas de expressão calculada pela quantidade de entregas. 


\subsubsection{Análise de fluxo no canal logístico}

Desde que os dados da transportadora sejam corretamente informados, e este tipo de informação, nota-se, tem sido mais precisa a partir de empresas emitentes de maior porte, é possível "mapear" etapas do fluxo de uma mercadoria no canal logístico.

Para demonstrar este potencial, efetua-se uma análise no segmento de cosméticos pela sua importância nas remessas externas para pessoa física no Distrito Federal. Como se observa na Tabela 4.18 identifica-se a empresa fornecedora $X^{29}$ com sua quantidade de remessas, de destinos e respectivas transportadoras, dentre as quais se destaca a Transportadora B.

Tabela 4.18 - Fluxo de mercadoria no canal cosméticos, Set 2013 - Ago 2014

\begin{tabular}{ccrr}
\hline Razão Origem & \multicolumn{2}{c}{ Qtd Entregas Qtd Destinos } \\
\hline \multicolumn{2}{c}{ Indústria de Cosméticos X } & 31.776 & 23.056 \\
\hline & & & \\
\hline \multirow{2}{*}{ RazaoOrigem } & Nome da transportadora & Quantidade & Quantidade \\
& de entregas & de destinos \\
\hline \multirow{5}{*}{ Empresa X } & Transportadora A & 1 & 1 \\
& Transportadora B & 31.769 & 23.049 \\
& Transportadora C & 3 & 3 \\
& Transportadora D & 3 & 3 \\
\hline
\end{tabular}

No caso, devido ao processo de seleção, todos os destinos são para pessoa física, porém há alternativa de se analisar os percentuais em que estes destinos são para outros tipos de clientes, as características econômicas principais dos agentes e produtos (peso, valor, categoria), datas de emissão das notas, o tipo do veículo, etc.

Demonstra-se, portanto, que a metodologia possibilita obter informações importantes de uma pesquisa no canal logístico e de modo abrangente, e pode reduzir custos das respectivas pesquisas realizadas geralmente por entrevistas e telefone, por isto caras e específicas para um projeto específico. No caso desta análise, pode-se identificar e selecionar os agentes de interesse para contatos no contexto de um processo de planejamento em transportes

\footnotetext{
${ }^{29}$ Nomes omitidos por questões de sigilo
} 


\subsubsection{Tabelas OD para roteirização}

Santos (2008) lista os atributos de um roteirizador e como os dados devem ser organizados para alimentá-lo. Neste contexto, a desagregação dos dados obtidos apresenta configuração adequada à roteirização de fluxos por meio de uma tabela origem-destino (TOD). Conforme indica o autor, a Tabela 4.19 ilustra a configuração de uma TOD com as informações básicas para roteirização sobre uma base de mapa georreferenciado. Os dados são de uma distribuidora de bebidas escolhida aleatoriamente para um dia de emissão de NFe's. A Tabela 4.19 contém uma representação dos dados de um ciclo diário da referida empresa, cujos veículos efetuam tipicamente uma rota por dia (raramente há recargas), com um padrão de 40 entregas por dia por veículo. (SANTOS, 2008).

Tabela 4.19 - Tabela origem-destino de mercadorias, 1.Ago.2014

\begin{tabular}{ccccccc}
\hline $\begin{array}{c}\text { Quantidade } \\
\text { de CEPs }^{(1)}\end{array}$ & $\begin{array}{c}\text { Peso da } \\
\text { mercadoria } \\
(\mathrm{kg})\end{array}$ & $\begin{array}{c}\text { Cep } \\
\text { Destino }^{(2)}\end{array}$ & $\begin{array}{c}\text { Latitude } \\
\text { Destino }^{(3)}\end{array}$ & $\begin{array}{c}\text { Longitude } \\
\text { Destino }^{(3)}\end{array}$ & $\begin{array}{c}\text { Pessoa Física } \\
\text { ou Jurídica } \\
\text { Destino }^{(4)}\end{array}$ & $\begin{array}{c}\text { Quantidade } \\
\text { de notas } \\
\text { fiscais }\end{array}$ \\
\hline 1 & 1106,96 & 72215 & -15.836118 & -48.0942774 & PJ & 1 \\
$\vdots$ & $\vdots$ & $\vdots$ & $\vdots$ & $\vdots$ & $\vdots$ & $\vdots$ \\
49 & 53,45 & 72110 & -15.7984883 & -48.0461233 & PJ & \\
50 & 41,80 & 72110 & -15.7984883 & -48.0461233 & PJ & $2^{(5)}$ \\
$\vdots$ & $\vdots$ & $\vdots$ & $\vdots$ & $\vdots$ & $\vdots$ & $\vdots$ \\
126 & 0,00 & 72101 & - & - & PF & 1 \\
127 & 0,00 & 72610 & -15.9040683 & -48.0618133 & PJ & 1 \\
\hline Totais & 8129,03 & & & & & 130 \\
\hline
\end{tabular}

Fonte: Elaborado pelo autor (2015)

\section{Notas:}

1) CEP no destino arbitrados como pontos de parada;

2) os três últimos dígitos foram omitidos por questões de sigilo;

3) latitude e longitude foram relacionadas ao CEP e não às empresas de destino por questões de sigilo;

4) os dados permitem segregar entregas para pessoas jurídicas ou físicas, o que apresenta utilidade na segmentação dos estudos;

5) nesta amostra identifica-se a entrega de duas notas fiscais para o mesmo CEP, ou seja, de acordo com as premissas adotadas, tem-se um ponto de parada e duas entregas. 
Enfim, a metodologia de extração de dados oferece as informações básicas, necessitando complementá-las com outros dados referentes às decisões logísticas dos estabelecimentos tais como política de carregamento de veículos, perfil da frota, restrições de acesso, etc. De qualquer forma, a obtenção de destinos desagregados por origem com as características da remessa representa um avanço na obtenção deste tipo de dado, geralmente realizada por meio de pesquisas nos veículos por meio de GPS e/ou diários de viagem.

\subsubsection{Padrões de frota e DFe: a escolha modal}

Em muitas situações fica difícil compreender as viagens de veículos no espaço urbano sem a modelagem da escolha do tipo de veículo utilizado (JONG, 2014). Portanto, um dos aspectos essenciais no planejamento de TUC é a modelagem da escolha modal que, segundo discutido, ainda está em desenvolvimento e, infere-se, limitada pela carência de dados que permitam estudos mais abrangentes.

Neste estudo, as placas de veículos indicadas nas NFe's são associadas às placas dos veículos registrados no cadastro fiscal do Distrito Federal. Esta associação permitiu vincular 6.596.181 notas fiscais aos veículos registrados, 15,1\% das 43.645.416 NFe's emitidas. A Figura 4.14 mostra a participação dos tipos de veículos ${ }^{30}$ na quantidade de NFe's vinculadas. O destaque vai para caminhão, que detém mais de $80 \%$ de participação.

Figura 4.14 - Quantidade de NFe's e tipos de veículos

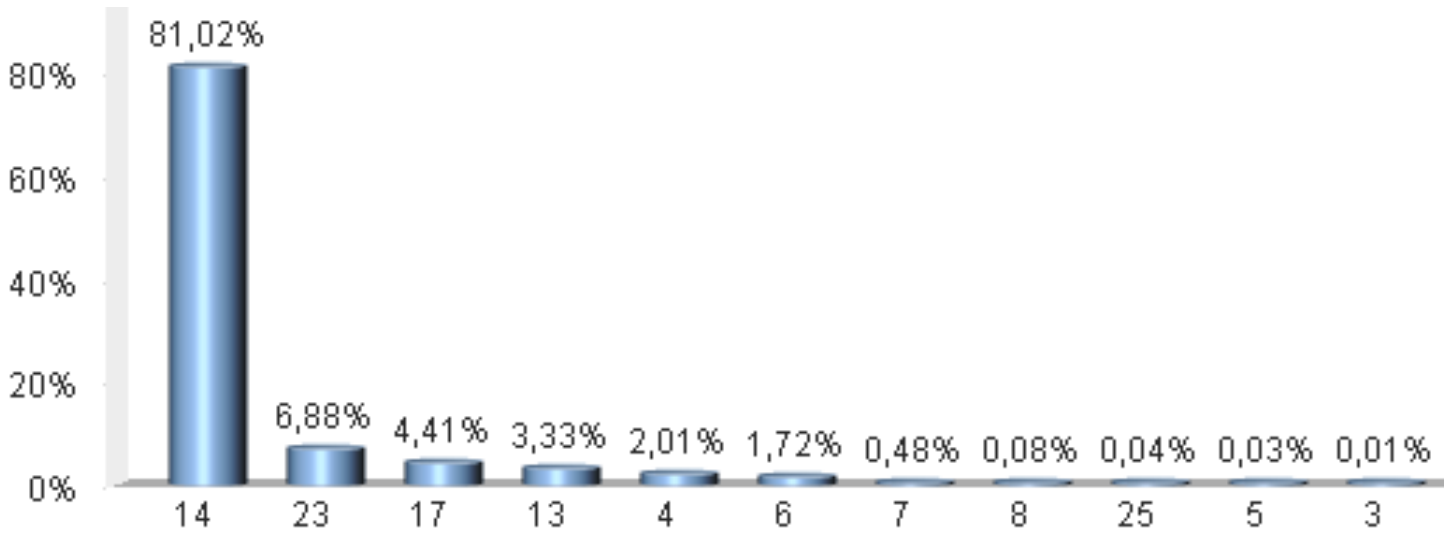

Legenda: 14 - Caminhão, 23 - Caminhonete, 17 - Caminhão Trator, 13 - Camionete, 4 - Motocicleta, 6 Automóvel, 7- Microônibus, 8 - Ônibus, 25 - Utilitário, 5 - Motocicleta, 3 - Motoneta

\footnotetext{
${ }^{30}$ O cadastro fiscal do DF fornece apenas o tipo do veículo conforme descrito naa Resolução 291/2008 do CONTRAN. Um convênio será realizado para obter dados sobre o porte dos veículos com o Departamento de Trânsito do DF.
} 
Além da análise do perfil da frota vinculada às NFe's, também é possível explorar os dados sobre o perfil da carga. Para isto escolhe-se uma empresa distribuidora de bebidas no banco de dados que, com base em Santos (2008), registra as placas nas NFe's de modo organizado e sistemático. Infere-se que isto deriva de um aspecto interessante: neste caso, os veículos de transporte são próprios, onde o processo interno do embarcador e transportador são interligados pelo mesmo sistema de emissão de notas e roteirização, fazendo com que as informações da placa do veículo sejam inseridas automaticamente e de modo preciso.

O resultado da associação das placas desta empresa com os dados proposta segue na Tabela 4.20, onde se tem a descrição da placa do veículo. Obtém-se então dados do ano e tipo do veículo, do peso da carga e da quantidade de entregas em um dia de emissão. Este tipo de análise pode ser estendido a outros períodos, empresas, etc. porém, como demonstra a literatura, pode ser uma informação enviesada por retratar apenas as empresas que fornecem as informações sobre placa dos veículos de modo correto, e também porque o cadastro fiscal do DF limita-se aos registros de veículos locais.

Tabela 4.20 - Quantidade de entregas e peso de carga por veículo, 1 Ago 2014

\begin{tabular}{|c|c|c|c|c|}
\hline $\begin{array}{l}\text { Placa do } \\
\text { veículo }^{(1)}\end{array}$ & $\begin{array}{c}\text { Cod_Tipo do } \\
\text { veículo }^{(2)}\end{array}$ & $\begin{array}{c}\text { Peso carga } \\
(\mathrm{kg})\end{array}$ & $\begin{array}{l}\text { Ano do } \\
\text { veículo }\end{array}$ & $\begin{array}{l}\text { Quantidade } \\
\text { de Nfe } \\
\text { (3) }\end{array}$ \\
\hline $\mathrm{J} * * * * 68$ & 14 & 7.380 & 2008 & 41 \\
\hline $\mathrm{J} * * * * 71$ & 14 & 6.046 & 2013 & 39 \\
\hline $\mathrm{J} * * * * 91$ & 14 & 4.675 & 2008 & 38 \\
\hline $\mathrm{J} * * * * 84$ & 14 & 6.562 & 2013 & 38 \\
\hline $\mathrm{J} * * * * 64$ & 14 & 6.189 & 2013 & 36 \\
\hline $\mathrm{J} * * * * 60$ & 14 & 4.782 & 2010 & 35 \\
\hline ... & ... & ... & ... & ... \\
\hline $\mathrm{J} * * * * 58$ & 14 & 4.837 & 2008 & 3 \\
\hline $\mathrm{J} * * * * 43$ & 14 & 5.237 & 2010 & 3 \\
\hline $\mathrm{J} * * * * 53$ & 14 & 15.379 & 2010 & 3 \\
\hline $\mathrm{J} * * * * 36$ & 14 & 1.940 & 2006 & 2 \\
\hline $\mathrm{J} * * * * 40$ & 14 & 4.191 & 2010 & 2 \\
\hline $\mathrm{O} * * * * 17$ & 14 & 1.744 & 2013 & 1 \\
\hline Veículos & Média & 4.525 & 2010 & 23 \\
\hline 68 & Desvio Padrão & 1.955 & 2 & 11 \\
\hline
\end{tabular}

Notas: (1) ***** dados omitidos por sigilo

(2) 14: Classificação no CFDF informa apenas que é caminhão

(3) Quantidade de Nfe para um dia (ciclo) de entregas 
De qualquer forma, trata-se de uma base de dados importante para análises de escolha modal e que, a partir de um cadastro nacional de veículos (RENAVAM) é possível estendê-la e, desde que esforços sejam feitos para que estas informações sejam mais precisas, torná-la eficiente.

Por fim, demonstra-se que, por meio de uma pesquisa documental de baixo custo, é possível gerar dados cuja obtenção até o momento se dá por meio de processos amostrais mais complexos, e de métodos caros que, em última análise, tem inviabilizado estudos de uma maneira mais dinâmica e abrangente em TUC. Considera-se que a metodologia de obtenção de dados de $\mathrm{DFe}$ e os produtos apresentados representam uma quebra de paradigma na geração de dados para modelagem. 


\section{COMENTÁRIOS FINAIS}

Os resultados obtidos com esta tese permitem algumas conclusões e, espera-se, contribua para avanços no processo de obtenção de dados, assim como no planejamento do transporte urbano de cargas. Com o objetivo de organizar estes comentários, este capítulo se divide nas seguintes seções: contribuições, conclusões, limitações do estudo e recomendações de estudos futuros.

\subsection{CONTRIBUIÇÕES}

Este trabalho efetua uma revisão bibliográfica de conceitos, métodos e técnicas de pesquisas utilizados para obter dados em estudos do transporte urbano de cargas, aspectos importantes para compreender e lidar com as especificidades do tema.

Neste contexto, apresenta-se uma metodologia para a obtenção, tratamento, disponibilização e uso dos dados da nota fiscal eletrônica como fonte alternativa de informações para o planejamento em transportes. Trata-se de uma contribuição significativa, pois considera-se que um dos principais desafios para os especialistas em transportes é a obtenção de dados para pesquisas do transporte urbano de cargas.

Por fim, infere-se que a principal contribuição desta tese é abrir um precedente para o acesso a informações de documentos fiscais eletrônicos, e inovar ao demonstrar que é possível utilizá-los em estudos sobre o TUC que, espera-se, irá estabelecer novas fronteiras para pesquisas relacionadas a este tema.

\subsection{CONCLUSÕES}

Cumprindo com os objetivos propostos e respondendo à questão científica formulada na introdução, esta tese demonstra ser possível utilizar dados de documentos físcais eletrônicos como fonte alternativa de informações para o planejamento do TUC. O referencial teórico, os resultados e as análises desta pesquisa demonstram que os dados da nota fiscal eletrônica, tratados e organizados, podem representar os fluxos de mercadorias 
no espaço urbano com expressivo nível de detalhes, abrangência e atualização contínua a um baixo custo.

Acredita-se que a metodologia proposta contenha aspectos fundamentais para ser amplamente utilizada em todos os estados brasileiros devido à padronização dos dados das NFe's, e às características similares dos cadastros fiscais de contribuintes. Esta metodologia foi elaborada com uma linguagem simples, com detalhes suficientes para que gestores e tomadores de decisão possam replicá-la e utilizá-la sem maiores investimentos.

A rigor, conclui-se que os dados das NFe's, integrados ao cadastro fiscal de contribuinte e a uma base de dados georreferenciados, fornecem uma rica fonte de informações para ser utilizada não somente no planejamento de transportes, mas também em outras áreas do conhecimento. O processo de obtenção dos dados proposto, por sua vez, traz consigo uma quebra de paradigma quanto aos métodos tradicionais de pesquisa utilizados, e uma perspectiva de redução significativa dos custos das mesmas no País.

Neste sentido, infere-se que alguns procedimentos de pesquisa e metodologias que utilizam análises agregadas e desconsideram os fluxos com viagens encadeadas devem ter seus usos reanalisados neste novo contexto. Por outro lado, considera-se que metodologias e técnicas até então com uso limitado devido à falta de dados e, principalmente, o próprio planejamento do TUC, passam a ter novos horizontes após a contribuição deste trabalho.

\subsection{LIMITAÇÕES DO ESTUDO}

Como destacado na metodologia, constata-se nas notas fiscais eletrônicas um alto percentual de campos vazios, com preenchimento incorreto ou que não são padronizados para análises em transporte de cargas. Atualmente, estes aspectos criam empecilhos para estudos das operações logísticas.

No entanto, a principal limitação da metodologia proposta é a restrição de acesso aos dados dos documentos fiscais eletrônicos, que por lei é exclusivo de alguns agentes públicos, e a necessidade em se manter o sigilo fiscal das informações. 


\subsection{RECOMENDAÇÕES DE ESTUDOS FUTUROS}

A fiscalização do trânsito de cargas no Brasil vem sendo aprimorada com os objetivos de aumentar a segurança contra o roubo de mercadorias e veículos, e de obter um maior controle da arrecadação de tributos. Estes objetivos têm ensejado iniciativas que estão abrindo novas fontes de informação para estudos do TUC, tais como: o projeto Brasil ID (BRASIL-ID, 2013) que busca monitorar o fluxo de cargas por meio de chips RFID; o manifesto eletrônico que consolida as cargas que transitam entre os estados (MDFE, 2015); a confirmação de recebimento da NFe pelo destinatário da mercadoria (NFE, 2015); a nota fiscal de consumidor eletrônica (NFCE, 2014), etc.

Iniciativas similares estão sendo desenvolvidas por outros agentes públicos e privados que buscam um maior controle de suas operações logísticas. Os investimentos em tecnologias de informação são expressivos que tendem a ampliar as fontes de informações digitais.

A partir destas constatações e da experiência obtida neste trabalho, recomenda-se:

- efetuar estudos de como estas iniciativas podem contribuir de maneira integrada para estruturar bases de dados que permitam a análise do transporte urbano, regional e internacional de cargas;

- estudar mecanismos que permitam disponibilizar a base de dados de DFe para pesquisas, em escala suficiente para que pesquisadores e gestores públicos possam utilizá-las em estudos do transporte de cargas;

- propor ajustes na validação e configuração da NFe para o uso de suas informações em estudos sobre o transporte de cargas;

- modelar o fluxo de carga urbano utilizando os dados dos DFe, dentre outros. 


\section{REFERÊNCIAS BIBLIOGRÁFICAS}

Allen J.; M. Browne e T. O. Cherrett (2012) Survey Techniques in Urban Freight Transport Studies. Transport Reviews, v. 32, n. 3, p. 287-311.

Ambite, J. L.; G. Giuliano; P. Gordon; Q. Pan e S. Bhattacharjee (2003) Integrating Heterogeneous Data Sources for Better Freight Flow Analysis and Planning. Anais do Annual Meeting of the Transportation Research Board, TRB, Washington, p. 1-20.

Anand, N.; R. Quak; R. V. Duin e L. Tavasszy (2012) City Logistics Modeling Efforts: Trends and Gaps - A Review. Procedia - Social and Behavioral Sciences, v. 39, p. 101-115.

Ballou, R. H. (2001) Gerenciamento da Cadeia de Suprimentos: Planejamento, Organização e Logística Empresarial (4 ${ }^{\mathrm{a}}$ ed). Bookman, Porto Alegre.

Beagan, D.; M. Fischer e A. Kuppam (2014) Quick Response Freight Manual II. Disponível em: <www.ops.fhwa.dot.gov/freight/publications/qrfm2/qrfm.pdf>. Acesso em: 1 set. 2014.

BRASIL-ID (2014) Manual de Orientação do Contribuinte. Brasil-ID Sistema Nacional de Identificação, Rastreamento e Autenticação de Mercadorias. Disponível em: <http://www.brasilid.org.br/index.php/home>. Acesso em: 5 set. 2014.

Bruton, M. J. (1979) Introdução ao Planejamento dos Transportes ( $1^{\mathrm{a}}$ ed.). Editora Interciência, São Paulo.

Carvalho, J. A. (1998) Uma contribuição ao planejamento do transporte de cargas em áreas urbanas. Dissertação de mestrado. Instituto Militar de Engenharia, Rio de Janeiro.

CFOP (2014) Código Fiscais de Operações e Prestações. Disponível em: <http://www1.fazenda.gov.br/confaz/confaz/convenios/sinief/CFOP_CVSN_70_vigente.htm>.

Acesso em: 1 ago. 2014.

Cintra, M. (2014) Os custos dos congestionamentos na cidade de São Paulo. Disponível em: $<$ http://bibliotecadigital.fgv.br/dspace/bitstream/handle/10438/11576/TD 356 - Marcos Cintra.pdf?sequence=1>. Acesso em: 29 ago. 2014.

CNAE (2015) Classificação Nacional de Atividades Econômicas V. 2.0. Disponível em: <http://www.ibge.gov.br/home/estatistica/economia/classificacoes/cnae2.0/cnae2.0.pdf $>$ Acesso em: 3 jun. 2015.

CODEPLAN (2015) Base Domicílio PDAD-2013. Companhia de Planejamento do Distrito Federal. Disponível em: http://www.codeplan.df.gov.br/component/content/article/261-pesquisassocioeconomicas/294-pdad-2013.html. Acesso em: 1 Jun.2015.

Comi, A.; P. D. Site; F. Filippi e A. Nuzzolo (2012) Urban freight transport demand modelling: A state of the art. European Transport - Trasporti Europei, n. 7, p. 1-17.

Comi, A.; R. Donnely e F. Russo (2014) Urban Freight Models. In: Tavasszy, L. e G. Jong (eds.) Modelling Freight Transport. (1 ${ }^{a}$ ed.). Elsevier Inc., p. 163-200.

Cruz-Ross, A.; D. P. K. Seedah; J. Prozzi; P. L. Fountain e C. M. Walton (2014) Exploring DataSharing Partnerships to Collect Primary Freight Data. Anais do Transportation Research Board 93rd Annual Meeting, TRB, Washington, D.C., n. 14-2922. 
CTE (2015) Portal do Conhecimento de Transporte Eletrônico. Disponível em: $<$ http://www.cte.fazenda.gov.br/listaConteudo.aspx?tipoConteudo=YIi+H8VETH0=>. Acesso em: 4 jun. 2015.

CTN (2012) Código Tributário Nacional. Lei $\mathrm{N}^{\circ}$ 5.172/1966. Disponível em: <http://www2.senado.leg.br/bdsf/bitstream/handle/id/496301/000958177.pdf?sequence=1>. Acesso em: 3 jun. 2015.

Dablanc, L. (2007) Goods transport in large European cities: Difficult to organize, difficult to modernize. Science Direct. Transportation Research Part A: Policy and Practice, v. 41, n. 3, p. 280-285.

Donnely, R.; A. H. Meyburg; H. Shen e R. Leachman (2008) Evaluation of Practice Today. In: Freight Demand Modeling Tools for Public-Sector Decision Making. Summary of a Conference. Transportation Research Board, Conference Proceedings 40, Washington, D.C., p. 27-36.

ENAT (2015) Encontro Nacional de Administradores Tributários. Disponível em: <https://www.enat.receita.fazenda.gov.br/pt-br>. Acesso em: 3 jun. 2015.

ENCAT (2015) Encontro Nacional dos Coordenadores e Administradores Tributários Estaduais. Disponível em: <http://www.encat.org/>. Acesso em: 3 jun. 2015.

Giuliano, G.; P. Gordon; Q. Pan; J. Park e L. Wang (2010) Estimating freight flows for metropolitan area highway networks using secondary data sources. Networks and Spatial Economics, v. 10, n. 1, p. 73-91.

González-Calderón, C. e J. Holguín-Veras (2014) Freight Tour Synthesis and the Influence of Sampling Procedures. Anais do Transportation Research Board 93rd Annual Meeting, TRB, Washington, D.C., v. 2, n. 651, p. 1-11.

Gonzalez-Feliu, J.; C. Ambrosini e A. Bonnafous (2014) An alternative to O-D matrix estimation for urban goods transport demand generation. Anais do Transportation Research Board 93rd Annual Meeting, TRB, Washington, D.C., n. 14-4132, p. 1-15.

Hair Jr., J. F.; W. C. Black; B. J. Babin; R. E. Anderson e R. L. Tatham (2009) Análise Multivariada De Dados (6 $6^{\mathrm{a}}$ ed). Artmed Editora S.A., Porto Alegre.

Holguín-Veras, J.; E. Thorson; Q. Wang; N. Xu; C. González-Calderón; I. Sánchez-Díaz e J. Mitchelll (2013) Urban Freight Tour Models: State of the Art and Practice. Freight Transport Modelling. Bingley, UK: Emerald Group, p. 335-352.

Holguín-Veras, J. ; J. Ban; M. Jaller; L. Destro e R. Marquis (2010) Feasibility Study for Freight Data Collection. New York. Disponível em: <http://trid.trb.org/view.aspx?id=1118315>. Acesso em: 6 jun. 2015.

Holguín-Veras, J. ; G. F. List; A. H. Meyburg; K. Ozbay; R. E. Passwell, H. Teng e S.

Yahalom (2001) An assessment of methodological alternatives for a regional freight in the NYMTC region. New york metropolitan transportation council, p. 181.

Holguín-Veras, J. ; K. Ozbay; A. Kornhauser; M. A. Brom; S. Iyer; W. F. Yushimito; S. Ukkusuri; A. Brandon e M. A. Silas (2010) Overall Impacts of Off-Hour Delivery Programs in New York City Metropolitan Area. Transportation Research Record: Journal of the Transportation Research Board, n. 2238, p. 68-76. 
Holguín-Veras, J.; M. Jaller, J. Amaya; C. Wang; C. González-Calderón; I. Sánchez-Díaz; M. Browne; J. Wojtowicz; S. Hodge; S. S. Rhodes e D. G. Haake (2014a) Public Sector Freight Interventions in Metropolitan Areas I: Governance, Supply Side, and Traffic Operations. Anais do Transportation Research Board 93rd Annual Meeting, TRB, Washington, D.C., n. 14-0835.

Holguín-Veras, J.; M. Jaller, J. Amaya; C. Wang; C. González-Calderón; I. Sánchez-Díaz; M. Browne; J. Wojtowicz; S. Hodge; S. S. Rhodes e D. G. Haake (2014b) Public Sector Freight Interventions in Metropolitan Areas II: Pricing, Logistics, and Demand Management. Anais do Transportation Research Board 93rd Annual Meeting, TRB, Washington, D.C., n. 14-0837.

Holguín-Veras, J.; M. Jaller; I. Sánchez-Díaz; S. Campbell e C. T. Lawson (2014c) Freight Generation and Freight Trip Generation Models. In: Modelling Freight Transport. Elsevier Inc., p. $43-63$.

Holguín-Veras, J. e M. Jaller (2014) Comprehensive Freight demand Data Collection Framework for Large Urban Areas. Sustainable Urban Logistics: Concepts, Methods and Information Systems, p. $91-112$.

Holguín-Veras, J.; E. Thorson (2003) Modeling commercial vehicle empty trips with a first order trip chain model. Transportation Research Part B: Methodological, v. 37, n. 2, p. 129-148.

IBGE (2010) Instituto Brasileiro de Geografia e Estatística. Censo 2010. Disponível em: <http://7a12.ibge.gov.br/pt/vamos-conhecer-o-brasil/nosso-povo/caracteristicas-da-populacao>.

Acesso em: 29 ago. 2014.

IPEA (2010) Instituto de Pesquisa Econômica Aplicada - IPEA. Infraestrutura Infraestrutura Social e Urbana no Brasil: subsídios para uma agenda de pesquisa e formulação de políticas públicas. Livro 6, v. 2, Brasília.

Jaller, M.; I. Sánchez-Díaz e J. Holguín-Veras (2014) Freight Trip Attraction, Freight Trip Production, And The Role Of Freight Intermediaries. Anais do Transportation Research Board 93rd Annual Meeting, TRB, Washington, D.C., n. 14-4882.

Jong, G. (2014) Mode Choice Models. In: Tavasszy, L. e G. Jong (eds.) Modelling Freight Transport. ( $1^{\mathrm{a}}$ ed.). Elsevier Inc., p. 117-141.

Lammers, C. C. P. (2012) The Potential of Transportation Demand Management in Brasilia. Sixth Urban Research and Knowledge Symposion, Barcelona, p. 1-18, 2012.

MANUAL-NFE (2015) NFe - Manual de Orientação Do Contribuinte. Brasília, DF. Disponível em: <http://www.nfe.fazenda.gov.br/portal/principal.aspx>. Acesso em: 4 jun. 2015.

MDFE (2015) Portal do Manifesto Eletrônico de Documentos Fiscais. Disponível em: <https://mdfe-portal.sefaz.rs.gov.br/>. Acesso em: 4 jun. 2015.

Mello, J. C. (1975) Planejamento dos Transportes (1 ${ }^{\mathrm{a}}$ ed). McGraw-Hill do Brasil, São Paulo.

MMA (2015) Relatório Final do 1o Inventário Nacional de Emissões Atmosféricas por Veículos Automotores Rodoviários. Ministério do Meio Ambiente, Brasília: Disponível em: <www.mma.gov.br/estruturas/163/_publicacao/163_publicacao27072011055200.pdf〉. Acesso em: 4 jun. 2015.

NCFRP (2012) Freight Trip Generation and Land Use - Report 19. National Cooperative Freight Research Program, Transportation Research Board, Washington, D.C. 
NCFRP (2013) Freight Data Sharing Guidebook - Report 25. National Cooperative Freight Research Program, Transportation Research Board, Washington, D.C.

NCM (2015) Nomenclatura Comum do Mercosul. Disponível em: $<$ http://www.desenvolvimento.gov.br/sitio/interna/interna.php?area=5\&menu=1090>. Acesso em: 4 jun. 2015.

NFCE (2015) Notícias - SEF - Secretaria de Estado de Fazenda do Distrito Federal. Disponível em: $<$ http://www.fazenda.df.gov.br/aplicacoes/noticia/detalhada.cfm?codNoticia=5669>. Acesso em: 11 jun. 2015.

NFE (2015) Portal da Nota Fiscal Eletrônica. Disponível em: <http://www.nfe.fazenda.gov.br/portal/principal.aspx>. Acesso em: 4 jun. 2015.

Novaes, A. G. N. (2001) Logística e Gerenciamento da Cadeia de Distribuição (1ª ed). Campus Editora, Rio de Janeiro.

NTC (2001) Manual de Cálculo de Custos e Formação de Preços do Transporte Rodoviário de Cargas. Associação Nacional do Transporte de Cargas. Disponível em: <http://www.guiadotrc.com.br/pdfiles/MANUAL.pdf>. Acesso em: 4 Jun. 2015.

Ogden, K. W. (1992) Urban Goods Movement: A Guide to Policy and Planning. Ashgate Publishing Company,Inglaterra.

Oliveira, L. K. DE; A. S. Braga e B. R. A. Abreu (2010) Relevant attributes in overnight goods delivery: researchers ', transporters ' and retailers ' preference in urban distribution. Proceeding of the 12th World Conference on Transport Research, July 11-15, Lisbon, Portugal.

Oliveira, L. K. e E. D. Guerra (2014) A Diagnosis Methodology for Urban Goods Distribution: A Case Study in Belo Horizonte City (Brazil). Procedia - Social and Behavioral Sciences, v. 125, p. 199-211.

Ortúzar, J. D. e L. G. Willumsen (2011) Modelling Transport (4ª ed). In: John Wiley \& Sons, Ltd. Chichester, UK.

PIARC (2012) A Guide to Implement road Freight Transport Management in urban environment. World Road Association (PIARC), La Défense, France.

QLIKVIEW (2011a) Manual de ReferênciaVersão 11.0 para Microsoft Windows. QlikTech International AB. Disponível em: <https://community.qlik.com/docs/DOC-3106>. Acesso em: 4 jun. 2015.

QLIKVIEW (2011b) O que torna o QlikView único. QlikTech International AB. Disponível em: <http://www.nordicasoft.com.br/dv_files/arquivos/20130115182238_dbarquivos.pdf>. Acesso em: 4 jun. 2015.

QLIVIEW (2015) QlikView - Software de Inteligência em Negócios. Disponível em: <http://www.in1.com.br/empresa/conhecendo-melhor-o-qlikview>. Acesso em: 4 jun. 2015.

Quack, H.; R. Van Duin e J. Visser (2008) City logistics over the years....lessons learned, research directions and interests. Innovations in City Logistics ( $1^{\mathrm{a}}$ ed.), New York, p. 37-53.

Richardson, A. J.; E.S. Ampt e A. H. Meyburg (1995) Survey Methods for Transport Planning. Eucalyptus Press,Melbourne. 
Roorda, M. J.; R. Cavalcante; S. McCabe e H. Kwan (2010) A conceptual framework for agentbased modelling of logistics services. Transportation Research Part E: Logistics and Transportation Review, v. 46, n. 1, p. 18-31.

Routhier, J.; E. Segalou e S. Durand (2002) Mesurer L'impact du transport de marchandises en ville. Paris. Disponível em: 〈http://tmv.let.fr/documents/rapports/plaquette2.pdf〉. Acesso em: 5 jun. 2015.

Routhier, J. L. e D. Patier (2006) Report on urban freight data collection in France. Bestufs. Lyon, França.

Sanches Junior, P. F. (2008) Logística de Carga Urbana: uma análise da realidade brasileira. Tese, Universidade Estadual de Campinas.

Sanches Junior, P. F.; E. W. Rutkwoski e O. F. Lima Jr. (2008) Análise Crítica das Políticas Públicas para Carga Urbana nas Metrópoles Brasileiras. XXVIII Encontro Nacional de Engenharia de Produção -13 a 16 de outubro. Rio de Janeiro. Disponível em: <http://www.abepro.org.br/biblioteca/enegep2008_tn_sto_069_492_11401.pdf〉. Acesso em: 21 nov. 2010.

Santos, E. M. (2008) Contribuição à Gestão da Distribuição de Cargas em Áreas Urbanas sob a Òtica do Conceito City Logistics. Dissertação, Universidade de Brasília, 2008.

Santos, E. M. e I. Sánchez-Díaz (2015) Exploring carriers perception about city logistics initiatives. 9th International Conference on City Logistics, 17-19 de junho. Ilhas Canárias, Espanha: (no prelo).

SINIEF (1970) Sistema Integrado de Informações Econômicas e Fiscais. Ministério da Fazenda/Confaz. Convênio s/n de 15 de dezembro de 1970. Disponível em: <http://www1.fazenda.gov.br/confaz/confaz/convenios/sinief/cvsn_70.htm>. Acesso em: 4 jun. 2015

SPED (2015) Sistema Público de Escrituração Digital. Receita Federal. Disponível em: <http://www1.receita.fazenda.gov.br/>. Acesso em: 4 jun. 2015.

Stathopoulos, A.; E. Valeri e E. Marcucci (2012) Stakeholder reactions to urban freight policy innovation. Journal of Transport Geography, v. 22, p. 34-45.

Taniguchi E.; R. G. Thompson e T. Yamada (2014) Recent Trends and Innovations in Modelling City Logistics. Procedia - Social and Behavioral Sciences, v. 125, p. 4-14.

Tavasszy, L. (2008) Freight Modeling: An Overview of International Experiences. Transportation Reasearch Board, Conference Proceedings n. 40, Washington.

Tavasszy, L. A. e G. Jong (2014) Data Availability and Model Form. In: Tavasszy, L. e G. Jong (eds.) Modelling Freight Transport. (1 ${ }^{a}$ ed.). Elsevier Inc., p. 229-244.

Tedesco, G. M. I. (2008) Metodologia para a Elaboração do Diagnóstico de um Sistema de Transporte. Dissertação, Universidade de Brasília.

Tenório, G. S. e Junior, R. G. S.(2009) Brasilia 's Urban Mobility Plan : review and speculations an environmental approach. 45th ISOCARP Congress, Porto. Disponível em: http://www.isocarp.net/Data/case_studies/1440.pdf . Acesso em: 25 Jun. 2015. 
ANEXO 
Figura A.1 - Modelo de DANFE

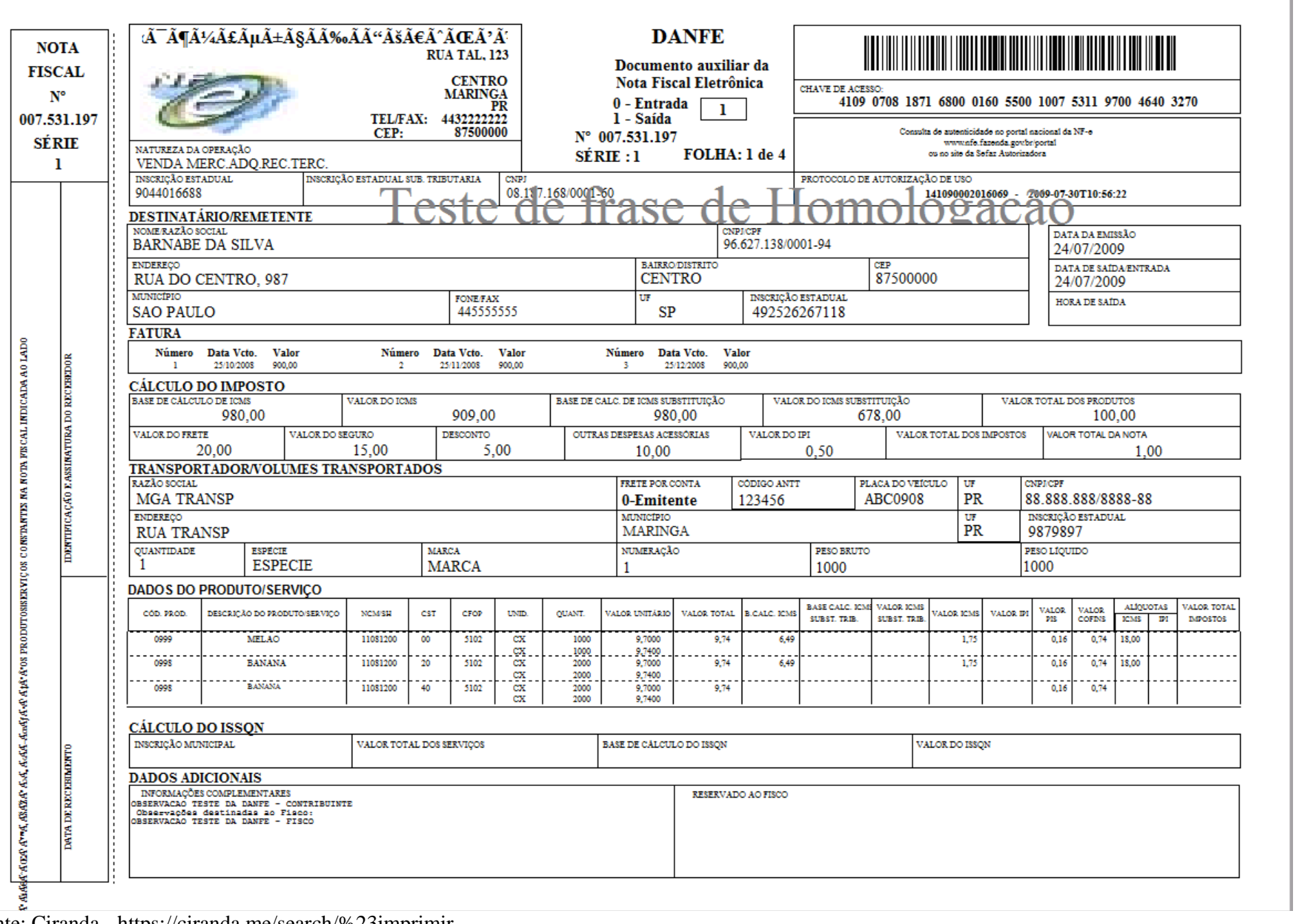

Fonte: Ciranda -https://ciranda.me/search/\%23imprimir 
APÊNDICE 


\section{A Aspectos característicos do TUC}

\section{DEFINIČÃO E DIFERENÇAS DO TUC PARA O TRANSPORTE DE PESSOAS}

Ogden (1992) define o transporte urbano de cargas como "o transporte de coisas (distinto do transporte de pessoas) para, a partir, dentro e através de áreas urbanas". Apesar desta definição, o autor afirma que a modelagem ${ }^{31}$ no transportes urbano de cargas adota uma lógica próxima à utilizada para o transporte de pessoas, não levando em conta diferenças fundamentais entre ambos, dentre as quais destacam-se: o tomador de decisão do serviço no transporte de pessoas é o indivíduo que faz a viagem e as pesquisas são centradas nos domicílios; no transporte de cargas há interações entre diferentes atores, como embarcadores, recebedores e transportadores de mercadorias e, para Chiang, Roberts e Ben-Akiva (1980 apud OGDEN, 1992, p. 265) ${ }^{32}$, o principal tomador de decisão é a empresa e, afirma-se, também o consumidor final;

a) a unidade no transporte de pessoas é o indivíduo que não se altera durante a viagem; por contraste, tal unidade no transporte de carga não existe, pois as mercadorias da origem ao destino sofrem transformações em sua natureza, transferências, consolidações, percorrem rotas que produzem diferentes padrões de viagens em diferentes modos de transporte (OGDEN, 1992); enfim, não se pode vincular aleatoriamente a origem e destino de uma mercadoria como linha de desejo de sua viagem por veículos;

b) pessoas são objetos animados que tomam decisões por si mesmas e as mercadorias são objetos inanimados que necessitam manuseio por diferentes equipamentos em diferentes origens e destinos, o que pode levar a diferentes processos de decisão sobre o sistema de transporte; por isto, conhecer as características dos produtos e seus respectivos requisitos para transporte, armazenagem e manuseio, são fundamentais;

\footnotetext{
${ }^{31} \mathrm{E}$, infere-se, também o processo de planejamento.

${ }^{32}$ Chiang Y. S., Roberts P. O., Ben-Akiva, M. (1980) Development of a policy-sensitive model for forecasting freight demand: Final Report. Report Number DOT-P-30-82-04. 231 p. (Department of Transportation, Washington, DC).
} 
c) NCFRP (2012) afirma também que uma das distinções entre transporte de passageiros e de cargas se dá entre a geração de demanda (ex.: viagens de passageiros, toneladas) e a geração de tráfego (ex.: viagens de carros, caminhões). Enquanto no transporte de passageiros tal diferença é considerada de menor importância, no transporte de cargas isto é vital, pois não há uma relação direta entre a demanda por cargas e a geração de viagens com cargas (ver Quadro A.1); em outras palavras, coletar dados sobre cargas, tais como sobre variáveis como quantidade de entregas ou coletas, não representa necessariamente a geração de viagens com carga.

Quadro A.1 - Geração de viagens: passageiros versus Carga

\begin{tabular}{|c|c|c|}
\hline Característica & Passageiro & Carga \\
\hline Demanda gerada & Viagens de passageiros & Toneladas produzidas/consumidas \\
\hline Tráfego gerado & Viagens de carros, ônibus, etc. & Viagens de caminhões, vans, etc. \\
\hline $\begin{array}{c}\text { Variáveis de } \\
\text { influência }\end{array}$ & $\begin{array}{c}\text { Renda, uso do solo, estrutura } \\
\text { familiar, propriedade de carro }\end{array}$ & $\begin{array}{c}\text { Atividade econômica, linha e tamanho } \\
\text { de negócio, uso do solo }\end{array}$ \\
\hline $\begin{array}{c}\text { Correspondência } \\
\text { entre demanda e } \\
\text { tráfego gerado }\end{array}$ & $\begin{array}{c}\text { Muito próxima, quase 1 para 1 } \\
\text { em áreas onde o uso de } \\
\text { transporte coletivo é baixo }\end{array}$ & $\begin{array}{c}\text { Muito distante, devido ao papel do } \\
\text { tamanho da remessa em função do } \\
\text { porte das empresas }(*) .\end{array}$ \\
\hline
\end{tabular}

(*) Empresas de maior porte geram maior volume de carga e produzem proporcionalmente menos tráfego devido a remessas em lotes maiores, pequenas empresas, o inverso.

Fonte: NCFRP (2012) - Tradução nossa, adaptado.

\section{VIAGENS ENCADEADAS, PARADAS E ENTREGAS}

O transporte urbano de cargas envolve diferentes atores (motoristas, embarcadores, transportadores, destinatários da mercadoria) com diferentes relações econômicas e de poder, múltiplas dimensões de carga (volume, peso) que produzem complexas viagens encadeadas de entrega e coleta em um ambiente dinâmico (GONZÁLEZ-CALDERÓN; HOLGUÍN-VERAS, 2014; HOLGUÍN-VERAS et al., 2013).

Uma configuração típica dessas viagens encadeadas ou rotas pode ser vista na sequência HB-S1-S2-S3-HB da Figura A.2, onde o ponto de origem e local de consumo da mercadoria (setas tracejadas) e da viagem do veículo com e sem a carga (setas preta e cinza) raramente coincidem. 
Figura A.2 - Viagens versus origem e destino de cargas

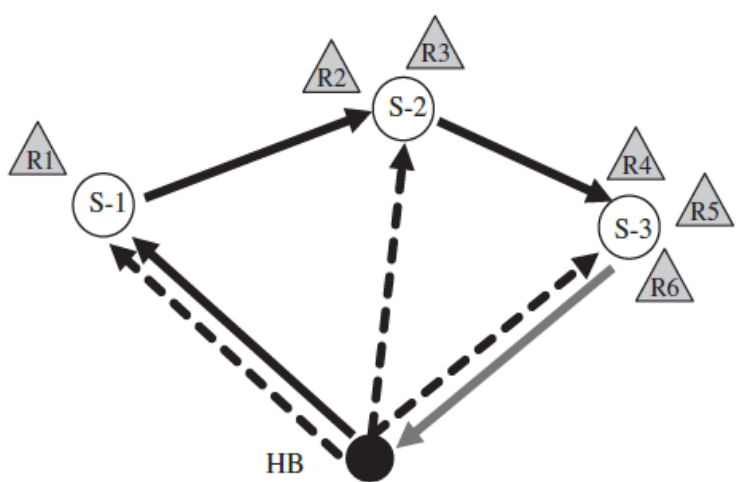

Legenda:

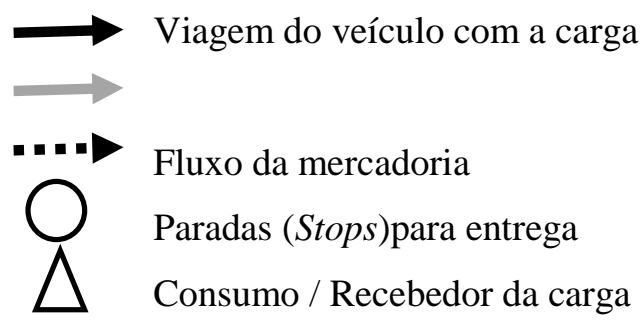

HB - Produçao/Ponto de origem da carga

Fonte: Holguin Veras et al. (2013, tradução nossa, adaptado)

A partir dessas referências, Holguín-Veras et al. (HOLGUÍN-VERAS et al., 2013) fazem algumas conclusões:

g) uma rota de entrega urbana pode ser feita com várias viagens individuais, também denominadas de viagens encadeadas;

h) cada ponto de parada pode ser utilizado para efetuar múltiplas entregas;

i) rotas geram viagens com carga e outras vazias, que necessitam ser consideradas;

j) o fluxo da mercadoria, ou seja, da transação entre o embarcador e o recebedor, raramente coincide com a direção do fluxo das viagens, ou seja, as origens e destinos das viagens raramente refletem a relação de demanda e suprimento.

\section{$O$ conceito de viagens (encadeadas)}

Verifica-se que as viagens se referem a trajetos entre um ponto de parada e outro, sendo o ponto de parada o local onde o veículo estaciona para que se efetuem múltiplas entregas. Esta definição vai ao encontro do que Mello (1975, p. 47) considera como o conceito americano de viagem: "viagem é uma jornada individual com certo propósito entre dois pontos por um meio específico de transporte" e indica que qualquer parada, excluídas as de motivo secundário (acidentes, congestionamentos), marca o início de uma nova viagem. Porém esta definição não está consolidada no TUC.

A título de ilustração, Gonzalez-Feliu, Ambrosini e Bonnafous (2014) também definem que a unidade de medida no transporte urbano de cargas são as viagens com determinado 
propósito a um destino. Porém sugerem traduzi-las como a quantidade de entregas e coletas realizadas em uma semana por determinado veículo em determinada empresa. Neste contexto, Richardon, Ampt e Meyburg (1995, p. 29) consideram que há diferentes tipos de definição de viagens dependendo do foco do estudo, porém orientam que o pesquisador deve escolher sobre a qual irá se basear.

Trata-se de um aspecto importante, pois definições diferentes podem se tornar conflitantes e levar a interpretações dúbias. Por exemplo - e seguindo a proposta de Gonzalez-Feliu, Ambrosini e Bonnafous (2014) - em pesquisas que avaliam as quantidades de viagens atraídas e geradas por estabelecimentos, como definir como viagem atraída a realizada para entregar mercadorias para 10 recebedores por meio de uma única parada? Esta abordagem do ponto de vista do estabelecimento gera 10 viagens, do ponto de vista do tráfego gerado, uma.

Este problema fica claro no estudo conduzido por Jaller, Sánchez-Díaz e Holguín-Veras (2014). Notadamente para não ferir o conceito de viagem exposto na Figura A.2, os autores assumem as entregas/embarques de mercadorias como viagens, porém com algumas premissas: as entregas/embarques não são feitas via rotas e não são vinculados a pontos de parada e, além disso, os transportadores que entregam e despacham não são os mesmos.

Assim, considera-se haver um certo equívoco entre os conceitos de viagens e entregas/despachos. Fica evidente que uma viagem é coincidente com uma entrega ou despacho se estiver vinculada a uma única parada. Caso contrário, considera-se necessário definir a quantidade paradas e, por conseguinte, de viagens para avaliar a ocupação e os movimentos nas vias.

Por isto, neste trabalho respeita-se quando autores tratam de viagens atraídas e geradas por estabelecimentos sem deixar claro se são fruto ou não de viagens encadeadas. Porém, para as análises desta tese adota-se o conceito de entregas e despachos realizados pelos estabelecimentos, aspecto fundamental na interpretação dos dados coletados. 


\section{Pontos de paradas e as múltiplas entregas}

Pode-se questionar se há uma participação significativa das viagens encadeadas no TUC, o que, de certa forma, minimizaria a importância dos aspectos levantados na discussão anterior. Porém a realização de viagens encadeadas é significativa e realizada por diversos segmentos econômicos.

Por exemplo, Holguín-Veras et al. (2013) demonstram por meio de pesquisa com 485 transportadores na região metropolitana de Nova Iorque, EUA, que diversos segmentos efetuam diversas paradas por rota (Figura A.3). Santos (2008) relata que o segmento de bebidas no Distrito Federal, cuja participação no número de entregas no meio urbano é expressiva, efetua regularmente cerca de 37 entregas por rota.

Além da quantidade de paradas e entregas, Ogden(1992) e Holguín-Veras et al. (2013) relatam que há uma maior frequência de entregas em curtas distâncias, com múltiplas paradas em uma rota para entregas predominantemente orientadas a estabelecimentos consumidores (varejo). Pode-se inferir, portanto, que identificar a quantidade de entregas/paradas por rota é fundamental para interpretar as viagens de carga no meio urbano.

Figura A.3 - Quantidade de paradas para entregas por rota por tipo de produtos

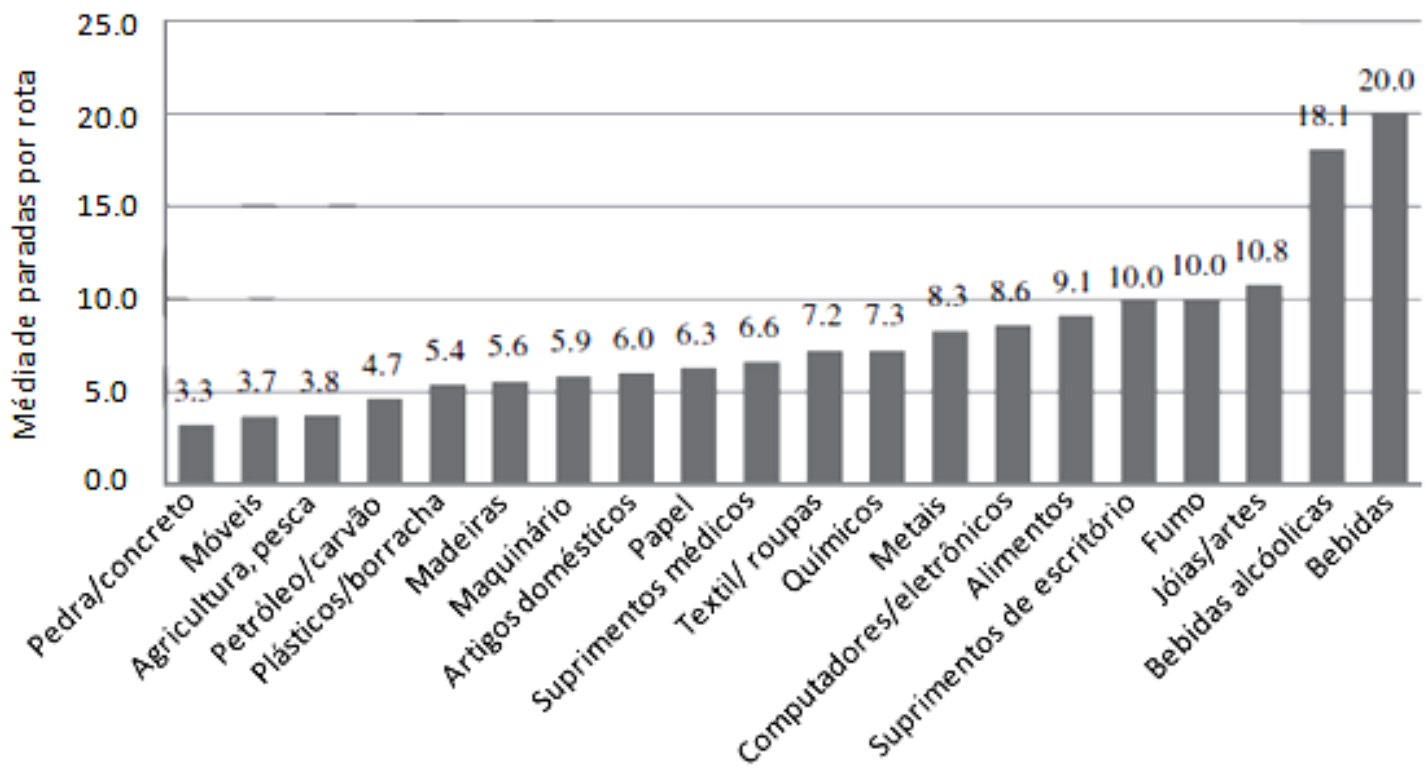

Fonte: Holguín-Veras et al. (2013, tradução nossa) 


\section{$\underline{\text { Viagens vazias }}$}

Outro conceito relevante é a divisão entre fluxos de viagens com ou sem cargas (viagens vazias), conceito iniciado por Ogden (1992). Por exemplo, ainda na Figura A.2 um embarcador envia cargas de sua base (HB) para seis recebedores (R1 a R6) que se traduz em uma rota do transportador com três paradas (S1 a S3) e três viagens individuais (HBS1, S1-S2, S2-S3) e uma viagem de retorno com o veículo vazio (S3-HB).

Este aspecto impacta significativamente no estudo do TUC, pois viagens vazias podem representar uma parte significativa das viagens de um veículo, no que Holguín-Veras e Thorson (2003) apontam valores próximos a 30\%. Enfim, interpretar os movimentos dos veículos em rotas que considerem as viagens vazias torna-se fundamental para prever os movimentos totais de viagens.

\section{Movimentos de cargas e de viagens de veículos com carga}

Outro ponto importante extraído da Figura A.2 é que considerar os movimentos de carga como de ida e volta ao destino como sendo o movimento das viagens distorce fortemente as análises. Assim, é importante reconhecer que utilizar os movimentos pendulares, conceito comumente utilizado em estudos sobre o transporte de pessoas, pode falhar ao interpretar os fluxos de cargas no meio urbano feitos por meio de rotas.

Isto é demonstrado por Donnely et al. (2008, p. 29) quando se utiliza, por exemplo, o modelo gravitacional para efetuar a distribuição de viagens com carga. Conforme se observa na Figura A.4, a matriz de origens e destinos (OD) à esquerda representam os fluxos de cargas entre embarcadores e recebedores de mercadorias. Supõe-se que este fluxo seja distribuído conforme os custos (tempos ou custos generalizados) da malha viária à direita.

Neste cenário, o movimento pendular contaria com custos quase duas vezes maiores do que o modelo de rotas seguindo o fluxo A, B, C, D. Além disso, a alocação dos fluxos na rede viária não representaria o que ocorre na realidade do encadeamento de viagens executado pelas rotas. 
Figura A.4 - Viagens pendulares versus encadeadas

Distribuição pelo modelo de gravidade... ...e suas implicações
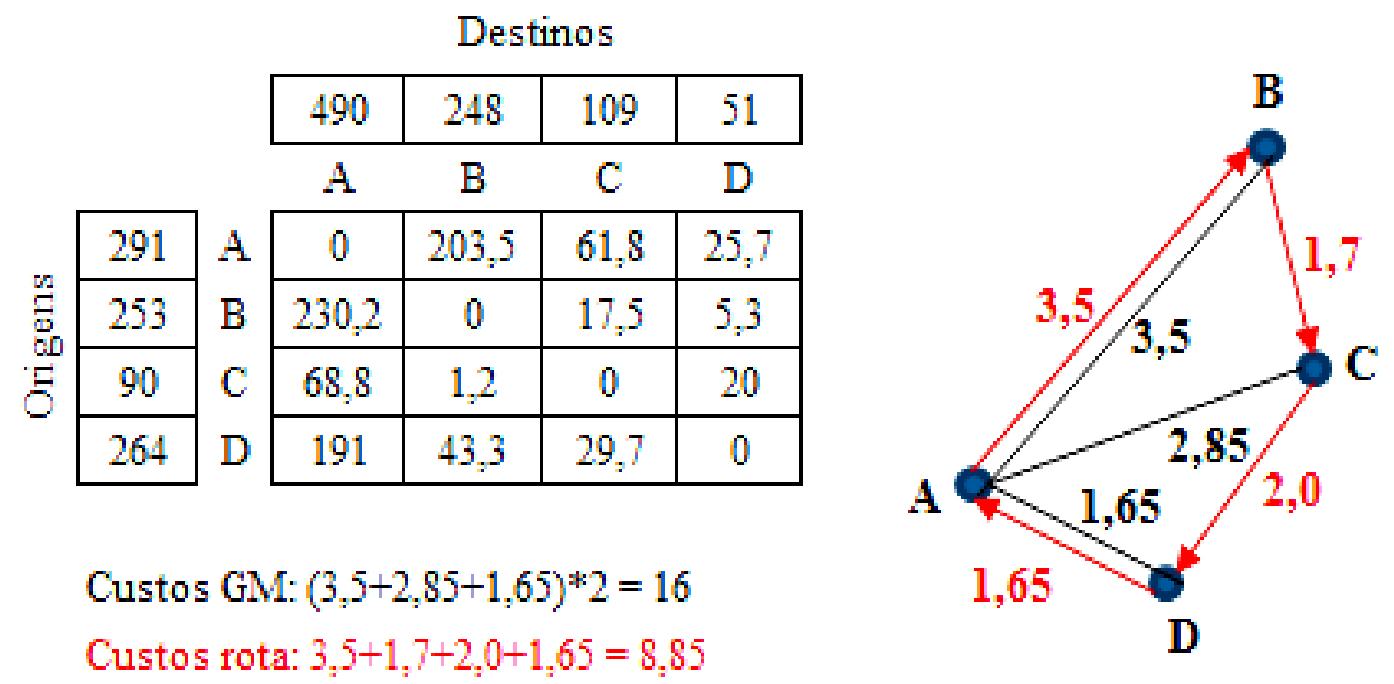

Fonte: Donnelly et al. (2008)

\section{GERACÃO E ATRACÃ̃ DE CARGAS E VIAGENS}

NCFRP (2012) e Holguín-Veras et al.(2014c) consideram importante compreender as diferenças entre geração ou atração de cargas (GC,AC) e geração ou atração de viagens com carga (GVC,AVC). GC/AC se referem à estimativa da quantidade de cargas produzidas e atraídas para determinada zona ou local e é medida geralmente por peso (toneladas) ou volume (metros cúbicos). GVC/AVC são medidas pelo número de viagens de veículos ou entregas necessários para transportar GC ou AC.

Estas subdivisões são importantes. Por exemplo, Jaller, Sánchez-Díaz e Holguín-Veras (2014) buscam compreender quais estabelecimentos geram e/ou atraem viagens de carga por meio dos embarques diários/viagens de veículos de carga produzidas e entregas diárias/viagens de veículos de carga recebidas. Os autores apresentam a Figura A.5 que ilustra tais conceitos.

O trabalho demonstra os diferentes padrões de geração e/ou atração de viagens dependendo da atividade econômica do estabelecimento. Exemplos:

a) hotelaria e serviços do setor de alimentos são considerados puros recebedores de cargas e atraem quatro vezes mais entregas do que os estabelecimentos que atraem e geram viagens. Isto se explica pelo consumo local dos produtos recebidos e a 
geração de viagens (resíduos, por exemplo), não é considerada na análise dos autores;

b) atacadistas produzem 4 vezes mais viagens do que varejistas, sendo considerados mais geradores do que atratores;

c) alguns segmentos como vestuário produzem mais viagens do que as lojas de móveis para cada viagem atraída, até porque os primeiros trabalham com a revenda de peças retalhadas a partir do recebimento de cargas consolidadas.

Figura A.5 - Esquema de atração e geração de viagens de carga por estabelecimentos

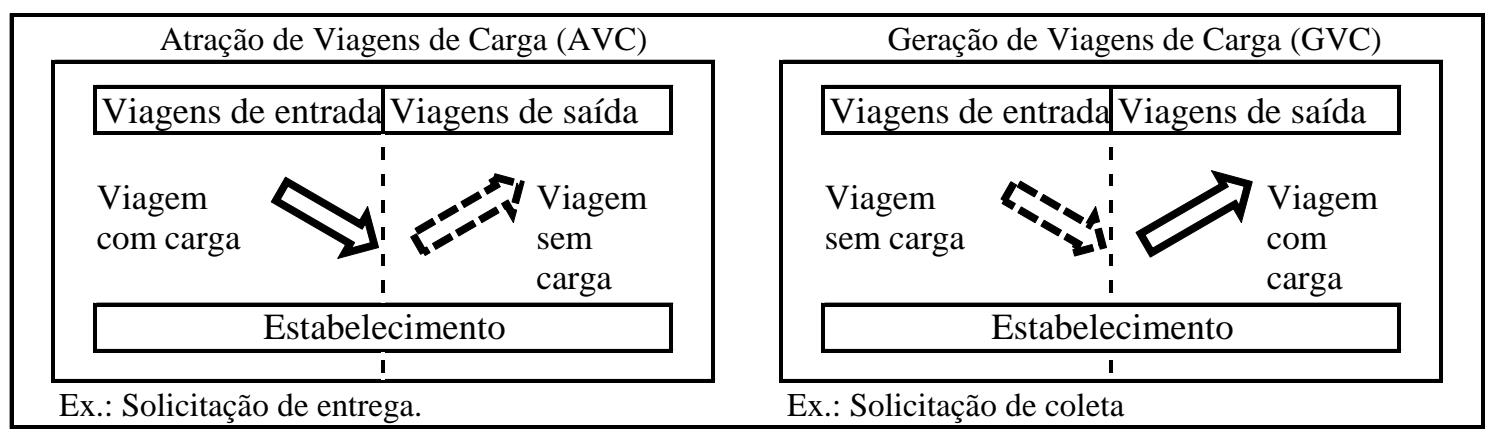

Fonte: Jaller, Sánchez-Díaz e Holguín-Veras (2014, tradução nossa)

A conclusão Jaller, Sánchez-Díaz e Holguín-Veras (2014) é que estes aspectos necessitam ser compreendidos de modo a dar suporte a políticas públicas relacionadas como, por exemplo, a avaliação de impacto da implantação de cada tipo de estabelecimento na capacidade local de cargas e descargas.

NCFRP (2012) e Holguín-Veras et al.(2014c) também citam que a análise de GC e GVC depende de uma série de fatores dentre os quais destaca-se a necessidade em adotar uma adequada nomenclatura de classificação para agrupar corretamente os tipos de negócio com características homogêneas. Os autores citam que estudos de caso demonstram que classificações mais detalhadas e com base nas atividades econômicas (pode-se inferir, do tipo CNAE, brasileiro) são mais adequadas.

Ainda NCFRP (2012)orienta que, devido à multiplicidade de agentes envolvidos e que estabelecem relações entre produção e consumo de bens que geram as viagens de carga, um estudo de GC/GVC deve considerar: 1) locais de produção e embarque de cargas; 2) pontos de processamento intermediários, incluindo armazenagem e; 3) locais de consumo, tanto final quanto intermediário. 


\section{MODOS DE TRANSPORTE E A ESCOLHA MODAL EM TUC}

Apesar de certas mercadorias moverem-se no espaço urbano por outros modos, estes movimentos são localizados, específicos ou não tão relevantes. Argumenta-se que, por praticidade e na maioria dos casos, não há necessidade em realizar a divisão modal, pois o transporte urbano de mercadorias se dá pelo modo rodoviário (JONG, 2014; OGDEN, 1992).

Holguín-Veras e Jaller (2014) citam que o modo de transporte, seja ele o tipo de veículo, determina as necessidades operacionais, as tecnologias e a infraestrutura utilizadas. Assim, uma clara compreensão sobre como as mercadorias são transportadas ajuda no desenho do procedimento de coleta de dados e a identificar quem, onde e como pesquisar.

Assim, ao invés de divisão modal alguns autores sugerem um processo de carregamento de veículos considerando o modal rodoviário. Nesta etapa a quantidade transportada de mercadorias entre origens e destinos é convertida em número de movimentos de veículos a partir das taxas de ocupação das cargas.

Se para algumas indústrias este número é calculado em função da capacidade e ocupação de carga dos veículos, no transporte urbano isto pode ser de uma complexidade maior. (OGDEN, 1992; TAVASSZY; JONG, 2014).

Ogden (1992), Holguín-Veras et al. (2014c) e Jong (2014), por exemplo, citam que a combinação de volume e peso da mercadoria, ou porte da remessa, estão correlacionados com o tipo e capacidade dos veículos. Como se observa na Figura A.6, conforme o porte da remessa aumenta há, em determinado ponto, uma ruptura no tipo de veículo utilizado e uma queda em na geração de viagens com carga (GVC). Isto ocorre, pois o transporte de remessas maiores torna-se mais econômico em veículos maiores ou porque os menores não as comportem.

NCFRP (2012) trata este comportamento também ao nível geográfico envolvido. Por exemplo, no transporte interestadual, regional, internacional predomina o uso de veículos de maior porte, o uso dos modos aéreos, marítimos e ferroviários. No contexto urbano, predominam os veículos de menor porte efetuando entregas ou prestando serviços, e os 
veículos de médio e maior porte são utilizados para transportar cargas de maior volume para centros de distribuição ou transbordos, estabelecimentos de maior porte, ou até para pontos de troca modal na localizados geralmente em zonas periféricas aos centros urbanos.

Figura A.6 - Relação entre geração de carga, de viagens e tamanho de remessa

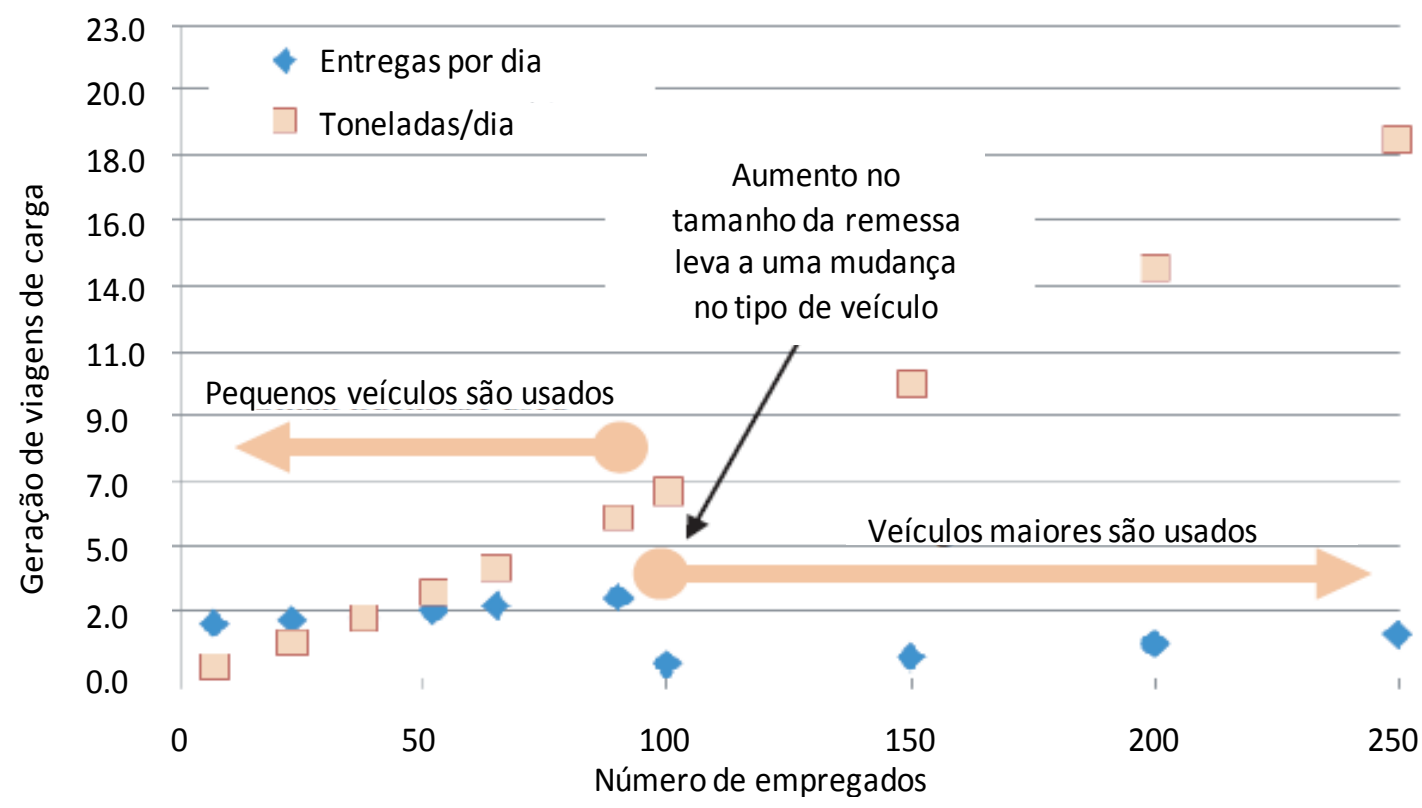

Fonte: NCFRP(2012), tradução nossa, adaptado)

Ainda, NCFRP (2012) considera que: devido à variedade de tipos de veículos, adotar tamanhos médios de veículos é distorcer fortemente as análises e; a definição do modo de transporte/tipo do veículo no planejamento do TUC é complexa e ainda pouco compreendida, pois é impactada pelas interações entre embarcadores, transportadores e recebedores no momento em que estes tomam decisões sobre o tamanho da remessa de carga e sobre a frequência de entregas.

Tavasszy (2008, p. 50) vai mais longe e afirma que, "num contexto de dificuldade para obtenção de dados, modelos para escolha modal em escala urbana ou regional ainda não existem". Para o autor, os desafios no contexto urbano concentram-se em diferenciar escolhas por veículos leves dos mais pesados, daqueles dedicados à prestação de serviços dos que focalizam o transporte de mercadorias. 


\section{ATORES E SUAS INTER-RELACÕES NO TUC}

Para implementar iniciativas de sucesso no âmbito do transporte urbano de cargas é necessário engajar o setor privado, [...] e considerar as preocupações dos atores envolvidos. Conflitos tendem a surgir entre o interesses públicos e privados, sendo o maior obstáculo para o sucesso dos projetos.(HOLGUÍN-VERAS et al., 2014a, p. 3).

Como se espera que a coleta de dados não seja um fim em si, mas ao final seja subsídio para o planejamento de projetos em transporte urbano, este item inicia com a descrição dos principais atores envolvidos no transporte urbano de cargas, discute como a interligação entre atores influenciam nas suas inter-relações e contextualiza como alguns públicos participam no fluxo de mercadorias.

Considera-se que conhecer estes aspectos levem à necessidade em coletar alguns dados específicos, de modo a destacar e diferenciar os atores envolvidos, bem como o tipo de relação que estabelecem. Apesar da agentes envolvendo o TUC, Holguín-Veras et al. (2014c) afirmam que a maior parte das pesquisas tem foco em três grupos de atores que desempenham funções chave no sistema: embarcadores, transportadores $\mathrm{e}$ recebedores/consumidores. NCFRP (2012) os definem da seguinte forma:

e) embarcadores são os que produzem e embarcam a carga de modo a atender suas necessidades de envio para os respectivos destinos. Os embarcadores podem contatar as transportadoras diretamente ou utilizar serviços intermediários (3PL third party logistics) que provêem todo o serviço logístico da cadeia de suprimento incluindo não somente o transporte, mas também armazenagem e gerenciamento do fluxo das mercadorias;

f) transportadores são os que transportam as mercadorias, podendo ser terceirizados (que oferecem o serviço de transporte no mercado aberto) ou privados (que estão vinculados a uma empresa não transportadora);

g) recebedores referem-se aos agentes onde há o destino da carga, podendo ser armazéns, consumidores finais, varejistas, atacadistas, etc. Os recebedores assumem papel importante no comportamento do TUC pois são quem, tipicamente, impõem restrições ao transporte, tais como horário e frequência de entrega, a tecnologia usada, etc.; 
h) por fim há os consumidores finais que merecem atenção especial, pois seu comportamento de compras, notadamente pelo canal internet, tem influenciado um encurtamento dos canais de distribuição ${ }^{33}$ (NOVAES, 2001, p. 114), ou seja, uma redução dos pontos intermediários de distribuição.

NCFRP(2012) realça ainda que um dos aspectos geralmente negligenciados no sistema de transporte de cargas é a natureza da ligação entre seus participantes. A Figura A.7 demonstra que para o caso de embarcadores, transportadores e recebedores, uma das possibilidades é que a mesma ocorra de modo independente ou integrado (ex.: embarcadores e transportadores da mesma empresa).

Trata-se de um aspecto importante no processo de planejamento pois, a título de ilustração, espera-se que em processos integrados os benefícios, tais como reduções de custos operacionais por projetos que venham a ser implementados, são internalizados mais facilmente. Por outro lado, em ligações independentes, cada participante busca maximizar seu lucro e há uma menor preocupação com o que ocorre com o outro agente envolvido.

Figura A.7 - Ligações potenciais entre embarcador, transportador e recebedor

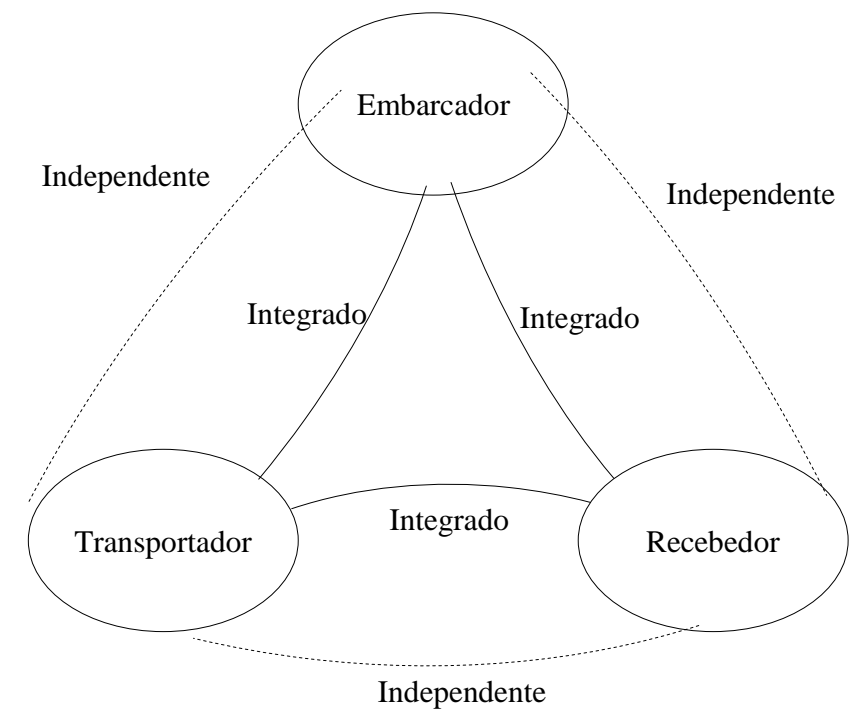

Fonte: NCFRP (2012, tradução nossa)

\footnotetext{
${ }^{33}$ Stern et al. (1996, apud Novaes, 2001, p. 108) "canais de distribuição constituem conjuntos de organizações interdependentes envolvidas no processo de tornar o produto ou serviço disponível para uso ou consumo”.Stern, L.W., El-Ansary, A.I. E Coughlan, A.T. (1996). Marketing Channels, Prentice-Hall, Upper Saddle River, NJ.
} 
Também é interessante observar como Routhier, Segalou e Durand (2002) descrevem a participação de alguns grupos de fluxos no TUC e assim destacam a importância de alguns dos atores listados anteriormente:

a) fluxos de coleta/entrega de transações comerciais entre empresas (comercial, industrial, serviços) representam entre 35 e $40 \%$ do tráfego de mercadorias em termos de taxas de ocupação das vias;

b) movimentos para consumidores finais, incluindo as viagens em carros particulares, entregas domiciliares e outros serviços de compras por catálogo, representam entre 50 e $55 \%$ do tráfego total de mercadorias;

c) movimentos relacionadas com a gestão urbana relacionados com coleta de resíduos, serviços postais, trabalhos na construção civil, em hospitais e serviços públicos representam entre 10 e $15 \%$ do tráfego de mercadorias.

Enfim, além da participação significativa dos movimentos entre empresas, os movimentos para consumidores merecem especial atenção não somente porque têm modificado a organização dos canais de distribuição, mas também participam de modo expressivo nos fluxos do TUC. Portanto, reconhecer o tipo de relação dos atores do TUC tanto quanto os aspectos operacionais que influenciam seu comportamento e configuração, se tornam importantes para o processo de planejamento de transporte de cargas.

\section{FATORES DE INFLUÊNCIA NO TUC}

Também é interessante observar os fatores que afetam o movimento de cargas, pois a partir destes pode-se identificar dados e análises necessárias para compreender os movimentos de mercadorias no espaço urbano. Ortúzar e Willumsen (2011) apontam alguns que necessitam ser conhecidos, dentre eles destacam-se:

a) localização das fontes de produção de cargas, seus intermediários e mercados finais para determinar as origens e destinos; 
b) fatores operacionais como o porte das empresas, políticas de distribuição e sua distribuição geográfica influenciam os tipos de modos e estratégias de carregamento escolhidos;

c) há diversos tipos de produtos e muitas vezes uma segmentação da modelagem é necessária, ocasionando matrizes por classes de mercadorias para determinar a demanda por transporte de cargas;

d) fatores dinâmicos como variações sazonais e padrões de consumo desempenham um importante fator na demanda por transporte de cargas.

Já Ballou (2001) e Novaes (2001) fazem uma abrangente descrição dos fatores que afetam a distribuição de mercadorias, destacando-se a necessidade em conhecer as características do produto, tais como seu valor, perecibilidade e periculosidade, que induzem a esquemas especiais de transporte. Outro aspecto é produtos com maior frequência de entrega tendem a proporcionar menor produtividade no uso da frota. 
Tabela B.1 - Matrizes de atacadistas como origem e destino, Set 2013 - Ago 2014

Atacadistas como Origem

\begin{tabular}{c|rrrrrrrrr}
\hline O/D & 71205 & 71208 & 72035 & 72035 & 72227 & 72265 & 72405 & 74980 & $\sum$ origens \\
\hline 71070 & - & - & 1 & - & 3 & 6 & - & - & $\mathbf{1 0}$ \\
71919 & - & 65 & 13 & 1 & 1 & 11 & 11 & - & $\mathbf{1 0 2}$ \\
72035 & - & 44 & 79 & 94 & 3 & 94 & - & 2.547 & $\mathbf{2 . 8 6 1}$ \\
72227 & 18 & 140 & 2 & 46 & 6 & 2 & - & - & $\mathbf{2 1 4}$ \\
72237 & 1 & 59 & 66 & 21 & - & 311 & 5 & - & $\mathbf{4 6 3}$ \\
72426 & 12 & 28 & 45 & 58 & 15 & 2 & 7 & - & $\mathbf{1 6 7}$ \\
72701 & - & - & - & 79 & - & 533 & 31 & - & $\mathbf{6 4 3}$ \\
73380 & 2 & 28 & 29 & 67 & 30 & 2 & 27 & - & $\mathbf{1 8 5}$ \\
\hline$\sum$ destinos & $\mathbf{3 3}$ & $\mathbf{3 6 4}$ & $\mathbf{2 3 5}$ & $\mathbf{3 6 6}$ & $\mathbf{5 8}$ & $\mathbf{9 6 1}$ & $\mathbf{8 1}$ & $\mathbf{2 . 5 4 7}$ & $\mathbf{4 . 6 4 5}$ \\
\hline
\end{tabular}

Atacadistas como destino

$+$

\begin{tabular}{c|rrrrrrrr|r}
\hline O/D & \multicolumn{1}{|c}{71070} & 71919 & 72035 & 72227 & 72237 & 72426 & 72701 & 73380 & $\sum$ origens \\
\hline 71205 & 323 & - & - & 20 & 156 & 375 & - & 511 & $\mathbf{1 . 3 8 5}$ \\
71208 & 20 & 231 & 6 & 122 & 748 & 378 & - & 576 & $\mathbf{2 . 0 8 1}$ \\
72035 & 6 & 668 & 4 & - & 637 & 547 & - & 822 & $\mathbf{2 . 6 8 4}$ \\
72035 & - & 9 & 52 & 26 & 81 & 508 & 156 & 699 & $\mathbf{1 . 5 3 1}$ \\
72227 & 127 & - & 2 & 80 & 5 & 1.223 & - & 1.010 & $\mathbf{2 . 4 4 7}$ \\
72265 & 138 & 3 & 4 & - & 823 & 20 & 1.903 & 19 & $\mathbf{2 . 9 1 0}$ \\
72405 & - & 302 & - & - & - & 406 & 869 & 506 & $\mathbf{2 . 0 8 3}$ \\
74980 & - & - & 5.408 & - & - & - & - & - & $\mathbf{5 . 4 0 8}$ \\
\hline$\sum$ destinos & $\mathbf{6 1 4}$ & $\mathbf{1 . 2 1 3}$ & $\mathbf{5 . 4 7 6}$ & $\mathbf{2 4 8}$ & $\mathbf{2 . 4 5 0}$ & $\mathbf{3 . 4 5 7}$ & $\mathbf{2 . 9 2 8}$ & $\mathbf{4 . 1 4 3}$ & $\mathbf{2 0 . 5 2 9}$ \\
\hline
\end{tabular}

